Uma abordagem baseada em técnicas de visualização de informações para avaliação de características de imagens e aplicações 



\section{Uma abordagem baseada em técnicas de visualização de informações para avaliação de características de imagens e aplicações}

\section{Laura Elizabeth Florian}

Orientadora: Profa. Dra. Rosane Minghim

Dissertação apresentada ao Instituto de Ciências Matemáticas e de Computação - ICMC-USP, como parte dos requisitos para obtenção do título de Mestre em Ciências - Ciências de Computação e Matemática Computacional. VERSÃO REVISADA 
Ficha catalográfica elaborada pela Biblioteca Prof. Achille Bassi e Seção Técnica de Informática, ICMC/USP, com os dados fornecidos pelo(a) autor(a)

\begin{tabular}{|c|c|}
\hline \multirow[t]{3}{*}{ F635a } & $\begin{array}{l}\text { Florian Cruz, Laura Elizabeth } \\
\text { Uma Abordagem Baseada em Técnicas de Visualização } \\
\text { de Informações para Avaliação de Caracteristicas de } \\
\text { Imagens e Aplicações / Laura Elizabeth Florian Cruz; } \\
\text { orientadora Rosane Minghim. -- São Carlos, } 2012 \text {. } \\
\quad 136 \text { p. }\end{array}$ \\
\hline & $\begin{array}{l}\text { Dissertação (Mestrado - Programa de Pós-Graduação en } \\
\text { Ciências de Computação e Matemática Computacional) -- } \\
\text { Instituto de Ciências Matemáticas e de Computação, } \\
\text { Universidade de São Paulo, 2012. }\end{array}$ \\
\hline & $\begin{array}{l}\text { 1. visualização de informação. } 2 \text {. mineração visual } \\
\text { de imagens. } 3 \text {. análise visual do espaço de } \\
\text { características. } 4 \text {. árvores de similaridade. } 5 . \\
\text { seleção de características. I. Minghim, Rosane, } \\
\text { orient. II. Título. }\end{array}$ \\
\hline
\end{tabular}


A minha mãe Clara pelo amor incondicional e a meu tío Jesús pelo valioso apoio. 



\section{Agradecimentos}

Agradeço primeiro a Deus pela oportunidade deste crescimento de vida e pela força que me deu durante todo este tempo.

Agradeço principalmente a minha mãe pelo apoio recebido, meu exemplo a seguir, com ela aprendi todo o valor desta vida. A meu pai, a minha avô, minhas tías, meus tios e primos pelo apoio incondicional oferecido durante toda minha formação. Sem vocês nada seria possível.

Agradeço à professora Rosane Minghim pela excelente orientação, paciência, compreensão e apoio na realização deste trabalho. Espero seguir seu exemplo de dedicação, responsabilidade e comprometimento.

Ao professor Moacir Ponti Junior pelos conselhos, apoio e amizade. Sua ajuda foi fundamental para prosseguir meus estudos.

Aos pesquisadores José Gustavo Paiva e Danilo Eler pelas sugestões e ajuda. A colaboração de vocês enriqueceu muito este trabalho.

Aos amigos do laboratório VICG pela colaboração direta e indireta para a conclusão deste projeto, em especial ao Christian Wong, Renato Rodrigues, Carlos Arminio, Vinicius Borges, Danilo Coimbra, Bruno Brandoli, Thiago Santos e Ivar Vargas.

Agradeço também aos meus amigos peruanos e brasileiros que fiz no ICMC, destaco aqui a Valeria Carvalho, Fernando Alva, Jorge Valverde, Nils Murrugarra, Pablo Pérez, Pedro Shiguihara, Alceu Ferraz Costa, Alvaro Gómez, Newton Spolaor e muitos outros pelo companheirismo e troca de idéias.

Aos amigos da república .Pe Maysa Ramos, Gabriel Humpire, Carlos Guillen, Carolina Guillen, Jeaneth Machicao, Davi Santos, Aurea Soriano, Oscar Cuadros e Karina Mamani. Sem a companhia deles, os momentos de alegria e felicidade longe de casa não existiriam e os momentos de tristeza, sofrimento e decepção teriam sido mais dolorosos. 
Aos meus amigos em Peru, obrigada pela força de vocês, e desde longe sempre ter uma palavra de consolo nas horas difíceis, pelas agradáveis conversas e muito mais, simplesmente pelo carinho de sempre.

Ao Instituto de Ciências Matemáticas e de Computação (ICMC-USP) pela oportunidade de realizar o curso de mestrado. Aos professores pelos ensinamentos e aos funcionários pelos excelentes serviços prestados.

Ao Conselho Nacional de Desenvolvimento Científico e Tecnológico (CNPq) pelo apoio financeiro concedido ao inicio da realização deste trabalho, processo 146401/2010-7.

À Fundação de Amparo à Pesquisa do Estado de São Paulo (FAPESP) pela concessão da bolsa de mestrado e pelo apoio financeiro para a realização desta pesquisa. Processo 2010/04477-8.

Agradeço, por fim, a todas as pessoas que, direta ou indiretamente, contribuíram para que este trabalho se realizasse. Obrigada! 
Florian-Cruz, L. Uma Abordagem Baseada em Técnicas de Visualização de Informações para Avaliação de Características de Imagens e Aplicações . 2012. Dissertação (Mestrado) - Instituto de Ciências Matemáticas e de Computação, Universidade de São Paulo, São Carlos, 2012.

$\mathrm{Na}$ maioria dos processos de análise de imagens há a necessidade de um pré-processamento, no qual são extraídos e calculados vetores de características que representem as imagens são utilizados no cálculo de similaridade. Uma dificuldade nessas tarefas é o grande número de características que definem um espaço de alta dimensionalidade, afetando fortemente o desempenho das tarefas que seguem, que podem envolver uma análise visual, um agrupamento ou uma classificação de dados, por exemplo. Lidar com esse problema normalmente exige técnicas de redução de dimensionalidade ou seleção de características. O presente trabalho dá sequência a trabalhos que utilizam técnicas de visualização como suporte para avaliar espaços de características gerados a partir de coleções de imagens. Nele, objetiva-se aprimorar um método baseado na análise visual de conjuntos de imagens empregando a árvore de similaridade Neighbor-Joining que apoia o usuário a selecionar um subespaço de características que mantenha ou melhore os resultados das visualizações do conjunto de imagens. A partir da metodologia proposta, a avaliação e a seleção de características representativas é realizada usando a visualização $N J$. A maior parte dos experimentos responde positivamente para diferentes conjuntos de imagens representados por vários extratores, obtendo-se processos de seleção personalizados mais precisos e eficazes, em termos de agrupamento, do que abordagens automáticas reportadas na literatura.

Palavras-chave: visualização de informação, mineração visual de imagens, análise visual do espaço de características, seleção de características, árvores de similaridade. 

Florian-Cruz, L. Approach Based on Information Visualization Techniques for Evaluation of Image Features and Applications. 2012. Dissertation (Master) - Institute of Mathematics and Computer Sciences, University of São Paulo, São Carlos, 2012.

In the majority of the image analysis processes there is need for a pre-processing step, in which feature vectors representative of the images are extracted and similarity methods are calculates. A difficult step in the process is to choose amongst the large number of features available, that will define a feature space of high dimensionality, impacting the cost of the subsequent processing tasks, such as visual analysis, clustering and classification. This problem is usually handled by dimension reduction of feature selection techniques. This work extends and improves previous work that employs visualization and visual analysis techniques to support evaluation of feature spaces created from image collections. The goal is to improve a previous method of feature selection through visualization to employ similarity trees via the Neighbor Joining (NJ) algorithm as the basis for the visual layout, as well as to improve the choices of the analyst regarding tools for visual selection of features. The same process can be employed to support evaluation of feature spaces using the NJ visualization. The majorities of experiments results in improvement of spaces generated by various extractors, yielding personalized selection process that are more precisely related to user's perspective of the data set and are perform similarly or better than automatic approaches available in the literature.

Keywords: information visualization, mining, visual images, visual analysis of the feature space, similarity trees. 



\section{Lista de Figuras}

2.1 Histograma de uma imagem cerebral de ressonância magnética. . . . . . . . . 9

2.2 Duas imagens distintas com histogramas similares. . . . . . . . . . . . . . 10

2.3 Fluxograma de um processo de seleção de características. . . . . . . . . . . . 18

3.1 Visualizações em Árvores . . . . . . . . . . . . . . . . . . . . . 26

3.2 Árvores em Cone. . . . . . . . . . . . . . . . . . . . . . . 27

3.3 Árvores hiperbólicas em 2D e 3D. . . . . . . . . . . . . . . . . . 27

3.4 Modelo da visualização TreeMap ou Mapas de Árvore. . . . . . . . . . . . . . 28

3.5 Árvore de similaridade do conjunto de 700 imagens COIL usando o algoritmo

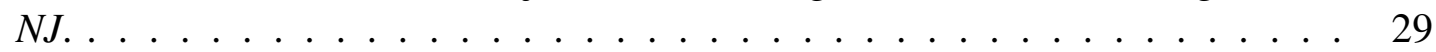

3.6 Árvore de cinco folhas . . . . . . . . . . . . . . . . . 30

3.7 Promoção de nós do algoritmo de Paiva et al.(2011). . . . . . . . . . . . . 32

3.8 Projeção LSP vs Árvore de similaridade $N J$ do mesmo conjunto de imagens COIL (Nene e Nayar, 1996). . . . . . . . . . . . . . . . . . . . 33

3.9 Etapas de processamento para visualizar a coleção de imagens por meio de uma Técnica de Projeção. . . . . . . . . . . . . . . . . . . . . 34

3.10 Red Pathfinder ou Pathfinder Scaling Network. . . . . . . . . . . . . . . . . . 35

3.11 A MoireGraph exibe imagens da NASA agrupadas pela hierarquia estelar. . . 36

3.12 Visualização hiperbólica usando o conceito de ontologia. . . . . . . . . . . . . 37

3.13 Sistema de Visualização de Imagens ImIk. . . . . . . . . . . . . . . . . . . 37

3.14 Coordenação entre duas projeções realizadas pelo Pex-Image. . . . . . . . . . 38

3.15 Visualizador de imagens 3D Miaow. . . . . . . . . . . . . . . 38

3.16 Esquerda: Projeção do conjunto original de dados. Direita: Projeção dos dados transpostos. Abaixo: Projeção do conjunto de dados usando as características

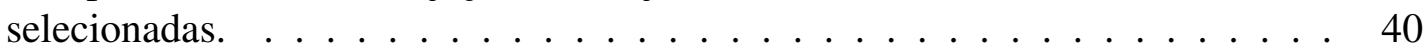

3.17 Espaço para escolher subconjuntos de imagens representativas, separando clas-

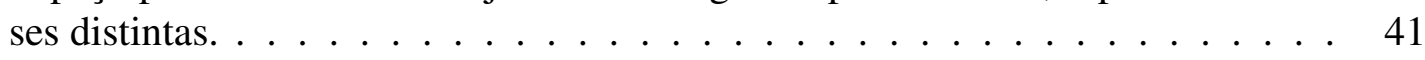

3.18 Interface do software Pex-Image, ilustrando o resultado de uma projeção. ... 43

3.19 Coordenação entre duas projeções realizadas pelo PEx-Image. . . . . . . . . . 44

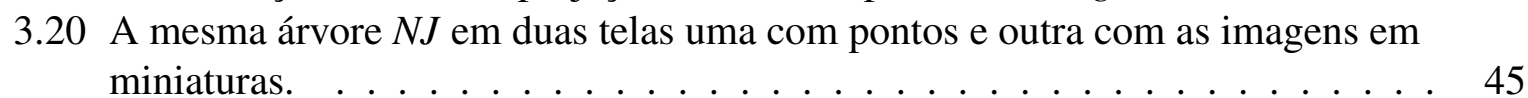


3.21 Janela principal do VisPipeline. . . . . . . . . . . . . . . . . . . 46

3.22 Gráfico da medida Neighborhood Preservation. . . . . . . . . . . . . . . . . . . 48

3.23 Gráfico da medida Neighborhood Hit. . . . . . . . . . . . . . . . . . 48

4.1 Esquematização da abordagem para seleção e avaliação de características usando visualização de informação. . . . . . . . . . . . . . . . . . . . 53

4.2 Processo de Transposição da Matriz de Instâncias. . . . . . . . . . . . . . . . . 54

4.3 Seleção Manual de características feita na ferramenta VisPipeline. . . . . . . . 56

$4.4 \quad$ Visualização em árvore, usando a técnica $N J$ das imagens COIL. . . . . . . . . 57

$4.5 \quad$ Visualização das imagens representativas do passo anterior. . . . . . . . . . . . . 58

4.6 Janela do Rotulador Manual de Classes. . . . . . . . . . . . . . . . . . . . . . 60

4.7 Visualização em árvore $N J$ das características do conjunto de Frutas-BIC. . . . . 60

4.8 Identificação dos centróides nos grupos definidos na visualização em árvore e seus 5 -vizinhos mais próximos. . . . . . . . . . . . . . . 62

4.9 Visualização das características do conjunto de Frutas-BIC. . . . . . . . . . . . 63

4.10 Processo de avaliação de espaços de características. . . . . . . . . . . . . . . 64

4.11 Visualização em árvore $(N J)$ do conjunto COIL. . . . . . . . . . . . . . . . . 66

5.1 Amostra de imagens do conjunto Supermarket Produce. . . . . . . . . . . . . 70

5.2 Amostra de imagens do conjunto COIL. . . . . . . . . . . . . . . . 71

5.3 Amostra de imagens do conjunto Corel com 10 classes diferentes. . . . . . . . 71

$5.4 \quad$ Amostragem das imagens do conjunto de Frutas e Vegetais. . . . . . . . . . . . 72

5.5 Gráfico de precisão/revocação da árvore $N J$ do conjunto de imagens Corel. . . . 74

5.6 Gráfico de precisão/revocação da árvore $N J$ do conjunto de imagens COIL. . . 75

5.7 Visualizações das árvores que representam o conjunto de imagens 8 (COIL) usando os extratores $C C V, B I C, G C H$ e a união dos extratores $B I C-C C V-G C H$. Em todas essas visualizações usa-se a distância logarítmica para medir a similaridade entre as imagens. . . . . . . . . . . . . . . . . 81

5.8 Gráfico Precisão /Revocação. . . . . . . . . . . . . . . . . . . . . . . . 82

5.9 Medida de avaliação gráfica Neighborhood Hit. . . . . . . . . . . . . . . . . . 83

5.10 Medida de avaliação gráfica Neighborhood Preservation. . . . . . . . . . . . . 83

5.11 Integração dos gráficos com as visualizações das árvores que representam o conjunto de imagens COIL. . . . . . . . . . . . . . . . . . . . . . . 85

5.12 Gráfico precisão/revocação da distância logarítmica. . . . . . . . . . . . . . . 86

5.13 Medida de avaliação gráfica Neighborhood Preservation. . . . . . . . . . . . . 87

5.14 Medida de avaliação gráfica Neighborhood Hit. . . . . . . . . . . . . . . . . 87

5.15 Visualização $N J$ do conjunto de imagens 3, caracterizado pelo extrator $C C V$. . . $\quad 89$

5.16 Visualização do subconjunto de características selecionadas. São escolhidas um subconjunto com 81 características escolhidas. . . . . . . . . . . . . . . . . . . . 90

5.17 Visualização das 93 características selecionadas . . . . . . . . . . . . . . . 91

5.18 Visualização do subconjunto de características selecionadas. São escolhidas 84 características escolhidas. . . . . . . . . . . . . . 92

5.19 Visualização $N J$ do conjunto de imagens 8 , caracterizado pelo extrator $C C V$. . . 93

5.20 Visualização das 76 características selecionadas. . . . . . . . . . . . . . . . . 94 
5.21 Visualização do conjunto de imagens representados pelas características selecionadas. Foram escolhidas no total de 62 características. . . . . . . . . . . . . 95

5.22 Visualização do subconjunto de características selecionadas com 45 características escolhidas. . ......................... 96

5.23 Visualização $N J$ do conjunto de imagens 6 , caracterizado pelo extrator BIC. . . 97

5.24 Visualização das 96 características selecionadas. . . . . . . . . . . . . . . . 97

5.25 Visualização do conjunto de imagens representados pelas características seleci-

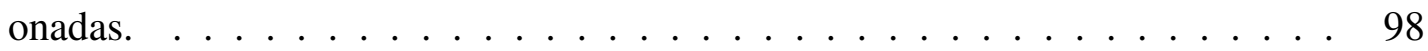

5.26 Visualização do subconjunto de características selecionadas. . . . . . . . . . . 99

5.27 Visualização $N J$ das 64 características do conjunto de imagens 3.

5.28 Visualização do subconjunto de características selecionadas. São escolhidos 53 características escolhidas. . . . . . . . . . . . . . . . . 101

5.29 Visualização $N J$ do conjunto de imagens 11, caracterizado pelo extrator BIC. . 102

5.30 Visualização do subconjunto de características selecionadas. São escolhidas 43 características selecionadas. . . . . . . . . . . . . . . . 104

5.31 Visualização $N J$ do conjunto de imagens 7, caracterizado pelo extrator BIC. . . 104

5.32 Visualização do subconjunto de características selecionadas. São escolhidas um subconjunto com 74 características selecionadas. . . . . . . . . . . . . . 105

5.33 Visualização $N J$ do conjunto de imagens 4, caracterizado pelo extrator $G C H$.

5.34 Visualização do subconjunto de características, identificando 5 grupos definidos pelos ramos triangulados das árvores. . . . . . . . . . . . . . 108

5.35 Visualização $N J$ do conjunto de imagens 1 , caracterizado pelo extrator $B I C$, usando a distância logarítmica. . . . . . . . . . . . . . . . . . . . . . . 109

5.36 Visualização do subconjunto de características, agrupadas em 5 grupos que são identificados pelos ramos triangulados das árvores. . . . . . . . . . . . . 110

5.37 Visualização $N J$ do conjunto de imagens 6, caracterizado pelo extrator $G C H$. $\quad 111$

5.38 Visualização do subconjunto de características, identificando 3 grupos pelos ramos triangulados das árvores. . . . . . . . . . . . . . . . . . . 112 



\section{Lista de Tabelas}

5.1 Conjuntos de imagens usadas nos experimentos. . . . . . . . . . . . . . 72

5.2 Definição do número de características que é obtido por cada extrator. . . . . . . 78

5.3 Desempenho dos extratores de características usando a visualização em árvore

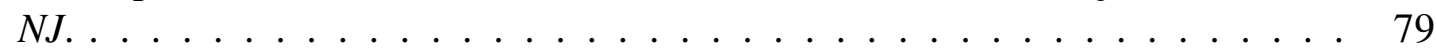

5.4 Avaliação das funções distância. . . . . . . . . . . . . . . . . . . . . 84

5.5 Avaliação da variação da quantidade de imagens e classes do conjunto Supermarket-Produce usando o algoritmo $N J . \ldots \ldots \ldots \ldots$. . . . . . . . . . . . . . . . . . .

\begin{tabular}{|ll|l|l|}
\hline 5.6 & Medidas de silhueta obtidas das seleções manuais ilustradas nas Figuras & 5.16, \\
\hline
\end{tabular} 5.17 $\mid \mathrm{e}$ 5.18 realizadas para o conjunto número 3 (Supermarket - Produce 1440). 92

5.7 Medidas de silhueta obtidas das seleções manuais ilustradas nas Figuras 5.20 , 5.21 e 5.22 , realizadas para o conjunto 8 (coil 720), caracterizado pelo extrator

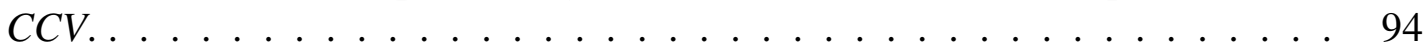

5.8 Medidas de silhueta obtidas das seleções manuais ilustradas nas Figuras [5.24 5.25 e 5.26, realizadas para o conjunto 6 (COIL 2520), caracterizado pelo extrator

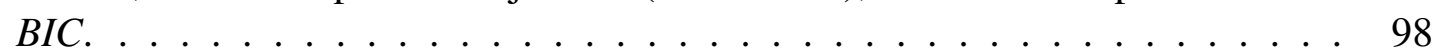

5.9 Medidas de silhueta obtidas antes e após a seleção ilustrada na Figura 5.28 usando 1204 imagens representativas realizada para o conjunto 3 (Supermarket-Produce

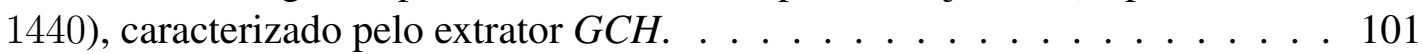

5.10 Medidas de silhueta obtidas antes e após a seleção ilustrada na Figura 5.30 usando 87 imagens representativas realizada para o conjunto 11 (Flores 120), caracterizado pelo extrator $B I C . \ldots \ldots \ldots \ldots 3$

5.11 Medidas de silhueta obtidas antes e após a seleção ilustrada na Figura 5.32 usando 1697 imagens representativas realizada para o conjunto número 7 (COIL 1800), caracterizado pelo extrator $C C V . \ldots \ldots$. . . . . . . . . . 106

5.12 Medidas de silhueta obtidas antes e após a seleção ilustrada na Figura 5.34 usando as 8-características centrais dos ramos realizada para o conjunto 4 (Supermarket-Produce

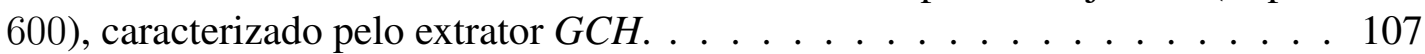

5.13 Medidas de silhueta obtidas antes e após a seleção ilustrada na Figura 5.36 usando as 21-características centrais dos ramos realizada para o conjunto 1 (Supermarket-Produce 2035), caracterizado pelo extrator BIC. . . . . . . . . . 110 
5.14 Medidas de silhueta obtidas antes e após a seleção ilustrada na Figura 5.38 usando as 16-características centrais dos ramos realizada para o conjunto 6 (COIL 2520), caracterizado pelo extrator GCH. . . . . . . . . . . . . . . . 113

5.15 Resultados das classificações dos dados gerados pelas seleções realizadas usando a visualização $N J$, mostrando as porcentagens das instâncias corretamente classificadas. . . . . . . . . . . . . . . . . . . . 114

5.16 Resultados das classificações dos dados gerados pelas seleções realizadas usando a visualização $N J$, mostrando as porcentagens das instâncias corretamente clas-

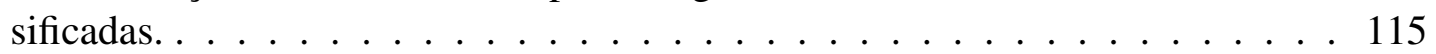

5.17 Medidas de silhueta obtidas antes e após as seleções de características realizadas sob o conjunto de imagens 1 (Supermarket-Produce 2035), caracterizado pelo

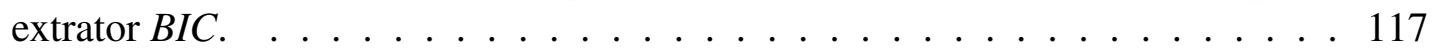

5.18 Medidas de silhueta obtidas das seleções de características realizadas para o conjunto número 3 (Supermarket - Produce 1440). . . . . . . . . . . . . . . . . 117

5.19 Medidas de silhueta obtidas antes e após a seleções de características realizadas para o conjunto número 4 (Supermarket-Produce 600 ), caracterizado pelo

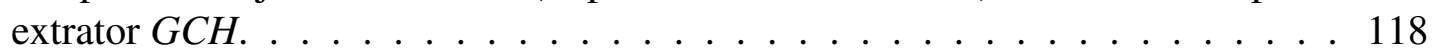

5.20 Medidas de silhueta obtidas das seleções de características realizadas para o conjunto número 6 (COIL 2520). . . . . . . . . . . . . . . . . . . . . 118

5.21 Medidas de silhueta obtidas antes e após a seleções de características realizadas para o conjunto número 7 (COIL 1800), caracterizado pelo extrator $C C V$. . . . . 119

5.22 Medidas de silhueta obtidas das seleções de características realizadas para o conjunto número 8 (coil 720), caracterizado pelo extrator $C C V$. . . . . . . . . . 119

5.23 Medidas de silhueta obtidas antes e após a seleção de características realizada para o conjunto 11 (Flores 120), caracterizado pelo extrator BIC. . . . . . . . . 119

5.24 Medidas de silhueta obtidas antes e após a seleção das 100 características usando o conjunto 3 (Supermarket-Produce 1440). . . . . . . . . . . . . . . . . 120

5.25 Medidas de silhueta obtidas antes e após a seleção das 120 características usando o conjunto 6 (COIL 1800). . . . . . . . . . . . . . . . . . . 120 
Resumo ix

Abstract $\quad$ xi

Sumário $\quad$ xix

\begin{tabular}{|lll}
\hline 1 & Introdução & 1
\end{tabular}

1.1 Contextualização e Motivação . . . . . . . . . . . . . . . . . . . . 1

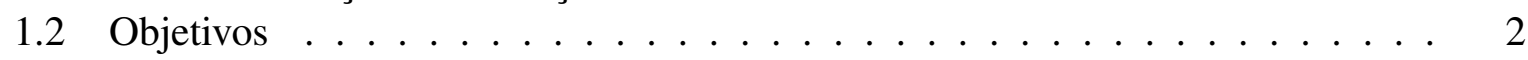

1.3 Organização do Documento . . . . . . . . . . . . . . . . 3

2 Conceitos Básicos 5

2.1 Considerações Iniciais $\ldots \ldots \ldots$. . . . . . . . . . . . . . . 5

2.2 Transformação e Representação de Imagens . . . . . . . . . . . . . . . . . . . 6

2.2 .1 Descrição de Imagens $\ldots \ldots \ldots \ldots$. . . . . . . . . . . . . . . . . . . . . . 6

2.2 .2 Extração de Características . . . . . . . . . . . . . . . . . . . 7

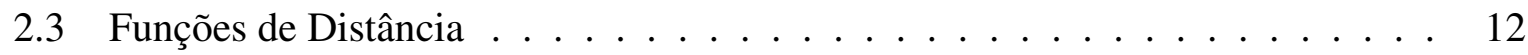

2.4 Técnicas de Redução de Dimensionalidade . . . . . . . . . . . . . . . . . . 14

2.4 .1 Transformação de Características . . . . . . . . . . . . . . . . . 15

2.4 .2 Seleção de Características . . . . . . . . . . . . . . . . . . . . . . . 17

2.5 Considerações Finais $\ldots \ldots \ldots \ldots$. . . . . . . . . . . . . 20

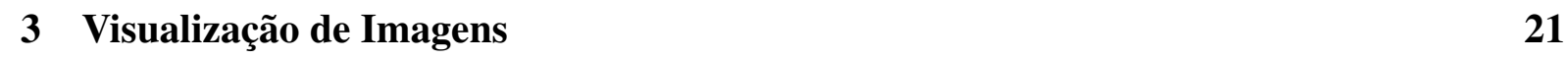

3.1 Considerações Iniciais $\ldots \ldots \ldots \ldots$. . . . . . . . . . . . . . 21

3.2 Técnicas de Visualização de Informação . . . . . . . . . . . . . . . . . . . . . 22

3.2.1 $\quad$ Projeção Multidimensional . . . . . . . . . . . . . . . . . . 22

3.2.2 Visualização Baseada em Ârvore . . . . . . . . . . . . . . . . . . . . . . . . 25

3.3 Visualização de Coleções de Imagens . . . . . . . . . . . . . . . . . . . . . . 33

3.3.1 Sistemas de Visualização de Imagens . . . . . . . . . . . . . . . . . . 34

3.4 Visualização Multidimensional na Seleção de Características . . . . . . . . . . 39

3.5 Interação e Avaliação para Visualização de Dados . . . . . . . . . . . . . . . . 41 
3.5.1 Ferramentas de Apoio à Visualização . . . . . . . . . . . . . . . . . . 42

3.5 .2 Avaliação da Qualidade da Visualização . . . . . . . . . . . . . . . . . . 46

3.6 Considerações Finais . . . . . . . . . . . . . . . . . . 48

4 Abordagem para Avaliação de Características de Imagens 51

4.1 Considerações Iniciais $\ldots \ldots \ldots \ldots \ldots \ldots$. . . . . . . . . . . . . 51

4.2 Visualização de Informação como Seletor de Características . . . . . . . . . . 52

4.2 .1 Seleção Manual de Características Representativas . . . . . . . . . . . 55

4.2.2 Seleção das k-Características em Grupos formados pela Visualização em Árvore . . . . . . . . . . . . . . . . . 58

4.3 Visualização de Informação para Avaliação de Espaços de Características . . 61

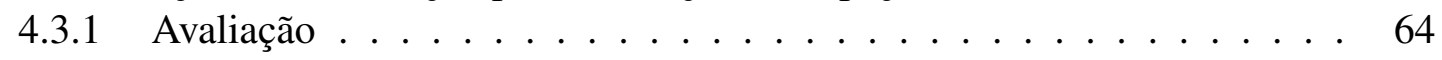

4.3.2 Retroalimentação . . . . . . . . . . . . . . . . . . . 65

4.4 Considerações Finais $\ldots \ldots \ldots$. . . . . . . . . . . . . . . 67

5 Experimentos e Resultados

5.1 Considerações Iniciais $\ldots \ldots \ldots$. . . . . . . . . . . . . . . . . . . . . . . . . . . 69

5.2 Conjuntos de Dados e Medidas . . . . . . . . . . . . . . . . . . . . 70

5.3 Medidas de Avaliação . . . . . . . . . . . . . . . . . . . . . . . . . . . . . . . . . . . . . . .

5.4 Configurações dos Experimentos . . . . . . . . . . . . . . . . . . 75

5.5 Análise dos Resultados . . . . . . . . . . . . . . . . . . . . . 77

$5.5 .1 \quad$ Comparação do desempenho dos extratores de características. . . . . . 77

5.5 .2 Avaliações de critérios na seleção manual de características . . . . . . 88

5.5.3 Avaliações de critérios na seleção manual de características obtidas pela seleção de um subconjunto de imagens representativas . . . . . . . . . 96

5.5 .4 Avaliações nas seleções das $k$-características em grupos formados pela visualização em árvore . . . . . . . . . . . . . . . . . 106

5.5 .5 Avaliação dos espaços de características selecionados através de algoritmos de classificação . . . . . . . . . . . . . . . . . 112

5.5 .6 Avaliações de outras abordagens de seleção de características . . . . 113

5.5 .7 Retroalimentação . . . . . . . . . . . . . . . . . . 118

5.6 Considerações Finais $\ldots \ldots \ldots \ldots \ldots$. . . . . . . . . . . . . . 121

6 Conclusões 123

6.1 Considerações Finais . . . . . . . . . . . . . . . . . . . . . 123

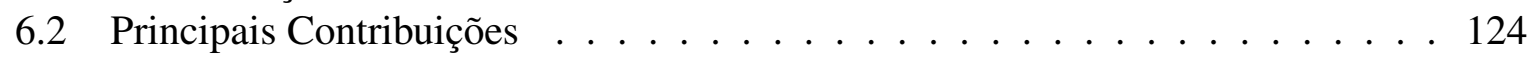

6.3 Limitações . . . . . . . . . . . . . . . . . . . . . . . . . . 125

6.4 Trabalhos Futuros . . . . . . . . . . . . . . . . . . . . . . 126

\begin{tabular}{ll}
\hline Referências Bibliográficas & 129
\end{tabular} 


\subsection{Contextualização e Motivação}

Pesquisas em análise de coleções de imagens e outros dados multidimensionais, como a visualização de imagens, focam-se na exploração de suas características (Botelho e Batista Neto, 2010; Brandoli et al., 2011; Joia et al., 2011) considerando o benefício do uso de determinadas características e a contribuição para o incremento da qualidade nas tarefas de classificação e agrupamento.

Apesar dos avanços e bons resultados alcançados pelas técnicas da visualização de informação, seus métodos ainda não incorporam adequadamente ferramentas para o tratamento e avaliação de espaços de características que representam o conjunto de dados sob estudo. É necessário então oferecer um conjunto de ferramentas para apoiar a tarefa de avaliação com base na distinção entre espaços de características, imerso em um processo iterativo seguido pelo usuário. O desafio é fornecer ao usuário um meio para detectar um subgrupo de características representativas ou identificar grupos onde as instâncias relevantes estão contidas.

Assim, explorar as características, avaliar métodos de extração ou determinar quais características permitem garantir o desempenho de um sistema de análise de imagens reduzindo o tamanho dos dados, são desafios em aberto, ainda não completamente desenvolvidos, que podem se beneficiar do apoio oferecido pelas técnicas de visualização de informação. Por meio 
dessas técnicas, usuários possuem acesso a uma interface visual na qual as relações de similaridade entre os dados podem ser imediatamente identificadas. Usuários tornam-se agentes no processo da mineração das informações assignadas no pré-processamento, pois conseguem, além de visualizar as relações entre os dados, interagir com o modelo em níveis global e local.

Várias abordagens para a seleção de características (Dy e Brodley, 2000a; Hall, 1998; Xing et al., 2001) têm sido propostas e usadas baseados em filtros e em estratégias wrapper. Porém, não muitos algoritmos tem o suporte de uma análise visual. Assim, é relevante a investigação de métodos para seleção e análise de características utilizando algoritmos de visualização, permitindo o uso de uma tela de baixa dimensão por um especialista, no apoio às tarefas de classificação de padrões.

Este trabalho da sequencia a pesquisa feita por Botelho e Batista Neto (2010), que propõe uma abordagem de busca por características não correlacionadas em projeções para apoiar o processo de seleção de características. Aprimorando esse trabalho, esta pesquisa propõe um modelo para a seleção de um espaço de características adequado para um conjunto de imagens, envolvendo um processo de visualização em árvore Neighbor-Joining. A proposta usa a identificação de grupos na árvore, onde a classe prioritária seja evidente; sugerindo três abordagens para amostragem de características: uma onde o usuário pode selecionar manualmente um subconjunto de características. A segunda abordagem é a seleção das características considerando apenas um subconjunto de imagens chamadas de representativas. A terceira abordagem emprega o agrupamento definido pelos ramos da árvore para amostrar as $k$-características nos ramos da árvore $N J$. Cada abordagem utiliza as informações fornecidas por um usuário.

Para determinar se um conjunto de características é adequado ou não para um conjunto de dados também é utilizada a visualização em árvore $N J$ dos diferentes resultados obtidos pelos diferentes espaços de características, antes e após do processo de seleção de características.

Com os resultados deste trabalho que, através da melhoria da qualidade da visualização, ha indicativos para o pesquisador em imagens, é possível definir quais espaços de características melhor definem seu conjunto de objetos, com respeito à distinção de classes de forma rápida e eficiente.

\subsection{Objetivos}

O objetivo principal deste trabalho é o desenvolvimento de uma abordagem para análise visual do espaço de características de uma coleção de imagens, usando a técnica de representação e visualização de dados multidimensionais em árvores Neighbor-Joining, a fim de permitir que 
um analista explore, defina e refine conjuntos de características visualmente, buscando preservar a informação estrutural dos dados.

Os objetivos específicos serão apresentados a seguir.

- Utilizando a técnica de visualização baseada em árvores de similaridade Neighbor-Joining, permitir a usuário explorar, definir e escolher os conjuntos de características, buscando preservar a informação estrutural dos dados.

- Estabelecer métodos para seleção e avaliação do espaço de características a partir da visualização, e possibilitar ao usuário interferir em cada um dos processos.

- Ajudar a complementar o processo de extração de características com as informações obtidas no processo de visualização, identificando quais características beneficiam a projeção.

- Estender a ferramenta Vispipeline (iniciada por Paulovich et al. (2007)) e estendida por vários pesquisadores incluindo as propostas de aprimoramentos aqui definidos e tornando-as de uso livre.

\subsection{Organização do Documento}

Esta dissertação está organizada da seguinte maneira:

No Capítulo 2, são detalhados os conceitos principais para que o trabalho possa ser melhor compreendido incluindo conceitos de representação e de análise de imagens.

No Capítulo 3, é apresentada uma revisão dos trabalhos relacionados à visualização de informação, principalmente os voltados a visualizar coleções de imagens, citando sistemas previamente desenvolvidos. Apresenta-se também, uma definição das técnicas de projeção multidimensional, e as baseadas em árvore, com ênfase nas árvores de similaridade $(N J)$.

No Capítulo 4, é apresentada a abordagem proposta por este trabalho, descrevendo cada etapa desenvolvida, quanto os métodos para seleção de características usando a visualização $N J$ das características e as variações desses métodos.

No Capítulo 5, são apresentado e discutidos os experimentos e seus resultados.

Finalmente, no Capítulo 6, são apresentadas as conclusões, contribuições, limitações e as sugestões de trabalhos futuros.

Os experimentos apresentados mostram que o processo de seleção de características personalizado pela abordagem visual é mais preciso e eficaz do que as abordagens tradicionais 
reportadas na literatura. Obtém-se resultados positivos para diferentes conjuntos de imagens representados por vários extratores baseados em cor, avaliados em termos de agrupamento em um espaço projetado e refletidos pela árvore $N J$, e em termos de algoritmos de classificação conhecidos. 


\subsection{Considerações Iniciais}

Em sistemas de recuperação por conteúdo (Content-Based Image Retrieval - CBIR), sistemas de visão computacional, reconhecimento de padrões e sistemas de visualização, as imagens são comumente representadas por conjuntos de atributos numéricos. Assim, cada instância do conjunto de imagens é representada por um vetor de características, obtidas por meio de extratores, que são algoritmos de processamento de imagens que procuram identificar atributos visuais (cor, textura, forma entre outros) e traduzi-los em atributos numéricos.

Um dos problemas comuns é a existência de informações redundantes que podem prejudicar a identificação de semelhanças entre seus objetos. Para resolver este problema, duas abordagens principais têm sido propostas e estudadas: a redução de dimensionalidade por transformação de características e a seleção de características.

Técnicas de redução de dimensionalidade por transformação de características criam uma descrição dos dados reduzida por projeção ou transformação das características originais para espaço de menor dimensão. Técnicas de seleção de características encontram e excluem características consideradas irrelevantes e redundantes.

Neste capítulo são descritas abordagens para a descrição de imagens que tem relevância neste trabalho, em especial as baseadas no atributo cor, adequadas para análise automática de 
imagens de cenas naturais (descritas na Seção 5.2). Além disso, também são descritas funções de distância úteis para encontrar a similaridade entre um par de imagens. Finalmente as técnicas de redução de dimensionalidade são apresentadas, as quais formam a base para as contribuições desta dissertação.

\subsection{Transformação e Representação de Imagens}

Segundo Gonzalez e Woods (2006), uma imagem pode ser definida como uma função bidimensional $I(i, j)$, onde $i$ e $j$ são coordenadas espaciais e a amplitude de $I$ em qualquer par de coordenadas $(i, j)$ é chamada de intensidade. Quando o par $(i, j)$ e os valores da amplitude de $I$ são finitos e discretos é possível denominar a imagem de uma imagem digital.

A função discreta $I$ é representada no computador usando uma matriz bidimensional de pontos. Um ponto na matriz é chamado de pixel (abreviatura de picture element). Se a imagem digital contém $m \times n$ pixels, então ela é representada por uma matriz $M$, de $m$ linhas e $n$ colunas (Jähne, 2005).

Representar uma imagem pela sua matriz $M$ não permite comparações rápidas e eficientes entre imagens, em especial nos em que o tamanho de $M$ é muito grande ou a quantidade de imagens para comparar é suficientemente extensa. Assim, são necessárias outras formas para caracterizar imagens que destaquem seus atributos ou propriedades e que possam ser usadas para estabelecer um alto nível de similaridade no processo de comparação.

A representação compacta de uma imagem identifica-la de maneira única e deve ser robusta a variações de escala, luminosidade, rotação, ruído, entre outros.

\subsubsection{Descrição de Imagens}

Uma característica é uma função de uma ou mais medidas, calculadas para quantificar alguma propriedade de um objeto. As características compõem a "assinatura"da imagem e são frequentemente utilizadas para descrever uma imagem: com base em suas propriedades externas (por exemplo, as bordas) ou internas (por exemplo, regiões planas ou de padrão contínuo) (Gonzalez e Woods, 2006). Costuma-se optar por uma representação externa quando o foco principal são as características morfológicas ou formas que estão presentes na imagem. Por outro lado, a representação interna é mais usada quando há interesse em propriedades como cor e textura. Em ambos os casos, é importante que as propriedades selecionadas como descritores sejam insensíveis a variações em escala, deslocamento e rotação (Burghouts e Geusebroek, 2009).

A maioria dos sistemas de análise de imagens considerados em visão computacional, recuperação baseada em conteúdo e reconhecimento de padrão, assim como no processo de visuali- 
zação de imagens, usam cor, textura e forma para representar uma imagem (Chen e Gagaudakis, 2000). A seguir, apresenta-se uma breve descrição sobre a representação cor, usado neste trabalho.

\section{Cor}

Diversos sistemas de visualização de imagens consideram a cor como parâmetro para obter uma fácil categorização do conjunto de imagens (Chen e Gagaudakis, 2000; Quadrianto et al., 2010; Yang et al., 2006). As informações de cores de uma imagem podem ser representadas de diferentes maneiras, considerando: a seleção de cores do modelo (espaços de cores) e a forma de representação da cor.

Os espaços de cores definem parâmetros para representar os pixels de forma padronizada através da decomposição da cor em canais distintos. Existem diferentes espaços de cor, como o tradicional $R G B$ (red, green and blue), que descreve as cores com base em três componentes: vermelho, verde e azul, sendo que cada componente pode ter um valor entre 0 e 255 , que resultando em 16 milhões de cores diferentes. Outro espaço de cor é Munsell, o qual descreve as cores com base em três atributos: matiz (pigmento), valor (tonalidade de preto $=0$ a branco $=$ 10) e croma (intensidade das cores: neutras e acinzentadas).

Adicionalmente, foi proposto o espaço de cor HSI, baseado também na matiz, saturação, intensidade; a saturação se refere ao grau de pureza da cor e a intensidade ao valor da claridade (Gonzalez e Woods, 2006). Existem outros modelos, e cada um possui características diferentes que definem os níveis de eficácia para representar uma imagem.

A forma básica de descrever a informação de cor de uma imagem em um vetor consiste em agrupar as informações das cores de cada pixel da imagem, gerando um histograma de cores. $\mathrm{O}$ histograma de cores é o descritor mais comumente utilizado em recuperação de imagens (Gang e Qigang, 2009; Hadjidemetriou et al., 2004; Schaefer, 2009).

\subsubsection{Extração de Características}

O processo de descrição de uma imagem com base em sua informação visual, forma um vetor de características em um espaço $n$-dimensional (Gonzalez e Woods, 2006). O algoritmo que gera esse vetor é chamado extrator de características.

Neste trabalho, considera-se o uso de extratores da informação de cor, devido ao fato de que os conjuntos de imagens utilizados são compostos por cenas naturais (fotografias reais, da atualidade e sem pré-processamento) e nesse contexto a informação da cor é a mais evidente. 
A seguir aborda-se o processo de quantização da cor de uma imagem, na qual a quantidade de cores presentes nela é modificada. Depois são apresentadas abordagens para descrever uma imagem com respeito ao uso dos histogramas de cores. Dentre elas estão as abordagens globais que descrevem o conteúdo visual de uma imagem como um todo, tentam capturar propriedades globais, sem levar em conta informações espaciais ou topológicas. Outras são as abordagens regionais que encontram regiões ou células espaciais para explorar o seu conteúdo visual.

Quantização da Cor Segundo Zhang (2002), antes de qualquer processamento de imagem considerando a cor como descritor, a quantização da cor é um passo importante devido ao grande número de cores diferentes na imagem. A quantização da cor é o procedimento utilizado para reduzir a quantidade de cores existentes.

Sob o modelo de cor $R G B$, por exemplo, existem 256 cores diferentes (em níveis de $0-255$ ) para cada cor primária: vermelho, verde e azul. Isso significa que, em uma imagem colorida com o modelo de cor $R G B$, existem $16.777 .216(256 \times 256 \times 256)$ cores possíveis ao todo.

Se fosse considerado esse conjunto grande de cores, o armazenamento e o processamento seria não-trivial. Adicionalmente, de acordo com a percepção humana, a diferença entre duas cores adjacentes é negligenciável. Portanto, manter tal conjunto de cores grande não é prático nem necessário, podendo ser reduzido a um pequeno número de cores possíveis. Por exemplo, uma imagem pode ser quantificada a partir da cor verdadeira com 16.777.216 de cores possíveis, a apenas 64 cores possíveis para que qualquer tratamento necessário seja mais eficiente.

Existem duas abordagens principais de quantização de cor: quantização de cor uniforme e quantização de cor não uniforme. Na primeira abordagem, todas as imagens são quantizadas para o mesmo conjunto de cores. Estas cores são produzidas através da combinação de muitas cores diferentes dentro de um intervalo pré-definido em uma única cor.

$\mathrm{Na}$ abordagem de quantização não uniforme, diferentes imagens podem ser quantizadas para diferentes conjuntos de cores de acordo com o seu conteúdo; assim as cores podem estar em níveis que são sensíveis à percepção.

Neste trabalho, uma cor $(R, G, B)$ em uma imagem é convertida uniformemente para a cor $(r, g, b)$ num espaço de cor quantizado de acordo com a Equação 2.1.

$$
\left(\begin{array}{l}
r \\
g \\
b
\end{array}\right)=\left(\begin{array}{c}
R * n / 256 \\
G * n / 256 \\
B * n / 256
\end{array}\right)
$$

onde $n$ é o número de subdivisões em que cada uma das três cores primárias está dividida. Por exemplo, a cor original $(23,242,162)$ em um espaço de cor de quantização de $4^{3}=64$ cores é 
convertida para a cor $(23 * 4 / 256,242 * 4 / 256,162 * 64 / 256)$. Em outras palavras, a cor original é convertida para $(0,3,2)$.

Histogramas Globais de Cor (GCH) Um histograma global de cor (Global Color Histogram - GCH) define a quantidade de pixels de cada cor existente em uma imagem (Swain e Ballard, 1991). Descreve-se o histograma $H$ de uma imagem $I$ como um vetor $\left(h_{1}, h_{2}, \ldots, h_{n}\right)$, no qual o valor de $h_{j}$ é a quantidade de pixels de cor $j$ existentes na imagem $I$, como o ilustrado na Figura 2.1. Para obter as características, a imagem é requantizada em um número de cores arbitrário (em geral são escolhidas 64 cores) e, em seguida, é calculado o histograma que representa as características globais de cor da imagem.

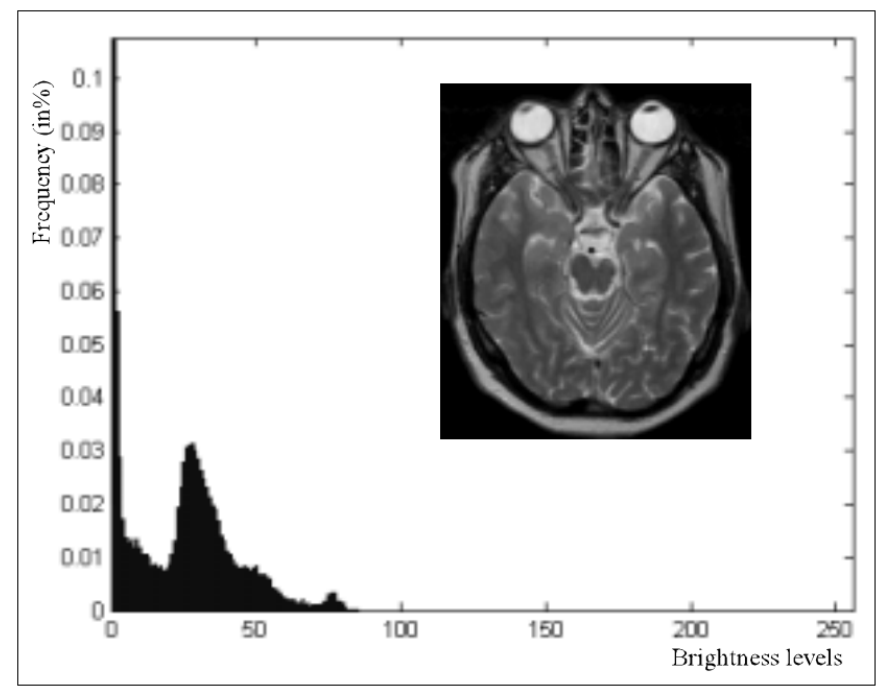

Figura 2.1: Histograma de uma imagem cerebral de ressonância magnética. Extraída de (Traina e Paulo, 2002).

As vantagens usando o $G C H$ são a fácil implementação, eficiência computacional, invariância à rotação e às diferentes visões geradas pelas variações da posição de uma câmera. Não obstante, as desvantagens são a sensibilidade à compreensão das imagens e às mudanças de luminosidade e contraste (Pass et al., 1996). Outra desvantagem importante é que GCH não considera a informação espacial, isto é, não identifica a localização das cores diferentes, mas apenas fornece sua quantidade dentro da imagem. Devido a isso, é possível que duas imagens completamente diferentes tenham histogramas muito semelhantes, como é ilustrado na Figura 2.2.

A implementação do $G C H$ requer a varredura da imagem, colocando cada pixel em uma grade com a cor apropriada. Portanto, o algoritmo para calcular um histograma é executado em $O(n)$, onde $n$ é o número de pixels que formam a imagem. 

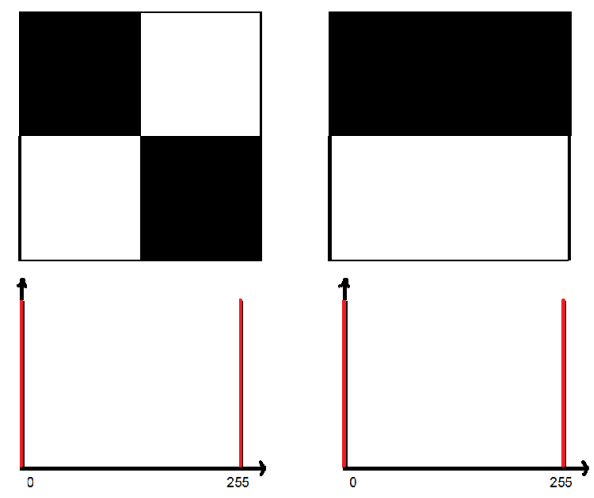

Figura 2.2: Duas imagens distintas com histogramas similares.

Vetores de Coerência de Cores (CCV) O uso dos vetores de coerência de cor (Color Coherence Vectors - CCV) (Pass et al., 1996) é uma maneira eficiente de combater a falta de informação espacial considerando informações sobre a localização das cores nas imagens. Esta técnica encontra grupos similares de pixels a fim de decompor a imagem em regiões. Busca-se assim, a divisão de áreas facilmente distinguíveis pelo olho humano.

A coerência de uma cor é definida como o grau de pertinência de seus pixels às regiões extensas de cores similares. Um pixel coerente é parte de uma grande região de cores semelhantes, caso contrário, é um pixel incoerente. O CCV compara então as imagens com base nessa classificação de pixels coerentes e incoerentes.

Os passos para o cálculo do CCV de uma imagem são:

1. Suavizar a imagem ligeiramente, substituindo os valores do pixel pelo valor médio em uma vizinhança, a fim de eliminar pequenas diferenças entre pixels adjacentes.

2. Reduzir a gama de cores existentes na imagem para $n$ cores diferentes, fazendo com que cada intervalo do vetor seja reduzido, ou seja, que aceite certa gama de tons da mesma cor como única (por exemplo, todos os tons de vermelho devem cair no mesmo intervalo).

3. Calcular as regiões conectadas na imagem. Uma região conectada é definida como um conjunto de pixels de uma mesma cor e que estejam conectados por pixels adjacentes dessa cor (incluindo vizinhos diagonais). O cálculo das componentes conectadas pode ser executado em tempo linear.

4. Determinar se cada pixel da imagem é coerente ou incoerente. Determinar a coerência do pixel em uma região conectada de tamanho $r$. Segundo resultados experimentais sugerem que $r=1 \%$ da área ${ }^{1}$ total da imagem.

\footnotetext{
${ }^{1}$ Definido como o numero total de pixels da imagem
} 
5. Para cada cor $j$ no histograma calcula-se o par $\left(\alpha_{j}, \beta_{j}\right)$, onde $\alpha$ representa o número total de pixels coerentes e $\beta$ é o número total de pixels incoerentes da cor $j$. Assim, o histograma fica como segue: $H=\left(\left(\alpha_{1}, \beta_{1}\right)\left(\alpha_{2}, \beta_{2}\right), \ldots,\left(\alpha_{n}, \beta_{n}\right)\right)$.

A principal desvantagem dos vetores de coerência de cor é a discriminação das imagens devido à mudança do brilho em duas imagens iguais.

Classificação dos pixels da borda/interior (BIC) Stehling e Nascimento (2002) apresentaram Border/Interior pixel Classification - BIC, uma abordagem compacta e eficiente para diversos tipos de imagens. Esta abordagem tenta representar uma imagem pelos objetos contidos nela, de modo similar ao que os humanos usam para observar e descompor uma imagem em objetos, considerando assim uma descrição semântica da imagem. A desvantagem também é a condição na qual a imagem foi obtida, isto é, na presença de iluminação, resolução, entre outros fatores.

Esta abordagem gera uma representação compacta de uma imagem e baseia-se em dois passos importantes apresentados a seguir:

1. Algoritmo de Classificação. Um algoritmo que classifica cada pixel da imagem como borda ou interior é aplicado para criar dois histogramas com todos os pixels classificados em histograma do interior e histograma da borda.

Primeiro a imagem é processada de forma a reduzir o espaço de cores. Por exemplo, o valor recomendado pelos autores é reduzir a 64 cores, mas outros valores podem ser usados. A seguir, deve-se classificar cada pixel da imagem segundo o critério abaixo:

- Um pixel é borda se pelo menos um dos quatro pixels adjacentes a ele (acima, abaixo, esquerda, direita) possui uma cor diferente a ele. Isto significa que o pixel em questão está localizado em uma região onde a divisão de cores pode indicar a borda de um objeto.

- Um pixel é interior se todos os pixels adjacentes a ele têm a mesma cor. Isto é, o pixel em questão é parte de uma região homogênea (na cor), o que pode indicar uma parte importante dentro de um objeto.

Então, devem-se criar dois histogramas de cores: um para pixels da borda e um para pixels interiores, cada um com 64 intervalos. Os valores de cada intervalo são normalizados de forma a eles estarem em uma faixa de 0 a 255 para representar o valor de uma célula com só um byte de memória $\left(2^{8}-1=255\right)$. 
2. Função de Distância Logarítmica. A função para medir a distância entre os histogramas calculados é chamado $d L o g$ porque compara as distâncias em uma escala logarítmica. Esta função reduz a diferença entre as distâncias maiores e menores, o que diminui os efeitos que essas distâncias extremas podem ter sobre a distância total entre os histogramas. Assim, se tem a função $d \log$ definida na Equação 2.2 .

$$
d \log (h, q)=\sum_{i=0}^{i<M}|f(h[i])-f(q[i])|,
$$

onde $h$ e $q$ são os histogramas de $M$ intervalos cada um, $h[i]$ é o valor do intervalo $i$ do histograma $h, q[i]$ é o valor do intervalo $i$ do histograma $q$, e a função $f(x)$ é o valor do intervalo na escala logarítmica, dada por:

$$
f(x)= \begin{cases}0, & \text { se } x=0 \\ 1, & \text { se } 0<x<1 \\ \left\lceil\log _{2} x\right\rceil+1, & \text { caso contrário }\end{cases}
$$

onde $x$ é o número de pixels no intervalo $i$ do histograma $h$.

O uso da função $d L o g$ é uma forma compacta de representar as propriedades extraídas das imagens, pois reduz o espaço de armazenamento dos valores de cada intervalo. Além disso, substitui o valor normalizado de cada intervalo pelo seu equivalente em uma escala logarítmica.

\subsection{Funções de Distância}

Tão importante quanto definir uma representação para as imagens de uma coleção é definir as medidas de similaridade entre elas. Essas medidas determinam o tipo de relação que será denotada pela distribuição dos elementos nos modelos gerados (por exemplo, a visualização da coleção de imagens). Jain et al. (1995) dividem as diversas medidas de similaridade em três categorias.

A primeira delas, baseada em métricas, utiliza a representação de imagens como vetores $n$-dimensionais, onde cada imagem é entendida como um ponto em um espaço multidimensional. Dessa maneira, a distância entre dois pontos representa a dissimilaridade entre duas imagens e, consequentemente, o complemento dessa dissimilaridade produz o valor de similaridade entre elas. Dentre as medidas de similaridade baseadas em métricas, destacam-se a 
classe de Minkowski (Equação 2.4) e, nessa classe, a distância Euclidiana (quando $r=2$ ) e distância city-block (quando $r=1$ ).

$$
d_{r}(X, Y)=\left[\sum_{i=1}^{n}\left|x_{i}-y_{i}\right|^{r}\right]^{1 / r}, r \geq 1
$$

onde $X=\left\{x_{1}, x_{2}, \ldots, x_{n}\right\}$ e $Y=\left\{y_{1}, y_{2}, \ldots, y_{n}\right\}$ representam os vetores de características de duas imagens a serem analisadas.

A segunda categoria, baseada em conjuntos teóricos, utiliza o conjunto de atributos comuns e o conjunto de atributos distintos entre duas imagens para computar sua similaridade. Jain et al. (1995) apresentam um conjunto de medidas com base teórica baseada na lógica crisp ou fuzzy.

A terceira categoria reúne técnicas que levam em consideração atributos binários, sendo baseada na teoria de detecção de sinais (teoria da decisão), e realiza operações utilizando informações sobre a quantidade de atributos cujos valores coincidem em 1 ou 0 e a quantidade de atributos cujos valores valem 1 em uma imagem e 0 em outra (e vice-versa). Algumas medidas de similaridade, como os coeficientes de Jaccard, Dice, Sokal e Sneath, se enquadram nesta categoria (Jain et al., 1995).

Neste trabalho são usadas as medidas de similaridade baseadas em métricas, dentre as quais se destacam as distâncias Euclidiana, city-block, logarítmica, quadrática, de Mahalanobis, bem como a distância jaccard, angular ou distância do cosseno (Tan et al., 2006; Zhang e Lu, 2003).

A distância quadrática, cujo cálculo é ilustrado na Equação 2.5, considera não só a correspondência entre um determinado atributo em duas imagens, mas também a relação entre os atributos da mesma imagem. Desta forma, se consideram só os atributos de uma imagem com informações mais relacionadas. Uma matriz de similaridade entre os atributos é utilizada no cálculo do valor da distância. Um caso especial da distância quadrática é a distância de Mahalanobis, na qual a informação de relação entre os atributos é dada por uma matriz de covariância obtida através de um conjunto de treinamento.

$$
d(X, Y)=\sqrt{(X-Y)^{t} X(X-Y)},
$$

onde $X=\left[x_{i j}\right]$ representa uma matriz de tamanho $N \times N$, e $x_{i j}$ é o coeficiente de similaridade entre as dimensões $i$ e $j$.

Já a distância angular (ou distância do cosseno), descrita pela equação 2.6, calcula a diferença de direção entre os vetores que representam as imagens, sem levar em conta o comprimento destes vetores. A distância é dada pelo ângulo $\theta$ entre os dois vetores de características 
$X$ e $Y$ :

$$
d(X, Y)=1-\cos \theta=1-\frac{X \cdot Y}{|X| \cdot|Y|}
$$

Canberra, é uma métrica também considerada neste trabalho, de cálculo simples, para dados positivos, identificado pelas diferenças da dimensão pela soma de seus valores (equação 2.7) (Emran e Ye, 2001).

$$
d(X, Y)=\sum_{i=1}^{n} \frac{\left|x_{i}-y_{i}\right|}{\left|x_{i}\right|+\left|y_{i}\right|}
$$

A medida de similaridade Jaccard (Strehl, 2002), permite la discriminación de vectores colineales, como descrive a siguinte equação:

$$
d(X, Y)=\frac{X \cdot Y}{\|X\|^{2}+\|Y\|^{2}-X \cdot Y}
$$

Um ponto importante a considerar neste trabalho é que esses tipos de distâncias podem causar uma limitação em relação à comparação entre dois histogramas de cores. Essa limitação ocorre quando um valor do histograma é muito alto e domina o valor da distância. Isso pode ocorrer, por exemplo, com imagens que possuem uma cor predominante; um valor muito alto tende a dominar a função e encobrir resultados das outras cores, que apesar de ser menos frequentes, podem ser importantes para diferenciar as imagens. Isso pode ser amenizado com o uso de uma distância logarítmica $d \log$, descrita anteriormente para o extrator $B I C$, que tem como principal objetivo atenuar este problema. Desse modo, a distância logarítmica atua de forma que as diferenças fiquem sempre entre um intervalo fixo ${ }^{2}$, atribuindo a mesma importância para todos os valores de um histograma na comparação.

\subsection{Técnicas de Redução de Dimensionalidade}

Encontrar um conjunto de características (valores numéricos) que representem um conjunto de dados é um desafio. Geralmente os objetos podem ser representados de várias maneiras e cada um dos descritores captura propriedades diferentes dos dados. Qual deles usar depende muito da tarefa atual e da semântica do descritor. Por exemplo, os diferentes descritores podem focar-se em propriedades como cor, textura e forma; como foi mencionado na Seção 2.2 .

Por um lado, um descritor tenta capturar tanto a informação disponível quanto possível e isso pode resultar em uma alta dimensionalidade. As causas podem ser extrair mais características

\footnotetext{
${ }^{2}$ Seguindo a condição que se os vetores sendo comparáveis possuírem valores entre 0 e 255 (normalização feita no $B I C)$
} 
ou acrescentam o número através da combinação de descritores disponíveis. Por outro lado, se extrair apenas um pequeno conjunto de características, a informação obtida pode mostrar semelhanças ou não entre os diferentes objetos que não foram discriminados um do outro.

O tamanho e o conteúdo de um vetor de características de um conjunto de imagens é um fator importante a ser considerado, por exemplo, para os sistemas $C B I R$. A ocorrência de muitos elementos no vetor pode afetar o desempenho ou tempo necessário para calcular o grau de similaridade entre imagens. Além disso, o vetor pode apresentar uma frequente correlação entre suas características, o que introduz a redundância de informações que prejudicam a capacidade de distinção entre objetos. Se existe alta cardinalidade e redundância na representação dos dados, então um processo de redução de dimensionalidade deve ser realizado (Berchtold et al. 1998).

Uma técnica de redução de dimensionalidade visa encontrar e agrupar características importantes, achando similaridades muitas vezes não percebidas em altas dimensões. Em geral, uma técnica de redução de dimensionalidade cria um novo espaço de características. Existem essencialmente dois métodos de redução de dimensionalidade: transformação de características e seleção de características. A primeira forma é o processo de criar novas características a partir de transformações ou combinações do conjunto de características original. Os algoritmos de transformação de características tentam manter a maioria do conteúdo de informação intrínseca dos dados em uma dimensão muito menor, quando comparado à dimensão dos dados originais (Artero et al., 2006; Avalhais et al., 2012; Johansson e Johansson, 2009; Paiva et al., 2012; Yang et al., 2003).

A outra abordagem, conhecida como seleção de características, é guiada por algum critério de avaliação para encontrar o subconjunto de características mais relevantes do conjunto original. Se as características redundantes ou de menor discriminação são ignoradas e o conjunto de dados consegue ainda assim manter as suas propriedades então as características de menor importância podem ser eliminadas. Em várias técnicas o critério de avaliação utilizado é a contribuição do subconjunto de características sob avaliação na tarefa de classificação de dados (Auffarth et al., 2010; Dash e Liu, 1997; Duchesnay et al., 2011; Guo et al., 2008; Hall, 1998; Ribeiro et al., 2009; Wang et al., 2003; Yang et al., 2003).

\subsubsection{Transformação de Características}

A seguir é apresentada uma técnica, que é uma das mais utilizadas na transformação de características, obtendo como resultado a redução da dimensionalidade. Outras técnicas de transformação de espaço de características são mencionadas na Seção 3.2.1. do ponto de vista da projeção multidimensional. 


\section{Análise de Componentes Principais (PCA)}

Sua criação é atribuída a Pearson (1901). Embora seja uma técnica antiga, trabalhos recentes ainda a utilizam como técnica-base para redução de dimensionalidade. A Análise de Componentes Principais (Principal Component Analysis - PCA) considera a transformação de variáveis relacionadas em um subconjunto de características com dimensionalidade reduzida, composta por componentes não relacionados, chamados componentes principais. A técnica permite extrair padrões que permitem realçar as similaridades e diferenças entre os elementos de um conjunto de dados. Seu funcionamento baseia-se na criação de componentes a partir de variáveis de um conjunto de dados, cujos valores possuem alta variância.

Seja $X$ um conjunto de dados $n$-dimensional formado por uma matriz $m \times n$, com valores numéricos. Seja o vetor $x_{i}=\left(x_{1 i}, x_{2 i}, \ldots, x_{m i}\right)$ com $i=1,2, \ldots, n$ isto é, um vetor-coluna para cada dimensão. A técnica $P C A$ pode ser executada através dos seguintes passos:

1. Calcular a média $\bar{x}_{i}$ para cada vetor e subtrair dos valores originais. Isto produz novos vetores $x_{i}$, cuja média é zero: $x_{i}=\left(x_{1 i}-\bar{x}_{i}, x_{2 i}-\bar{x}_{i}, \ldots, x_{m i}-\bar{x}_{i}\right) ; i=1,2, \ldots, n$.

2. Calcular a matriz de covariância $C$, tal que: $C_{n \times n}=\left[c_{i j}\right]$, onde $c_{i j}=\operatorname{cov}\left(x_{i} ; x_{j}\right)$.

3. Determinar os autovalores e autovetores da matriz $C$. Uma vez que $C$ é uma matriz simétrica real, então um possível número real $\lambda$ e um vetor não-nulo $\alpha$ podem ser encontrados tal que $C \alpha=\lambda \alpha$; onde $\lambda$ é chamado um autovalor e $\alpha$ um autovetor de $C$.

4. Ordenar os autovalores e correspondentes autovetores tal que $\lambda_{1}>\lambda_{2}>\ldots>\lambda_{n}$. Na realidade o autovetor com o maior autovalor é a componente principal do conjunto de dados.

5. Selecionar os primeiros $p \leq n$ autovetores para formar um vetor de características.

6. Para gerar o conjunto de dados na nova representação, multiplica-se o vetor de características pelo conjunto de dados com a média ajustada. Para reduzir a dimensionalidade deixam-se de fora alguns autovetores, de modo que o novo conjunto de dados é representado somente em termos dos vetores que foram mantidos.

O maior problema com $P C A$, no entanto, é que o tamanho da matriz de covariância é proporcional à dimensionalidade do conjunto de dados. Como consequência, o cálculo dos autovetores pode ser impraticável para dados com dimensão muito alta.

Na Seção 3.2.1, a técnica $P C A$ também é apresentada como uma técnica de projeção multidimensional. 


\subsubsection{Seleção de Características}

Para resolver o problema de determinar a dimensionalidade adequada para a entrada de algum algoritmo, pode-se usar a seleção de características. A tarefa é desconsiderar termos irrelevantes e redundantes das características que descrevem o conjunto de imagens.

Segundo Kohavi e John (1997) uma característica $x$ é fortemente relevante se sua remoção degrada a performance de alguma tarefa de mineração de dados, como classificação ou agrupamento. Por sua vez, Yu e Liu (2004) propõem que as características fracamente relevantes sejam divididas em redundantes e não redundantes. Uma característica é redundante com relação à outra se seus valores estão completamente correlacionados. Então um subconjunto ótimo é constituído por características fortemente relevantes e não redundantes.

A seleção de características têm benefícios importantes que incluem (Faceli et al., 2011):

- Aprimoramento do desempenho dos métodos de mineração, visualização e de consultas aplicados aos dados, em termos de eficiência (economia de espaço de memória e de operações computacionais) e eficácia (remoção de características irrelevantes, ruidosas e correlacionadas).

- Geração de modelos de dados mais simples e compreensíveis.

- Auxílio na limpeza e compreensão dos dados, possibilitando relacionar as características aos conceitos meta como sumarização, identificação de classes, entre outros.

Segundo Tan et al. (2006) um processo de seleção de características consiste em quatro partes importantes (Figura 2.3):

1. A medida de avaliação da qualidade do subconjunto de características.

2. A estratégia de busca que tem o controle da geração de novos subconjuntos de características.

3. O critério de parada.

4. Avaliação dos resultados com base no algoritmo de aplicação (um classificador por exemplo).

Assim, um dos desafios principais da seleção de características é explorar o espaço de busca para encontrar o subconjunto de características que melhor represente um conjunto de dados. Algumas estratégias incluem ordenação de características, busca sequencial, estratégia meta-heurísticas, busca aleatória e incremental (Dash e Liu, 1997). 


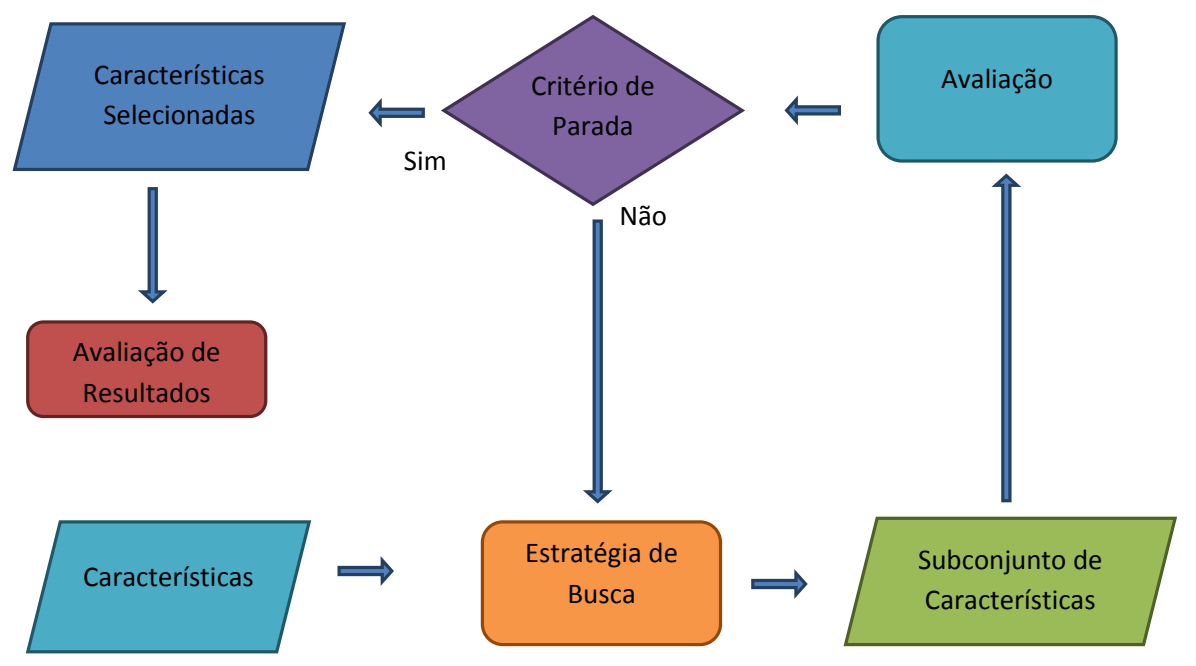

Figura 2.3: Fluxograma de um processo de seleção de características. (Modificado de (Tan et al., 2006).

- Buca por Ordenação: Ordena as características por mérito individual, avaliando-as uma a uma.

- Busca sequencial para a frente. As características são adicionadas ao subconjunto candidato uma a uma.

- Busca sequencial para trás: A partir do conjunto completo de características, as características são removidas sucessivamente uma a uma.

- Estratégias meta-heurísticas: São estratégias de alto nível pelo uso de diferentes métodos, reúnem a busca tabu, algoritmos genéticos, colônia de formigas, dentre outros.

- Busca Aleatória: Subconjuntos de características candidatas são geradas aleatoriamente até se encontrar uma solução ótima.

- Busca Incremental: Une-se à estratégia sequencial com uma avaliação constante de um subconjunto de candidatos pertencentes a um ranking de características. 


\section{Categorização dos Métodos de Seleção de Características}

Tan et al. (2006) classifica os métodos de seleção de características, de acordo com o critério de avaliação empregado, em filtro, wrapper, embutido e híbrido. Os métodos de cada grupo podem ser categorizados também como supervisionados ou não supervisionados.

- Filtros. Realiza um pré-processamento nos dados, de modo que as características sejam agrupadas dependendo de alguma propriedade intrínseca dos dados. O processo é independente da aplicação de qualquer algoritmo de classificação. A maneira mais básica de aplicar um algoritmo filtro é usar, por exemplo, alguma propriedade estatística dos dados para ordenar as características de acordo a sua importância, ortogonalidade e alto conteúdo de informação (Hall, 1998; John et al., 1994; Liu e Setiono, 1996).

- Wrappers. Avalia cada subconjunto de características a partir do resultado obtido na aplicação de um algoritmo de classificação, por exemplo. Ou seja, considera o algoritmo classificador como uma caixa preta e utilizá-lo no algoritmo de busca heurística para avaliar cada subconjunto de características candidato. Em geral, o custo computacional é grande comparado ao emprego de filtros, pois cada conjunto candidato é avaliado com um algoritmo de classificação. Este fato gerou muitas pesquisas que tentaram aplicar essa abordagem de modo eficiente em grandes conjuntos de dados. Por exemplo, para percorrer o espaço de soluções, duas estratégias foram pesquisadas: a busca exaustiva e a busca heurística (Dy e Brodley, 2000a; John et al., 1994; Kohavi e John, 1997).

- Embutidos. A seleção de características é incorporada a um algoritmo de aprendizado, por exemplo, dentro de um classificador. A busca pelas características mais relevantes é guiada pelo processo de aprendizado, construindo um modelo de predição. As árvores de decisão são um exemplo que realiza esse tipo de seleção interna (Ankerst et al., 2000).

- Híbridos. Avaliam as características pelas abordagens filtro e wrapper. Por exemplo, o filtro é empregado para melhorar a eficiência de um método wrapper (Das, 2001; Xing et al., 2001).

Por outro lado, de acordo com a interação do procedimento de seleção de características, por exemplo, com um algoritmo de classificação, a seleção de características pode ocorrer de forma global ou local (Dash e Liu, 1997).

- Seleção Local de Características. Um subconjunto de características é escolhido para cada classe, usando a suposição de que cada grupo possui seus termos mais importantes que ajudam a discriminar esse grupo dos demais. 
- Seleção Global de Características. Processo que seleciona um único subconjunto de características no processo de busca; o que ajuda a conhecer as características importantes antes de realizar o processo de classificação, tornando o processo mais eficiente e focado somente nas características mais relevantes.

\subsection{Considerações Finais}

Neste capítulo foram abordados métodos de extração de características capazes de representar imagens, em especial às imagens com cenas naturais, considerando a cor como atributo principal para representá-las. Apresentaram-se também as funções de distância mais utilizadas e técnicas de redução de dimensionalidade.

Após a descrição dos métodos, é importante considerar que:

- Após obter um conjunto de vetores que representam uma coleção de imagens, surge a importante necessidade de fazer um estudo sobre eles, a fim de revelar informações úteis para os usuários, como conhecimento implícito, relacionamento dos dados ou padrões não explícitos nas imagens. Assim, todos esses fins pertencem ao objetivo principal da visualização de imagens.

- Na seleção de características o objetivo é escolher um subconjunto de características, a fim de melhorar o desempenho e a eficiência em relação a uma tarefa. No nosso caso, a tarefa é avaliar a boa visualização que é refletida na similaridade ou separação em agrupamentos e na redução da ocorrência de ruídos. A perda de informação na redução do espaço características deve ser mantida tão pequena quanto possível, de modo que o espaço resultante possa fornecer informação suficiente para o agrupamento.

- Frequentemente, nos sistemas CBIR (Avalhais et al., 2012; Rodrigues e Traina, 2005; Traina e Paulo, 2002) e de reconhecimento de padrões, a extração de características precede a seleção, que elimina os atributos mais irrelevantes segundo um determinado critério. Esse processo pode ser levado também no âmbito da visualização de imagens. 


\section{Visualização de Imagens}

\subsection{Considerações Iniciais}

Segundo Tan et al. (2006) a visualização de dados refere-se a uma representação gráfica na qual dados multidimensionais são posicionados na tela de um computador (por exemplo) a fim de refletir suas relações de similaridade. Assim, esses dados podem ser analisados e reportados atendendo a necessidades específicas e suas aplicações.

A visualização de grandes conjuntos de dados multidimensionais como imagens apresenta vários desafios. Um deles é a identificação de informações ou conhecimento relevante na visualização, permitindo a discriminação dos objetos em diferentes classes ou grupos; sem perder a capacidade de identificar elementos não facilmente agrupáveis.

Outro desafio é encontrar representações simples que sejam fiéis ao conjunto de dados completo e às relações entre eles, considerando a limitação da baixa dimensionalidade dos dispositivos de apresentação. Neste sentido existem diversos métodos para representar dados multidimensionais. Dois deles foram estudados no presente trabalho: as projeções multidimensionais e as estruturas em árvore (Cuadros et al., 2007).

Os tópicos desenvolvidos neste capítulo são: os métodos de projeção e as árvores de similaridade. Depois, foca-se na visualização de imagens, citando os sistemas e técnicas desenvolvidas na atualidade. Descreve-se também, um estudo da visualização multidimensional na seleção 
de características. Finalmente, apresentam-se as propriedades de interação a serem integradas em todo o sistema de visualização e as medidas de avaliação estudadas.

\subsection{Técnicas de Visualização de Informação}

Técnicas de Visualização de Informações buscam representar graficamente os dados de um determinado domínio de aplicação de modo que a representação visual gerada sirva de apoio na interação direta do usuário ao explorar e transformar o conhecimento em informação útil (Ferreira de Oliveira e Levkowitz, 2003).

Algumas ferramentas de visualização existentes (Eler et al., 2008; Fruchterman e Reingold, 1991; Jourdan, 2004; Paulovich et al., 2007; Ward e Rundensteiner, 2005) usam técnicas baseados em projeções multidimensionais, as quais frequentemente possibilitam o layout em baixas dimensões, como 2 ou 3 (2D ou 3D). O resultado da projeção é o posicionamento, por exemplo, de pontos em um plano onde a proximidade entre eles sugere similaridade. Outras técnicas utilizadas são estruturas em árvore (Cuadros et al., 2007; Evans et al., 2006; Lamping et al., 1995; Nguyen e Huang, 2002; Paiva et al., 2011; Robertson e Mackinlay, 1991; Saitou e Nei, 1987), as quais são baseadas no mesmo critério de projeção mas impõem uma hierarquia nos dados. A seguir, as técnicas são apresentadas com maiores detalhes.

\subsubsection{Projeção Multidimensional}

A projeção de dados multidimensionais consiste na redução de dimensionalidade, preservando o máximo possível as relações de distância existentes entre os dados (Ward e Rundensteiner. 2005), isto é, buscando garantir que os pontos posicionados próximos entre os dados no layout, representem dados similares de acordo com a distância escolhida. Entende-se por "distância", a métrica que melhor representa a diferença entre os objetos do domínio em estudo. Assim, quanto menor for a distância entre dois objetos, maior será a correlação entre eles.

Segundo Tejada et al. (2003), uma técnica de projeção multidimensional é definida como um conjunto de dados $X=\left\{x_{1}, x_{2}, \ldots, x_{n}\right\} m$-dimensional tal que pertence a $\Re^{m}, \delta: \Re^{m} \times \Re^{m} \rightarrow$ $\Re$ uma medida de dissimilaridade entre os dados e $p$ o numero de dimensões do layout, por exemplo $p=2$. Um conjunto de pontos $X^{\prime}$ em $\Re^{p}$ é o resultado da projeção tal que $\alpha$ : $X \rightarrow X^{\prime}$ é uma função bijetora, que mapeia o conjunto de dados para o espaço bidimensional $(p=2)$ cujas coordenadas podem ser usadas para uma representação gráfica. Então, busca-se minimizar a diferença: $\delta\left(x_{i}, x_{j}\right)-d\left(\alpha\left(x_{i}\right), \alpha\left(x_{j}\right)\right)$, para $\forall x_{i}, x_{j} \in X$, onde $d: \Re^{p} \times \Re^{p} \rightarrow \Re$ é uma distância para espaços bidimensionais. Assim, a similaridade apresenta-se por meio da vizinhança espacial entre as instâncias na projeção. 
Segundo apontam Cuadros et al. (2007); Paulovich et al. (2007), as técnicas de projeção multidimensional podem ser divididas em dois grupos de acordo com as funções empregadas: técnicas de projeção lineares e não lineares. As técnicas de projeção lineares criam combinações lineares dos atributos dos dados, definindo-os em uma nova base ortogonal de pequena dimensão. Uma técnica linear amplamente conhecida é Análise de Componentes Principais -PCA (Jolliffe, 2002).

As técnicas lineares, apesar de ter um bom desempenho na distribuição normal (Gaussiana) de dados (Paulovich, 2008), geralmente não conseguem capturar padrões relevantes nos dados que apresentam estruturas não-lineares, como quando são agrupados de formas arbitrárias ou curvas. Em tais casos, as técnicas de projeção não lineares são capazes de gerar projeções melhores.

Por outro lado, as técnicas não lineares lidam com o problema acima mencionado considerando um processo de otimização na tentativa de minimizar a perda de informações (relações de distância) ocorrida na projeção. A técnica de projeção não linear Multidimensional Scaling $(M D S)$ (Torgerson, 1952), compreende toda uma classe de técnicas de projeção não-linear como: Sammomn's Mapping (SM) (Sammon, 1969) e aquelas baseadas em Force-Directed Placement (FDP) (Fruchterman e Reingold, 1991). Como alternativa que visa reduzir a complexidade dos algoritmos mencionados, Paulovich et al. (2008) propõem uma técnica de redução de dimensionalidade denominada Least Square Projection (LSP). As técnicas mais relevantes estudadas ao longo deste trabalho são apresentadas a seguir.

\section{Análise de Componentes Principais}

Análise de Componentes Principais (Principal Component Analysis - PCA) (Jolliffe, 2002), como já foi vista na Seção 2.4.1 do capítulo anterior, fornece-se que na área de técnicas de projeção multidimensional sua principal desvantagem é a baixa qualidade dos layouts resultantes, devido à baixa dimensão (2D) para expressar características importantes em conjuntos de dados heterogêneos. Outra desvantagem é o custo computacional, $O\left(m^{2} n\right.$ ) (onde $m$ é o número de dimensões), que é inaceitável quando o número de elementos $n$ dos conjuntos de dados é muito grande, por exemplo, a partir de mil elementos.

\section{Multidimensional Scaling}

Técnicas Multidimensional Scaling MDS (Torgerson, 1952) compõem uma família de métodos matemáticos que focam em descobrir o subespaço que melhor preserva as distâncias inter-pontos. Tipicamente, a classe de técnicas $M D S$ busca aproximar as distâncias entre pontos $d_{i, j}$ de suas dissimilaridades $\delta_{i, j}$ para todos os pares de objetos $i, j$ do espaço original, de 
maneira que: $d_{i, j} \approx f\left(\delta_{i, j}\right)$, onde $f$ é uma função paramétrica monotônica ${ }^{1}$ contínua que tenta transformar a medida de proximidade em distâncias. De acordo com Cox e Cox (2001), a razão de existir diferentes modelos $M D S$ é devido à diferentes noções de aproximação definidas por $f$. Dentre as técnicas que seguem o modelo MDS destacam-se as técnicas chamadas Sammon's Mapping e Force Directed Placement.

\section{Sammom Mapping}

Na técnica Sammon Mapping (Sammon, 1969) aplica-se uma função de otimização para minimizar a quantidade de informação perdida durante o processo do cálculo das similaridades entre itens dos dados (Zhang, 2008). Essa função é otimizada aplicando procedimentos não lineares de busca local na direção do gradiente da função. O custo computacional da técnica é de ordem quadrática $O\left(n^{2}\right)$ o que representa uma desvantagem em relação às técnicas de projeção mais rápidas descritas a seguir.

\section{Force Directed Placement}

Uma classe relevante das técnicas MDS é composta por projeções baseadas em Force-Directed Placement (FDP) (Fruchterman e Reingold, 1991). Originalmente foi proposta como uma heurística para desenho de grafos, pois tenta gerar um sistema composto por instâncias ligadas por fontes imaginárias em um estado de equilíbrio, em que cada objeto é associado aos outros por esta "força".

Para aplicar o modelo de FDP como uma técnica de $M D S$, as forças das fontes devem ser proporcionais à diferença entre as dissimilaridades $\delta\left(x_{i}, x_{j}\right)$ e as distâncias $d\left(f\left(x_{i}\right), f\left(x_{j}\right)\right)$, isto é, proporcional à distância calculada no espaço original.

A complexidade do algoritmo é de $O\left(n^{3}\right)$ e Jourdan (2004) conseguiu reduzir a complexidade para $O(n \log n)$.

\section{Least Square Projection - LSP}

Uma técnica de projeção de mínimos quadrados foi desenvolvida por Paulovich et al. (2008), com o objetivo de criar uma superfície onde os dados estejam agrupados por relações de proximidade, garantindo a capacidade de preservação local e global por meio da projeção da vizinhança entre os objetos e pela posição de seus "pontos de controle" conservando as relações de similaridade.

\footnotetext{
${ }^{1}$ Uma função é denominada monotônica quando for uma função crescente, decrescente ou constante.
} 
Essa abordagem é realizada em três passos: Primeiro, define-se uma relação de vizinhança entre os objetos. Uma lista $V_{i} \in V=\left\{V_{1}, \ldots, V_{n}\right\}$ de objetos vizinhos $V_{i}=\left\{x_{i_{1}}, \ldots, x_{i_{i}}\right\}$ para cada objeto $x_{i} \in X$, criada com o algoritmo de $k$ vizinhos mais próximos de $x_{i}$ (o valor de $k$ é fornecido pelo usuário) segundo uma função de distância $d$. Logo se estabelece a vizinhança dos objetos como se a mesma fosse uma malha com um único componente conexo. Se algum objeto $x_{i}$ está desconexo dos demais, então deve-se incluir na sua lista de vizinhos $V_{i}$ um novo vizinho que faça parte do componente conexo principal.

Depois se escolhe um subconjunto de pontos $P=\left\{p_{1}, \ldots, p_{n c}\right\}$ chamado de pontos de controle. A escolha dos $n c$ pontos de controle pode ser feita de duas formas: aleatória ou baseada em agrupamentos. A abordagem baseada em agrupamentos divide o conjunto de objetos em $n c$ agrupamentos e escolhe o medoide de cada agrupamento como sendo o ponto de controle.

Então, constrói-se um sistema linear esparso baseado nas relações de vizinhança e nas coordenadas cartesianas dos pontos de controle projetados. A projeção de cada ponto de controle $x_{i}$ será o centroide das projeções dos objetos da sua vizinhança $V_{i}$. Finalmente, são projetados todos os dados por um método de projeção convencional como MDS ou FDP.

LSP é uma técnica de projeção rápida e precisa sobre dados complexos e de alta dimensionalidade comparada com outras técnicas. No entanto, possui um alto custo computacional em conjuntos de dados muito grandes, e requer uma considerável quantidade de memória. A complexidade computacional é determinada pelo número de agrupamentos identificados com que trabalha a técnica. Para $\sqrt{n}$ agrupamentos será $O(n \sqrt{n})$.

\subsubsection{Visualização Baseada em Árvore}

Uma alternativa ao mapeamento de dados baseado em projeções é a imposição de uma hierarquia sobre algum relacionamento significativo dos dados, por exemplo, o grau da similaridade calculada sobre as coordenadas da representação vetorial. A hierarquia extraída deste processo é refletida na forma de uma árvore (daí o termo "árvore de similaridade"), que é visualizada através de algoritmos apropriados de apresentação de árvores.

As árvores têm uma estrutura hierárquica que organiza as entidades de dados por meio de conexões pai-filho. Para ser uma árvore clássica, cada entidade filho deve ter apenas um pai e cada filho posiciona-se "embaixo" de um ancestral comum. No qual os nós representam objetos e as arestas representam a ligação entre eles.

Quando se usa uma árvore como estrutura visual, é muito importante a maneira como o espaço é utilizado no posicionamento dos nós. Porém, ele pode ser adaptado para produzir um layout que cobre todo espaço visualizável. Nguyen e Huang (2002) apresentam diferentes 
técnicas para gerar árvores, com mais destaque as ilutradas na Figura 3.1. Árvore-H, Visão Radial, Visão em Balão e Mapa em Árvore.

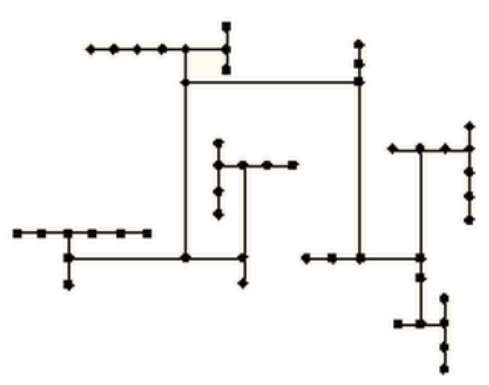

(a)

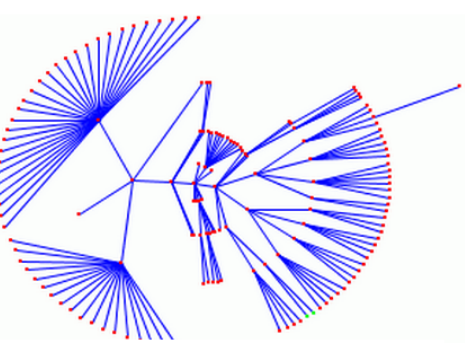

(b)

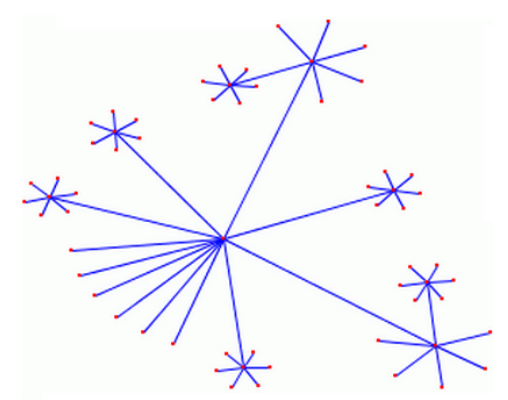

(c)

Figura 3.1: Visualizações em Árvores. a) Árvore-H, b) Visão Radial, c) Visão em Balão. Extraído de (Nguyen e Huang, 2002).

Uma Árvore-H representa em geral uma árvore binária. A árvore se expande por todo o layout, mas quanto à efetividade destas árvores só apresentam um bom desempenho se a árvore for equilibrada.

A Visão Radial posiciona os filhos em fatias circulares de uma sub-árvore. Contudo, essa técnica não é otimizada no uso do espaço disponível. Por outro lado, a visão em balão é formada por sub-árvores irmãs que são dispostas em círculos ligados ao nó pai. O algoritmo se comporta bem para árvores com dados equilibrados, mas desperdiça uma grande parte do espaço de exibição como a visão radial.

A maioria destas estruturas se preocupa na organização dos nós, mas não usam todo o espaço visual (por exemplo, a visão em balão) ou tem estruturas hierárquicas grandes que geram árvores de difícil visualização (por exemplo, a visão radial). Por isso, alguns sistemas de visualização usam interações e distorções. Por exemplo, a técnica chamada Árvores em Cone (Cone Trees (Robertson e Mackinlay, 1991)) consegue exibir grandes hierarquias organizando sub-árvores em cones 3D. Dessa maneira, essa técnica aumenta drasticamente a quantidade de nós exibidos na tela como mostra a Figura 3.2 Porém, as árvores em cone possuem a deficiência de ocultar muitos nós, mas isso é controlado pelo uso da animação e interação com usuário. 


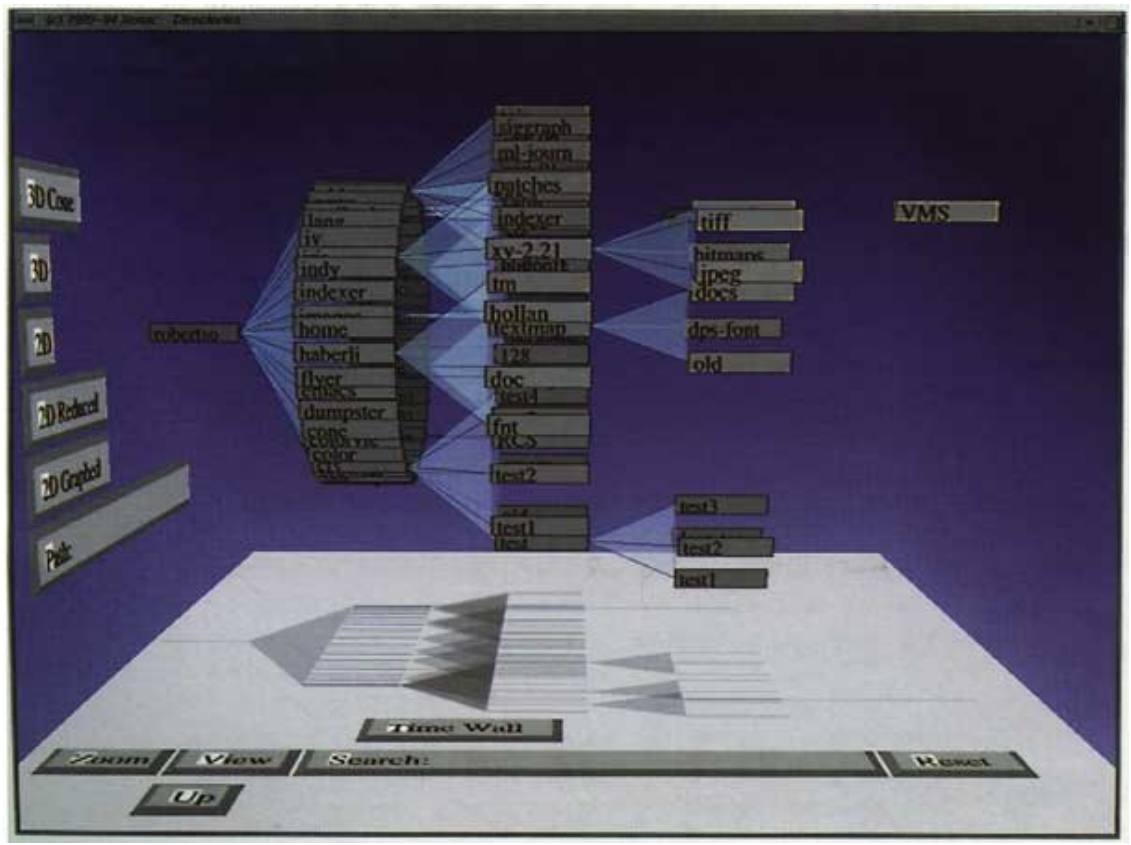

Figura 3.2: Árvores em Cone. Extraído de (Robertson e Mackinlay, 1991).

Outra técnica, chamada de Árvore Hiperbólica usa a projeção hiperbólica, a qual tenta diminuir o tamanho dos nós próximos à periferia para agrupar mais nós na tela e mostrar mais detalhes de uma vizinhança desde um determinado ponto de foco (Lamping et al., 1995). Um exemplo desta visualização é mostrado na Figura 3.3 .
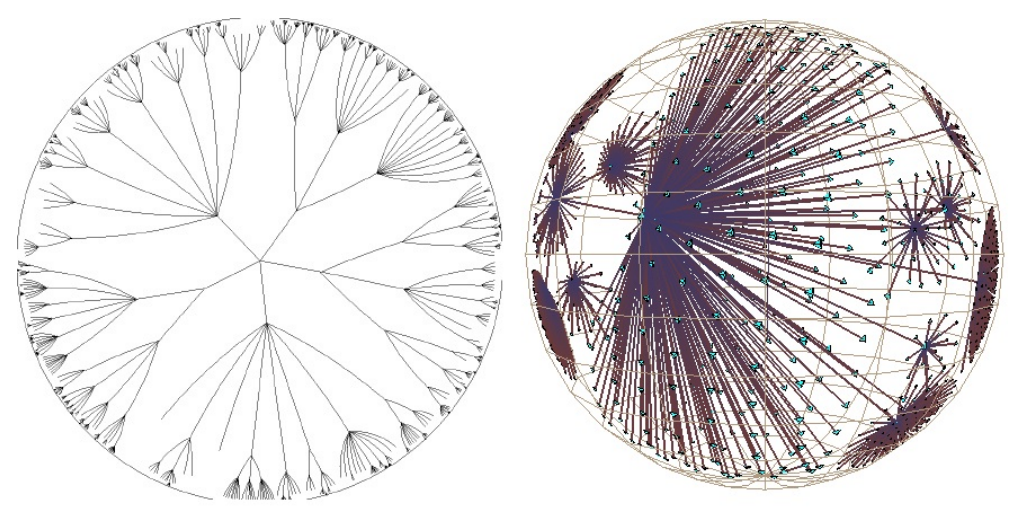

Figura 3.3: Árvores hiperbólicas em 2D e 3D. A estrutura apresenta uma árvore de informações hierárquica com sua raiz inicialmente no centro. Extraído de (Lamping et al., 1995).

O Mapa em Árvore ( Tree-Maps (Shneiderman, 1992)) é um método de visualização em árvore, em caixas, de preenchimento do espaço utilizado em estruturas hierárquicas. $\mathrm{O}$ atributo visual "tamanho" é especialmente útil na representação das variáveis que podem ser decompostas hierarquicamente. Como mostrado na Figura 3.4, o Mapa em Árvore pode ser usado para 
fazer com que os nós de maior importância sejam colocados em regiões maiores que aqueles de menor importância. Isso permite aos usuários comparar os tamanhos dos nós e das sub-árvores, ajudando a mostrar padrões hierárquicos incomuns.

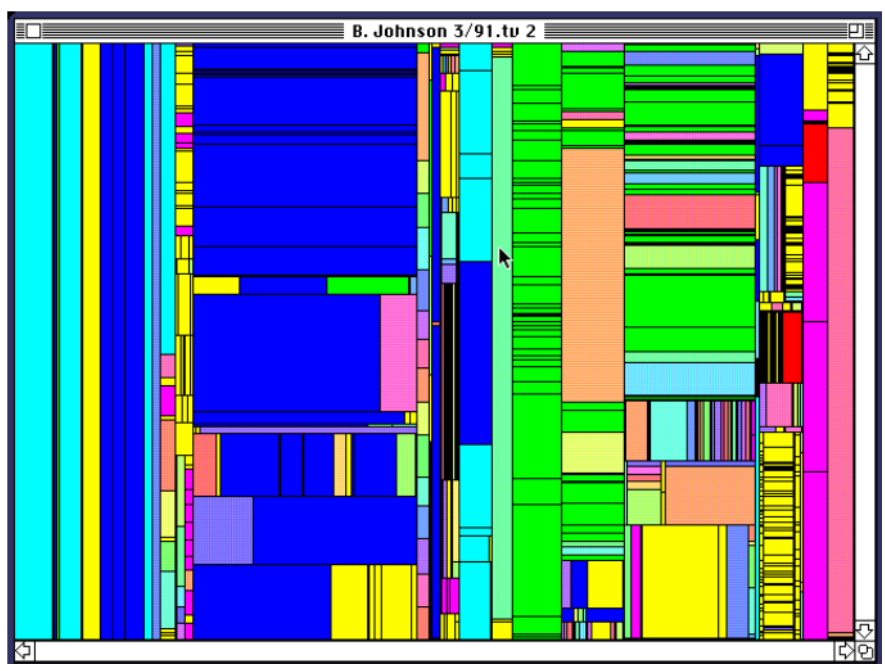

Figura 3.4: Modelo da visualização TreeMap ou Mapas de Árvore. Extraído de (Shneiderman, 1992).

O Mapa em Árvore começa a ter deficiência quando o número de dimensões dos dados cresce. Neste caso, as estratégias baseadas em pontos tomam vantagem.

A seguir, cita-se a técnica de árvore de similaridade Neighbor-Joining (NJ) com a capacidade de resolver o aumento da dimensionalidade e refletir sobre a tela os dados como pontos e suas vizinhanças encontradas no espaço multidimensional.

\section{Neighbor-Joining - NJ}

Segundo Saitou e Nei (1987), as árvores de similaridade podem ser construídas a partir de matrizes de distâncias, por meio de algoritmos de reconstrução de árvores filogenéticas. Essas árvores buscam refletir relações de similaridade a partir de princípios de evolução mínima² entre os organismos vivos, codificando relações de ancestralidade entre espécies. Assim, em uma árvore filogenética as folhas representam os objetos originais da matriz de distâncias, os nós internos são ancestrais hipotéticos e os ramos (arestas) indicam a distância evolutiva entre os objetos, como pode ser observado na Figura 3.5 .

O método Neighbor Joining ( $N J)$, é amplamente usado na construção de filogenias e é comparado positivamente em relação às projeções multidimensionais, que trabalham com conceitos de redução de dimensionalidade e similaridade por proximidade no plano de projeção.

\footnotetext{
${ }^{2} \mathrm{O}$ critério de evolução mínima tenta minimizar a soma dos tamanhos de todos os nós da árvore.
} 


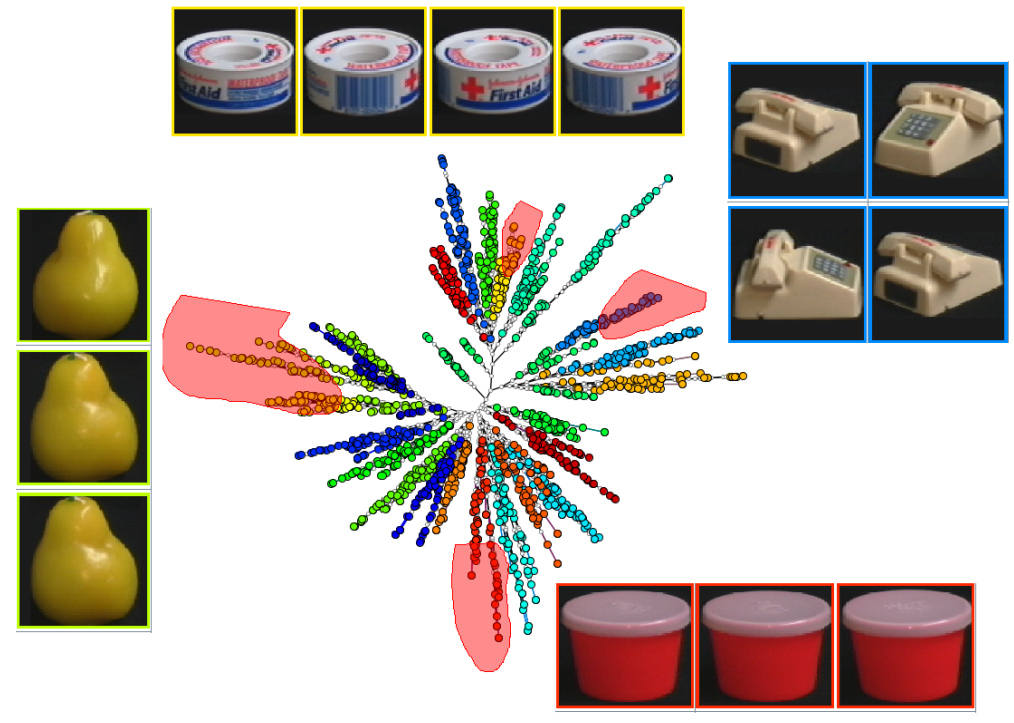

Figura 3.5: Árvore de similaridade do conjunto de 700 imagens COIL usando o algoritmo NJ. Nota-se a revelação de agrupamentos definidos pelos ramos das árvores, recuperando por cada ramo, com as imagens do mesmo grupo igual ao espaço original (imagens recuperadas perto de cada ramo).

O algoritmo do Neighbor Joining foi proposto inicialmente por Saitou e Nei (1987) e modificado em muitos trabalhos (Cuadros et al., 2007; Eickmeyer et al., 2008; Elias e Lagergren, 2009; Evans et al., 2006; Mailund et al., 2006; Paiva et al., 2011; Simonsen e Mailund, 2008). Cita-se como um trabalho importante o de Cuadros et al. (2007), onde apresenta-se uma árvore filogenética sem raiz capaz de representar relacionamentos que permite ao usuário recuperar rapidamente a informação detectada pela semelhança métrica. Usada para uma variedade de dados de diferentes naturezas, permite alcançar a maior eficiência da exploração e capacidade de visualização mais clara das relações entre os dados.

No desenvolvimento do algoritmo é considerado, inicialmente, que todos os $n$ objetos da matriz de distâncias $D$, representados como nós folha, estão conectados por ramos a um único nó interno, formando uma árvore-estrela. No passo seguinte, é realizada uma junção de dois nós, os quais são substituídos na árvore por um novo nó resultante. Essas junções são realizadas, sucessivamente, até que a árvore estrela fique com apenas dois nós (ver Figura 3.6).

Como descreve o Algoritmo 1, extraído de (Cuadros et al., 2007), para a ligação dos nós considera-se os vizinhos mais próximos, onde no passo inicial se calcula uma medida de divergência $r$ para cada nó e é acrescentada à distância do nó a todos os demais na Equação 3.1 , onde $i$ denota um nó qualquer.

$$
r_{i}=\sum_{j \neq i} d_{i, j}
$$




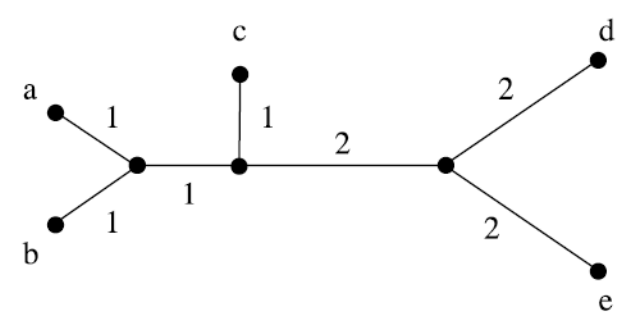

Figura 3.6: Árvore de cinco folhas. Extraído de (Mihaescu et al., 2007)

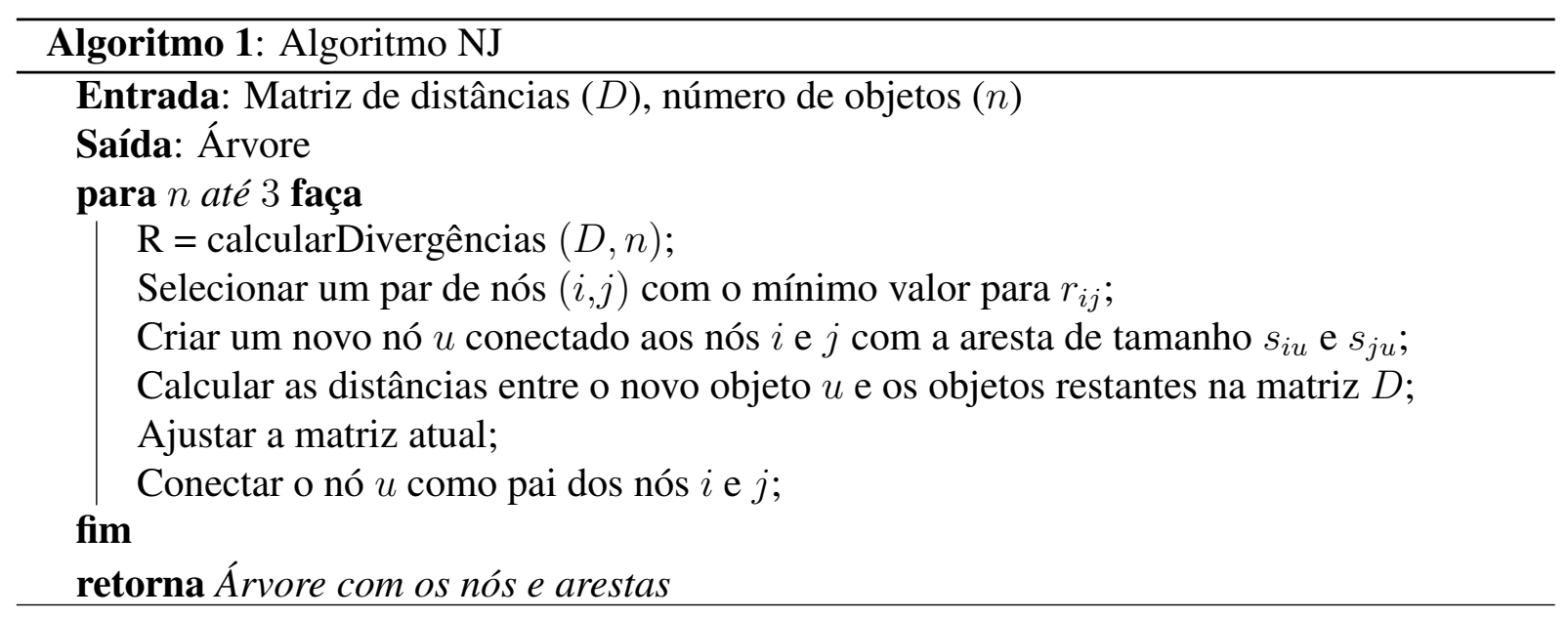

No passo seguinte é selecionado um par de nós $(i, j)$ a serem unidos. Para isso, inicialmente são calculadas duas matrizes, a matriz de distâncias ajustadas $D^{\prime}$, criada a partir de $D$ e das divergências $r$, por meio da Equação 3.2 .

$$
d_{i j}^{\prime}=d_{i j}-\frac{r_{i}+r_{j}}{n-2}
$$

Entre todos os possíveis pares de nós a serem unidos é selecionado aquele que tem o menor valor em $d_{i j}^{\prime}$. Assim, são escolhidos os nós $i$ e $j$ em $D$ para os quais $d_{i j}^{\prime}$ em $D^{\prime}$ é mínimo. Esses nós são unidos em um novo nó $u$ (um nó interno na árvore), que possui $i$ e $j$ como filhos. Em seguida, calculam-se os tamanhos dos novos ramos $s$ que ligam o objeto $u$ aos objetos $i$ e $j$ por meio das Equações 3.3 e 3.4

$$
\begin{gathered}
s_{i u}=\frac{d_{i j}}{2}+\frac{r_{i}+r_{j}}{2 *(n-2)} \\
s_{j u}=d_{i j}-s_{i u}
\end{gathered}
$$


O passo seguinte é a substituição dos objetos $i$ e $j$ na matriz de distâncias $D$ pelo novo objeto $u$ e o cálculo das distâncias entre esse novo objeto e os demais por meio da Equação 3.5, sendo $k<n$. Desse modo, $i$ e $j$ são excluídos do processo.

$$
d_{k u}=\frac{d_{i k}+d_{j k}-d_{i j}}{2}
$$

Finalmente, o número de objetos $n$ é reduzido em 1 e o procedimento é repetido a partir do cálculo das divergências dos objetos remanescentes até que a matriz seja reduzida a dois objetos apenas. A cada repetição são encontrados e unidos os dois vizinhos mais próximos presentes na matriz $D$. A busca pelos vizinhos mais próximos opera sobre uma matriz e possui complexidade $O\left(n^{2}\right)$. Como essa busca precisa ser feita $n-2$ vezes, a complexidade do $N J$ passa a ser de $O\left(n^{3}\right)$ no algoritmo apresentado.

Existem vários trabalhos que modificam e buscam melhorar o algoritmo $N J$ considerando vários critérios. A maioria dessas pesquisas aperfeiçoa o tempo de busca para encontrar o par de vizinhos que formarão um novo. Por exemplo, Elias e Lagergren (2009) melhora a complexidade utilizando heurísticas que reduzem o espaço de busca para a construção dos ramos para $O\left(n^{2}\right)$ no pior caso com o Fast Neighbor Joining (FNJ). Mailund et al. (2006) tenta também diminuir o tempo de busca usando a estrutura Quad-tree. Este algoritmo conseguiu apenas melhorar o tempo de execução para o melhor caso ordem $O\left(n^{2}\right)$, pois o pior caso se manteve em ordem $O\left(n^{3}\right)$.

A adaptação Relaxed Neighbor Joining realizada por Evans et al. (2006) apresenta o melhor desempenho, em que o tempo de processamento é $O\left(n^{2} \log n\right)$. Esse algoritmo consegue gerar árvores na mesma qualidade das geradas pelo algoritmo $N J$ tradicional e sem usar espaço adicional para realizar os cálculos. Por outro lado, Simonsen e Mailund (2008) apresenta Rapid Neighbour-Joining, uma heurística usada para acelerar a busca dos pares que só melhora o tempo de execução, eliminando as partes do espaço de busca que não podem conter o nó par ideal ao utilizar estruturas de dados auxiliares que armazenam informações necessárias para a construção dos ramos. O tempo de execução no pior caso permanece em $O\left(n^{3}\right)$.

$\mathrm{O} N J$, além de construir a topologia no formato de uma árvore sem raiz, também fornece o valor do comprimento dos ramos da árvore resultante. A interpretação permite que se analisem os dados em "grupos" identificados pelos ramos externos da árvore. Desta forma, o algoritmo ocupa melhor o espaço em uma projeção, pois é possível expandir o desenho da árvore de forma a reduzir significativamente ou eliminar sobreposições.

No entanto, a árvore $N J$ gera um grande número de nós intermediários (ou virtuais), os quais, para grandes conjuntos de dados, ocupam um espaço visual que pode interferir no número de itens apresentados em cada vez. Isso contrasta com a capacidade das árvores de similaridade 
de permitirem análises globais e locais usando o mesmo tipo de layout, ou seja, a análise global pode ser prejudicada em configurações específicas da árvore.

Paiva et al. (2011) também apresentam uma modificação ao algoritmo introduzido por $\mathrm{Cu}-$ adros et al. (2007). Os autores abordam o problema dos nós intermediários. Essa proposta consiste na substituição de um nó interno com uma folha sempre que uma configuração dada dos nós ocorre, como na Figura 3.7. Essa operação é chamada de promoção. A lógica relacionada à promoção é: um par de folhas $u$ e $v$ são ligados ao mesmo nó interno $a$, e outro nó interno $b$ liga $a$ e a folha $w$; como nenhum outro nó esta mais próximo a $w$ que $a$, então nenhum outro nó está mais próximo de $u$ e $v$ do que $w$. Portanto, a pode ser substituído por $w$ e $b$ pode ser removido completamente sem perda do poder de representação. A proposta considera que os pesos dos ramos também são substituídos e avaliados de acordo com a reconstrução do algoritmo. A busca dos nós padrão é linear e leva ao tempo de $O(n \log n)$. Os autores também melhoram o algoritmo usando as idéias das pesquisas de Elias e Lagergren (2009); Simonsen e Mailund (2008) na busca otimizada de pares de nós, melhorando muito o algoritmo e aproximando a ordem $O\left(n^{2}\right)$. Para este trabalho usa-se esta modificação do algoritmo $N J$ por Paiva et al. (2011).

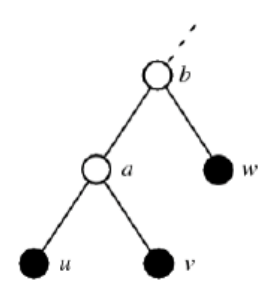

(a) exemplo

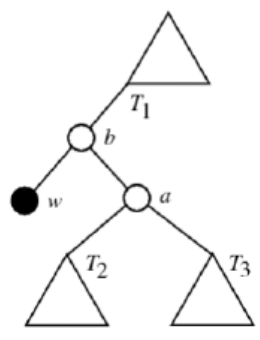

(b) padrão

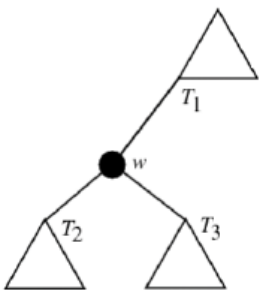

(c) substituto

Figura 3.7: Promoção de nós do algoritmo de Paiva et al. (2011). Os círculos preenchidos representam objetos reais, os brancos nós internos e os triângulos representam sub-árvores folhas.

Por outro lado, alguns problemas das técnicas de projeção multidimensional podem ser destacados. Por exemplo, a técnica pode sofrer de sobreposição, dificultando assim a análise visual, ou alguns pontos são mal posicionados. Adicionalmente, pode haver dificuldade de estimar a densidade dos grupos e para distinguir pontos individuais em grupos densos. Uma alternativa, segundo a literatura (Cuadros et al., 2007) é usar as árvores filogenéticas, cuja principal vantagem é melhorar a exploração e visualização, tornando mais claras as relações de similaridade. A Figura 3.8 mostra um exemplo do problema mencionado. 


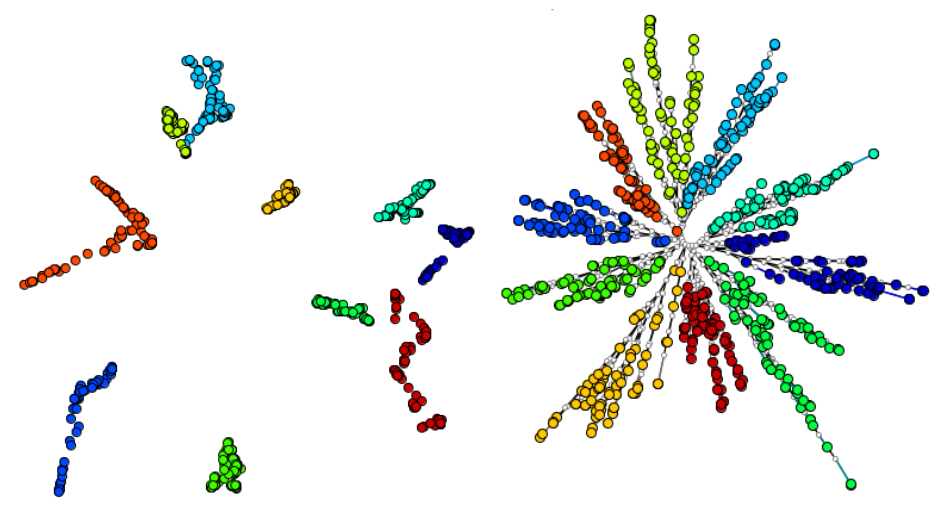

(a)

(b)

Figura 3.8: Projeção LSP vs Árvore de similaridade $N J$ do mesmo conjunto de imagens COIL (Nene e Nayar, 1996). Usando as características do extrator CCV e usando a distância $d \log$ (Stehling e Nascimento, 2002) para o calculo das similaridades em ambas técnicas.

\subsection{Visualização de Coleções de Imagens}

Um dos desafios das pesquisas conhecidas na área de recuperação de imagens é exibir grandes quantidades de imagens por similaridade. Por exemplo, na proposta de Rodrigues e Traina (2005), é desenvolvido um sistema de recuperação baseado em conteúdo de imagens (CBIR) para dar suporte à análise das características empregadas em consultas por similaridade. Neste e outros trabalhos como Eler et al. (2009); Moghaddam et al. (2002); Nguyen e Worring (2008a); Worring et al. (2007), os autores defendem que uma representação visual auxilia a análise e a identificação de padrões existentes na coleção de dados, permitindo que o usuário entenda o comportamento do espaço de características dos dados.

Existem muitas aplicações e sistemas que apóiam a exploração de coleções, em que os usuários possuem acesso a uma interface visual na qual podem interagir e reconhecer similaridade, fazer seleções, ampliar detalhes, recuperar informações, entre outras atividades. Além disso, permitem que o usuário tenha uma visão geral de toda a coleção de imagens, por meio da qual se pode criar um processo de busca para recuperar uma ou várias imagens desejadas, ou ainda detectar tendências e características particulares que seriam extremamente difíceis de serem detectadas analisando imagem a imagem.

Um exemplo de estrutura de um sistema para visualização de grandes coleções de imagens é apresentado na Figura 3.9. Realiza-se primeiro, um processo de extração de características aplicado a um conjunto de imagens no qual algumas características de baixo nível são extraídas. Assim, cada imagem da coleção corresponde a um ponto em um espaço de alta dimensão. Em 
segundo lugar, uma métrica é selecionada a fim de comparar as imagens. Essa comparação fornece um valor real que define quão semelhantes são as imagens por meio de uma função de similaridade. Em terceiro lugar, uma matriz de distâncias entre todas as imagens é construída e, finalmente, um algoritmo de projeção considera só as $k$ dimensões baseada na matriz de distância. Neste caso, $k$ têm o valor de 2 e as duas dimensões têm como coordenadas $(x, y)$ para a visualização de cada imagem em um espaço $2 D$ (Camargo et al., 2009).

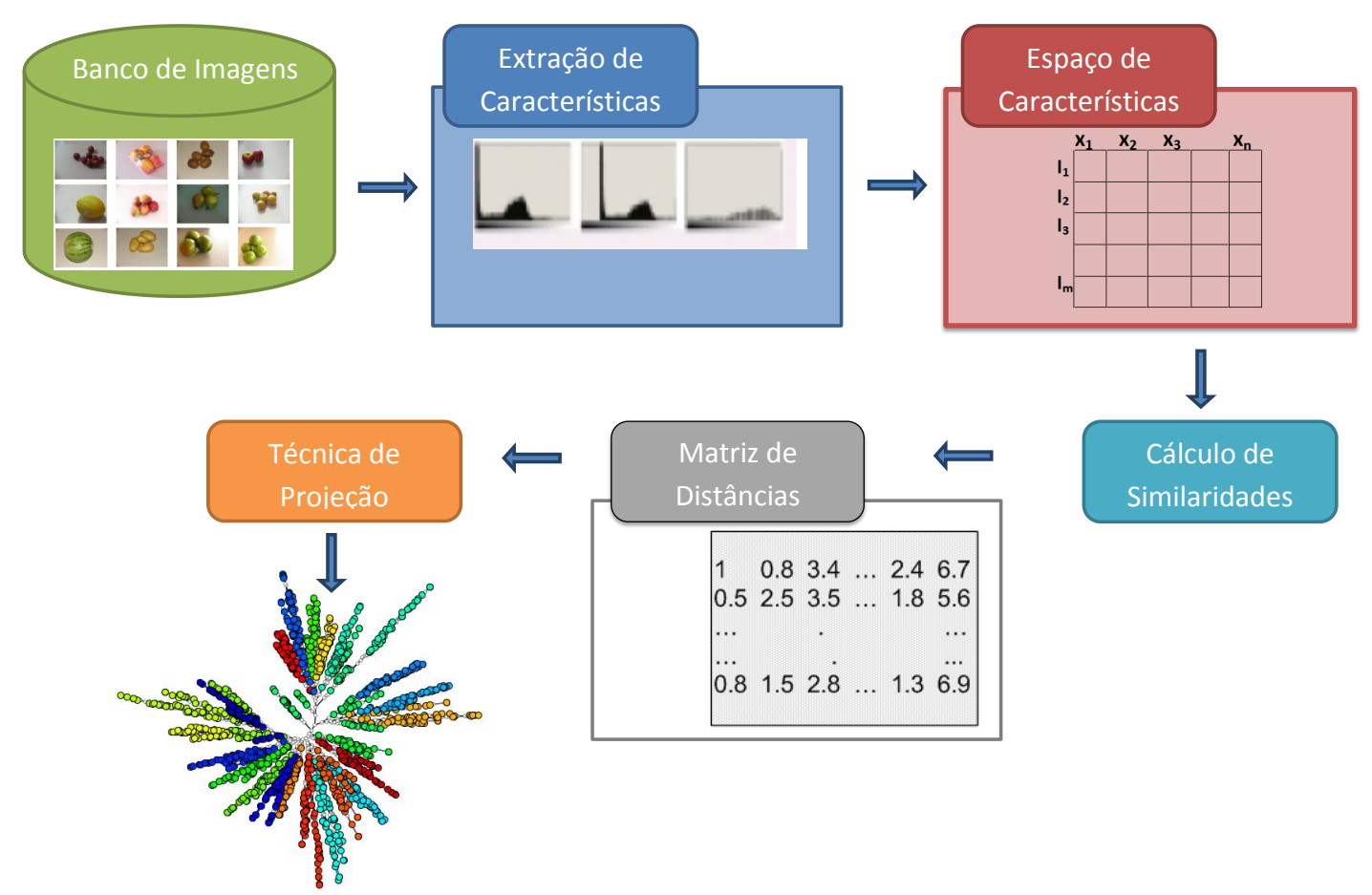

Figura 3.9: Etapas de processamento para visualizar a coleção de imagens por meio de uma Técnica de Projeção. Adaptado de (Camargo et al., 2009).

A seguir, são apresentados alguns sistemas que utilizam as técnicas de visualização com o objetivo de refletir as tendências e características de uma determinada coleção de imagens.

\subsubsection{Sistemas de Visualização de Imagens}

É possível enumerar as diversas aplicações que podem se beneficiar com o uso de técnicas de visualização de informação aplicadas a imagens. Por exemplo, Chen e Gagaudakis (2000) utilizou técnicas de visualização para comparar as imagens com base em três sistemas de extração de características distintas que usam forma, cor e textura. As imagens são classificadas por um sistema que emprega redes associativas obtidas com o método Pathfinder Scaling Network 
(PFnets - Schvaneveldt (1990)), tal como é mostrado na Figura 3.10. Assim, as imagens são relacionadas por meio de ligações para refletir proximidade e similaridade entre imagens.

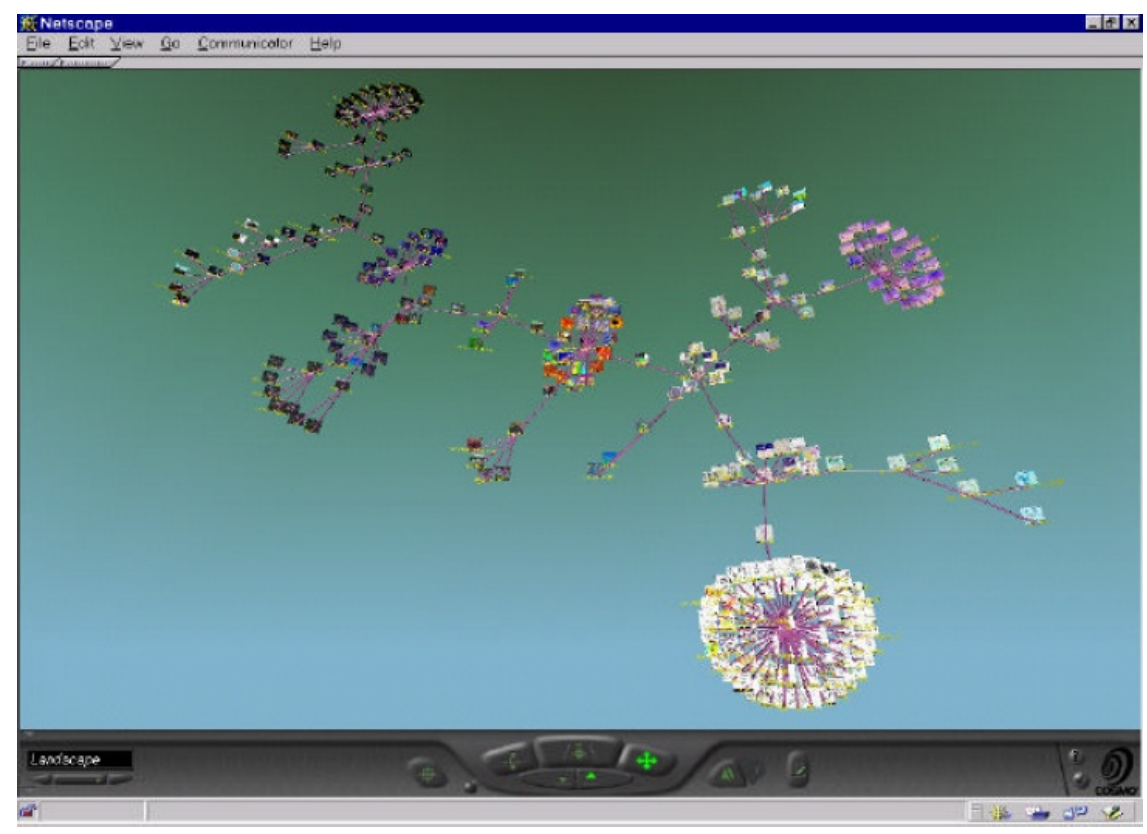

Figura 3.10: Red Pathfinder ou Pathfinder Scaling Network. Banco de imagens agrupados por modelos de histograma de cores. Eextraído de (Chen e Gagaudakis, 2000)

Por outro lado, diversos autores apresentam modelos de visualização que têm como objetivo apoiar a capacidade de interação com o usuário, usando modelos que melhoram a forma de organização e exploração de dados. Por exemplo, Jankun-Kelly e Kwan-Liu (2003) sugerem uma abordagem de visualização MoireGraph, o qual exibe uma árvore geradora que combina um layout de um grafo radial com um conjunto de técnicas de interação para auxiliar na exploração de grafos. Os autores escolheram um método focado no contexto que permite uma exploração rápida de um grafo através do destaque de níveis e focos secundários. A fim de proporcionar uma visão suficiente dos nós de um grafo. Realiza o ocultamento dos nós quando uma redimensão da tela é exigida pelo usuário. Tal qual é mostrado na Figura 3.11, apresenta a distorção gerada aplicada aos níveis da árvore e tamanhos visuais dos nós. O centro do nó tem a maior área de exposição e foco visual, enquanto os níveis exteriores são mostrados em áreas menores. MoireGraphs garante a interatividade para grafos com mais de uma centena de nós.

Fan et al. (2007) apresentam um sistema que utiliza a visualização hiperbólica. Neste trabalho, uma estrutura de classificação hierárquica incorpora a idéia de ontologia, no qual cada nó da estrutura representa um conceito de imagem em certo nível semântico. Desta maneira obtém-se um novo esquema para gerar o conceito orientado à sumarização de coleções de imagens em grande escala. Usando o algoritmo de classificação Support Vector Machines, a técnica 


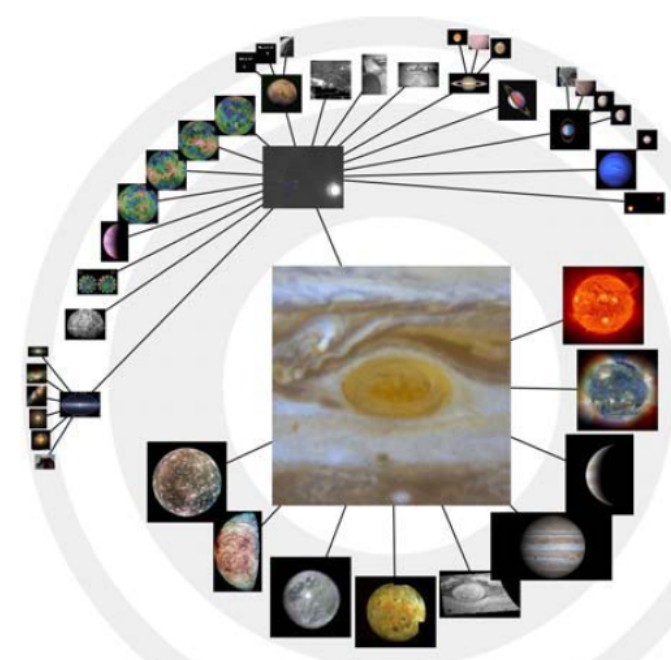

Figura 3.11: A MoireGraph exibe imagens da NASA agrupadas pela hierarquia estelar. Extraído de (Jankun-Kelly e Kwan-Liu, 2003).

seleciona as imagens que pertencem à sumarização e o Kernel PCA é utilizado para agrupá-las. Como é apresentado na Figura 3.12, as imagens representativas com os conceitos de cada imagem são projetados em um plano hiperbólico de acordo com suas relações contextuais. Cada projeção preserva as relações entre o contexto original e os conceitos das imagens.

Por outro lado, Nguyen (2005); Nguyen e Worring (2008a), se apresenta o ImIk (Interactive disclosure of Multimedia Information and Knowledge), um sistema que fornece ao usuário uma melhor maneira de acessar interativamente uma coleção de imagens enfatizando maneiras de encontrar posições ideais de imagens no espaço de visualização. Para os autores é importante a sobreposição de imagens e preservação na sua projeção. Logo a visibilidade é essencial para a interação entre o usuário e as imagens exibidas. Algumas técnicas usadas no sistema são: $M D S$, ISOMAP (ISOmetric MAPping), SNE (Stochastic Neighbor Embedding), LLE (Local Linear Embedding), ISOSNE (ISOmapSNE) e ISOLLE (ISOsneLLE). Na Figura 3.13, a tela principal mostra o sistema de visualização com o conjunto representativo das imagens.

Do mesmo modo, Eler et al. (2008) apresentam o software Pex-Image, um framework visual que suporta todo o processo de análise e exploração visual de coleções de imagens e textos associados. Pex-Image implementa diversas técnicas de projeção e posicionamento baseado em árvore para visualizar coleções de imagens que enfatizam a similaridade entre as imagens, além de oferecer funcionalidades complementares para ajudar na exploração dos dados. O software permite que seja feita uma coordenação entre várias projeções da mesma coleção de imagens conforme a Figura 3.14, de modo que o usuário possa selecionar uma ou várias imagens em 


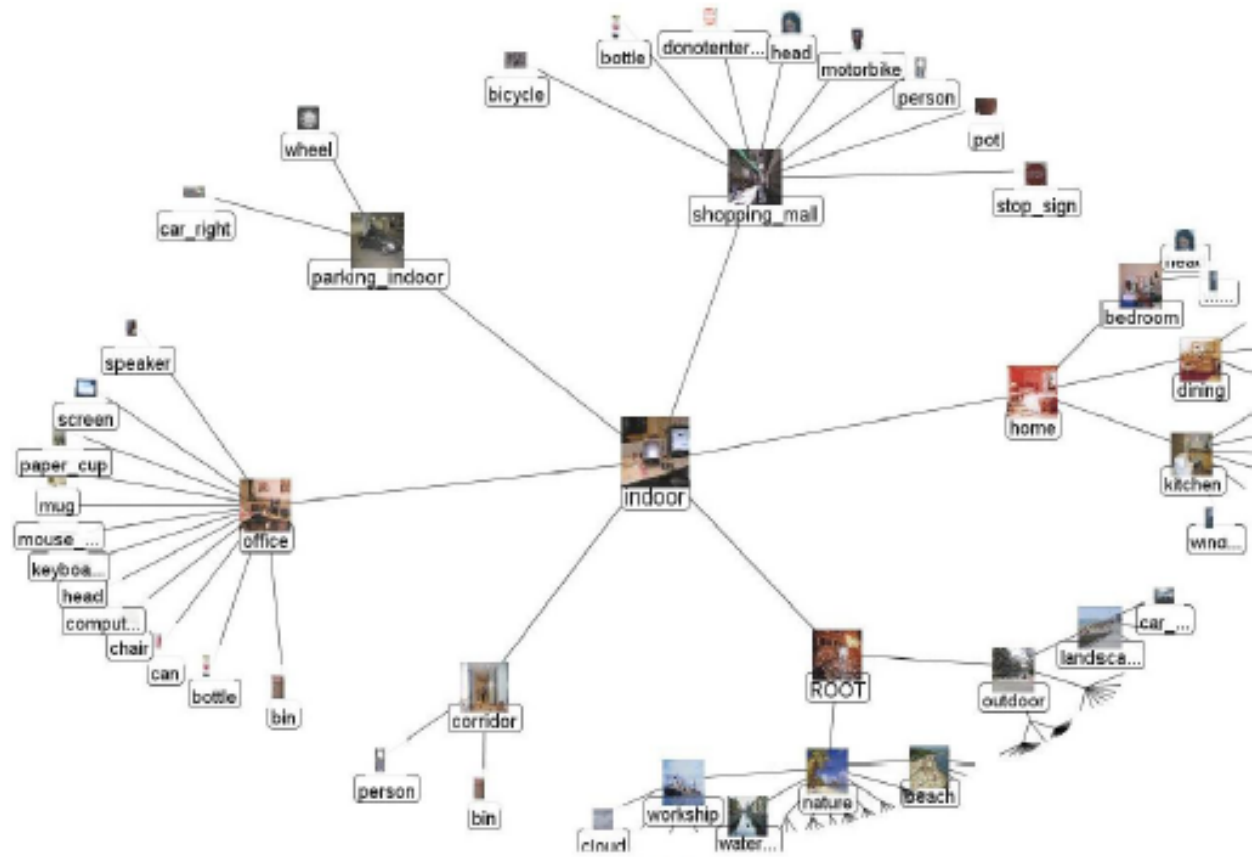

Figura 3.12: Visualização hiperbólica usando o conceito de ontologia. Extraído de (Fan et al. 2007).

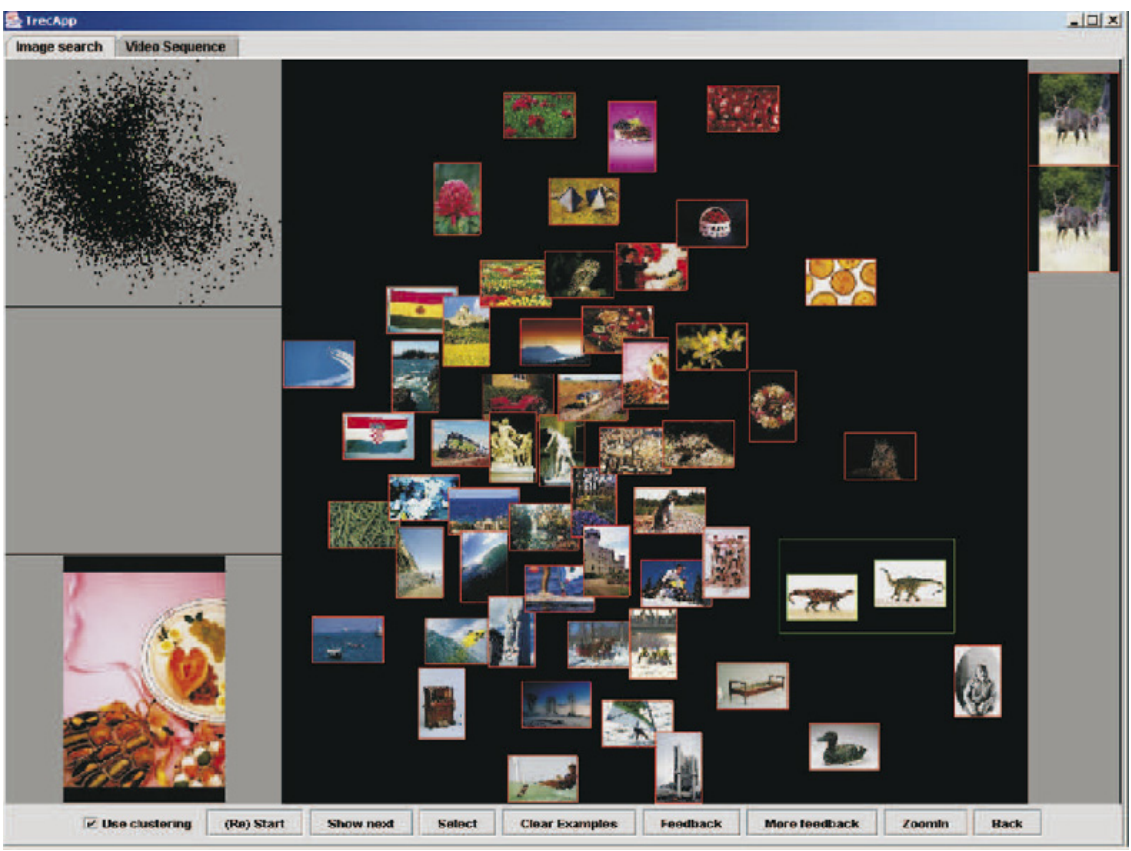

Figura 3.13: Sistema de Visualização de Imagens ImIk (Interactive disclosure of Multimedia Information and Knowledge). Extraído de (Nguyen e Worring, 2008a). 
uma projeção e visualizar a posição dessas imagens em outra projeção (identity coordination), ou ainda visualizar os $k$-vizinhos mais próximos dessa seleção em outra projeção (distance coordination) instantaneamente.

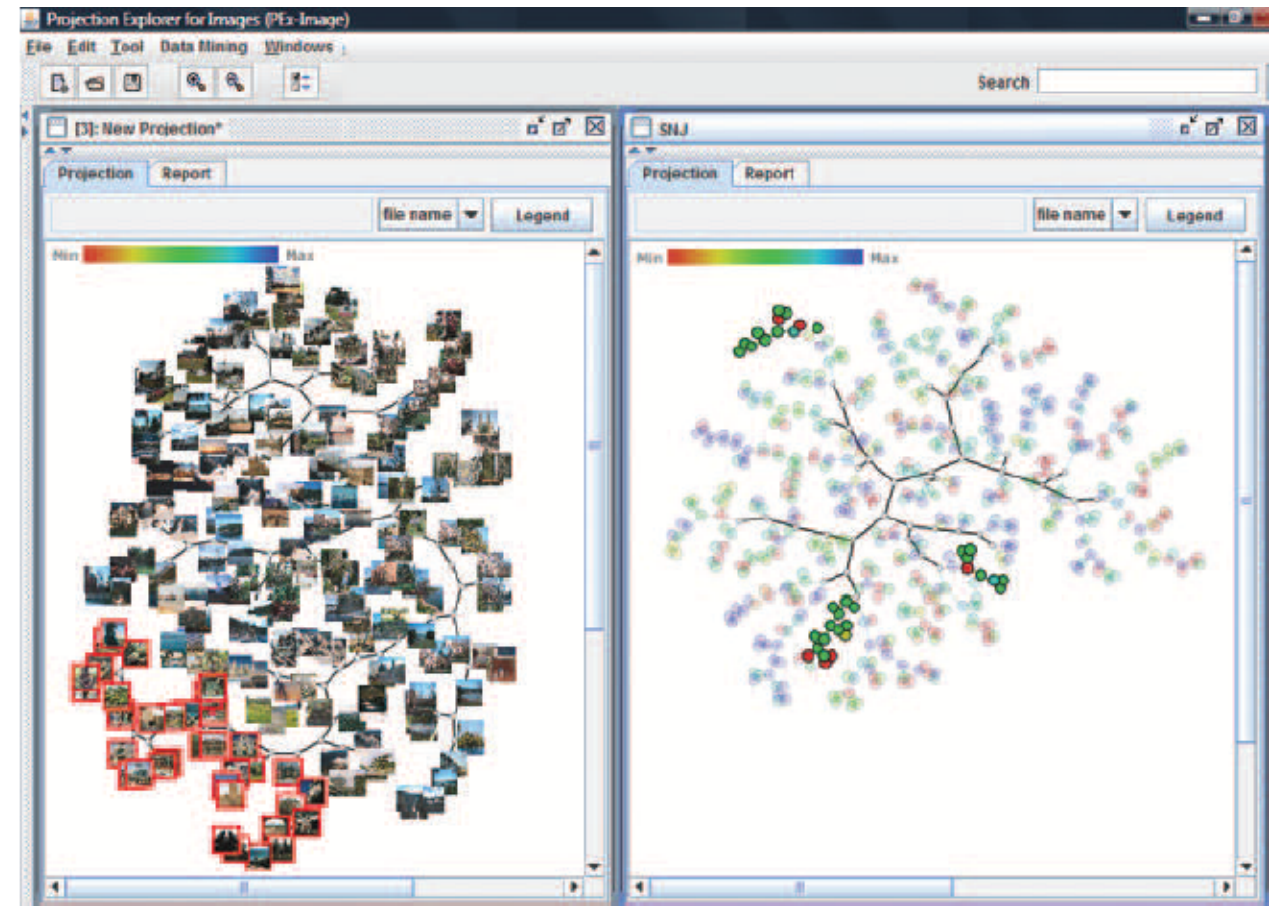

Figura 3.14: Coordenação entre duas projeções realizadas pelo Pex-Image (Eler et al., 2008).

Gomi e Itoh (2010) propõem Miaow (Memorized Image Album Organized by When/Where), um visualizador de imagens em 3D que representa fotografias hierarquicamente classificadas com base em suas coordenadas (eixos X e Y) e o tempo (eixo Z), correspondente à data das fotos, aninhadas em regiões retangulares. A Figura 3.15, mostra a navegação em algumas fotografias usando Miaow.
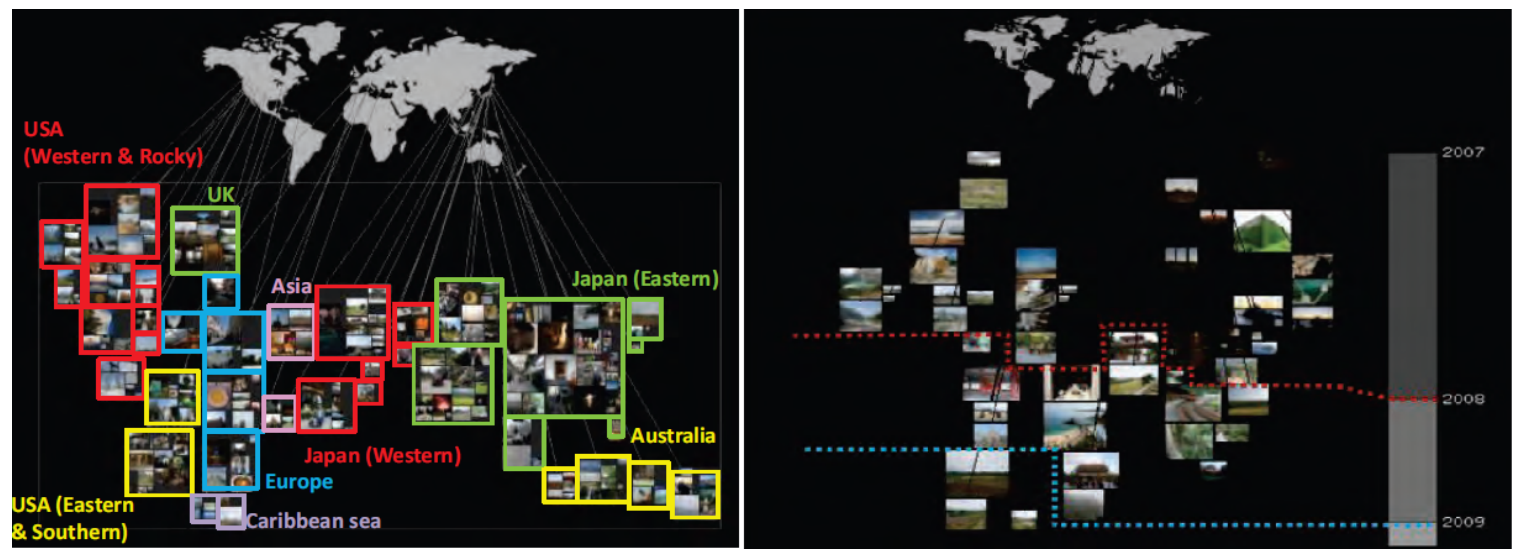

Figura 3.15: Visualizador de imagens 3D Miaow. Extraído de (Gomi e Itoh, 2010). 


\subsection{Visualização Multidimensional na Seleção de Ca- racterísticas}

Existem poucas pesquisas que utilizam o estudo da visualização multidimensional na seleção de características. Uma das pesquisas, é apresentada por Yang e Moody (2000), afirma que a visualização de dados e a seleção de características estão intimamente relacionados. Além disso, esse trabalho assegura que uma técnica de visualização é capaz de apresentar características significativas, então é assim que a seleção de características surge como o passo mais importante no processo da seleção de um modelo que representa um conjunto de dados.

Yang e Moody (2000) propõem em sua pesquisa a análise de componentes independentes (Independent Component Analysis- ICA) como uma técnica de visualização que usa iterativamente a seleção de características para encontrar um subespaço que represente bem o conjunto de dados. O novo espaço é avaliado como ótimo considerando que sua visualização deve revelar estruturas não-Gaussianas nos dados.

A outra pesquisa relacionada é apresentada por Dy e Brodley (2000b), na qual se sustenta que para resolver o problema da seleção de características, um analista de dados deve definir as características que são potencialmente úteis (relevantes) de cada classe e, baseadas nelas em seguida um subconjunto de características pode ser escolhido a partir do conjunto original utilizando um algoritmo de seleção automática de características. Esse trabalho difere-se de outras abordagens de seleção de características onde as informações de classe não estão disponíveis para orientar a busca de características.

Dy e Brodley (2000b) apresentam Visual-FSSEM ( Visual Feature Subset Selection using Expectation - Maximization Clustering ou Seleção Visual de Subconjunto de Características usando Agrupamento de Expectativa Máxima)), o qual incorpora técnicas de visualização, agrupamento e interação, permitindo ao usuário avaliar agrupamentos de características baseadas na percepção visual e medidas de avaliação. Também a ferramenta permite ao usuário realizar tanto a busca forward quanto backward com backtracking.

Outro trabalho relacionado é de Botelho e Batista Neto (2010), que propõe a inclusão de técnicas de projeção de dados multidimensionais, para apoiar o processo de seleção de características de um conjunto de imagens. A proposta usa a projeção das características, de modo que, ao invés de projetar-se imagens como instâncias, projetam-se as características.

Os autores consideram uma propriedade importante das projeções, correspondente à revelação de agrupamentos na tela da projeção, em que pontos próximos indicam similaridade. Assim, se assume que as características pertencentes ao mesmo grupo possuem poder discriminatório semelhante. Com participação do usuário especialista esses agrupamentos são identificados 
para, após obter amostras de cada agrupamento usando o algoritmo de agrupamento $K$-means. Assim o processo de seleção termina configurado utilizando as amostras de cada agrupamento é configurado, como apresentado na Figura 3.16 .

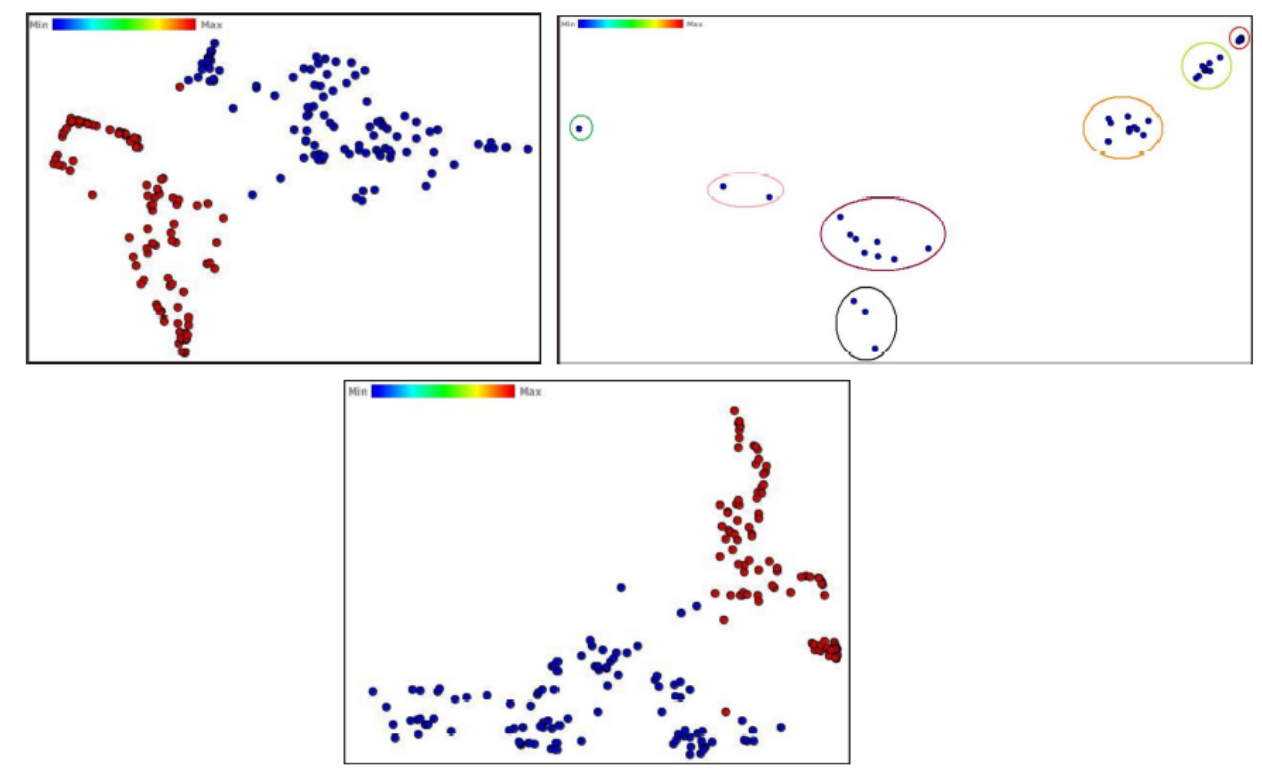

Figura 3.16: Esquerda: Projeção do conjunto original de dados. Direita: Projeção dos dados transpostos, onde cada ponto representa uma característica e o usuário seleciona os agrupamentos que localiza visualmente, em que um subconjunto é selecionado pela aplicação do K-means. Abaixo: Projeção do conjunto de dados usando as características selecionadas. (Extraído de (Botelho e Batista Neto, 2010)).

Além disso, o trabalho de Botelho e Batista Neto (2010) compara resultados com um seletor de características baseado no cálculo de saliências de uma rede neural Perceptron multicamadas. Seus resultados mostram que a seleção de características baseada em projeção obtém subconjuntos capazes de gerar novas projeções com qualidade visual satisfatória.

Finalmente, a pesquisa de Joia et al. (2011) apresenta uma combinação de métricas de classe específicas e técnicas de projeção multidimensional para elaborar um sistema interativo de recuperação de imagens. Além disso, o trabalho assegura a exploração visual de conjuntos de imagens, tornando-se uma alternativa interessante para o gerenciamento desses conjuntos.

O sistema opera da seguinte maneira: após a extração das características, o próximo passo é a seleção na projeção de um subconjunto de imagens representativas de cada classe, isto é realizado pelo usuário, como é ilustrado na Figura 3.17. Logo, a partir da informação de classe, o sistema automaticamente realiza um procedimento de seleção de características, de modo a calcular o subconjunto de características que melhor representa cada classe. Finalmente, o subconjunto resultante de características é usado para definir as métricas específicas de classe que 
serão usadas para montar a matriz responsável de uma nova técnica de projeção multidimensional.

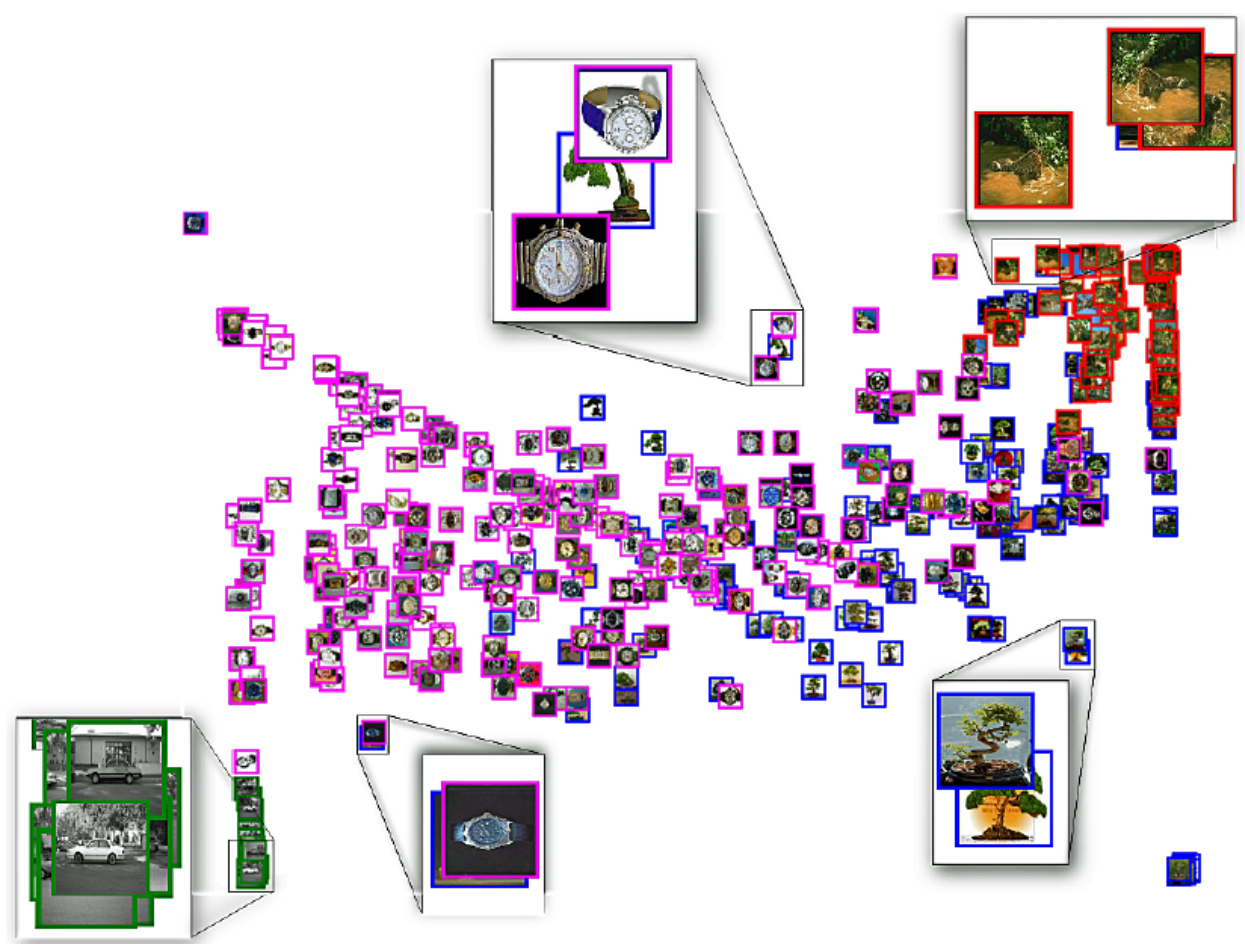

Figura 3.17: Espaço para escolher subconjuntos de imagens representativas, separando classes distintas. Extraído de (Joia et al., 2011).

\subsection{Interação e Avaliação para Visualização de Dados}

Grinstein et al. (2002) apontam como as técnicas para visualização de dados são consideradas como instrumentos importantes no processo de mineração de dados. Portanto, uma ferramenta de visualização pode ser particularmente útil quando o processo inclui a mineração de dados. No entanto, a mineração requer uma grande integração com o usuário, a qual pode ser bastante complexa. Devido a isso, sistemas de visualização podem ser beneficiados por um ambiente de mineração de dados que integre técnicas que facilitem ao usuário interagir, manipular, explorar e inferir os dados.

Chengzhi e Chenghu (2003) classificam os sistemas de visualização em cinco fatores. Um dos fatores esta relacionado acordo a seu estilo de interação, quando o sistema permite a focalização, vinculação, e arranjo de exibições; e de acordo a suas tarefas analíticas: quando o sistema de visualização possibilita a identidade, localização, distinção, classificação, agrupamento, distribuição, avaliação, comparação entre entidades, associação, e correlação. 
Em adição a estas propriedades, Keim (2001) propõe que a exploração de dados também dependa da interação e técnicas de distorção. Técnicas de interação permitem aos usuários interagir diretamente com a visualização e incluem filtragem, zoom e vinculação, permitindo assim que o analista de dados possa fazer alterações dinâmicas na visualização de acordo com os objetivos de exploração, além de tornar possível relacionar e combinar múltiplas visualizações independentes. Adicionalmente, técnicas de distorção interativa apóiam o processo de exploração de dados, preservando uma visão geral dos dados durante operações de drill-down. Basicamente, as técnicas mostram porções dos dados com um elevado nível de detalhe e outras porções com um menor nível.

Para permitir ao usuário cumprir suas tarefas, os sistemas de visualização devem atender a estas características mencionadas, como os sistemas apresentados a seguir.

\subsubsection{Ferramentas de Apoio à Visualização}

Descrevem-se duas ferramentas desenvolvidas pelo Grupo de Visualização, Imagens e Computação Gráfica (VICG) do ICMC - USP São Carlos, que servem da base para o desenvolvimento deste trabalho.

PEx-Image O Projection Explorer for Images (PEx-Image) ${ }^{3}$ (Eler et al., 2008) é uma ferramenta de visualização de imagens destinada à exploração interativa de imagens por meio de projeções rápidas de alta precisão. Ela incorpora várias técnicas de projeção e oferece funcionalidades para criar representações visuais, interagindo com elas em busca de relacionamentos interessantes em uma coleção de imagens e possibilitando a avaliação de processos de manipulação de imagens e mineração de dados, entre outras tarefas. A Figura 3.18 mostra uma imagem da interface do Pex-Image.

O sistema recebe como entrada uma coleção de imagens, das quais são extraídas as características visuais que são combinadas para compor vetores de características. O usuário pode escolher o tipo de projeção que irá gerar um modelo de visualização 2D. Esta ferramenta disponibiliza diferentes algoritmos de extração de características e técnicas de projeção. Adicionalmente, diversas métricas de distância podem ser utilizadas para computar a posição das imagens, as quais são representadas por pontos no espaço de visualização ou por miniaturas de imagens. O modelo resultante provê um mapa que aproxima e agrupa imagens semelhantes, provendo uma ferramenta útil na exploração da coleção.

Após visualizar o modelo gerado, diversas funcionalidades podem ser utilizadas pelo usuário, tais como aproximações (zoom) e a visualização de uma determinada imagem escolhida

\footnotetext{
${ }^{3}$ http://infoserver.lcad.icmc.usp.br/infovis2/PExImage
} 


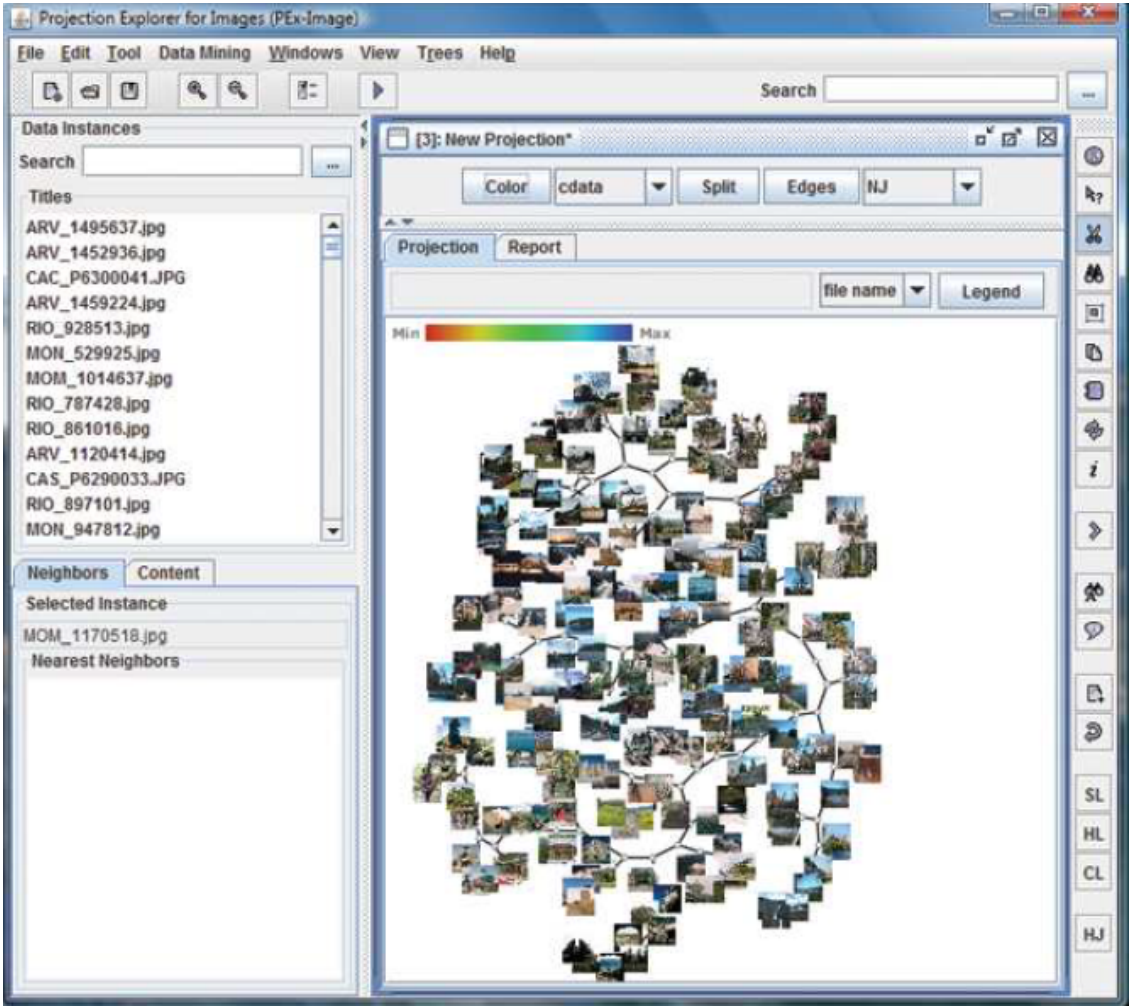

Figura 3.18: Interface do software Pex-Image, ilustrando o resultado de uma projeção.

ou de todas as imagens de determinado grupo ou seleção. Destaca-se também a possibilidade de se exibir no modelo os objetos da coleção na forma de miniaturas de imagens, ao invés de pontos ou círculos, o que elimina a necessidade de abrir a imagem para visualizar seu conteúdo, tornando mais rápida a compreensão do modelo.

O software também faz uma coordenação entre várias projeções de uma mesma coleção de imagens (Figura 3.19), de modo que o usuário pode selecionar uma ou várias imagens em uma projeção e visualizar a posição dessas imagens em outra projeção (identity coordination), bem como oferece a possibilidade de visualizar os $k$-vizinhos mais próximos desta seleção em outra projeção (distance coordination) instantaneamente. Isso permite que sejam feitas comparações de como diferentes visões estão organizando as imagens da mesma coleção. Os autores utilizam este recurso para comparar diversos conjuntos de características de imagens com o intuito de verificar qual conjunto consegue gerar uma organização mais precisa das coleções.

VisPipeline Além do PEx-Image, existe outra ferramenta que está sendo desenvolvida dentro do grupo de pesquisa na área de Visualização, denomina-se VisPipeline. Este novo software parte da melhoria do PEx-Image, de modo que todas as funcionalidades existentes no PEx-Image já estão inseridas no VisPipeline. Adicionalmente, existem outras funcionalidades 


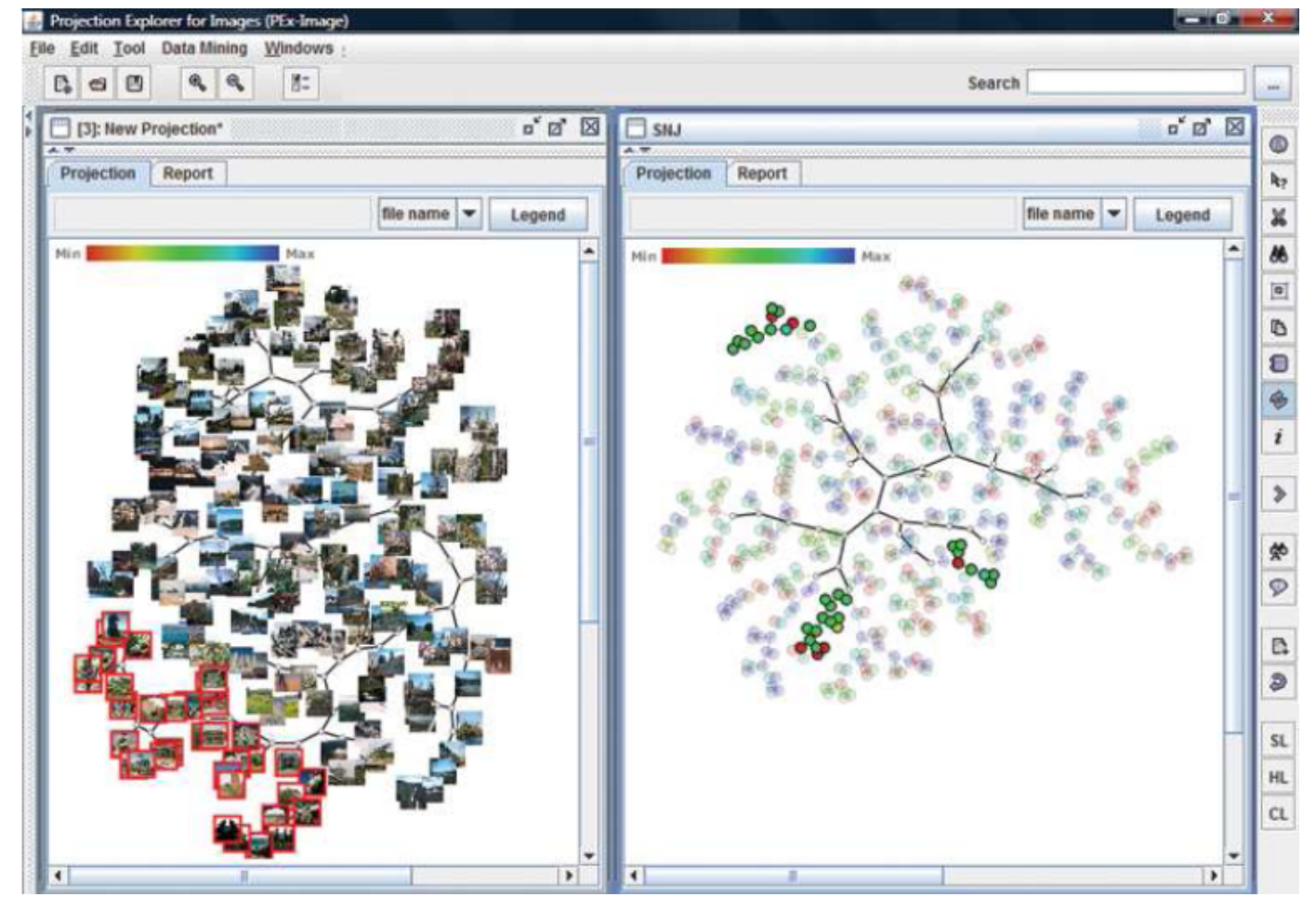

Figura 3.19: Coordenação entre duas projeções realizadas pelo PEx-Image, com destaque para duas imagens (que pode ser visto pelo destaque vermelho nas bordas das imagens selecionadas). 
que permitem, por exemplo, exibir os objetos da coleção na forma de miniaturas de imagens, como mostra a Figura 3.20 .

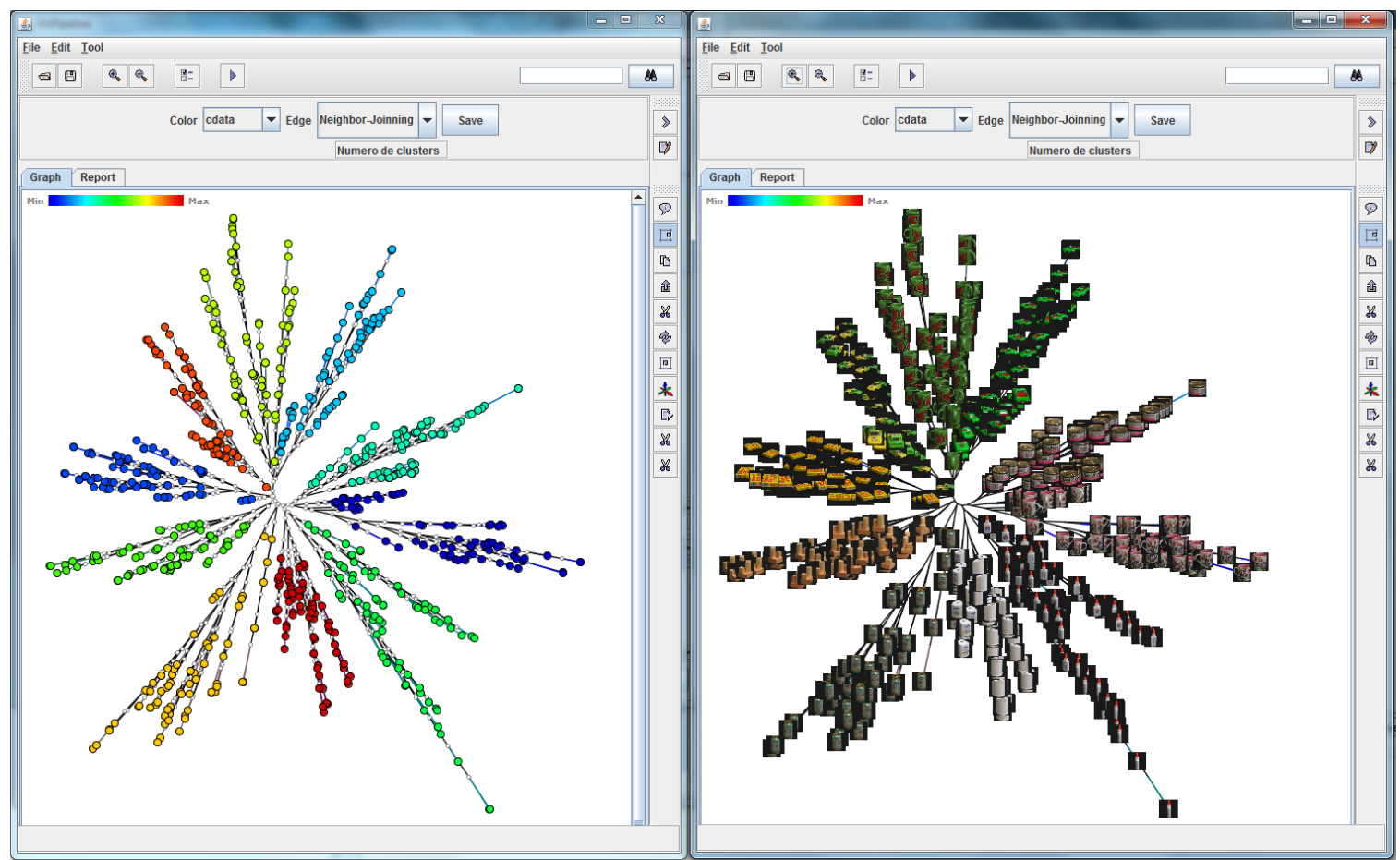

Figura 3.20: A mesma árvore $N J$ em duas telas uma com pontos e outra com as imagens em miniaturas. O conjunto de imagens usado é o conjunto COIL.

Um vantagem em relação ao PEx-Image é a existência de módulos com técnicas e funcionalidades independentes. O usuário (um pesquisador, por exemplo) pode integrar diferentes técnicas de visualização de maneira independente sem que tenha que ser reprogramado, isso sem se preocupar se os outros módulos existentes foram construídos. Assim, o usuário preocupa-se apenas com a informação que necessitará como entrada, o que produzirá como saída.

O VisPipeline define uma nova interface gráfica onde o usuário pode adicionar os módulos disponíveis e conectá-los, indicando o fluxo dos dados através de processos desejados. Ao conectar os módulos, a informação produzida pelo primeiro módulo servirá como informação de entrada para o segundo módulo, sendo processada de acordo com a funcionalidade existente naquele módulo, e assim segue-se sucessivamente, até o fim do processo. Módulos de interação também podem ser inseridos nestes pipelines, permitindo a exploração da informação contida nos modelos gerados.

A Figura 3.21 mostra a janela principal da ferramenta onde foi montado um pipeline que é usado para a visualização de um conjunto de imagens por uma árvore $N J$. Os retângulos azuis representam os módulos específicos para cada parte do processo. Existe um módulo para 
a leitura de um arquivo que contém os vetores de características de uma coleção de dados, identificado como Points Matrix Reader, e um módulo gera as conexões entre os objetos de acordo com o método NJ (identificado como Neighbor Joining Connection.

Adicionalmente, existe um módulo que cria um modelo de árvore de similaridade, identificado na Figura 3.21 como Tree Model, um módulo para geração de um layout de visualização (identificado como Radial Layout), e finalmente um módulo de exibição do layout criado, identificado como Tree View Frame. As conexões entre os módulos são representadas pelas linhas em vermelho. Os módulos possuem portas de entrada e saída representadas pelos conectores em cinza e verde, as quais permitem que a informação de entrada seja recebida e que a informação gerada seja passada para o próximo módulo. O resultado da execução deste pipeline pode ser visto à direita da imagem do pipeline.

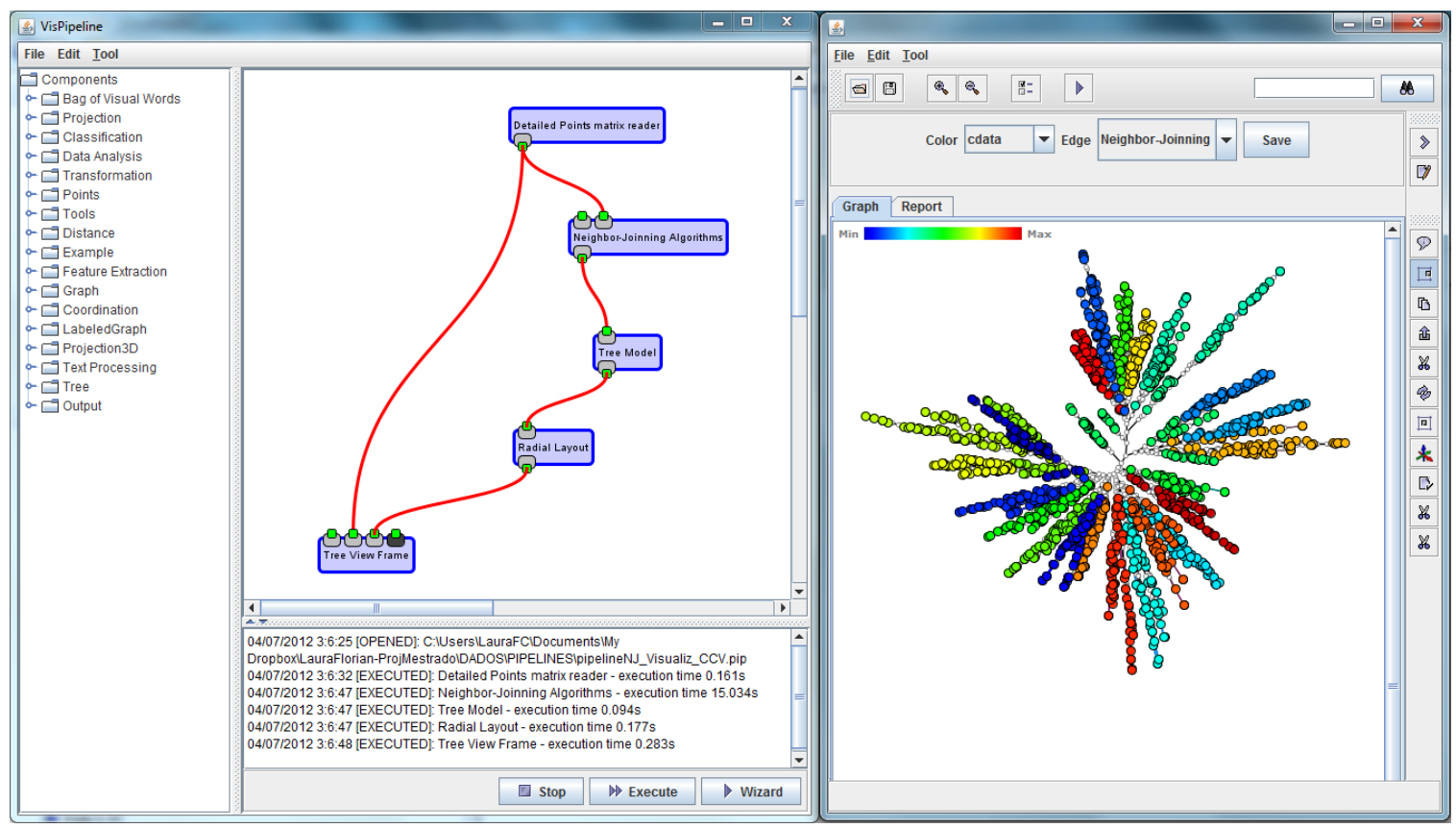

Figura 3.21: Janela principal do VisPipeline: definição de um pipeline da visualização de um conjunto de imagens usando $N J$.

\subsubsection{Avaliação da Qualidade da Visualização}

Segundo Brandoli et al. (2011), o objetivo de avaliar a qualidade da representação visual é reduzir a subjetividade durante análise das diferentes projeções. Embora a habilidade visual dos usuários possa ser empregada para determinar a qualidade de uma projeção, muitas vezes é difícil distinguir diferenças na formação de grupos e subgrupos. A seguir apresentam-se as medidas para avaliar uma técnica de visualização de informação. 


\section{Silhueta}

A medida da silhueta (Kaufman e Rousseeuw, 2008) avalia a qualidade de um agrupamento com as diferenças entre as distâncias intra-grupo e inter-grupos das instâncias. Isso é aplicado na projeção porque é possível verificar nela a revelação de agrupamentos e relacionamentos entre os diferentes grupos, como asseguram autores como Brandoli et al. (2011); Eler et al. (2008); Joia et al. (2011); Paiva et al. (2011); Paulovich et al. (2008) e outros autores.

Seja $S=x_{1}, x_{2}, \ldots, x_{n}$ um conjunto de $n$ instâncias e $k$ agrupamentos não sobrepostos representados por $C=\left\{C_{1}, C_{2}, \ldots, C_{k}\right\}$. Considere uma instância $i$ pertencente a um grupo $C_{j}$. Sua coesão $a_{i}$ é calculada pela média das distâncias entre $i$ e todas as outras instâncias pertencentes ao mesmo grupo (relação intra-grupo). Agora, a separação $b_{i}$ é a distância mínima entre $i$ e todos os exemplos de outros grupos $C_{k}$ (tal que $k \neq j$ ) (relação inter-grupo). Este valor representa a dissimilaridade de $i$ para o grupo vizinho. A silhueta $S$ de um agrupamento é calculado pela média de todas as instâncias $n$, a qual é definida pela Equação 3.6 .

$$
S=\frac{1}{n} \sum_{t=1}^{n} \frac{\left(b_{i}-a_{i}\right)}{\max \left(a_{i}, b_{i}\right)},
$$

onde o denominador é apenas um termo para normalizar. O índice da silhueta pode variar entre $-1 \leq S \leq 1$. Se o agrupamento possui apenas um elemento, assume-se que o valor da silhueta é zero. Os valores mais altos para $S$ indicam a melhor coesão e separação entre os grupos, o que significa minimizar a distância intra-grupo e maximizar a distância inter-grupo. O índice da silhueta é caracterizado por privilegiar partições com grupos compactos e bem separados. O custo para o cálculo da silhueta é de complexidade $O\left(n^{2}\right)$.

Em estudos comparativos, Vendramin e Campello (2009) concluíram que a medida da silhueta foi a melhor medida de avaliação em relação a outros 30 índices. Assim, a medida de silhueta é uma das medidas implementadas na ferramenta VisPipeline com o intuito de avaliar a qualidade das projeções obtidas.

\section{Baseadas na Vizinhança}

Medir a precisão de um layout gerado tem como objetivo verificar até que ponto a distância no layout corresponde à similaridade (ou vizinhança) no espaço de características original. Algumas projeções têm como objetivos reproduzir o espaço visual das distâncias no espaço original e reconstruir suas vizinhanças.

Para avaliar a precisão, duas medidas para as projeções são apresentadas. A primeira medida é a Preservação da Vizinhança (Neighborhood Preservation) (Paulovich et al., 2008), a qual 
avalia a frequência com que os $k$-vizinhos mais próximos de um objeto no layout também são seus $k$-vizinhos mais próximos no espaço de características original. Logo, a Figura 3.22 mostra um gráfico da preservação da vizinhança de duas projeções.

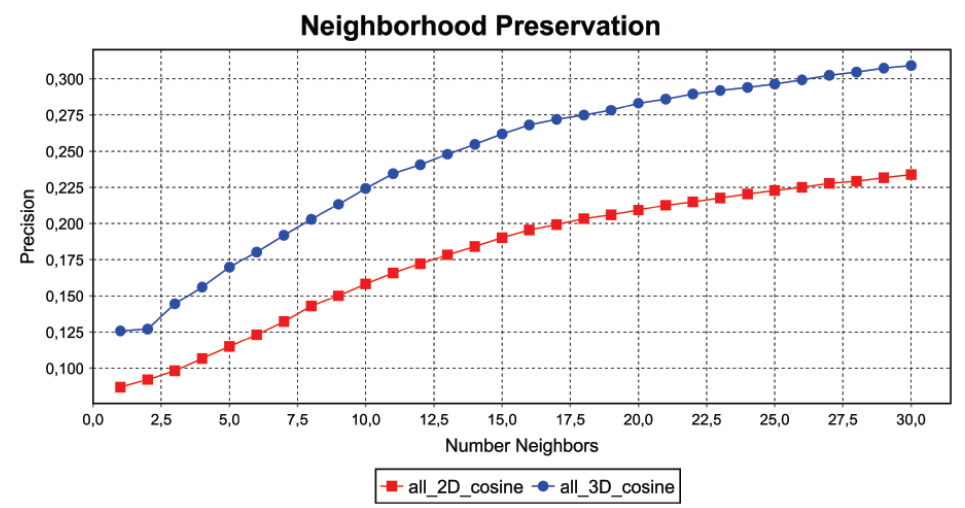

Figura 3.22: Gráfico da medida Neighborhood Preservation para avaliar o algoritmo LSP 2D e 3D de um corpus de artigos científicos. Extraído de (Poco et al., 2011).

A segunda medida é denominada Impacto da Vizinhança (Neighborhood Hit) (Paulovich et al., 2008). Essa medida consiste na frequência média em que um objeto e seus $k$-vizinhos mais próximos pertencem à mesma classe. A Figura 3.23 mostra os resultados de Neighborhood Hit.

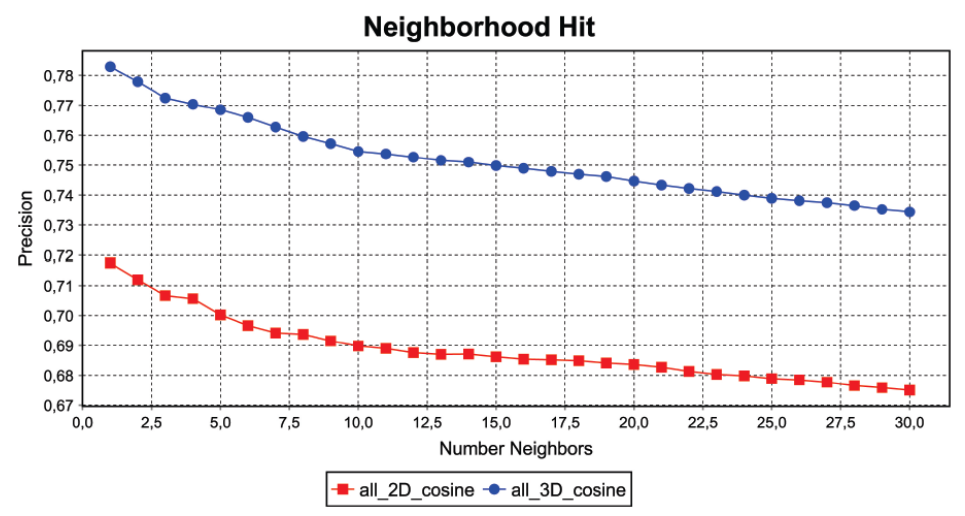

Figura 3.23: Gráfico da medida Neighborhood Hit para avaliar o algoritmo LSP 2D e 3D de um corpus de artigos científicos. Extraído de (Poco et al., 2011).

\subsection{Considerações Finais}

Neste capítulo foi apresentada uma visão geral de algumas técnicas de visualização multidimensional baseadas em projeções, onde cada item de dados é descrito por um conjunto de 
características. Esse conjunto é reduzido para ser mapeado em 2 dimensões, por exemplo, de modo que se tenta preservar a estrutura original e a proximidade dos dados nesses espaços, indicando a alta correlação de conteúdo.

Além disso, apresentaram-se as árvores de similaridade com as quais as folhas representam os objetos da coleção e as arestas definem a distância (similaridade) entre os dados. Um dos métodos utilizados para a construção desse tipo de árvore é o Neighbor Joining (NJ).

Os sistemas de visualização aplicados a coleções de imagens possuem acesso a uma interface visual na qual as relações de similaridade possuem prioridade. Assim, a parte exploratória da visualização de imagens concentra-se em como fornecer ao usuário uma maneira de navegar e explorar os dados visualizados e uma maneira de prover, com o mínimo de esforço possível, as tarefas relacionadas à mineração de informação. Para isso existem atualmente vários sistemas que desenvolvem uma boa interação com o usuário, tanto em um ambiente de 2 como de 3 dimensões, como descrito nesse capítulo.

Em outra seção do capítulo, foram apresentadas abordagens que vinculam a visualização multidimensional na seleção de características, ou seja, que usam a visualização como suporte para encontrar um espaço de características que melhor representa a um conjunto de dados. Finalmente, apresentam-se as ferramentas e medidas de avaliação que auxiliam os modelos de visualização de informação considerados neste trabalho de mestrado. 



\section{Abordagem Baseada em Visualização de Informação para Avaliação de Características de Imagens}

\subsection{Considerações Iniciais}

Várias abordagens para a seleção de características têm sido propostas e usadas (apresentadas na Seção 2.4.2). Existem diferentes algoritmos que são altamente usados e efetivos baseados em filtros e em estratégias wrapper, poucas abordagens são baseadas na análise visual (Tan et al. 2006). Assim, é relevante a investigação de métodos para seleção e análise de características utilizando algoritmos de visualização, permitindo uso de uma tela de baixa dimensão por um especialista, no apoio a tarefas de classificação de padrões. Em particular, a interferência do usuário através de uma abordagem visual pode reduzir o numero de iterações para definir o espaço ideal.

Entre as vantagens da visualização de informação, segundo o visto na Seção 3, revelar ou não informações interessantes e mostrar principalmente similaridades ou dissimilaridades de instâncias numa tela, podem servir de ajuda ao usuário em verificar se um conjunto de características podem ser consideradas importantes para representar um conjunto de dados. 
Este capítulo apresenta as propostas deste trabalho para métodos de análise semiautomática de espaços de características como o objetivo final de apoiar a seleção de características importantes a partir do uso de técnicas de visualização, conhecidas pelo bom desempenho nas tarefas de análise e exploração de dados. A idéia básica é usar a visualização das características e identificar manualmente ou de maneira semiautomática características visualmente relevantes, conforme descrito na Seção 4.2 .

A proposta se baseia em considerar a visualização de informação como base para avaliar diferentes espaços de características, a partir da análise visual dos diferentes resultados obtida pela visualização dos dados representando os diferentes espaços de características. Foi definido também um processo de realimentação na escolha do melhor espaço que represente a um conjunto de dados, permitindo trocar ou criar novos critérios de seleção de características, modificando parâmetros na obtenção das características, etc.

\subsection{Visualização de Informação como Seletor de Ca- racterísticas}

A visualização de informação fornece ao usuário uma visão completa dos dados e mostra fenômenos, padrões ou correlações globais ou locais existentes entre eles. Já a abordagem proposta inclui a exploração visual das características, então o desafio é fornecer ao usuário um meio para detectar um subgrupo de características representativas ou identificar grupos onde as instâncias relevantes estão contidas.

Este trabalho da sequência à pesquisa feita por Botelho e Batista Neto (2010), que propõe a abordagem da procura de características não correlacionadas em projeções $2 \mathrm{D}$ para apoiar o processo de seleção de características. A proposta usou a revelação de grupos bem definidos na projeção, sugerindo duas abordagens. Uma das abordagens o usuário pode selecionar manualmente um subconjunto de características, considerando os pontos projetados isolados e a seleção de um ponto quando ocorre uma sobreposição. A outra abordagem emprega o algoritmo $K$-Means sobre as características projetadas, considerando um número de grupos e um número de características por grupo informados pelo usuário, sumarizando assim o espaço de características de um conjunto de imagens.

As duas abordagens propostas por Botelho e Batista Neto (2010), são desenvolvidas neste trabalho. Na primeira o usuário seguindo sua experiência analítica, identifica visualmente as características relevantes. Na outra escolhe dentro de um grupo definido pela visualização um numero $k$ de características (as mais próximas do centróide de cada grupo). No entanto a 
forma de visualização, neste trabalho é modificada também são adicionadas novas abordagens de seleção visual com resultados promissores.

Uma visão geral da proposta é apresentada na Figura 4.1, onde descreve-se os passos desenvolvidos para considerar a visualização de informação como um método para seleção de características. Esse pipeline é composto por várias etapas que são descritas a seguir, incluindo as definições necessárias para sua formalização e compreensão das abordagens desenvolvidas:

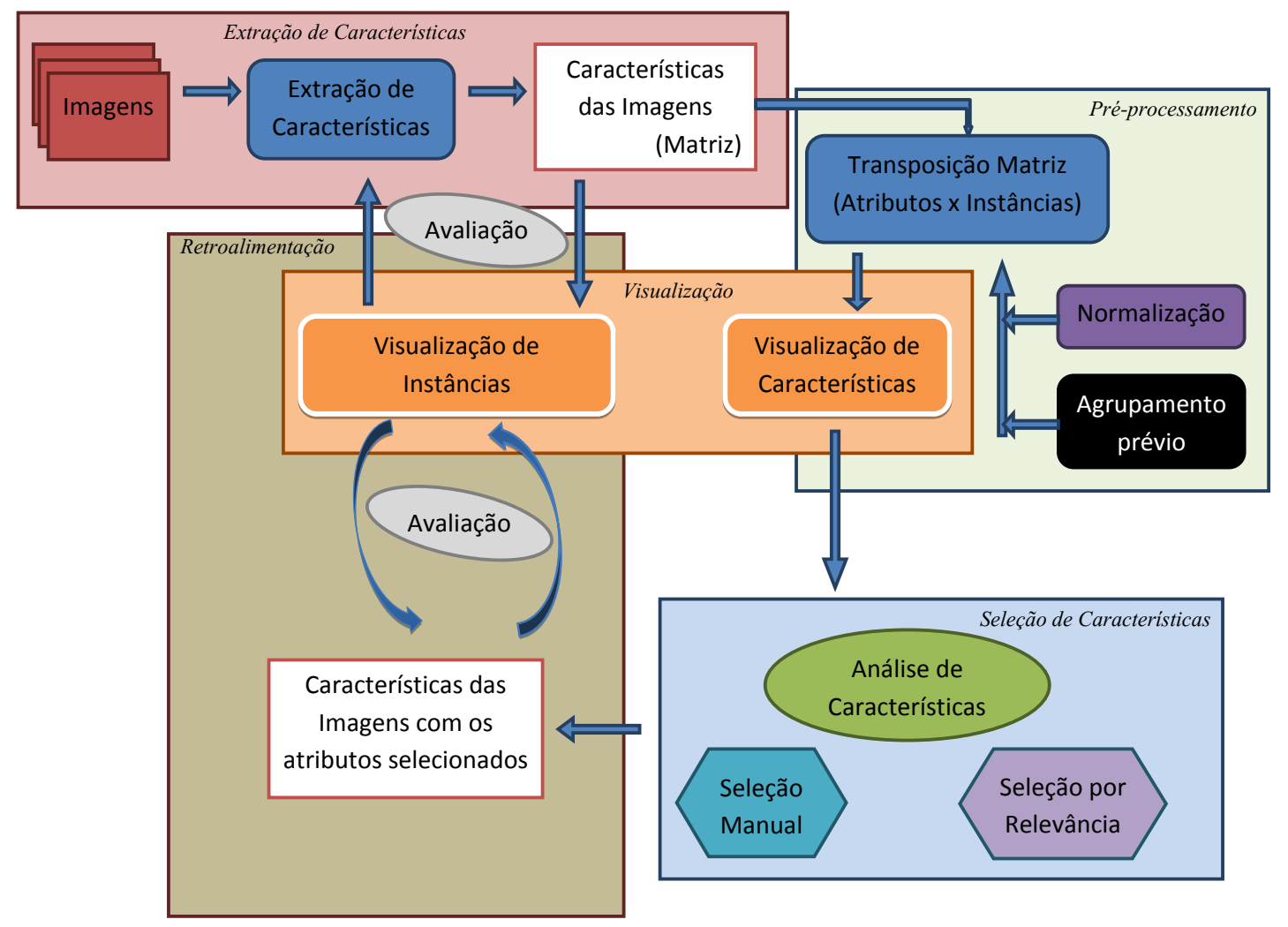

Figura 4.1: Esquematização da abordagem para seleção e avaliação de características usando visualização de informação. Ao usuário é fornecida uma visualização, que pode ser utilizado como um ponto de partida para a análise de características interativamente.

1. Extração de Características de um Conjunto de Imagens - Um conjunto de tamanho $m$ de imagens $I, I=\left\{I_{1}, I_{2}, \ldots, I_{m}\right\}$ descritos no espaço de dimensionalidade $E_{n}$, onde $n$ é o numero de características de cada imagem $I_{i}$, obtida pelo extrator $\epsilon$. Dada uma matriz $D(D A T A)$ de ordem $m \times n$ formada por um conjunto de vetores de características $V=\left\{v_{1}, v_{2}, \ldots, v_{m}\right\}$, onde $\epsilon\left(I_{i}\right)=v_{i}=\left\{x_{i}^{1}, \ldots,{ }_{i}^{n}\right\}$ e $x_{i}^{1}$ é a característica número 1. 


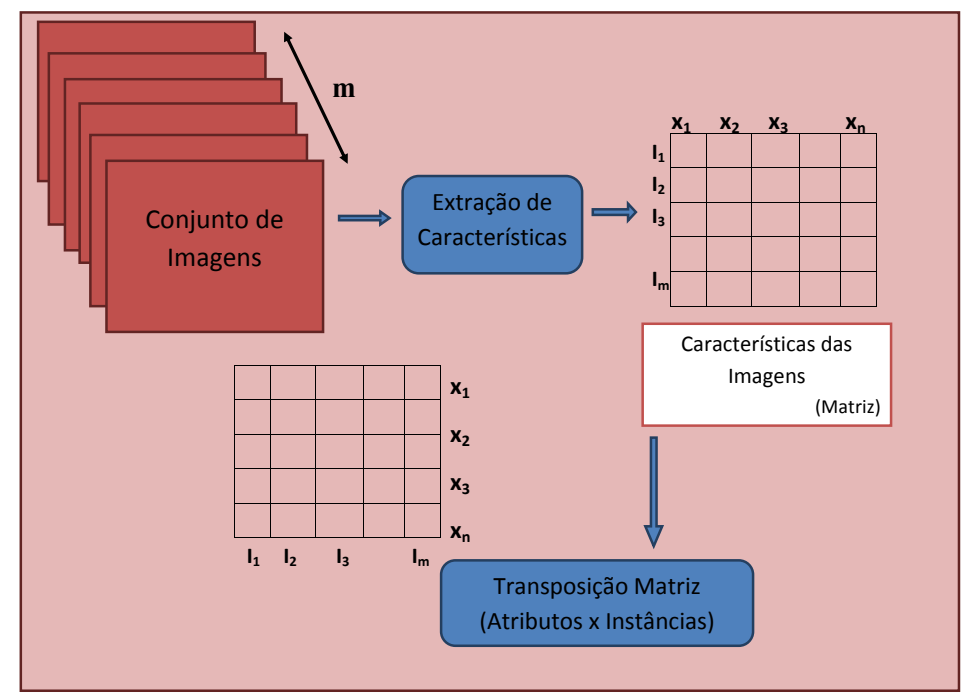

Figura 4.2: Processo de Transposição da Matriz de Instâncias.

2. Transposição da Matriz de Instâncias - As características se convertem em instâncias e as instâncias originais em características. Isto é, dada a matriz $D$ de ordem $m \times n$, sua matriz transposta será representada por $D^{T}$ de ordem invertida $n \times m$.(Ver Figura 4.2)

3. Pré-Processamento - É feito antes de que a matriz transposta seja visualizada e emprega-se algoritmos de normalização e agrupamento. À matriz $D^{T}$ emprega-se uma função de normalização de dados $H$ e, como resultado, obtêm-se a matriz transposta normalizada $D_{h}^{T}$, a fim de colocar em uma mesma faixa de valores as características antes de ser transposta. Então emprega-se também uma função de agrupamento $R$, com o objetivo de rotular cada instância com uma classe prévia, para obter uma melhor visão dos dados, no momento de comparar a similaridade das classes nos grupos criados na tela da visualização. Os algoritmos considerado para normalização é z-score, para o agrupamento é utilizado o algoritmos K-Means.

4. Visualização das Características - A matriz transposta $D^{T^{*}}$ de pontos (características) pré-processada e visualizada usando a técnica Neighbor-Joining (ver Seção 3.2.2) para a construção de árvores filogenéticas.

5. Análise e Seleção das Características Importantes - De acordo com a visualização o usuário pode escolher quais características poderiam representar melhor os dados, por meio de uma seleção manual, ou de acordo com a posição das características dentro dos grupos definidos pelos ramos da árvore. Serão escolhidos automaticamente os pontos centrais dos ramos e seus $k$-vizinhos mais próximos. As duas abordagens serão discutidas em detalhe nas subseções 4.2.1 e 4.2.2. 
6. Obtenção das Características Selecionadas - Após a escolha seja realizada, o processo continua com a modificação da matriz original de instâncias pela exclusão das características não selecionadas no passo anterior.

7. Avaliação - Do conjunto resultante de características selecionadas, gera-se a visualização, que é avaliada com as diferentes medidas indicadas na Seção 3.5.2. O objetivo é medir a qualidade dos diferentes pontos de vista (de cada escolha) a fim de fornecer o conjunto de características que melhor representem ao conjunto de imagens usando a visualização.

8. Retroalimentação - Os conjuntos resultantes também serão avaliados usando também a visualização, e se os resultados não satisfizerem ao usuário, pode ser empregado um processo de retroalimentação em busca de melhores resultados até obter um melhor espaço de características que represente um conjunto de dados. A Seção 4.3.2 detalha o processo.

\subsubsection{Seleção Manual de Características Representativas}

Esta abordagem tem base na combinação de técnicas de visualização e interação com o usuário para criar um método efetivo e interativo de seleção de características. O usuário pode fazer uma seleção manual na tela de visualização das características, como é apresentada na Figura $4.3{ }^{1}$. Com ajuda da ferramenta VisPipeline (ver Seção 3.5.1), a seleção das características é feita por clique ou arraste do mouse nos pontos que formam a visualização em árvore $(N J)$.

Definem-se as características selecionadas como $S=\left\{x^{1}, \ldots, x^{r}\right\}$. O critério da eleição do usuário também é um tema de discussão neste trabalho. A visualização das características revela a formação de grupos e a existência de pontos isolados que poderiam interpretar-se como outliers. Com base nesse critério, segundo Botelho e Batista Neto (2010), deveriam escolher-se os pontos projetados isolados e a seleção de um só ponto quando ocorre uma sobreposição de pontos. Para os autores, os pontos próximos uns aos outros indicam correlação, juntos não contribuem para aumentar o poder de discriminação, enquanto amostras de grupos distintos podem indicar não correlação, essencial em um processo de classificação. Considerando as árvores como apoio à classificação, segundo Paiva et al. (2011), considera-se a contribuição de Botelho e Batista Neto (2010) essencial na execução de este trabalho.

Um dos objetivos deste projeto também é avaliar os subconjuntos obtidos por amostragem do conjunto grande de imagens; e realizar também a seleção de características sobre esses subconjuntos. Se, por um lado, ajuda-se a obter uma melhor qualidade na visualização, avaliando o tamanho e o numero de classes, levanta-se uma questão: deveria considerar apenas as imagens

\footnotetext{
${ }^{1}$ Características do conjunto de imagens COIL (Nene e Nayar, 1996)(total de 720 imagens divididos igualmente em 10 classes), usando o extrator $G C H$ (total de 64 características) e usando a distância euclidiana.
} 


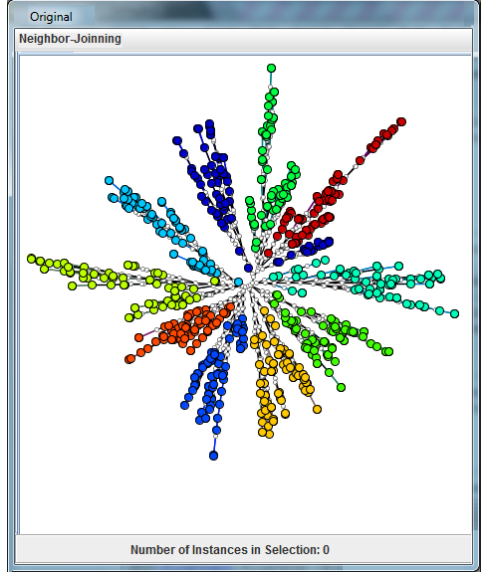

(a)

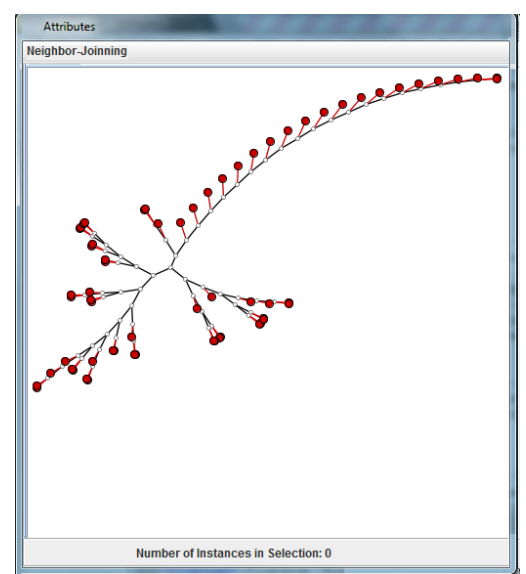

(b)

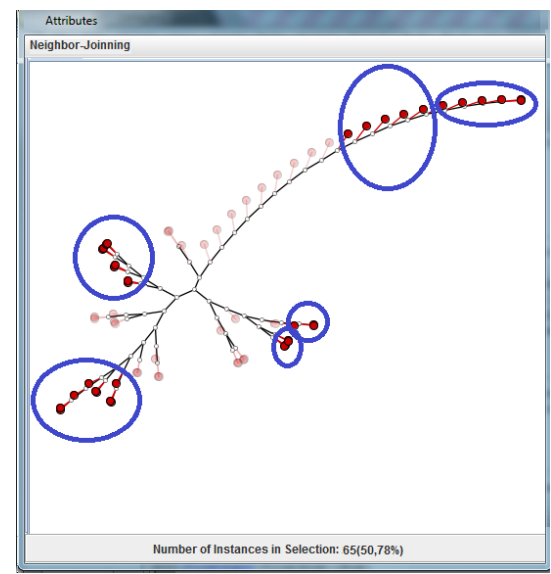

(c)

Figura 4.3: Seleção Manual de características feita na ferramenta VisPipeline. a) Visualização usando uma árvore $N J$ dos dados originais, pela matriz $\mathrm{D}$ do conjunto de imagens COIL 720 e usando a distância logarítmica. b) Visualização $N J$ das características a partir da matriz $D^{T}$ usando a distância Jaccard. c) As características selecionadas manualmente pelo usuário.

representativas de cada classe do conjunto total, antes de fazer a transposição da matriz de instâncias? Para tentar resolver esse problema foi adotado um critério para usar um subconjunto de dados que represente o conjunto total, conforme é descrito a seguir.

\section{Seleção de Características a partir de Imagens Representativas}

É mais difícil filtrar e extrair informação relevante a partir de massas grandes de dados do que a partir de um grupo com menor complexidade. Segundo Joia et al. (2011), a seleção de um subconjunto de imagens, chamados pelos autores de consulta, é realizado pelo usuário e consiste em selecionar um conjunto de imagens com similares instâncias pertencentes a classes distintas. A partir da informação de cada classe com as imagens de consulta o sistema dos autores executa automaticamente um processo de seleção de características, de modo de encontrar um subconjunto de características que representa melhor cada classe. Para os autores, o subconjunto de características resultante é usado para definir as métricas usadas para criar a matriz responsável da execução do algoritmo de projeção multidimensional.

Em concordância com a idéia proposta por Engel et al. (2011), a decomposição dos dados, em detalhe até suas características, provê uma coordenação, rápida e interação intuitiva com o usuário. Assim, foi desenvolvido um modelo baseado na visualização dos dados, na seleção do subconjunto de imagens representativas e na seleção das características do subconjunto. $\mathrm{Na}$ 
ferramenta Vispipeline esse modulo implementado é composto basicamente por duas janelas com todas estas opções interativamente orientáveis:

- Visualização de todos os dados mapeados (Figura 4.4): nessa janela é selecionado um subconjunto de imagens, chamadas de representativas, denotadas por $Q$, selecionadas pelo usuário a partir do conjunto geral. Tais imagens marcadas serão submetidas ao processo de seleção características, a fim de identificar o subconjunto de características que melhor representa as imagens e, com a intenção, de manter as distribuições da semelhança ao considerar todas às instâncias originais.

- Visualização das características das imagens representativas (Figura 4.5), é a janela resultante do vínculo (coordenação) que se tem entre a visualização de todos os dados e sua matriz transposta. Nesse ponto o usuário pode explorar em detalhe as características e pode escolher manualmente as que melhor representam o subconjunto de dados selecionado, por exemplo, ramos ou grupos identificados por uma única classe.

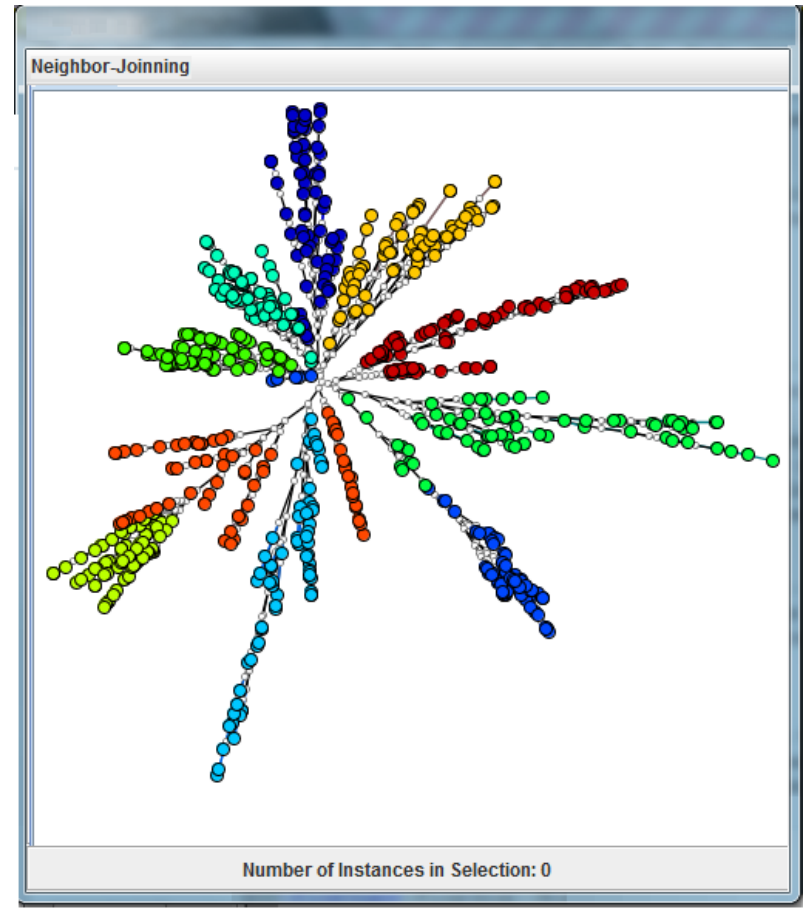

(a)

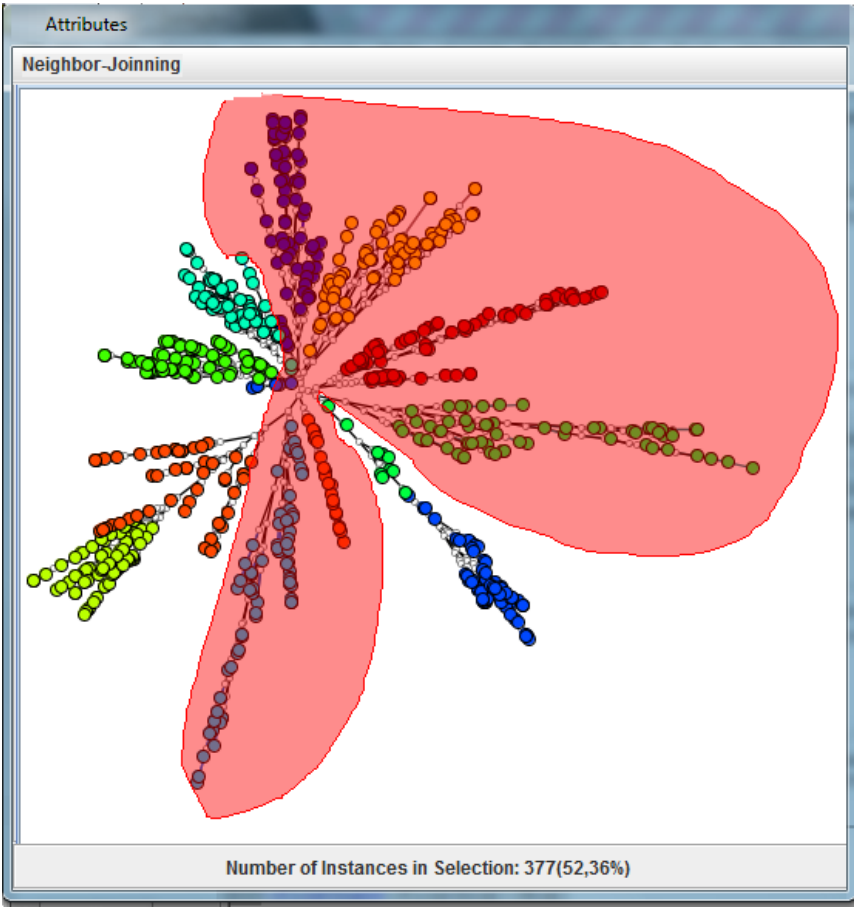

(b)

Figura 4.4: Visualização em árvore, usando a técnica $N J$ das imagens $C O I L$, com as características do extrator $B I C$ e usando a distância Logarítmica. À esquerda é exibida a visualização do conjunto total de imagens e à direita é exibida a mesma árvore e em destaque as imagens selecionadas como representativas. 


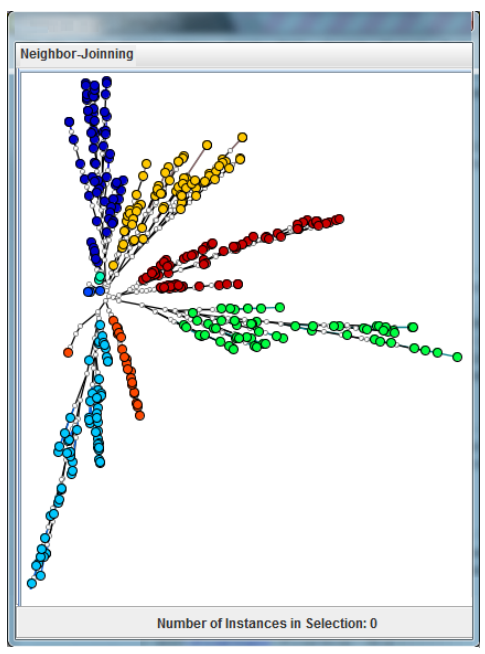

(a)

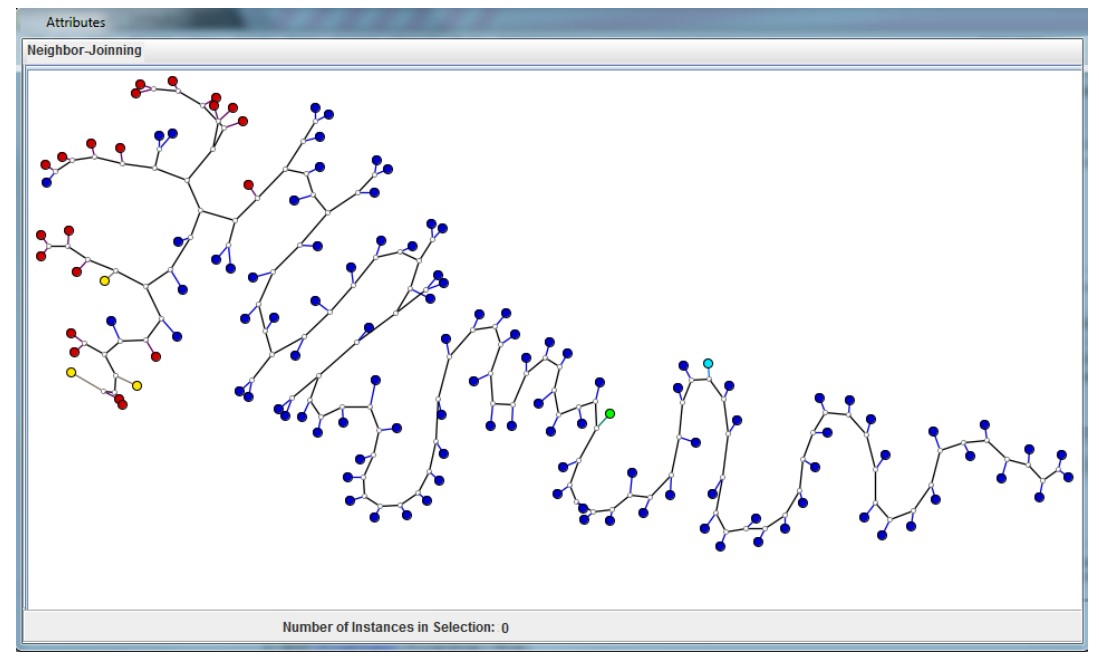

(b)

Figura 4.5: À esquerda é exibida a visualização das imagens representativas do passo anterior (Figura 4.4). À direita é exibida a visualização das características das imagens representativas, usando $N J$, distância Euclidiana e um pré-processamento do agrupamento usando k-Médias, considerando cinco grupos. A visão da árvore utiliza Force Directed Placement.

\subsubsection{Seleção das k-Características em Grupos formados pela Vi- sualização em Árvore}

Em nosso estudo, como já foi mencionada a visualização de dados incorpora uma visão em detalhe e também uma visão mais geral do conjunto de dados. Isso pode efetivamente facilitar a tarefa de encontrar, por exemplo, comportamentos das características nas visualizações, ou revelar propriedades importantes que podem ser de interesse para o usuário. Como foi descrito na Seção 4.2.1 pode-se definir um processo de seleção manual de características usando a visualização, mas é necessário definir também um processo de seleção automática usando a visualização.

O processo de seleção de características proposto possui duas etapas: criação do modelo de grupos das características na tela de visualização (criado com ajuda do usuário) e a seleção das características regionais por grupos no modelo criado.

A fase de criação do modelo de agrupamentos é necessária para identificar os grupos de caraterísticas similares. Essa fase também é explorado por algoritmos conhecidos de seleção de características (Wang et al., 2003; Yang et al., 2003). Esta etapa é interativa. O usuário trabalha sobre a visualização do conjunto de características e manualmente delimita as regiões que ele interpreta como um grupo. Um ponto de vista é considerar os ramos de uma árvore 
$N J$ como um conjunto de instâncias de um mesmo grupo pois suas instâncias mostram um alto nível de similaridade inter e intragrupos. Aproveitando os grupos definidos e usando técnicas de triangulação para interligar cada ponto do ramo, se define por grupo o fecho convexo de cada grupo.

São apresentadas algumas definições necessárias para compreender esta abordagem:

- Rotulação Manual - Uma ferramenta para rotular manualmente as classe, foi proposta no contexto deste trabalho ( veja Paiva et al. (2011)). Com apoio da visualização, o analista pode rotular as classes de acordo com algum critério pessoal. A Figura 4.6 mostra o trabalho do Rotulador Manual na visualização de um conjunto de imagens. É possível verificar os grupos definidos pelos ramos da árvore $N J$. A figura mostra que algumas instâncias não tem a mesma cor (classe) que a maioria das instâncias no ramo selecionado (em vermelho). Com o rotulador manual consegue-se definir, por exemplo, um ramo como uma classe única. O mesmo processo pode ser feito com uma visualização de características.

- Triangulação Delaunay - Para Alencar et al. (2008), para ressaltar a percepção de vizinhança em uma projeção multidimensional é possível conectar os pontos e gerar uma triangulação com o fim de agrupá-los, considerando-se um grupo com uma classe e uma cor que representa os dados nessa classe. A triangulação de Delaunay para um conjunto $P$ de pontos em um plano é uma triangulação $T D(P)$, tal que nenhum ponto $P$ está dentro da circunferência de qualquer triângulo em $T D(P)$. O limite da face exterior da triangulação Delaunay é o limite do fecho convexo de um conjunto de pontos (de Berg et al., 2000). Estas propriedades são usadas para separar conjuntos de pontos numa visualização.

A Figura 4.7 exemplifica uma representação gráfica da visualização em árvore do conjunto de características do conjunto de imagens Frutas-BIC ${ }^{2}$. A cor dos pontos mapeia a classe que o usuário define usando o Rotulador Manual. Cada grupo é delimitado usando a triangulação de Delaunay dos pontos selecionados, num processo chamado delimitação das regiões. Esta figura também ilustra a utilidade das árvores de similaridade para identificar grupos como indica Paiva et al. (2011).

Posteriormente à seleção de características regionais por grupo é realizada automaticamente a seleção de amostras, calculando primeiro o centróide e em seguida seus $k$ vizinhos mais próximos. O centróide é encontrado de acordo com a forma do grupo. Usando a técnica $k N N$

\footnotetext{
${ }^{2}$ Conjunto de Imagens referenciadas por Rocha et al. (2010). Total de 1200 imagens divididas em 200 classes
} 


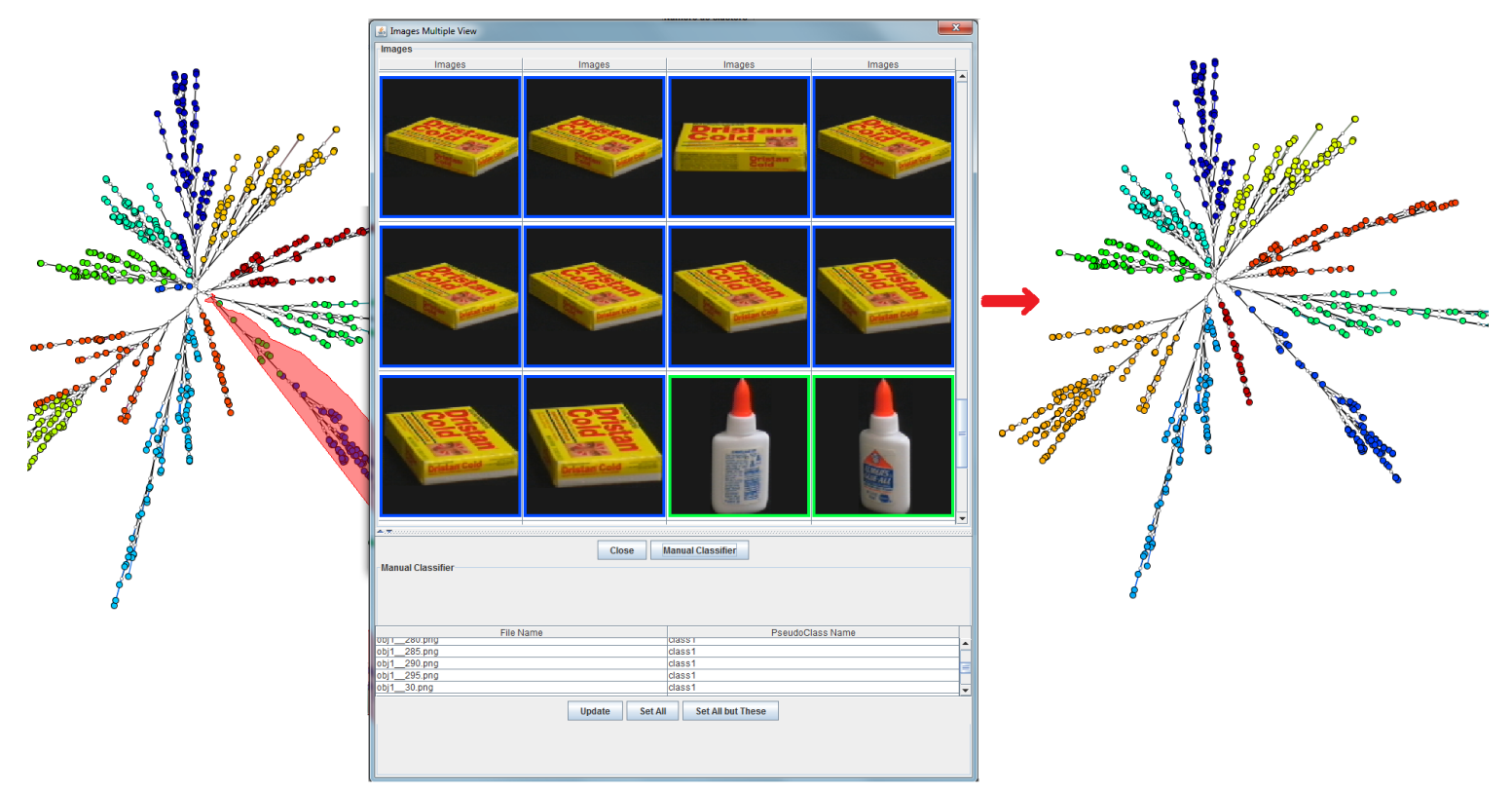

Figura 4.6: $\mathrm{Na}$ esquerda apresenta-se uma visualização em árvore das imagens COIL. Identifica-se que os ramos na sua maioria são bem agrupados com elementos de uma única classe. No centro da figura é mostrado o Rotulador Manual de Classes. Rotulando o conjunto selecionado no ramo da árvore (lado esquerdo), consegue-se rotular todas as instâncias como uma classe única Class 1. Do lado direito apresenta-se o resultado.

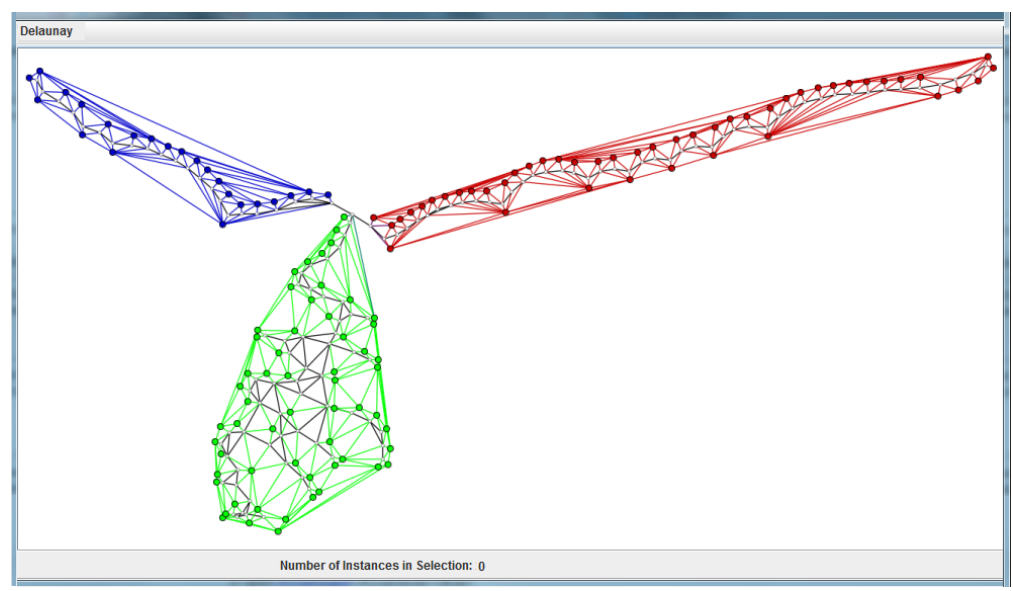

Figura 4.7: Visualização em árvore $N J$ das características do conjunto de Frutas-BIC, empregando o mesmo extrator $C C V$ (com número total de 128 características) e a distância Euclidiana. Emprega-se na visualização a triangulação dos três grupos definidos pela visualização e confirmados pelo usuário. 
achamos as $n$ características em torno do centróide. As $n+1$ (considerando os centróides) são as características que representarão esse grupo, e a união de todas as características selecionadas dos grupos será o conjunto de características geral que representam o um conjunto de dados e que precisam ser conservadas juntas. O numero $k$ é fornecido pelo usuário.

As Figuras 4.8 e 4.9 mostram a identificação dos centróides e seus $k$ vizinhos mais próximos. Definem-se os centros dos ramos como: $\left\{c_{1}, c_{2}, \ldots, c_{b}\right\}$. Definindo a $X$ como o conjunto geral de características e $d$ a função de distância, o subconjunto de características $T$ por relevância é definido pela função kNN (como define Avalhais et al. (2012)) e a união dos centróides, nas equações $4.1 \mathrm{e} 4.2$.

$$
\begin{gathered}
\bigcup_{i=0}^{b} c_{i} \cup k N N\left(c_{i}, k, d, X\right) \\
k N N\left(c_{i}, k, d, X\right)=\left\{T \subseteq X,|T|=k \wedge \forall x_{p} \in T, x_{q} \in X \backslash T: d\left(c_{i}, x p\right) \leq d\left(c_{i}, x_{p}\right)\right\}
\end{gathered}
$$

A relevância é um termo considerado pelo número $n$ de pontos selecionados, de forma similar aos dados relevantes após uma consulta (neste caso os centroides) segundo a concepção da recuperação de informação ( veja Auffarth et al. (2010); Avalhais et al. (2012); Huang et al. (1998)).

Na seleção de características, o objetivo é escolher um subconjunto de características, a fim de melhorar o desempenho e a eficiência em relação a uma tarefa (no nosso caso classificação) e para reduzir ruídos. A perda de informação na redução do espaço característica deve ser mantida tão pequena quanto possível de modo que o espaço resultante possa fornecer informação suficiente para a classificação.

Relevância mede a "qualidade"da projeção de atributos individuais a rótulos. Redundância mede como características semelhantes são (ou inversamente, quanto a adição de um recurso para um dado conjunto de características contribui para uma predição).

\subsection{Visualização de Informação para Avaliação de Es- paços de Características}

As tarefas de mineração de dados são normalmente apoiadas por eficientes algoritmos de classificação, agrupamento e de recuperação de dados com base no cálculo da similaridade dos objetos como referência Bremm et al. (2011). Além desses algoritmos mais conhecidos, Eler et 


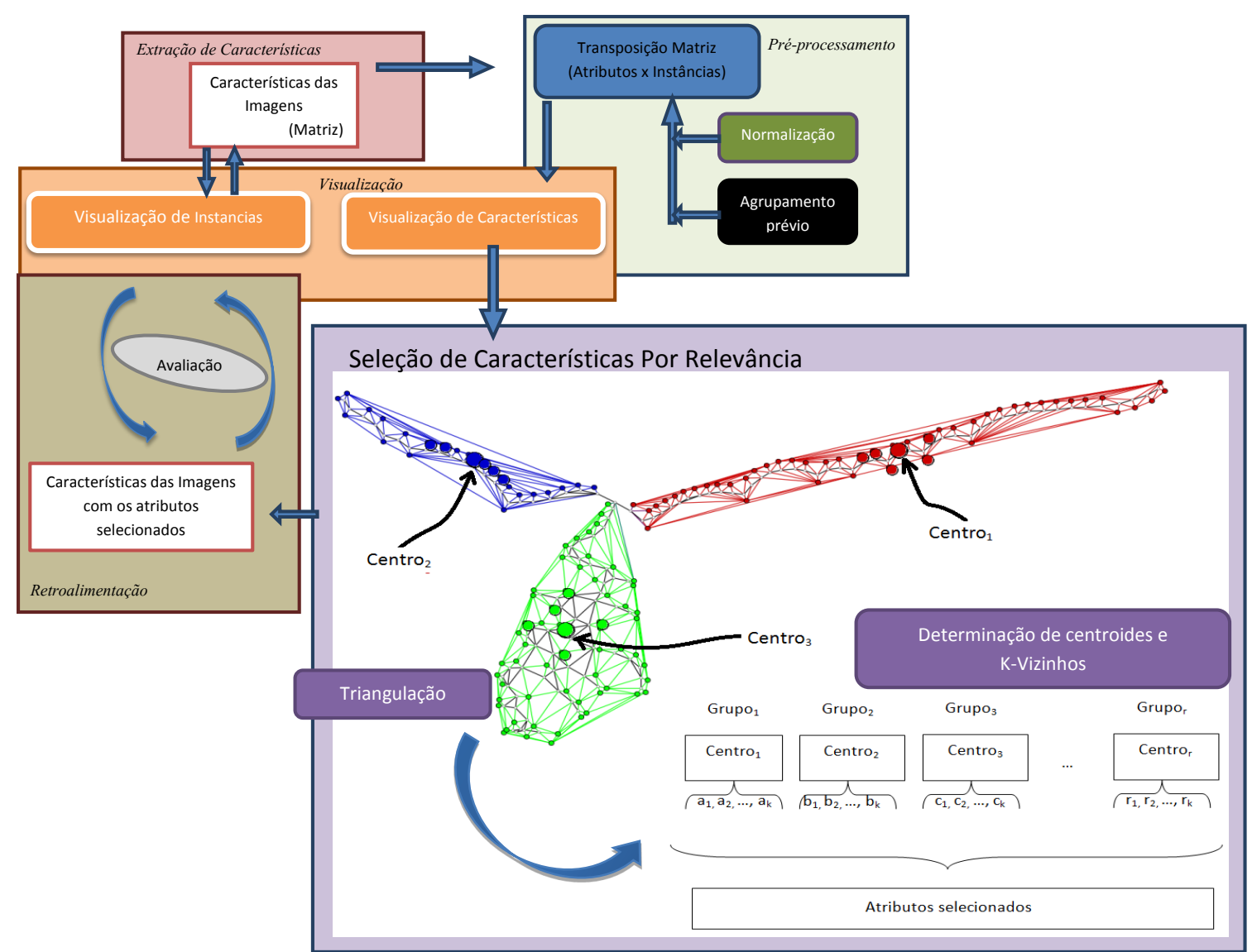

Figura 4.8: Identificação dos centróides nos grupos definidos na visualização em árvore e seus 5-vizinhos mais próximos, os centróides são achados de acordo a forma do grupo. Mostra-se um quadro que sumariza como esta abordagem é realizada.

al. (2009); Jankun-Kelly e Kwan-Liu (2003); Nguyen e Worring (2008a); Ward e Rundensteiner (2005) reconhecem a visualização de informação como um método para medir a similaridade para muitos tipos de dados como texto, vídeo, áudio, imagens, etc.

Neste trabalho usa-se a visualização de informação para medir a qualidade de espaços de características de conjuntos de imagens. A visualização converte-se em um ponto de entrada para um exame mais profundo de espaços de características. Esta exploração pode levar a ajustes no processo de análise e mineração de dados, além de uma retroalimentação (feedback), como é ilustrado na Figura 4.10 .

Dentro do processo da visualização dos dados, como foi visto no Capítulo 3, a entrada dos algoritmos são os dados representados por um conjunto de vetores de $n$ dimensões de valores numéricos. Dependendo da técnica de visualização, a similaridade entre os objetos é então 


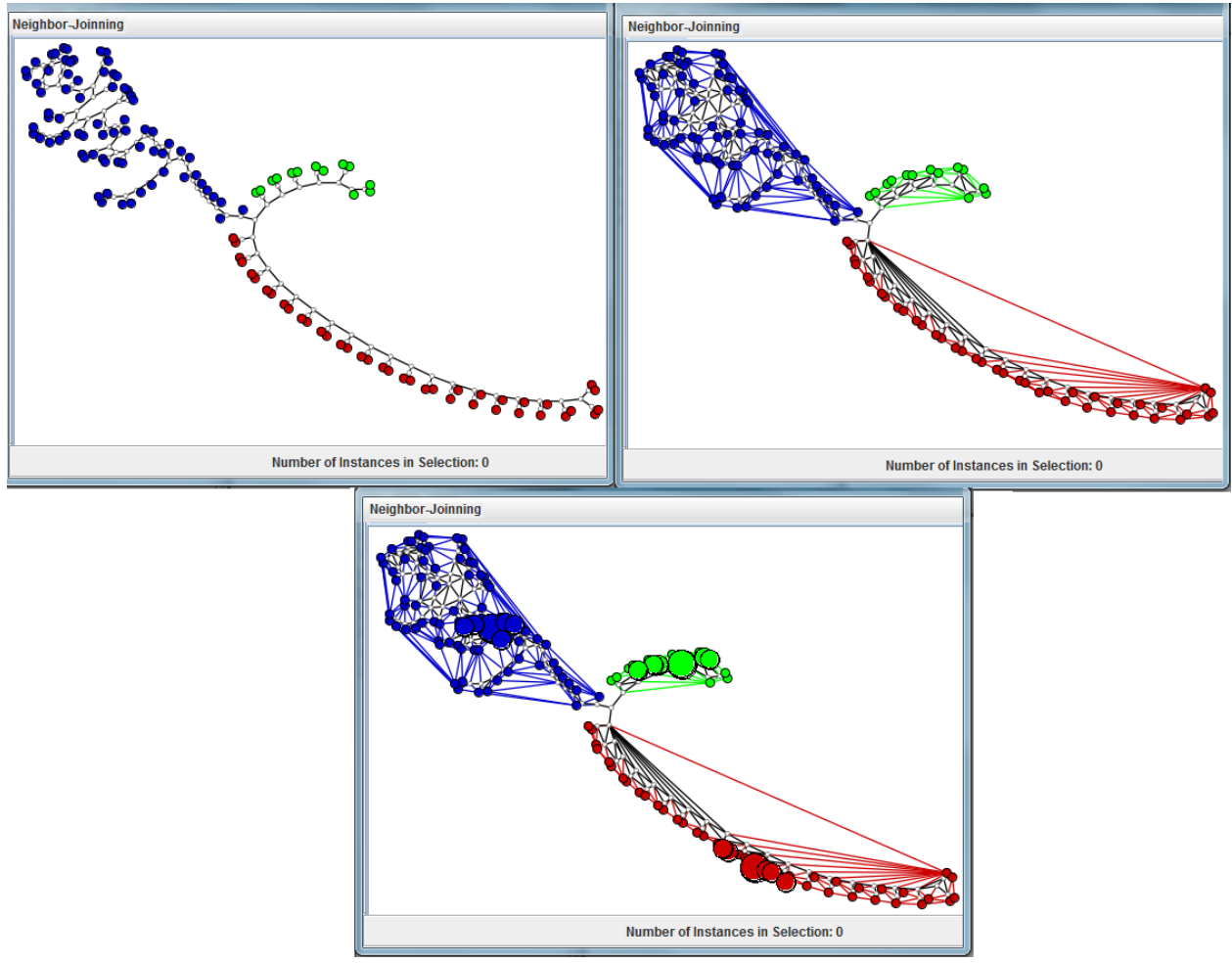

Figura 4.9: Visualização das características do conjunto de Frutas-BIC (Total de 2520 imagens divididas em 35 classes), usando o mesmo extrator BIC com um total de 128 características. Identifica-se os centróides e os 5-vizinhos mais próximos.

calculada usando, por exemplo, diferentes medidas. Assim, os algoritmos de visualização de informação baseiam-se em como os dados foram representados, e a qualidade da visualização depende dessa descrição dos dados.

De acordo como Figura 4.10, o primeiro passo do pipeline é a avaliação da representação dos dados antes e após do processo de seleção usando a visualização. O resultado é analisado e serve como ponto de partida para um processo de análise interativa. $\mathrm{O}$ suporte visual inicia um processo de refinamento, o que oferece ao usuário a possibilidade de refinar os resultados de forma interativa (feedback).

A comparação de espaços de características pode ser interativamente explorada pelo usuário, e possibilita ao usuário comparar visualmente, para um mesmo conjunto de dados espaços de características diferentes. A exploração do espaço interativo de dados pode revelar novas informações, ajudando ao usuário a tomar melhores decisões sobre o critério de seleção, modificação ou ajuste de parâmetros ou a escolha de outros extratores que melhor representem o conjunto de dados.

São descrita a seguir com mais detalhe as etapas de avaliação e de retroalimentação que exigem melhor esclarecimento. 


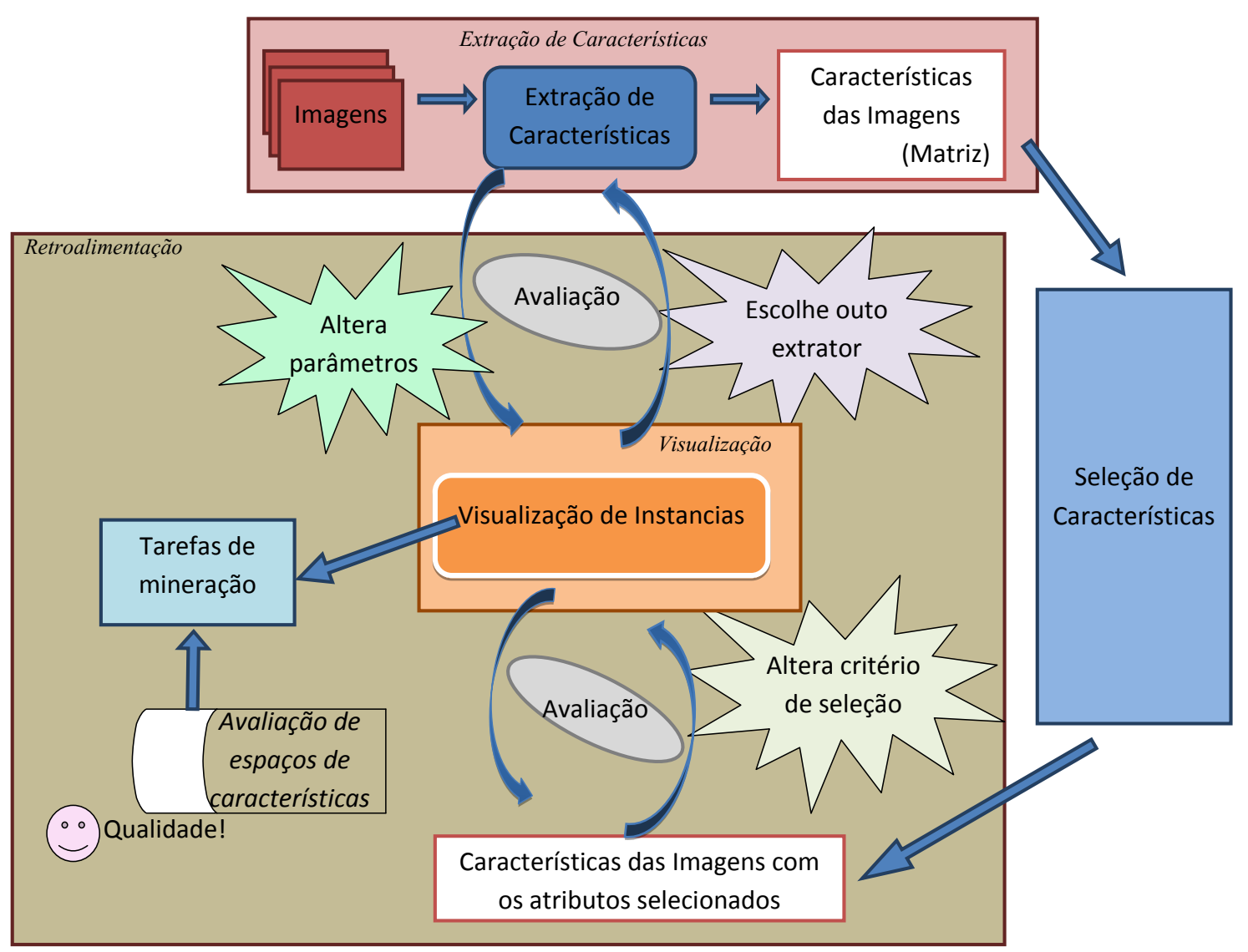

Figura 4.10: Processo de avaliação de espaços de características. Por exemplo, após um processo de seleção de características, avalia-se a nova representação dos dados, e se os resultados não forem favoráveis para o usuário pode-se alterar o critério de seleção, ou escolher outro extrator ou alterar seus parâmetros.

\subsubsection{Avaliação}

Um dos objetivos deste projeto é avaliar e analisar visualmente diferentes espaços de características criados pela seleção de características sob diferentes critérios. Cada espaço de características é apresentado e avaliado para determinar se tais características representam apropriadamente ao um conjunto de imagens.

Por um lado, segundo Cuadros et al. (2007); Paiva et al. (2011), para implementar um algoritmo $N J$ (técnica considerada importante para este projeto) precisa-se primeiro calcular a matriz de distâncias entre os vetores de características de cada elemento. Então, se os dados são representados de diferentes maneiras (diferentes vetores para cada dado), obtêm-se diferentes representações usando o algoritmo $N J$. Cada visualização é avaliada e comparada. Assim, com 
as alternativas se existe melhoria ou não fica demonstrado que a visualização de dados ajuda avaliar diferentes espaços de características.

Além disso, segundo Brandoli et al. (2011), se as relações de similaridade correspondem ao que é esperado pelo especialista o conjunto escolhido é considerado ótimo. Caso contrário, os parâmetros do extrator poderiam ser alterados, outra técnica de extração pode ser empregada ou pode-se mudar o critério para a seleção de características (abordagem considerada nesse trabalho), produzindo finalmente um novo conjunto de características que pode ser novamente explorado, de tal forma que a representatividade deste novo conjunto possa ser avaliada.

Este processo é executado até convergir para um conjunto de características que reflita em uma boa separação das classes na projeção. Isto é, a visualização representa um domínio do espaço de características, que pode fornecer informações importantes e ajudar o usuário a construir modelos mais robustos aplicados à análise de imagens.

Avaliar a visualização do conjunto de dados antes e depois da seleção, pode indicar um alto ou baixo nível de confiança na decisão da seleção. As diferenças que ocorrem quando um subconjunto de características é bem ou mal capturado pela visão do usuário, são revelados na avaliação da sua visualização do conjunto de dados com as características escolhidas. Tipicamente, se a visualização revela melhoria de segregação, o espaço ou similaridade que gerou a visualização representa melhor o conjunto, Medidas adicionais calculadas no espaço projetado (como valores de silhueta) fornecem a confirmação da melhoria identificada visualmente.

A Figura 4.11 mostra as árvores resultantes antes e após de uma seleção de características que interativamente foi realizada pelo usuário e ilustra a seleção manual das características que foi realizada. Obtém-se um melhoramento nos resultados avaliando com a medida Silhueta como mostra a primeira figura, antes da seleção com um valor de 0.3427 e após com uma melhoria com valor de $0.3457^{3}$.

\subsubsection{Retroalimentação}

O processo de seleção de características, exposto na Seção 4.2, não possui critério de parada sendo iterativo e depende dos resultados da avaliações. Se estes não satisfazem ao usuário, este toma a decisão de corrigir e pode refazer a seleção quando julgar necessário. O usuário está envolvido em todo processo de adaptar os dados, parâmetros, critérios, considerações para um conjunto de dados e melhorar a especificidade do resultado.

Entre as razões que se consideram principais pelas quais o usuário tenta variar o espaço de características obtido, incluem:

\footnotetext{
${ }^{3}$ Um mínimo valor possível é importante
} 


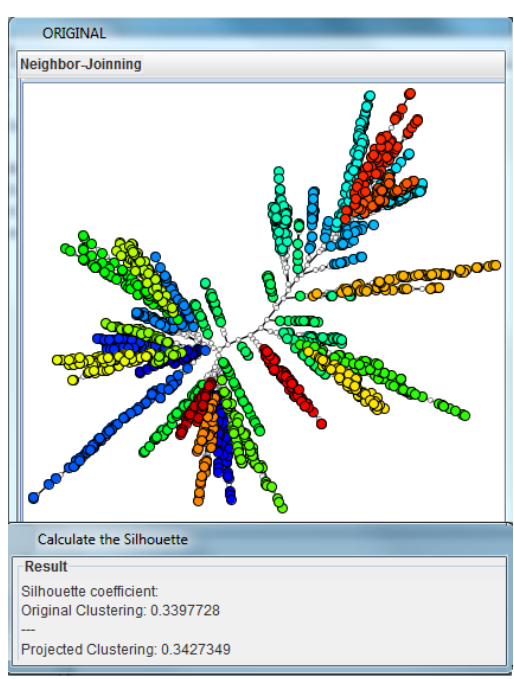

(a)

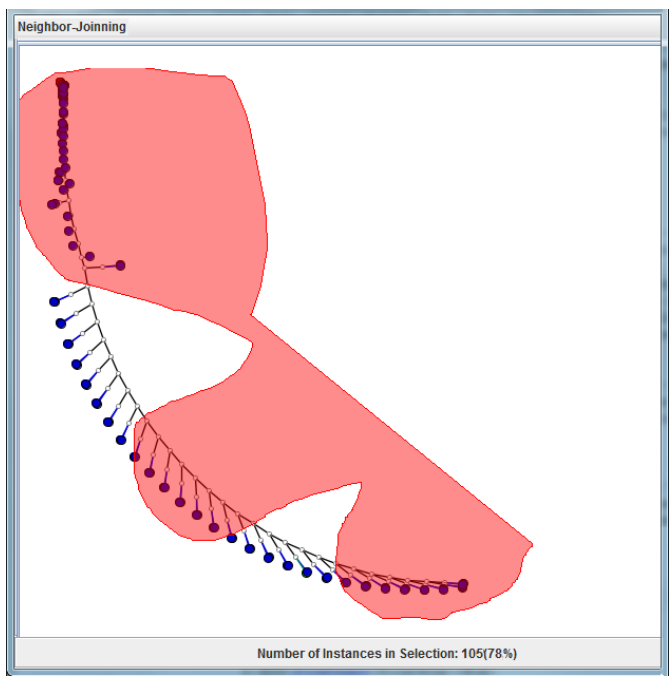

(b)

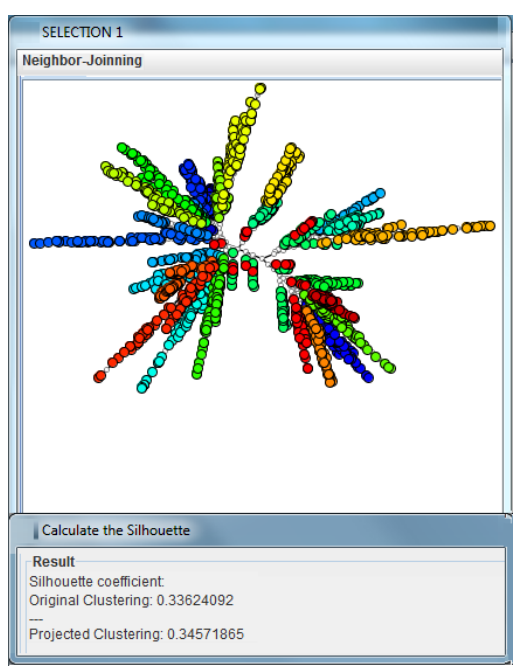

(c)

Figura 4.11: a) Visualização em árvore $(N J)$ do conjunto COIL(1800 imagens em 25 classes) caracterizado pelo extrator BIC usando 64 cores (com 128 características e usando a distância Logarítmica). Abaixo o resultado da avaliação com a medida Silhueta do conjunto no espaço original e no espaço projetado, perceba-se a melhoria no espaço projetado. b) Seleção manual das características do conjunto COIL, usando a técnica $N J$ e a distância euclidiana. O critério da seleção escolher os extremos e o centro da árvore com um total de 105 características. c) Visualização do mesmo conjunto apos de uma seleção manual de 105 características usando a visualização e abaixo o resultado da avaliação com a medida Silhueta (definida na Seção 3.5.2 do conjunto no espaço original e no espaço projetado, perceba-se não só a melhoria da projeção senão também em comparação com a visualização antes da seleção (lado Direito). 
- Variar o critério escolhido para a seleção manual de características usando a visualização, tentar mudar o critério o ponto de vista.

- De acordo com o resultado obtido, considera-se, por exemplo, demonstrar que se pode modificar os parâmetros escolhidos pelo extrator. Por exemplo, se esta usando o extrator BIC, pode-se mudar o número para reduzir as cores.

- Alterar a seleção das imagens representativas antes de fazer a seleção manual das suas características, como foi visto na Subseção 4.2.1.

- Mudar o algoritmo de extração que descreve o conjunto de dados.

- Mudar o tamanho dos dados, como o numero de classes ou a quantidade de dados por classe.

\subsection{Considerações Finais}

Este capítulo apresentou as abordagens consideradas e desenvolvidas durante este projeto. São apresentados os conceitos para incluir a visualização de informação dentro de um processo seleção e avaliação de características descritoras de imagens. Para a proposta de seleção são consideradas duas abordagens: seleção manual de características e seleção semiautomática das $k$-características em grupos definidos pela visualização das características; ambas abordagens conta com a ajuda de um usuário especialista.

É importante esclarecer as diferenças entre o trabalho de Botelho e Batista Neto (2010) e este projeto:

- O uso da árvore $N J$ como principal técnica de visualização, com base nas pesquisas feitas por Cuadros et al. (2007); Eler et al. (2009); Paiva et al. (2011). Substitui o uso de projeções multidimensionais, estendendo seus resultados para esta forma de visualização.

- No nosso caso, é possível trabalhar com imagens representativas por ramo ou classe e escolher dentro desse subconjunto as melhores características que representarão o conjunto completo (Subseção 4.2.1).

- Consideram-se os ramos das árvores como principais atores no cálculo dos grupos existentes retificados pelo usuário, ao contrario de Botelho e Batista Neto (2010), em que são definidos pelo usuário. 
- Adota-se o uso das triangulações Delaunay para definir grupos, e encontrar amostras nestes grupos determinando nos ramos as características regionais numa seleção semiautomática de características (Subseção 4.2.2).

- Foi incluído o pré-processamento da matriz transposta dos dados a fim de normalizar e agrupar em classes para uma melhoria na visualização de características.

- Foram criadas ferramentas de ajuda ao usuário em todo o processo de seleção, análise e avaliação.

Neste capítulo, também foi discutido como a visualização ajuda a avaliar espaços de características de um conjunto de dados, criando-se um processo de retroalimentação em busca de um melhor conjunto de espaços de características que representem um conjunto de imagens.

No próximo capítulo, serão apresentados os resultados obtidos em vários estudos envolvendo as várias etapas e alternativas do método aqui proposto. 


\section{Experimentos e Resultados}

\subsection{Considerações Iniciais}

Este capítulo descreve os experimentos realizados para avaliar a abordagem desenvolvida para definir os melhores conjuntos de características que representem as diferentes coleções de imagens.

Considera-se que todas as avaliações são realizadas usando a visualização de informação, isto é, considerando as medidas de avaliação usadas nesse âmbito. A metodologia começa avaliando os extratores que geraram as características que representam cada um dos conjuntos de imagens multivariados. Depois desse processo, e considerando os resultados obtidos, são realizados e avaliados diferentes processos de seleção de características, empregando a visualização em árvore das características de todo o conjunto de imagens e também de um subconjunto de imagens denominadas imagens representativas. Em seguida, algoritmos de classificação são executados para avaliar cada espaço de características obtido, com o auxílio da ferramenta $W E K A^{1}$. Finalmente, comparam-se os resultados obtidos com outras técnicas de seleção conhecidas no ambiente da mineração de dados considerando os mesmos conjuntos de imagens.

Todos os experimentos são realizados usando a ferramenta Vispipeline (apresentado na Seção 3.5.1). O Vispipeline é um sistema que associa ao seletor e o avaliador de características

\footnotetext{
${ }^{1}$ WEKA: Disponível em http: / / www. cs.waikato.ac.nz/ml/weka (Acessado o dia 23/07/2012)
} 
com técnicas de visualização implementadas, possibilitando ao usuário a interferência nos processos de forma a refinar resultados.

\subsection{Conjuntos de Dados e Medidas}

Para a realização dos experimentos são usados quatro conjuntos de imagens:

- O conjunto Supermarket Produce ${ }^{2}$ usado por Rocha et al. (2010), em um sistema de recuperação de imagens de frutas e vegetais obtidas originalmente de um supermercado. O conjunto contém um total de 2633 imagens, as quais pertencem a 15 classes diferentes, apresentando produtos agrícolas. Cada imagem possui um tamanho de $1024 \times 768$ pixels, no formato JPG. A Figura 5.1 apresenta uma amostra do conjunto.
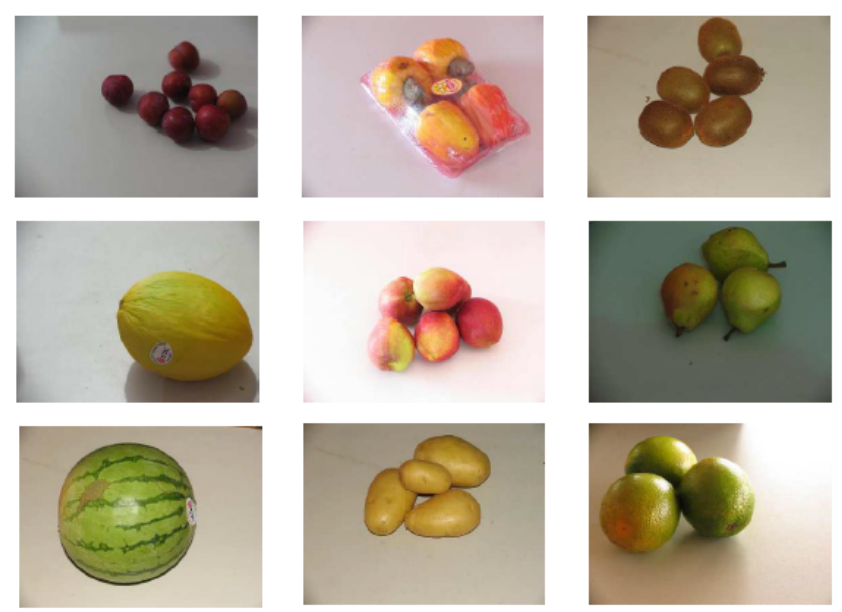
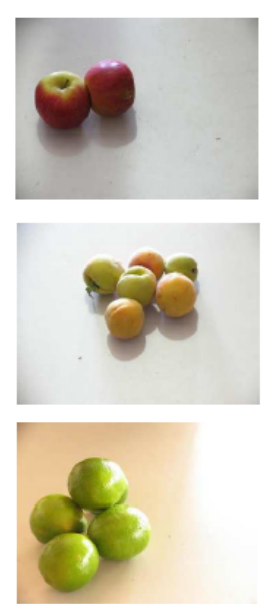

Figura 5.1: Amostra de imagens do conjunto Supermarket Produce.

- O conjunto de imagens $\mathrm{COIL}^{3}$ (Columbia Object Image Library, COIL-100 Nene e Nayar (1996)), contém 7200 imagens correspondentes a 100 diferentes objetos vistos de 72 ângulos de vista, no formato $P N G$ (Ver Figura 5.2). Para os experimentos deste trabalho, as imagens são redimensionadas para $128 \times 128$ pixels.

- O conjunto COREL-1000 (Li e Wang, 2003) contém 1000 imagens de cenas naturais e objetos artificiais separados em 10 classes (ver Figura 5.3). Ele é usado em pesquisas de recuperação de imagens (Nguyen, 2005; Nguyen e Worring, 2008b; Vasconcelos e

${ }^{2}$ Disponível em http://www.ic.uni camp.br/ rocha/pub/communications.html (Acessado o dia 25/09/2010)

${ }^{3}$ Disponível em http://www.cs.columbia.edu/CAVE/software/softlib/coil-100.php (Acessado o dia 19/02/2012) 

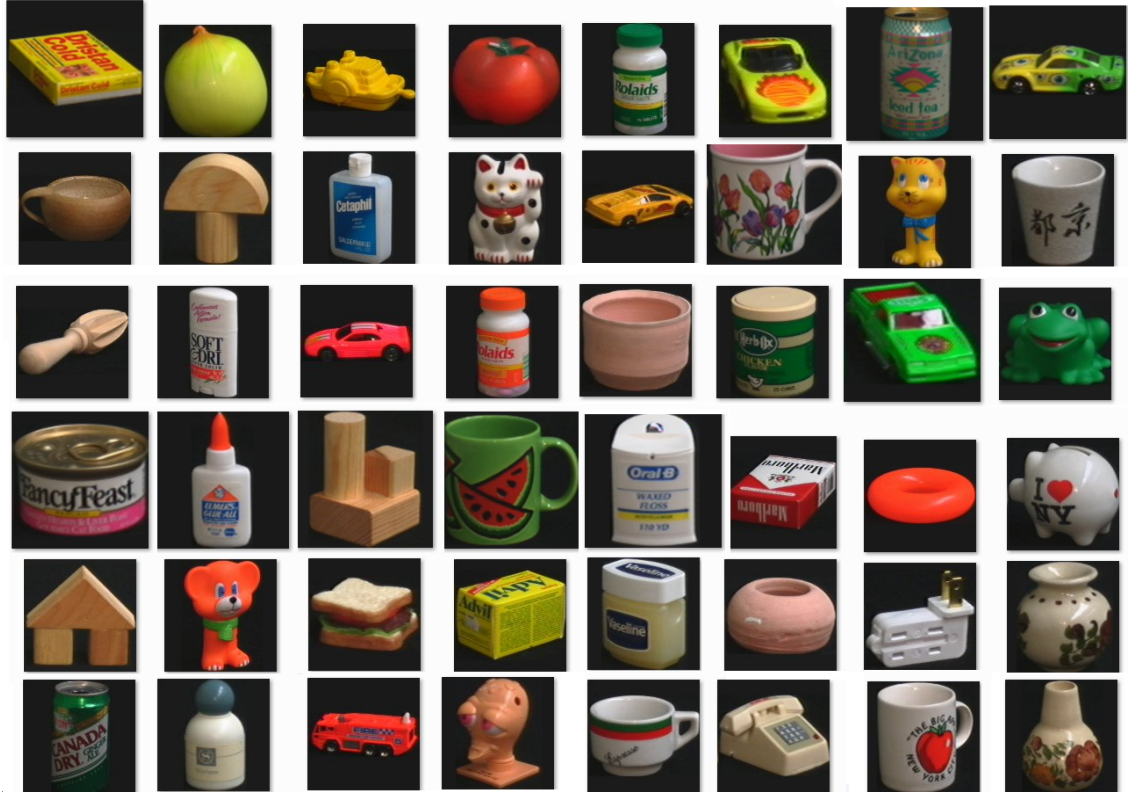

Figura 5.2: Amostra de imagens do conjunto COIL.

Vasconcelos, 2009; Yang et al., 2006; Zhang, 2002). As imagens possuem um tamanho de $116 \times 77$ pixels no formato $J P G$.
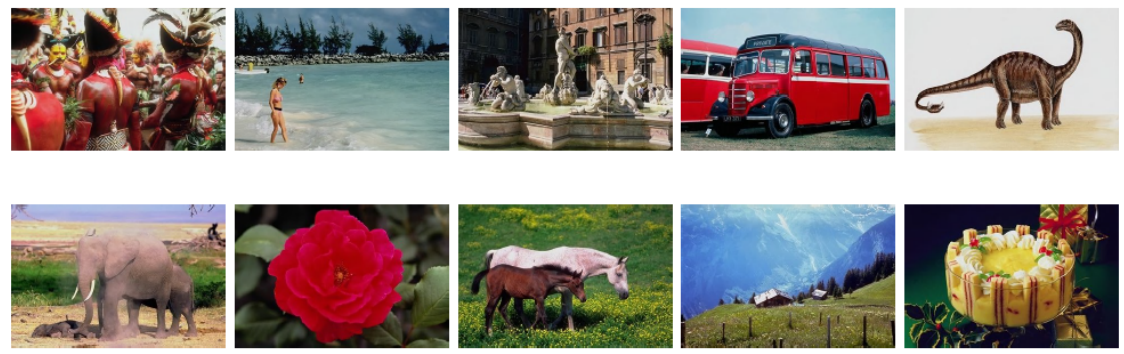

Figura 5.3: Amostra de imagens do conjunto Corel com 10 classes diferentes.

- O conjunto de imagens Frutas e Vegetais ${ }^{4}$ contém originalmente mais de 1000 imagens entre fotografias de frutas, vegetais, folhas e flores de frutas conhecidas, como as apresentadas na Figura 5.4. Cada imagem possui um tamanho $512 \times 384$ pixels, no formato $J P G$. O conjunto de imagens é usado na área de processamento de imagens e biologia, por exemplo, pesquisas realizadas por Balqis (2006); Kleinke et al. (2012).

A Tabela 5.1 descreve as características dos diferentes conjuntos de imagens usados nos experimentos. Nesta tabela, apresenta-se o número de classes, número de imagens por classe e a quantidade total do conjunto. Os grupos são obtidos por amostragem aleatória do conjunto maior.

\footnotetext{
${ }^{4}$ Disponível em http://www.flowers.vg/flowers/lgardens.htm (Acessado o dia 29/09/2011)
} 

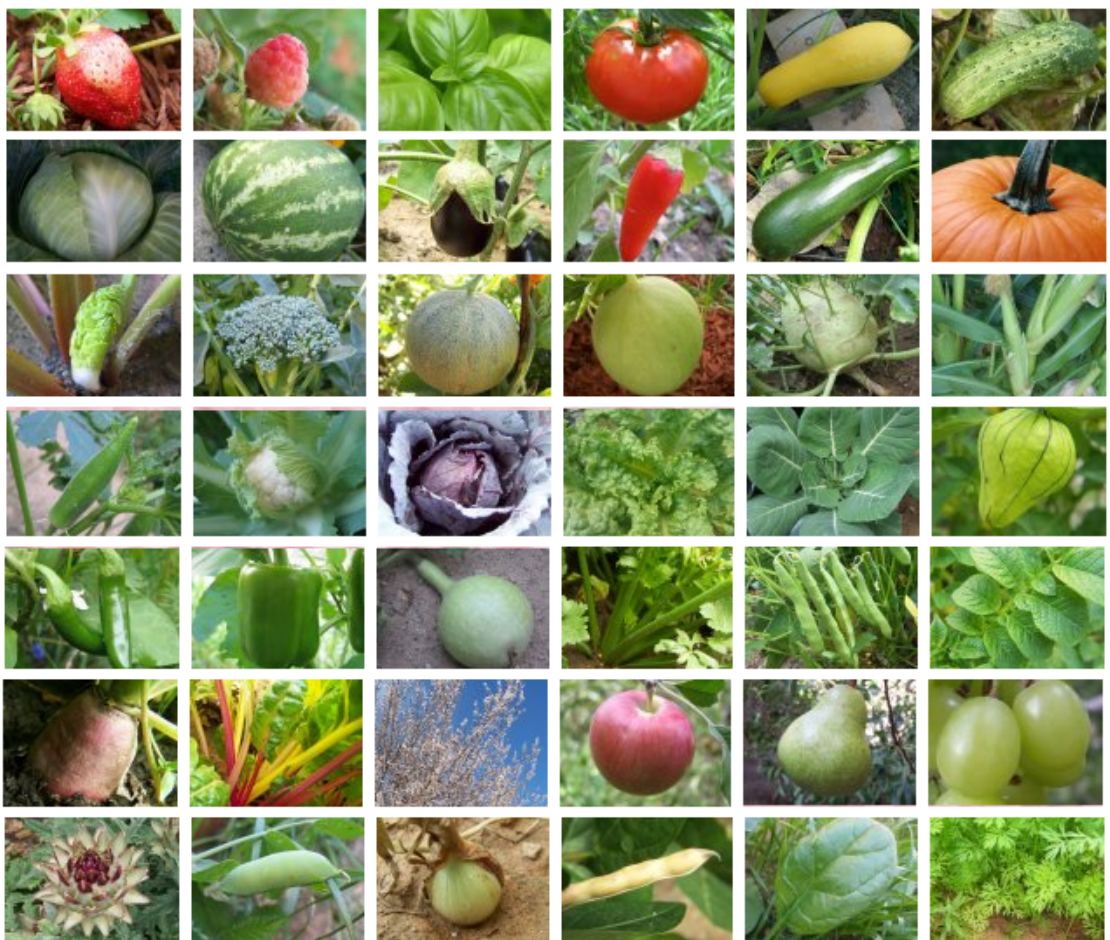

Figura 5.4: Amostragem das imagens do conjunto de Frutas e Vegetais.

Tabela 5.1: Conjuntos de imagens usadas nos experimentos.

\begin{tabular}{|l|l|r|r|r|}
\hline & $\begin{array}{l}\text { Subconjunto } \\
\text { de Imagens }\end{array}$ & $\begin{array}{r}\text { Número de } \\
\text { Classes }\end{array}$ & $\begin{array}{r}\text { Número de Imagens } \\
\text { por Classe }\end{array}$ & $\begin{array}{r}\text { Número Total } \\
\text { do Conjunto }\end{array}$ \\
\hline 1 & Supermarket-Produce & 15 & - & 2035 \\
\hline 2 & Supermarket-Produce & 15 & 70 & 1050 \\
\hline 3 & Supermarket-Produce & 12 & 120 & 1440 \\
\hline 4 & Supermarket-Produce & 15 & 40 & 600 \\
\hline 5 & Supermarket-Produce & 15 & 20 & 300 \\
\hline 6 & COIL & 35 & 72 & 2520 \\
\hline 7 & COIL & 25 & 72 & 1800 \\
\hline 8 & COIL & 10 & 72 & 720 \\
\hline 9 & COREL & 10 & 100 & 1000 \\
\hline 10 & Frutas e Vegetais & 16 & 20 & 320 \\
\hline 11 & Frutas e Vegetais (Flores) & 10 & 20 & 120 \\
\hline 12 & Frutas e Vegetais (Folhas) & 14 & 10 & 140 \\
\hline
\end{tabular}

\subsection{Medidas de Avaliação}

Como foi indicado na Seção 3.5.2, existem diferentes medidas para avaliar o desempenho de técnicas das visualização. Por sua natureza, uma possível medida é derivada da avaliação con- 
vencional de técnicas de agrupamento, como a silhueta (Seção 3.5.2), a qual quantifica a qualidade da projeção de imagens, medindo o grau de coesão das amostras pertencentes à mesma classe e o grau de separação entre as classes.

São também consideradas as medidas baseadas na vizinhança do gráfico da projeção com relação ao espaço original, como as apresentadas na Seção 3.5.2. A Neighborhood Preservation e a Neighborhood Hit são as medidas com maior destaque usadas para avaliar o grau de semelhança de uma projeção (Paulovich et al., 2008).

Além disso, adapta-se neste trabalho a medida precisão/revocação, conhecida para as avaliações de técnicas de aprendizado de máquina, para avaliação de técnicas de projeção. Esta adaptação é apresentada a seguir.

\section{Precisão/Revocação}

A precisão/revocação (precision/recall) é uma das medidas mais utilizadas para apresentar resultados no contexto da recuperação da informação e, além disso, têm a facilidade de representação na forma de gráfico. Um gráfico precisão/revocação fornece uma boa indicação do desempenho dos extratores de características e medidas de distância, especialmente quando se trabalha com uma grande quantidade de dados. (Arevalillo-Herráez et al., 2008; Luo, 2004).

Na recuperação de informação, os dados que respondem a uma consulta são denominados de dados recuperados e quando cumprem algum critério definido pelo usuário, por exemplo, a similaridade de classe, são denominados dados relevantes. A revocação mede a proporção de dados relevantes que foram retornados como resultado de uma consulta. A precisão mede quantos dados relevantes foram recuperados de uma consulta (Tan et al., 2006), isto é, dado um conjunto $X$ de imagens relevantes e $Y$ um conjunto de imagens recuperadas, os valores: $x=|X \cap Y|, y=|\bar{X} \cap Y|$ e $z=|X \cap \bar{Y}|$, definem as equações 5.1 e 5.2. Segundo Rodrigues e Traina (2005), idealmente o conjunto de objetos recuperados deve ser igual ao conjunto de objetos relevantes para uma consulta específica.

$$
\begin{aligned}
\text { Revocação } & =\frac{x}{x+y} \\
\text { Precisão } & =\frac{x}{x+z}
\end{aligned}
$$

Adaptou-se a medida de avaliação precisão/revocação para técnicas de visualização em uma árvore $N J$. Os valores dos objetos são suas posições coordenadas no gráfico da árvore. Os conceitos de objetos recuperados e relevantes são definidos com base na identificação dos grupos 
formados na árvore, conforme descrito descrita na Seção 4.2.2. Utiliza-se o método de agrupamento semi-supervisionado para identificar os grupos em uma árvore, na qual o usuário identifica cada ramo como um grupo. Cada ramo ou grupo é identificado por uma única classe, que é determinada pela classe (predefinida) majoritária dos dados que pertencem ao ramo. Os dados em um grupo identificado podem ser qualificados como recuperados-relevantes e como recuperados-irrelevantes. Recuperados-relevantes são os dados em um ramo e pertencem à mesma classe definida como majoritária. Os dados que não pertencem à classe majoritária são referenciados como recuperados-irrelevantes porque estão dentro do mesmo ramo.

Seja um grupo $j$ da classe majoritária $i$, as medidas precisão/revocação para avaliar os algoritmos de visualização em árvore são definidas pelas equações 5.3 e 5.4 , respectivamente.

$$
\begin{gathered}
\operatorname{Precição~}(i, j)=\frac{n_{i, j}}{n_{i}} \\
\operatorname{Revocação~}(i, j)=\frac{n_{i, j}}{n_{j}}
\end{gathered}
$$

Para construir o gráfico considera-se o algoritmo proposto por Baeza-Yates e Ribeiro-Neto (2008), considerando primeiro a ordenação em uma lista dos elementos recuperados do grupo, de acordo com sua distância em relação ao objeto em observação. Para cada elemento da lista ordenada, calculam-se os valores da precisão e revocação. Para cada intervalo da revocação, é calculada a média aritmética do valor da precisão e os pontos são traçados em um gráfico. $\mathrm{O}$ gráfico precisão/revocação é ilustrado no exemplo da Figura 5.5.
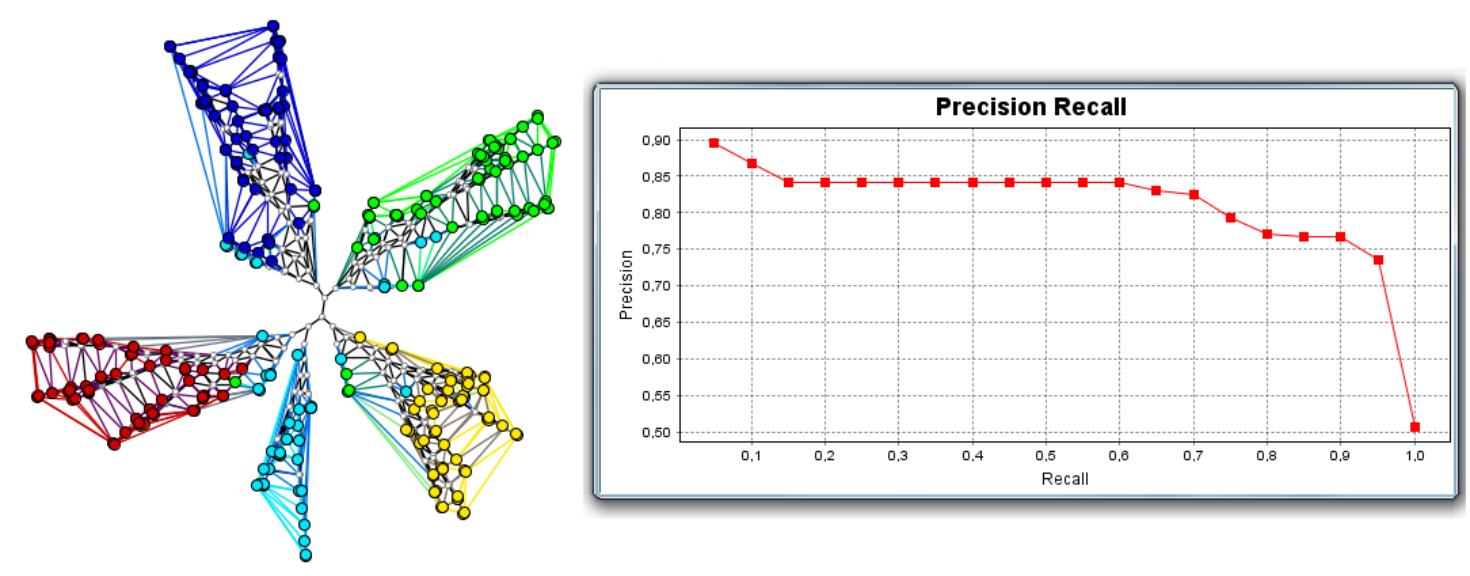

Figura 5.5: À esquerda apresenta-se a visualização da árvore $N J$ do conjunto de 300 imagens Corel usando a distância euclidiana. Identifica-se na árvore a formação de 5 grupos. À direita o gráfico de precisão/revocação da árvore é mostrado.

Segundo Baeza-Yates e Ribeiro-Neto (2008), a curva de precisão/revocação deve ser decrescente. Os valores próximos à parte superior indicam a capacidade de melhor recuperação dos 
dados usando o algoritmo avaliado, pois o maior valor da precisão em cada intervalo de revocação é 1 . Por exemplo, na Figura $5.5^{5}$, mostra-se um total de 5 grupos formados pelos ramos da árvore, e cada ramo identificado é triangulado e delimitado com o fecho convexo. Percebe-se que em cada ramo existem pontos de diferentes cores da maioria dos pontos que pertencem ao ramo. Com isso é possível predizer que as medidas precisão/revocação em cada ramo serão diferentes, pois no gráfico de precisão/revocação percebe-se que os valores da precisão caem enquanto os valores da revocação aumentam. O caso ideal é ilustrado na Figura 5.6, na qual o gráfico precisão/revocação é a curva ideal. Em consequência, a árvore avaliada apresenta em todos seus ramos identificados uniformidade da classe.
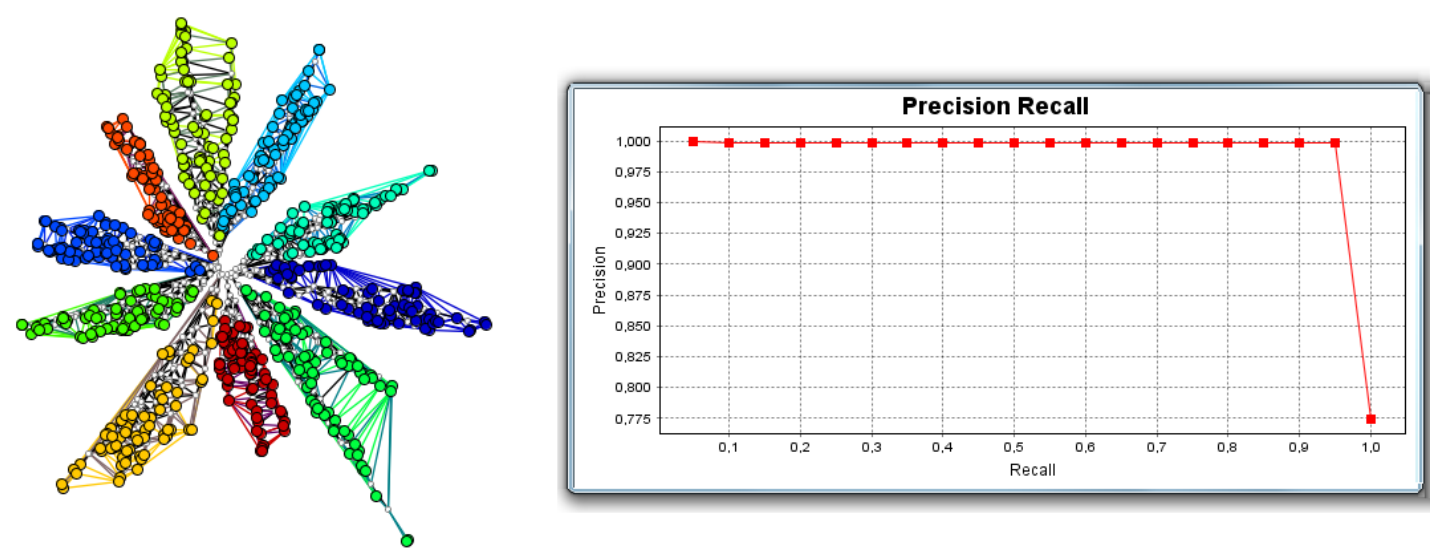

Figura 5.6: À esquerda apresenta-se a visualização da árvore $N J$ do conjunto de 720 imagens COIL (100 classes) usando $C C V$ e a distância euclidiana. Identifica-se 10 ramos ou classes, e por cada classe todas as instâncias pertencem também à mesma classe do grupo. Enquanto na direita o gráfico de precisão/revocação da árvore.

\subsection{Configurações dos Experimentos}

Os métodos e ferramentas propostos foram submetidos a uma série de experimentos descritos a seguir:

1. Comparação do desempenho dos extratores de características. Os experimentos realizaram-se sobre conjuntos de imagens que pertencem a diferentes classes, a fim de comprovar o potencial da relevância de seu agrupamento na hora de visualizar em uma árvore (usando o algoritmo $N J$ ). O objetivo é avaliar os extratores de características de diferentes conjuntos de imagens, a fim de encontrar informação imprecisa ou redundante. Segue

\footnotetext{
${ }^{5}$ Apresentam-se os gráficos precisão/revocação com palavras no idioma inglês, devido à escolha da linguagem para o sistema Vispipeline.
} 
um processo de melhora das características usando seleção de características anterior à execução do algoritmo $N J$. Os extratores usados são descritos na Seção 2.2.2. $B I C, C C V$, $G C H$. Também são avaliadas as funções de distância, descritas na Seção 2.3. Euclidiana, Logarítmica, Canberra, City-block e Cosseno. Adicionalmente, emprega-se a expansão e contração do conjunto de imagens original, incluindo ou excluindo o número de classes ou número de imagens por classe, como o intuito de descobrir diferenças também no espaço de visualização, dependendo da quantidade de imagens na representação de um conjunto.

2. Avaliações de critérios na seleção manual de características. Neste experimento ocorre a escolha manual de um subconjunto de características no espaço de visualização das características de vários conjuntos de imagens. Como apresentado na Seção 4.2.1, o usuário pode selecionar manualmente um subconjunto de características, de acordo com o critério que ele ou ela escolhe. A acurácia do modelo de seleção é medida de acordo com as avaliações na visualização dos dados antes e após do emprego de cada critério na seleção manual.

3. Avaliações de critérios na seleção manual de características obtidas pela seleção de um subconjunto de imagens representativas. O usuário escolhe primeiro um subconjunto de imagens representativas do conjunto original e, sobre esse subconjunto, escolhem-se manualmente as características, seguindo algum critério do usuário especialista. Avalia-se cada critério de seleção de características dos diferentes subconjuntos de imagens.

4. Avaliações nas seleções das $k$-características em grupos formados pela visualização em árvore. A seleção é baseada na identificação manual de grupos visualmente marcados pela árvore $N J$ das características. (veja Seção 4.2.2). Automaticamente, identifica-se para cada grupo o centróide e seus $k$ vizinhos mais próximos, que são incluídos ao subconjunto de características que sumariza o espaço de características, obtendo-se $k+1$ características para cada grupo identificado. Por fim, avaliam-se os subconjuntos de características selecionados para cada conjunto de imagens. O numero $k$ é fornecido pelo usuário.

5. Avaliação dos espaços de características selecionados através de algoritmos de classificação. Novas avaliações dos espaços de características, usando as abordagens mencionadas acima, também são realizadas usando a ferramenta WEKA. Transforma-se cada matriz de instâncias dos novos espaços escolhidos para um arquivo .arff, o qual é válido para ferramenta WEKA. Considera-se na avaliação o uso dos classificadores: $M L P$ (Multilayer Perceptron) e Naive-Bayes, e a porcentagem de instâncias corretamente classificadas para cada espaço. 
6. Avaliações de outras abordagens de seleção de características. Com o objetivo de medir a confiabilidade das abordagens propostas, as abordagens são aferidas comparando-se seus resultados com as avaliações das diferentes abordagens de seleção de características apresentadas na Seção 2.4.2. Entre os algoritmos de seleção a comparar, consideram-se o algoritmo baseado em filtro CFS (Correlation - based Feature Selection), e em funções Wrapper usando o classificador $k$-NN ( $k$-vizinhos mais próximos). As avaliações são feitas sobre as árvores de similaridade, usando as mesmas imagens e as mesmas características originais.

7. Retroalimentação. Com o objetivo de melhorar a visualização e a representação de um conjunto de imagens, associam-se os critérios de qualidade de espaço de características. O objetivo formulado no início do trabalho é a análise visual de espaços de características, usando a visualização em árvore, como detalhado na Seção 4.3 . Os diferentes passos do processo foram também descritos: primeiro são realizadas as visualizações de coleções de imagens antes e após, um processo de seleção de características. De acordo com a aprovação do usuário sobre a qualidade dos resultados, o processo poderia ser reexecutado. Se algum erro significativo fosse encontrado, os parâmetros ou métodos de extração de características usados poderão ser alterados. Este processo será realizado até que o resultado desejável seja atingido.

Nas análises a seguir, denomina-se espaço projetado ou espaço de visualização, e.g. a árvore $N J$, e denomina-se espaço original o conjunto de características sob análise.

\subsection{Análise dos Resultados}

Seguindo as configurações dos experimentos já definidos, os resultados são apresentados a seguir.

\subsubsection{Comparação do desempenho dos extratores de característi- cas}

De acordo com os objetivos do projeto, implementaram-se extratores de características estudados nas Seções 2.2.2, assim como, comparou-se seu desempenho usando a visualização em uma árvore $N J$.

Em primeiro lugar, considera-se importante definir o número de características que cada extrator de características fornece. Esses dados são apresentados na Tabela 5.2. 
Tabela 5.2: Definição do número de características que é obtido por cada extrator.

\begin{tabular}{|l|r|}
\hline Extrator & $\begin{array}{r}\text { Número de } \\
\text { Características }\end{array}$ \\
\hline$B I C$ & 128 \\
\hline$C C V$ & 128 \\
\hline$G C H$ & 64 \\
\hline$B I C \cup C C V \cup G C H$ & 320 \\
\hline
\end{tabular}

\section{Experimento 1}

Os resultados da avaliação dos extratores usando a medida da silhueta são apresentados na Tabela $5.3^{5}$. As diferenças entre os valores da silhueta no espaço projetado e no espaço original indicam a efetividade ou a não efetividade de vários parâmetros: o extrator que representa o conjunto de dados, a função distância para definir a similaridade e o algoritmo de visualização, neste caso, o algoritmo $N J$. Se a diferença for positiva, isso significa que o algoritmo de visualização $N J$ contribui na melhoria do agrupamento dos dados no plano, o extrator usado representa com mais fidelidade o conjunto de dados e a medida de similaridade empregada se adeque aos dados.

Segundo a informação apresentada na Tabela 5.3 , considera-se as seguintes observações:

- Nos quatro grupos de imagens, as características que foram extraídas usando GCH mostram o melhor desempenho segundo a silhueta. Usando apenas 64 características (64 cores), o extrator $\mathrm{GCH}$ pode representar melhor as características dos conjuntos de imagens em observação.

- As características que foram extraídas por meio da união dos extratores $B I C-C C V$ - $G C H$ não favorecem na discriminação suficiente das classes das imagens para a medida silhueta. Existem valores maiores usando extratores independentes. Acredita-se que este resultado pode ser causado por duas razões, o aumento da quantidade do número de características afeita o algoritmo $N J$ ou que unidos os extratores forneçam informação redundante, por serem três extratores de cor e pode precisar-se de algum outro descritor considerando, por exemplo, a forma ou a textura.

- O maior valor da silhueta encontrado é de 0,6437 usando o conjunto de imagens 8 (COIL) e com as características que foram extraídas usando $G C H$ no espaço original e um valor

\footnotetext{
${ }^{6} \mathrm{O}$ numero do conjunto de imagens é de acordo à Tabela 5.1

${ }^{7}$ Os valores com “-"são resultados negativos que não são considerados. As diferenças numéricas pequenas, é dizer menores a 0,005 são consideradas como uma grande vantagem numérica na avaliação. Considera-se quatro dígitos de precisão após a virgula decimal.
} 
Tabela 5.3: Desempenho dos extratores de características usando a visualização em árvore $N J$ e a distância logarítmica para refletir a similaridade.

\begin{tabular}{|l|l|r|r|}
\hline $\begin{array}{l}\text { Conjunto } \\
\text { de Imagens }\end{array}$ & Extrator & $\begin{array}{r}\text { Silhueta } \\
\text { Esp. Orig. }\end{array}$ & $\begin{array}{r}\text { Silhueta } \\
\text { Esp. Proj. }\end{array}$ \\
\hline 2 & $B I C$ & 0,1952 & 0,0905 \\
\hline 2 & $C C V$ & 0,2570 & 0,1968 \\
\hline 2 & $G C H$ & 0,3044 & 0,2515 \\
\hline 2 & $B I C \cup C C V \cup G C H$ & 0,2097 & 0,1656 \\
\hline 8 & $B I C$ & 0,3863 & 0,3987 \\
\hline 8 & $C C V$ & 0,5623 & 0,5594 \\
\hline 8 & $G C H$ & 0,6437 & 0,6392 \\
\hline 8 & $B I C \cup C C V \cup G C H$ & 0,5784 & 0,5601 \\
\hline 9 & $B I C$ & 0,0863 & 0,0281 \\
\hline 9 & $C C V$ & 0,0909 & - \\
\hline 9 & $G C H$ & 0,1004 & - \\
\hline 9 & $B I C \cup C C V \cup G C H$ & 0,1185 & 0,0501 \\
\hline 10 & $B I C$ & 0,2914 & 0,2989 \\
\hline 10 & $C C V$ & 0,3321 & 0,3456 \\
\hline 10 & $G C H$ & 0,3478 & 0,3501 \\
\hline 10 & $B I C \cup C C V \cup G C H$ & 0,2854 & 0,2913 \\
\hline
\end{tabular}

de 0,6392 no espaço projetado. Os valores superam o valor médio de 0,5 , considerando assim que o extrator $\mathrm{GCH}$ represente melhor esse conjunto de imagens.

- Todas as representações usando os quatro extratores do conjunto de imagens 10 apresenta diferenças positivas da medida silhueta comparando os valores do espaço projetado com o espaço original. As imagens que compõem o conjunto contem frutas e vegetais, as quais possuem maior discriminação de cores que os outros conjuntos de imagens. Sendo assim um conjunto de imagens apropriado para o uso de extratores de cor.

- O conjunto de imagens 8 com as características extraídas usando $B I C$ também mostra uma diferença positiva entre os valores da silhueta do espaço projetado e o espaço original, mostrando que o extrator $B I C$ representa bem esse conjunto de imagens.

- As diferenças negativas entre dois valores de silhueta apresentam valores entre 0,5 e 0,005. Por exemplo, se as diferenças dos resultados entre o espaço original e o espaço projetado são mínimas, os resultados são considerados como próximos, e na visualização se reflete quase os mesmos grupos considerados no espaço original. 
- As diferenças positivas entre os valores de silhueta do espaço projetado e o espaço original, mostram que a visualização em árvore $N J$ melhora a discriminação de grupos e classes do conjunto de imagens.

- Observa-se que a distância logarítmica ajuda a representar bem a similaridade de dados com os extratores usados, o que é corroborado no próximo experimento apresentado.

A diferença observada dos valores obtidos com a medida silhueta, avalia-se a qualidade visual, que é verificada na Figura 5.7. Observa-se que as árvores das imagens que se caracterizam com os extratores $C C V$ e a união $B I C-C C V-G C H$ representam melhor o conjunto de imagens 8. Isto acontece devido às árvores geradas com $C C V$ e $B I C-C C V-G C H$ apresentarem grupos melhor definidos e mais povoados que as outras árvores.

Em uma árvore $N J$, cada círculo representa uma imagem do conjunto, sendo colorido de acordo com a classe conhecida previamente, e defina-se como um grupo o conjunto definido por um ramo da árvore. Assim, cada ramo é qualificado como idealmente definido se possui elementos de apenas uma classe, indicando um bom agrupamento das características dessa classe. Considerando esse critério, uma árvore pode ser avaliada usando o gráfico precisão/revocação, ilustrado nas Figuras 5.8a e 5.8b. O gráfico precisão/revocação do $C C V$ se iguala ao gráfico de $B I C-C C V-G C H$.

Outras avaliações também são feitas para o conjunto de imagens 8. São as avaliações usando as medidas baseadas na vizinhança em uma árvore: Neighborhood Hit e Neighborhood Preservation, ilustradas nas Figuras 5.9 e 5.10. O gráfico Neighborhood Hit, mostra a avaliação usando a frequência média em que um objeto e seus $k$-vizinhos mais próximos pertencem à mesma classe. Com base nesta medida (veja a Figura 5.9 , o melhor desempenho no gráfico é da visualização usando a união dos extratores $B I C-C C V-G C H$, seguido do extrator $C C V$ e, o pior, é usando o extrator BIC. Nota-se que a avaliação visual deve ser considerada, já que segundo essa interpretação, os extratores $B I C-C C V-G C H$ e $C C V$ representam melhor as classes do conjunto de imagens desde o espaço original. Aparentemente, a silhueta não coincide com essas medidas para a análise dos extratores.

Do mesmo modo, a medida Neighborhood Preservation avalia a frequência com que os $k$-vizinhos mais próximos de um objeto no layout também são seus $k$-vizinhos mais próximos no espaço de características original. Conforme observado na Figura 5.10, os extratores que melhor preservam a vizinhança na visualização em árvore são os extratores $G C H$ e $B I C$. E o pior que preserva a vizinhança é usando a união dos extratores $B I C-C C V-G C H$.

Observando os gráficos apresentados e os valores de silhueta obtidos na Tabela 5.3 pode-se notar a diferença nas que essas avaliações qualificam a diferentes extratores como melhor e pior. 


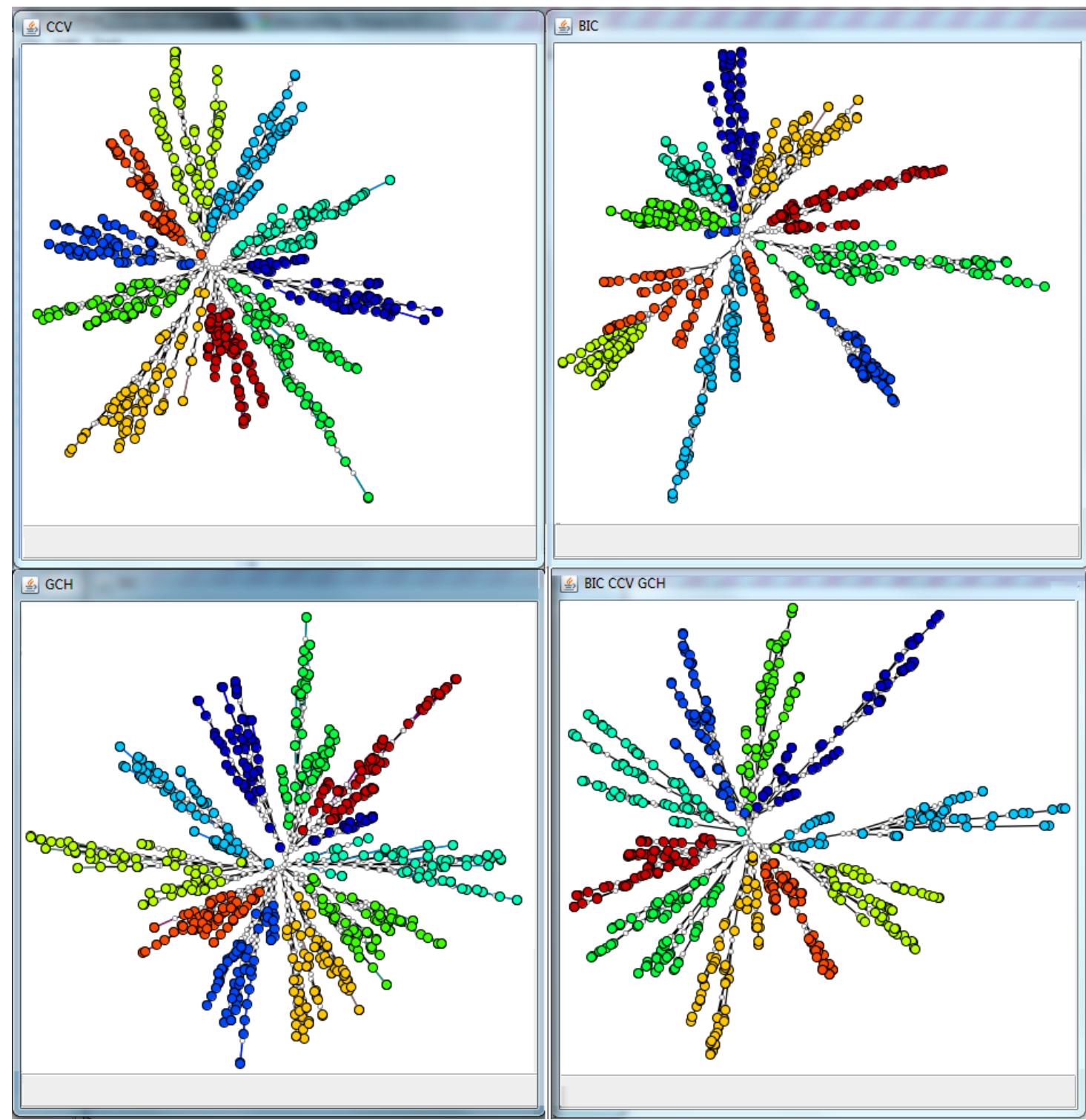

Figura 5.7: Visualizações das árvores que representam o conjunto de imagens 8 (COIL) usando os extratores $C C V, B I C, G C H$ e a união dos extratores $B I C-C C V-G C H$. Em todas essas visualizações usa-se a distância logarítmica para medir a similaridade entre as imagens.

Isto é, porque essas técnicas de avaliação consideram diferentes indicadores e com diferente enfoque. Para este trabalho considera-se em destaque a medida silhueta, porque persegue-se avaliar os agrupamentos revelados nas árvores geradas. 


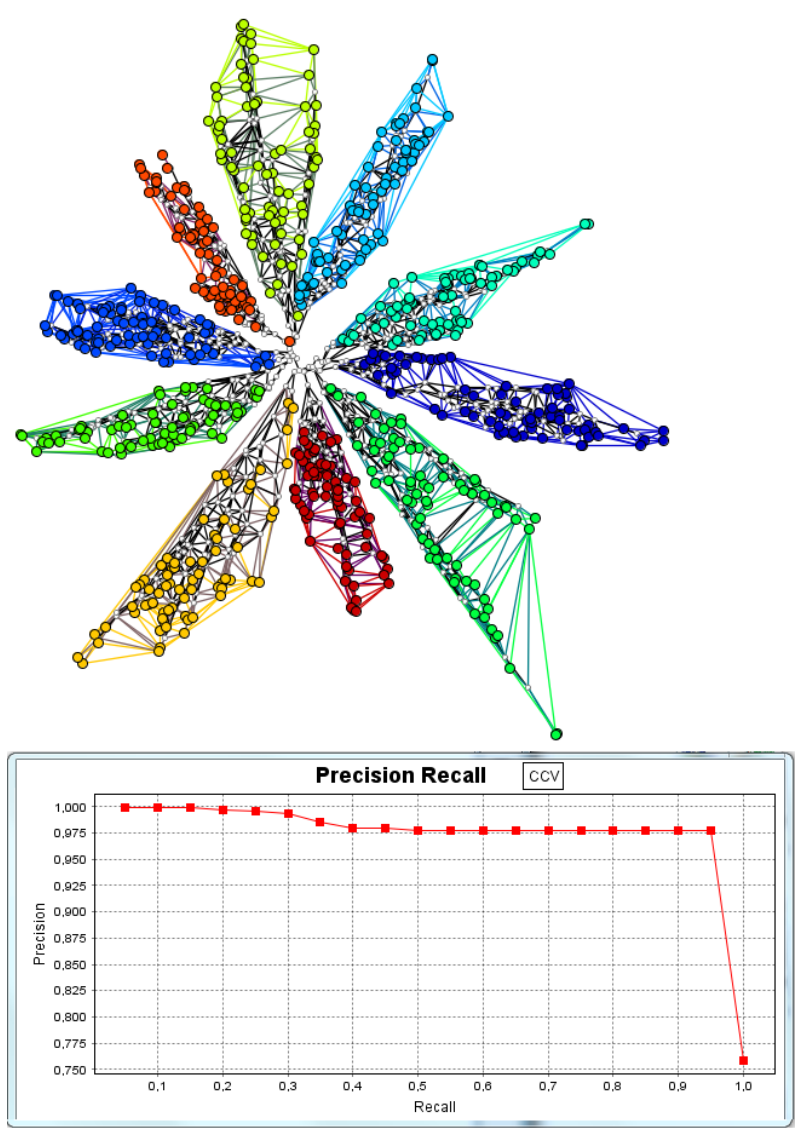

(a)
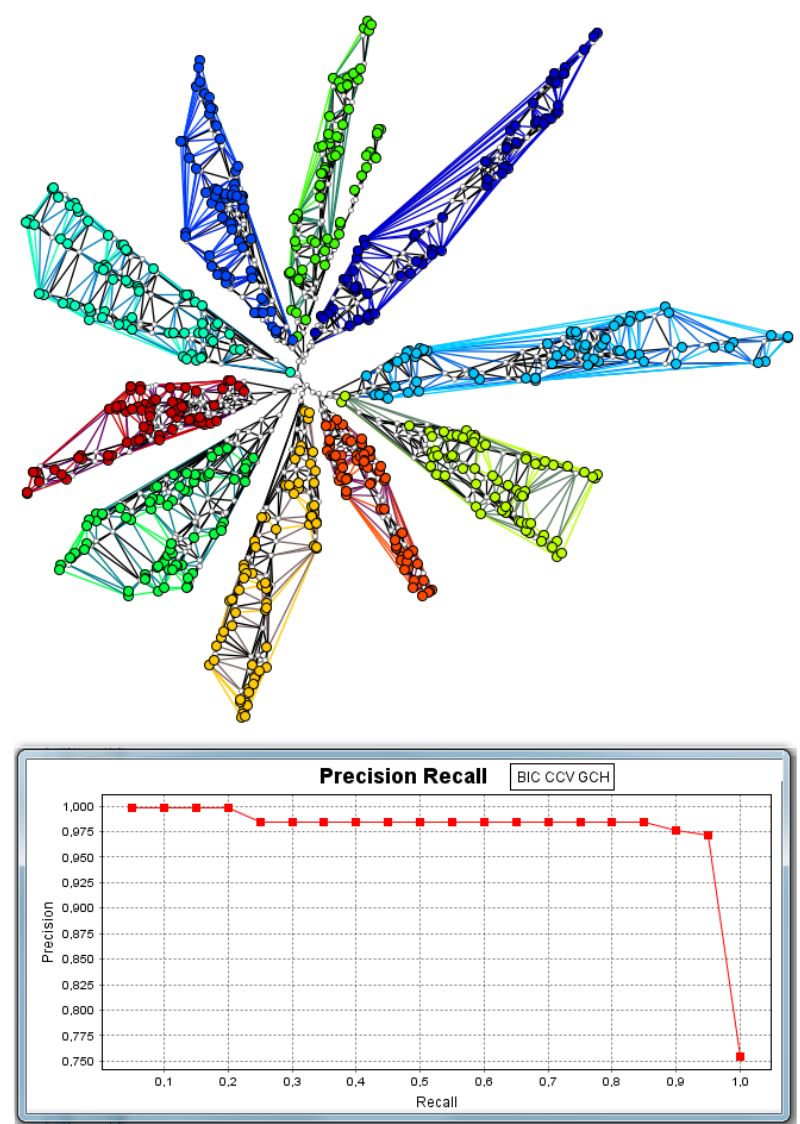

(b)

Figura 5.8: a) Gráfico Precisão /Revocação do extrator $C C V$. b) Gráfico Precisão /Revocação do extrator $B I C-C C V-G C H$ para o conjunto de imagens 8. Observa-se visualmente que as duas árvores são semelhantes.

\section{Experimento 2}

Com a mesma metodologia empregada para a avaliação de espaços gerados por diferentes extratores, também foram comparadas as medidas de distância usadas: Logarítmica, Euclidiana, Canberra, City-block, e Cosseno empregando-as também para diferentes extratores e conjuntos de imagens. A tarefa de análise das funções distância é achar quanto elas apóiam um algoritmo de visualização para encontrar a similaridade entre duas imagens; isto é, quando geram proximidade física entre dois pontos semelhantes na tela de visualização ou na estrutura da árvore.

As avaliações das funções de distância são apresentadas na Tabela 5.4. As similaridades das imagens são consequência também do uso das funções de distância, que o algoritmo $N J$ leva em consideração para sua execução. Essa é muitas vezes a razão da diferença dos valores da silhueta entre o espaço original e do espaço projetado. Consideram-se importantes as observações apresentadas a seguir: 


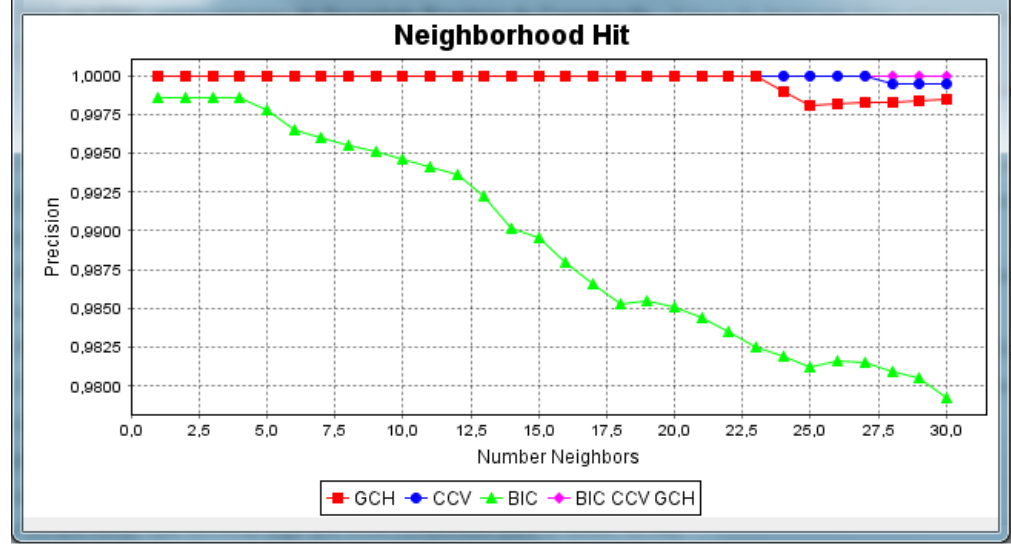

Figura 5.9: Medida de avaliação gráfica Neighborhood Hit em relação à visualização em árvore $N J$ do conjunto de imagens 8 , usando a distância logarítmica, caracterizados por diferentes extratores de características. Destaca-se com o melhor desempenho a união dos extratores $B I C-C C V-G C H$.
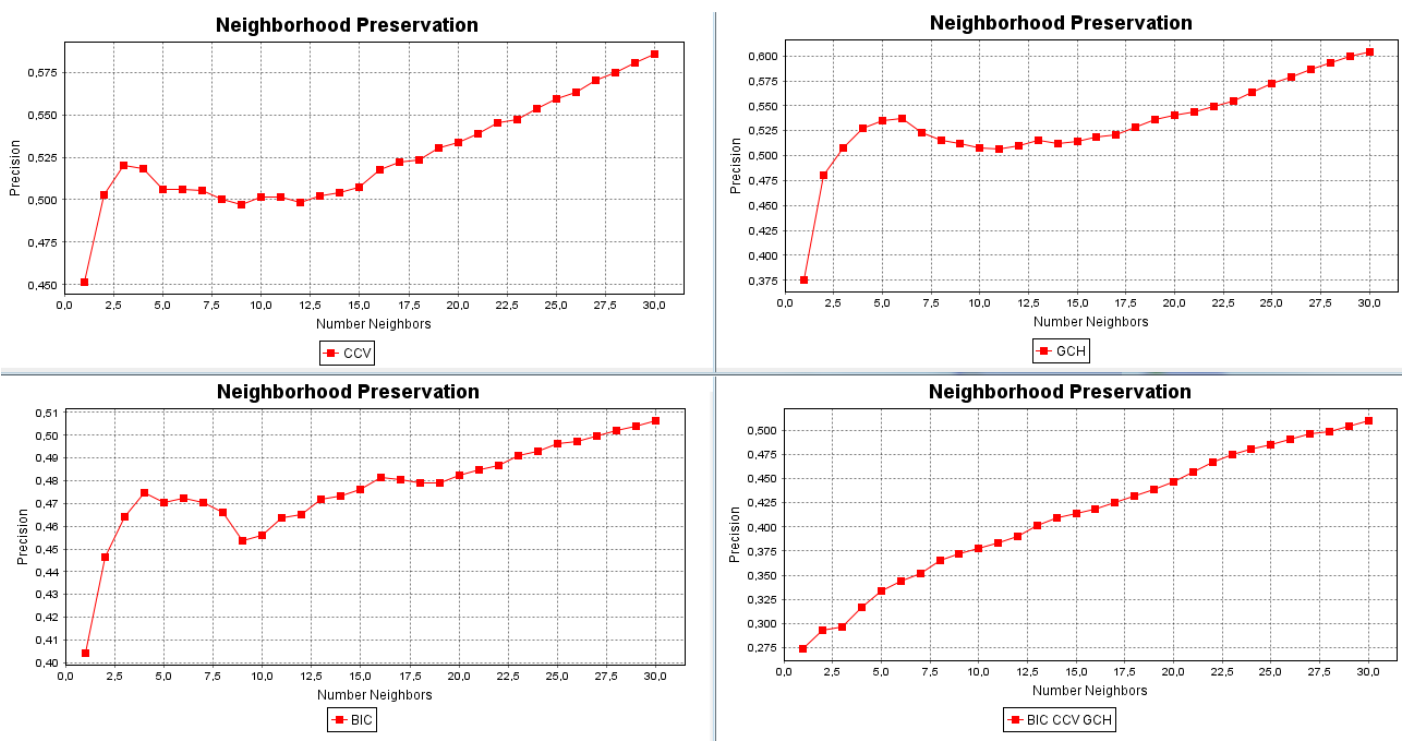

Figura 5.10: Medida de avaliação gráfica Neighborhood Preservation em relação às visualizações em árvore $N J$ de diferentes representações do conjunto de imagens 8 , caracterizado por os extratores $C C V, G C H, B I C$ e $B I C-C C V-G C H$, usando distância logarítmica. Comparando os gráficos apresentados os melhores desempenhos na visualização são os extratores $G C H$ e $B I C$, que preservam a vizinhança ao aumentar o número de vizinhos.

- Observando os valores da silhueta obtidos, a distância que melhor representa a similaridade das imagens usando os três extratores e conjuntos de imagens é a distância logarítmica, confirmando-se a dedução do experimento número 1 . 
- As diferenças dos valores de silhueta, em todos os casos, entre o espaço original e o espaço projetado são mínimas e seus valores são muito próximos.

- Outra distância a considerar, além da distância logarítmica, é a distância Canberra, para a qual os valores no espaço projetado se aproximam muito ao do espaço original.

- O conjunto de imagens 7 (COIL) é igualmente representado por todas as distâncias. Observando a tabela, o conjunto de imagens 8 (COIL) com a distância logarítmica, têm o maior valor de silhueta ( 0,5623 no espaço original e 0,5594 no espaço projetado).

- Pela segunda vez o extrator $G C H$ mostra melhor representação na árvore, independente das distâncias.

Tabela 5.4: Avaliação das funções distância. Os resultados são avaliados com a medida silhueta em uma visualização em árvore $N J$.

\begin{tabular}{|l|l|l|r|r|}
\hline $\begin{array}{l}\text { Conjunto } \\
\text { de Dados }\end{array}$ & Extrator & Distância & $\begin{array}{r}\text { Silhueta } \\
\text { Esp. Orig. }\end{array}$ & $\begin{array}{r}\text { Silhueta } \\
\text { Esp. Proj. }\end{array}$ \\
\hline 5 & $B I C$ & Logarítmica & 0,3905 & 0,3692 \\
\hline 5 & $B I C$ & Euclidiana & 0,1818 & 0,1237 \\
\hline 5 & $B I C$ & Canberra & 0,3405 & 0,3225 \\
\hline 5 & $B I C$ & City-block & 0,2628 & 0,1505 \\
\hline 5 & $B I C$ & Cosseno & 0,1681 & 0,0744 \\
\hline 7 & $G C H$ & Logarítmica & 0,4868 & 0,4795 \\
\hline 7 & $G C H$ & Euclidiana & 0,3253 & 0,3448 \\
\hline 7 & $G C H$ & Canberra & 0,4594 & 0,4441 \\
\hline 7 & $G C H$ & City-block & 0,4052 & 0,4318 \\
\hline 7 & $G C H$ & Cosseno & 0,3381 & - \\
\hline 8 & $C C V$ & Logarítmica & 0,5623 & 0,5594 \\
\hline 8 & $C C V$ & Euclidiana & 0,3979 & 0,4090 \\
\hline 8 & $C C V$ & Canberra & 0,5070 & 0,4805 \\
\hline 8 & $C C V$ & City-block & 0,5116 & 0,5094 \\
\hline 8 & $C C V$ & Cosseno & 0,4956 & - \\
\hline
\end{tabular}

A avaliação visual também é apresentada na Figura 5.11, a qual mostra que as distâncias Logarítmica, Canberra e City-Block ilustram melhor o conjunto de dados 8 (COIL), representado pelo extrator $C C V$. Isto acontece devido à discriminação das classes visualmente identificadas na árvore. Os gráficos precisão/revocação (5.12a, 5.12b, 5.12c e 5.12d mostram as avaliações feitas nas árvores considerando o número de classes pertencentes à classe majoritária de cada ramo da árvore, destacando que a distância city-block tem o pior desempenho. 


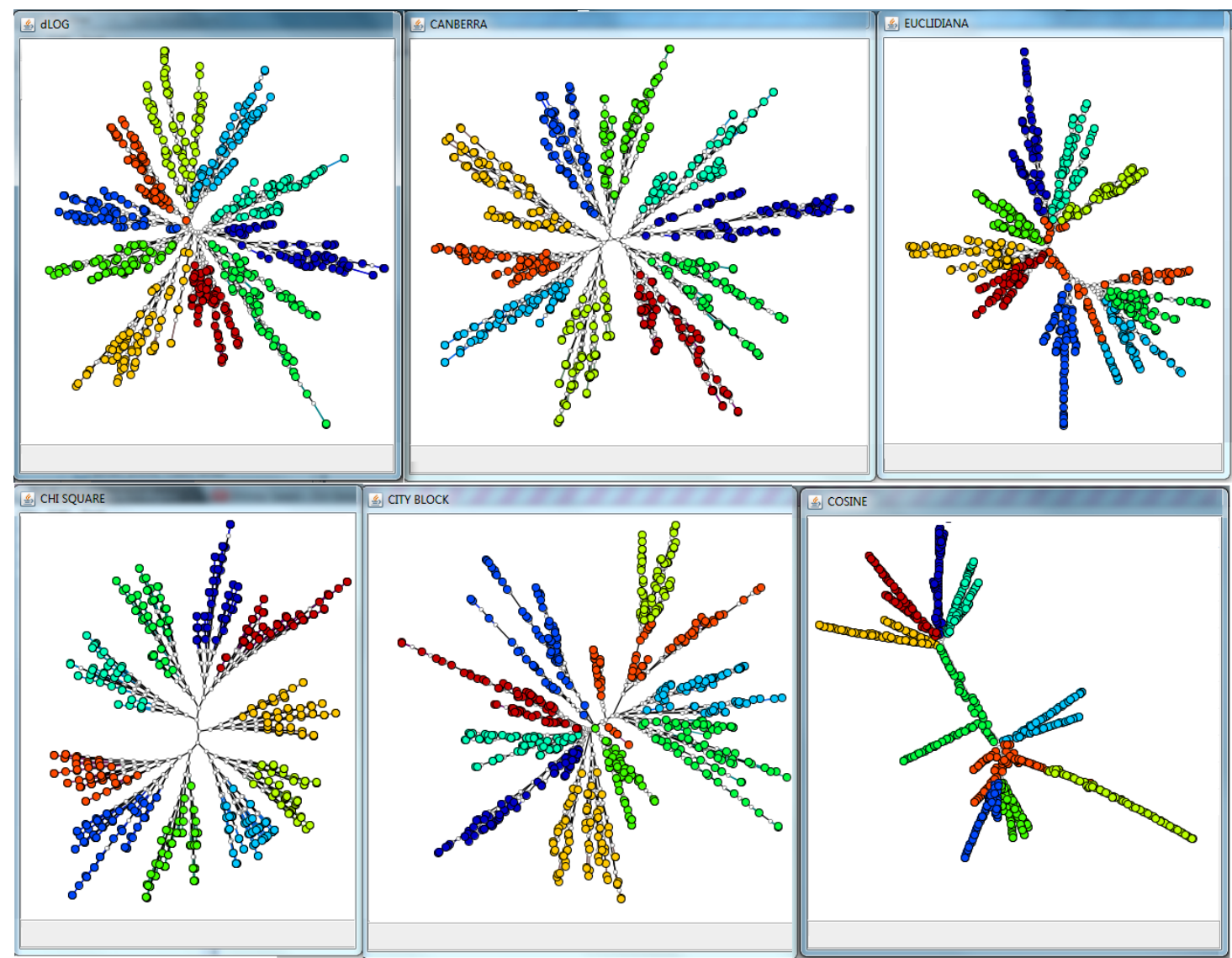

Figura 5.11: Integração dos gráficos com as visualizações das árvores que representam o conjunto de imagens 8 (COIL) usando o extrator $C C V$ e as diferentes distâncias logarítmica, canberra, euclidiana, city-block e cosseno para medir a similaridade entre as imagens.

As avaliações usando as medidas baseadas na vizinhança também são consideradas, Neighborhood Preservation na Figura 5.13, e as medidas de Neighborhood Hit, na Figura 5.14. Segundo o gráfico do Neighborhood Preservation, a que apresenta melhor desempenho é a visualização realizada usando a distância logarítmica e a pior é usando a distância city-block. Ao contrário do experimento 1 , neste experimento a avaliação visual confirma as avaliações usando a medida silhueta, mostradas na Tabela 5.4, pois a distância logarítmica é a que ajuda a mostrar melhor a similaridade entre as imagens usando os extratores baseados em histogramas de cor.

No gráfico Neighborhood Hit, pode deduzir-se que o melhor desempenho é usando a distância logarítmica e o pior é usando a distância cosseno, isto é, a distância logarítmica consegue encontrar melhor a similaridade entre as imagens para uni-las em um só grupo e discriminá-las dos demais grupos. 


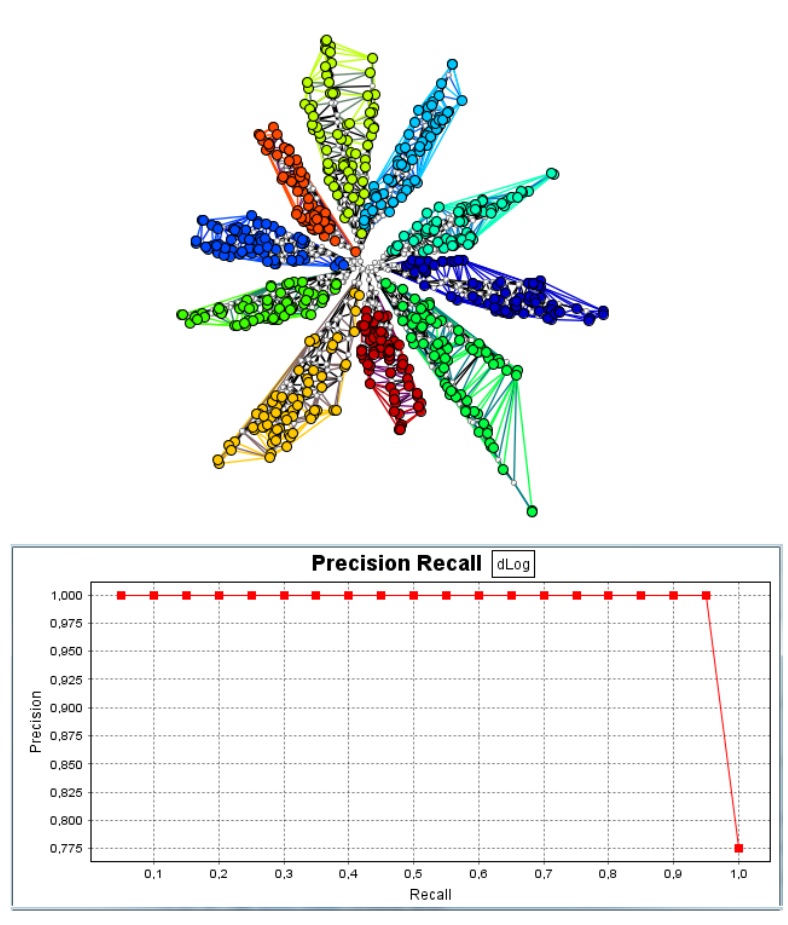

(a)

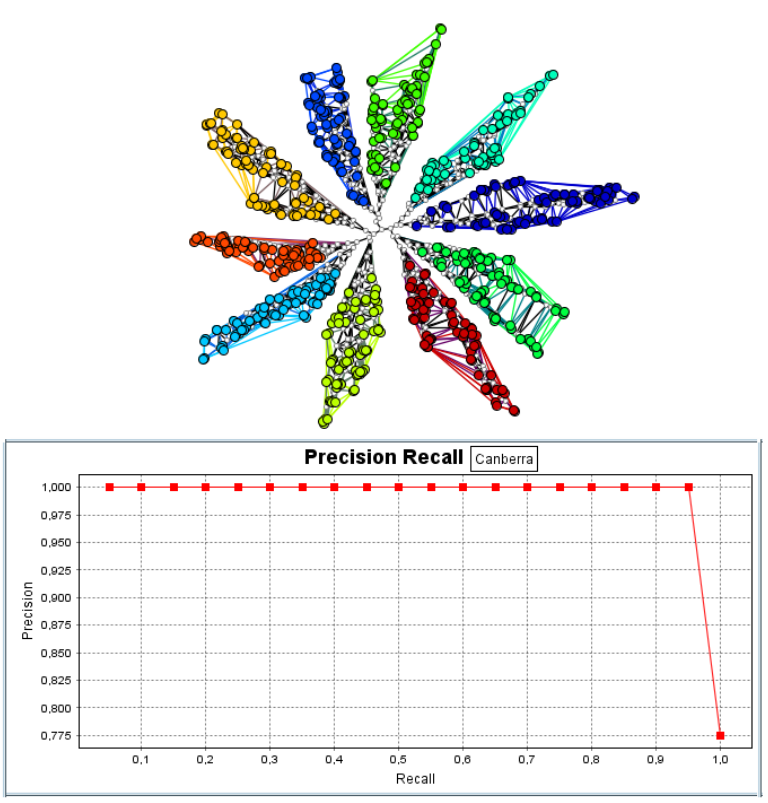

(c)
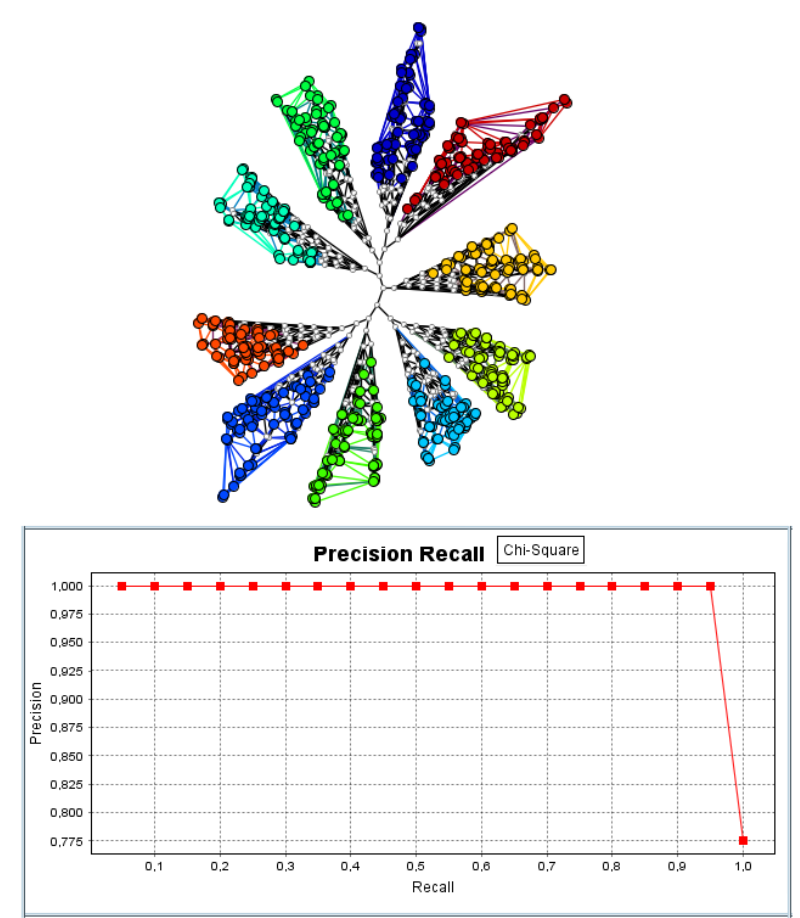

(b)
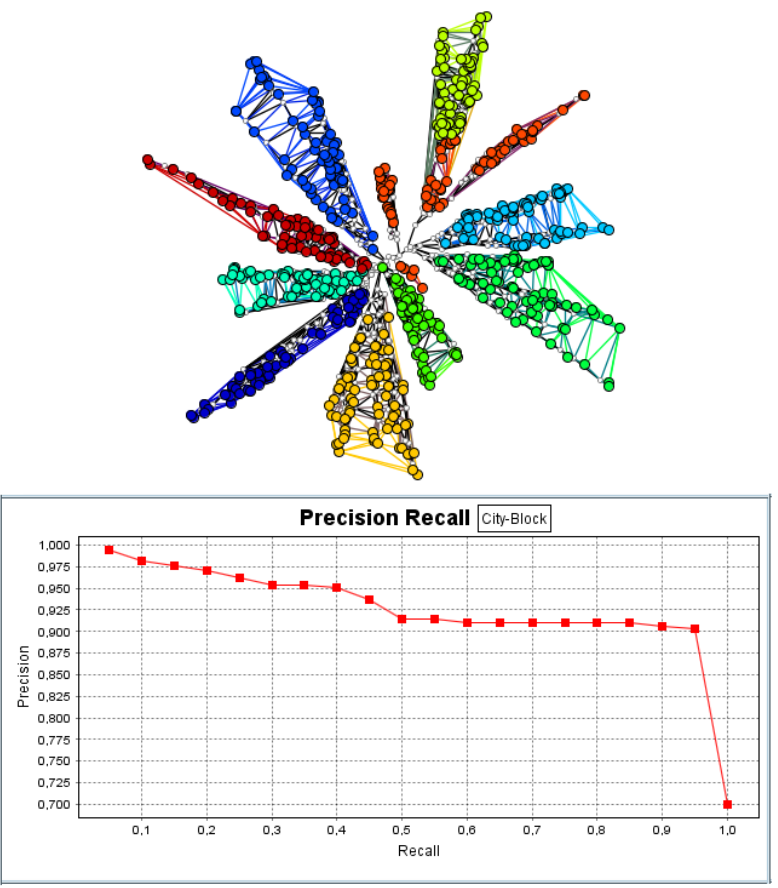

(d)

Figura 5.12: a) Gráfico precisão/revocação da distância logarítmica. b) Gráfico precisão/revocação da distância chisquare. c)Gráfico precisão/revocação da distância canberra. d)Gráfico precisão/revocação da distância city-block do conjunto de imagens 8 . Observa-se visualmente a curva da distância city-block tem o pior desempenho. 

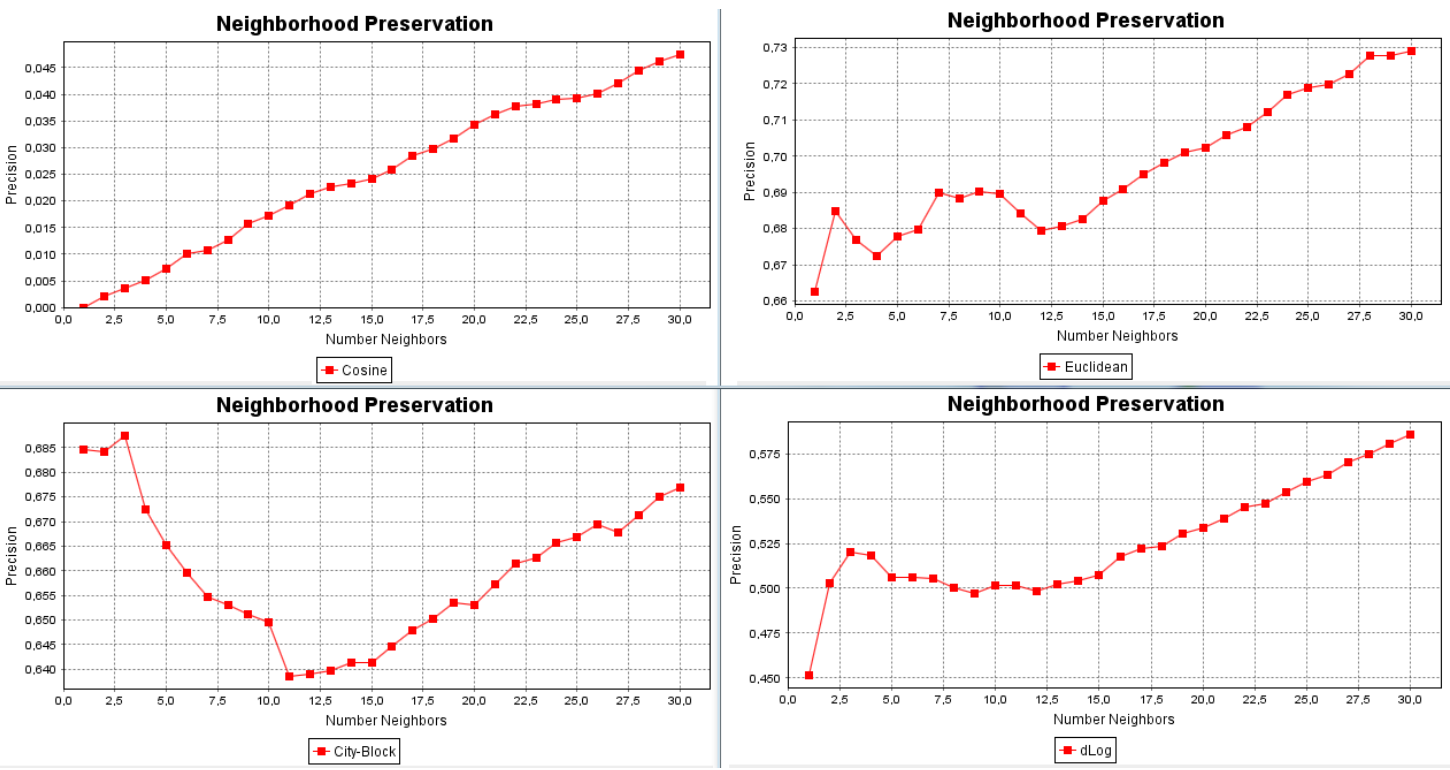

Figura 5.13: Medida de avaliação gráfica Neighborhood Preservation em relação à visualização em árvore $N J$ do conjunto de imagens 8, usando as distâncias Logarítmica, Canberra e City-block. Destaca-se com melhor desempenho a distância logarítmica.

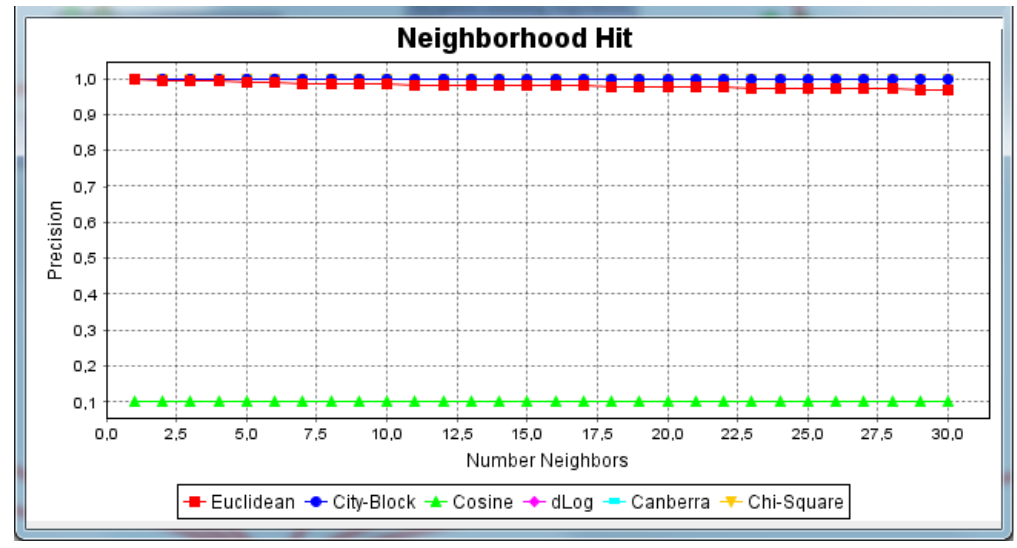

Figura 5.14: Medida de avaliação gráfica Neighborhood Hit em relação à visualização em árvore $N J$ do conjunto de imagens 8, usando as distâncias Logarítmica, Canberra e City-block. Destaca-se com melhor desempenho a distância logarítmica.

\section{Experimento 3}

Para este experimento, emprega-se a expansão do conjunto de imagens Supermarket-Produce, partindo de um conjunto de 75 imagens, aumentando ou variando o número de classes e o número de imagens por classe até chegar ao conjunto total de 2035 imagens, avaliando a propriedade de escalabilidade do extrator. 
Os resultados das avaliações são apresentados na Tabela 5.5. Para os testes usa-se a distância logarítmica e o algoritmo $N J$ para visualizar. Com esses resultados chega-se às seguintes observações:

- Ao aumentar o número de imagens por classe, seus valores de silhueta vão diminuindo levemente no espaço original e no espaço projetado.

- Pode-se notar, a falta de escalabilidade do algoritmo de extração BIC para esse conjunto de imagens.

- Um resultado importante que deve ser considerado ao aumentar o número de elementos do conjunto, isto é, perde-se o grau de coesão das imagens pertencentes à mesma classe e o grau de separação entre suas classes.

Tabela 5.5: Avaliação da variação da quantidade de imagens e classes do conjunto Supermarket-Produce usando o algoritmo NJ para visualizar e a distância logarítmica. Os resultados são obtidos usando a silhueta no espaço original e no espaço projetado.

\begin{tabular}{|l|l|l|r|r|}
\hline $\begin{array}{l}\text { Número Total } \\
\text { do Conjunto }\end{array}$ & $\begin{array}{l}\text { Número de } \\
\text { Classes }\end{array}$ & $\begin{array}{l}\text { Número de Imagens } \\
\text { por Classe }\end{array}$ & $\begin{array}{r}\text { Silhueta } \\
\text { Esp. Orig. }\end{array}$ & $\begin{array}{r}\text { Silhueta } \\
\text { Esp. Proj. }\end{array}$ \\
\hline 75 & 15 & 5 & 0,5023 & 0,5062 \\
\hline 150 & 15 & 10 & 0,4361 & 0,4220 \\
\hline 300 & 15 & 20 & 0,3905 & 0,3692 \\
\hline 600 & 15 & 40 & 0,2955 & 0,2413 \\
\hline 1050 & 15 & 70 & 0,1952 & 0,0905 \\
\hline 1200 & 6 & 200 & 0,1392 & 0,0231 \\
\hline 1440 & 12 & 120 & 0,1117 & 0,0493 \\
\hline 2035 & 15 & 136 & 0,0774 & 0,0151 \\
\hline
\end{tabular}

\subsubsection{Avaliações de critérios na seleção manual de características}

No procedimento aqui avaliado, escolhem-se manualmente características em um espaço de visualização das características de vários conjuntos de imagens, usando a visualização em árvore $N J$. A acurácia do modelo de seleção é medida de acordo com as avaliações na visualização das imagens antes e após do emprego de cada critério da seleção manual, como pode ser observado nas figuras dos experimentos seguintes.

Sabe-se que diferentes subconjuntos de características podem revelar estruturas diferentes do conjunto de dados, e isso é o que se avalia nesta Seção. O envolvimento do usuário no 
processo é vantajoso especialmente em casos em que o conhecimento do usuário contribui para a seleção, ou seja, o usuário se converte em uma parte principal do processo de seleção de características.

\section{Experimento 1}

Usando a matriz com as características que foram extraídas por meio de $C C V$ de cada uma das imagens do conjunto número 3 (Supermarket - Produce 1440), gera-se a matriz transposta das imagens para obter visualizações onde os pontos representam as características. Segundo a Tabela 5.2, o extrator $C C V$ apresenta 128 características e o conjunto 8 tem 1440 imagens, então a matriz transposta possui um tamanho de $1440 \times 128$. Essa matriz é normalizada usando o algoritmo $z$-score e visualizada como mostra a Figura $5.15 \mathrm{~b}$, usando a distância Jaccard $^{8}$.

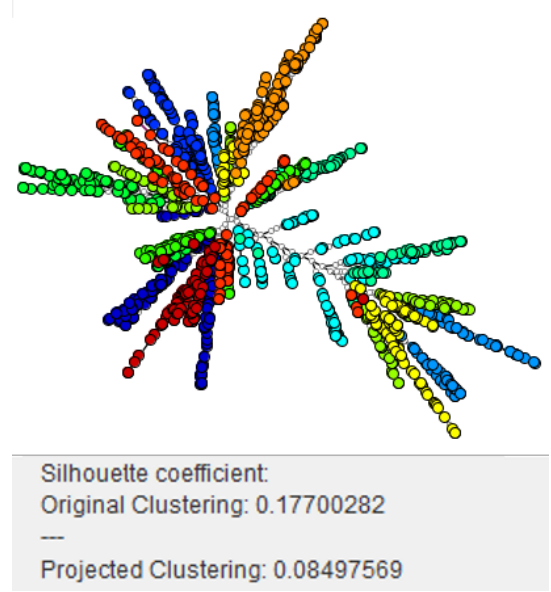

(a)

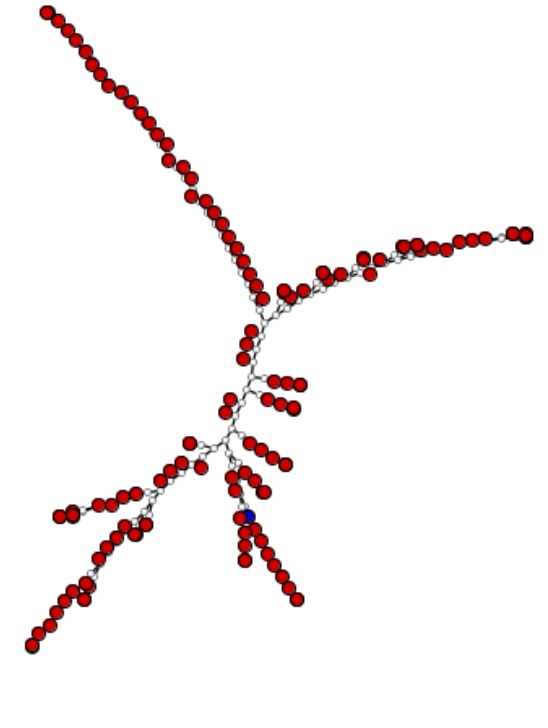

(b)

Figura 5.15: a)Visualização $N J$ do conjunto de imagens 3, caracterizado pelo extrator $C C V$, usando a distância logarítmica. Abaixo, a avaliação com a medida silhueta no espaço original e no espaço projetado. b) Visualização $N J$ das 128 características usando a matriz transposta do conjunto e a distância Jaccard, onde cada ponto representa uma característica.

Realizam-se seleções das características feitas por clique ou arraste do mouse nos pontos que formam a visualização em árvore $N J$ (como da Figura 5.15b). As características selecionadas podem ser vistas na Figura 5.16a. Elas são consideradas na criação de um novo arquivo de dados

\footnotetext{
${ }^{8}$ Depois de testes usando diferentes medidas, a medida Jaccard é a que têm melhor desempenho para representar as características (matriz transposta).
} 
contendo apenas as características selecionadas. Os novos dados são visualizados e avaliados, por exemplo, como apresentado na Figura 5.16b.

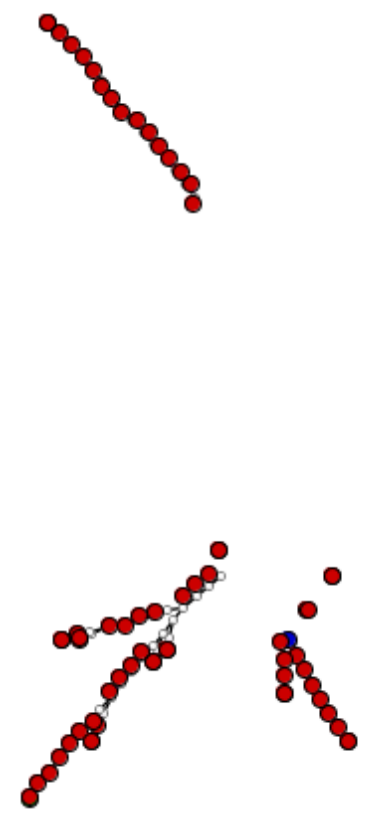

(a)

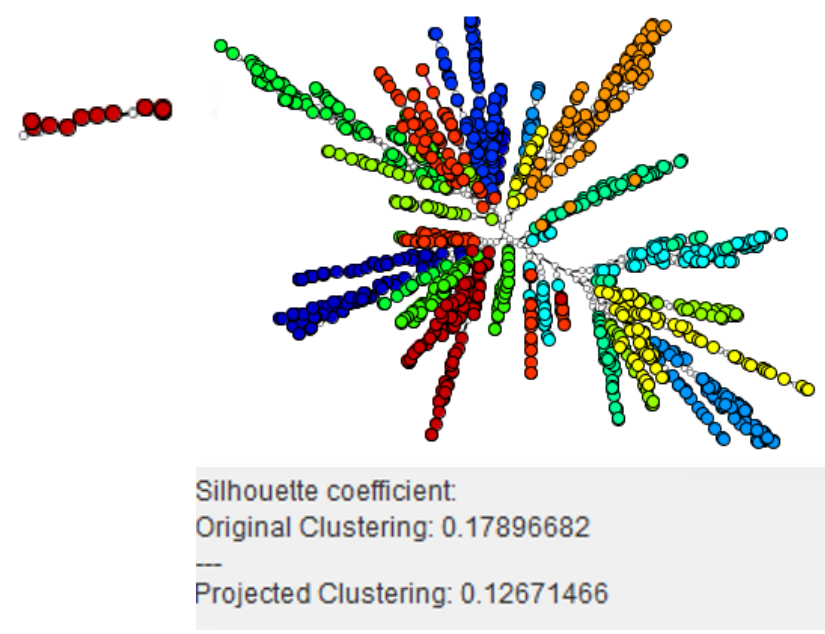

(b)

Figura 5.16: Seleção 1. a)Visualização do subconjunto de características selecionadas, as quais foram escolhidas considerando os pontos projetados isolados na árvore da Figura 5.15b, nos extremos da árvore. São escolhidas 81 características escolhidas. b) Visualização do conjunto de imagens representado pelas características selecionadas em a).

As Figuras 5.16, 5.17 e 5.18, apresentam, respectivamente, no lado esquerdo características de três seleções manuais e no lado direito a visualização e a avaliação do conjunto de imagens representado com as características selecionadas. Chamaremos essas três seleções de seleção 1, seleção 2 e seleção 3, respectivamente. A avaliação é feita usando a medida silhueta no espaço original e no espaço projetado. 


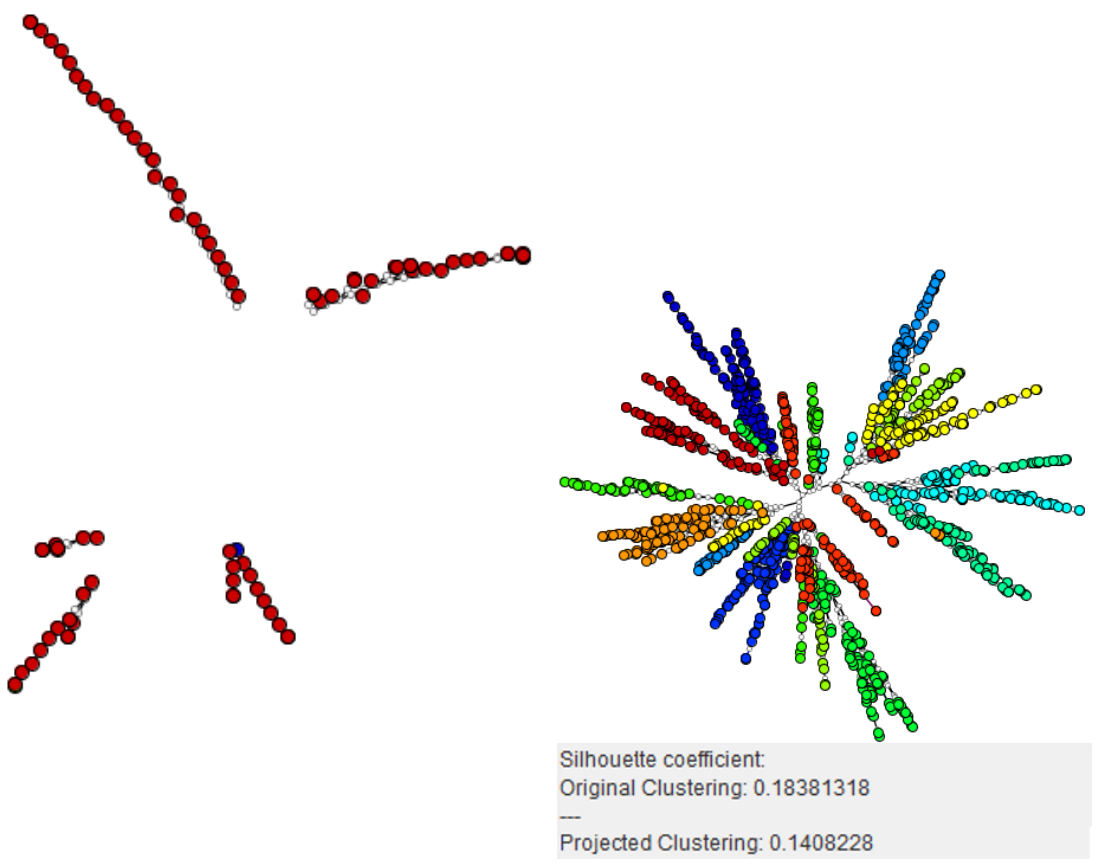

(a)

(b)

Figura 5.17: Seleção 2. a)Visualização das 93 características selecionadas a partir da visualização da Figura 5.15b. Elas foram escolhidas considerando pontos extremos e menos isolados que os da seleção 5.16a. b) Visualização do conjunto de imagens representados pelas características selecionadas em a).

A Tabela 5.6 apresenta as medidas de silhueta obtidas considerando o conjunto com todas as características e com as características selecionadas, para sua comparação e discussão:

- As seleções manuais baseadas na visualização das características, conseguem gerar novas árvores com valor de silhueta maior do que aquele obtido quando se utiliza o conjunto completo, melhorando a representação do conjunto de imagens.

- Ainda que existam diferenças negativas entre os valores da silhueta das seleções entre o espaço projetado e o espaço original, esses valores obtidos superam os valores de silhueta antes da seleção.

- A seleção 2 mostrado na Figura 5.17 é a que apresenta melhor valor silhueta para a seleção de características, ou seja, é melhor escolher manualmente pontos extremos sem considerar muito os pontos perto do centro da árvore, como é observado na Figura $5.18 \mathrm{a}$.

- Observando as três seleções realizadas, são necessárias apenas 93 características para representar melhor o conjunto de imagens 3 usando o algoritmo $N J$ na visualização. 


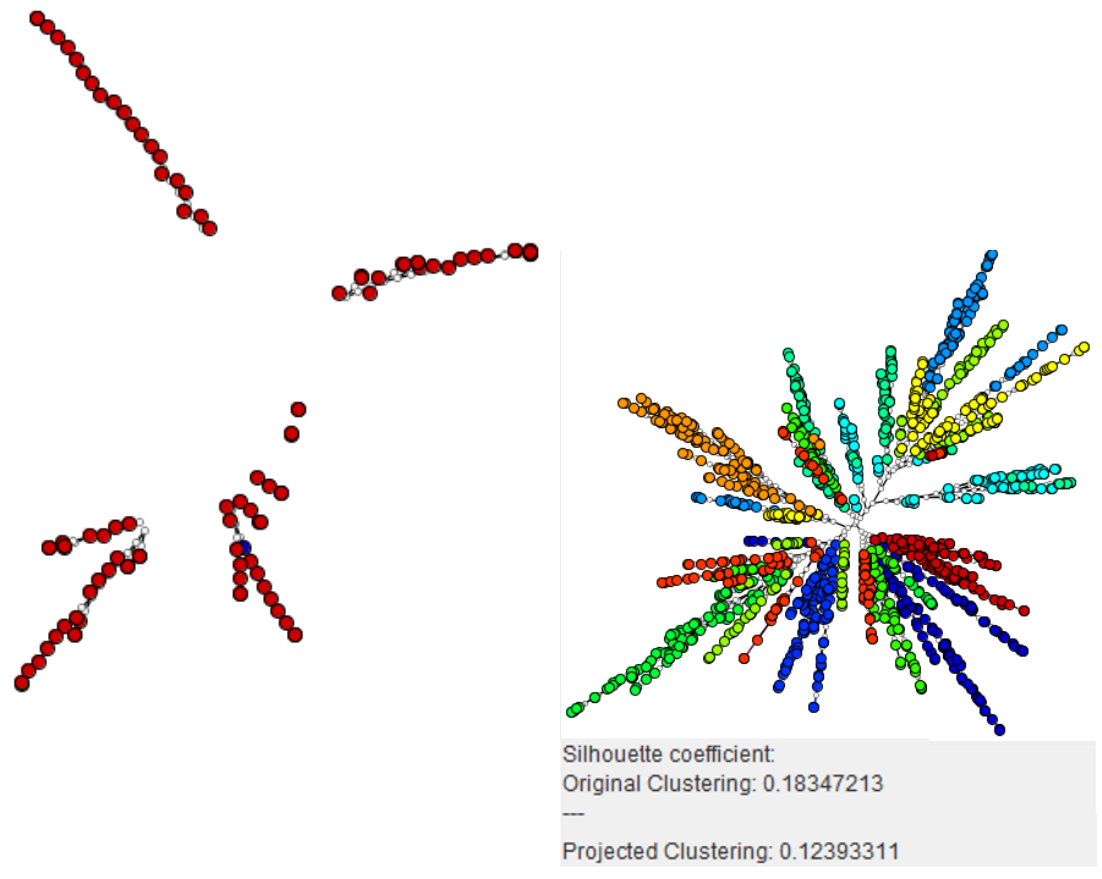

(a)

(b)

Figura 5.18: Seleção 3. a)Visualização do subconjunto de características selecionadas a partir da visualização da Figura 5.15b, as quais foram escolhidas considerando os pontos extremos, isolados e pontos do médio da árvore. São escolhidas 84 características escolhidas. b) Visualização do conjunto de imagens representados pelas características selecionadas em a).

- Observando visualmente as árvores é possível verificar variações de acordo com as seleções realizadas. A árvore gerada usando as características da seleção 2 tem melhor qualidade visual e gera grupos mais coesos comparando com o agrupamento antes da seleção.

Tabela 5.6: Medidas de silhueta obtidas das seleções manuais ilustradas nas Figuras 5.16, 5.17 e 5.18 realizadas para o conjunto número 3 (Supermarket - Produce 1440).

\begin{tabular}{|l|r|r|r|r|}
\hline & $\begin{array}{r}\text { Silhueta } \\
\text { Esp. Orig. }\end{array}$ & $\begin{array}{r}\text { Silhueta } \\
\text { Esp. Proj. }\end{array}$ & $\begin{array}{r}\text { Número de } \\
\text { Características }\end{array}$ & $\begin{array}{r}\text { Porcentagem \% de } \\
\text { Características }\end{array}$ \\
\hline Antes da seleção & 0,1770 & 0,0849 & 128 & $100 \%$ \\
\hline Após a seleção 1 & 0,1789 & 0,1267 & 81 & $63,28 \%$ \\
\hline Após a seleção 2 & 0,1838 & 0,1408 & 93 & $72,65 \%$ \\
\hline Após a seleção 3 & 0,1834 & 0,1239 & 84 & $65,62 \%$ \\
\hline
\end{tabular}




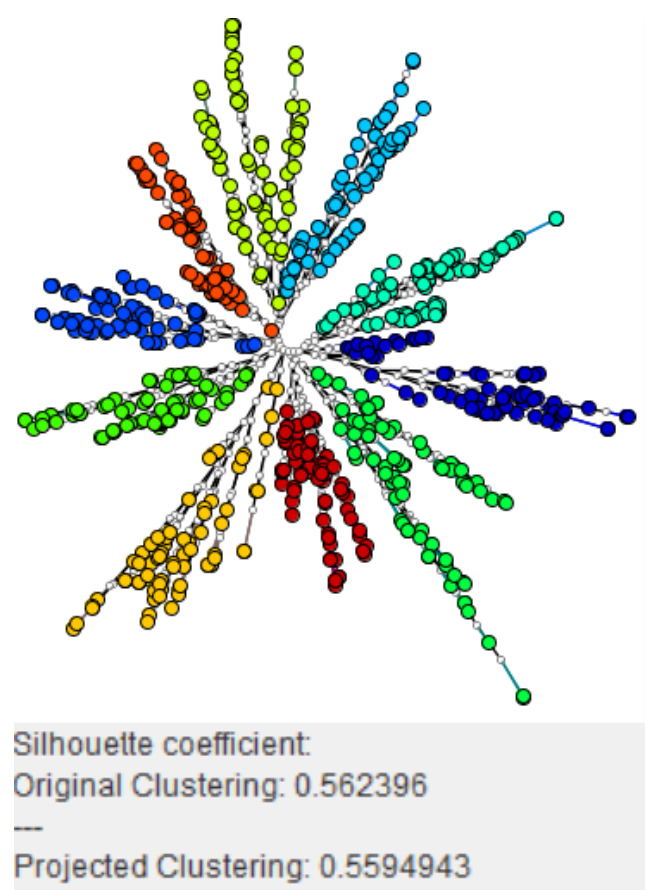

(a)

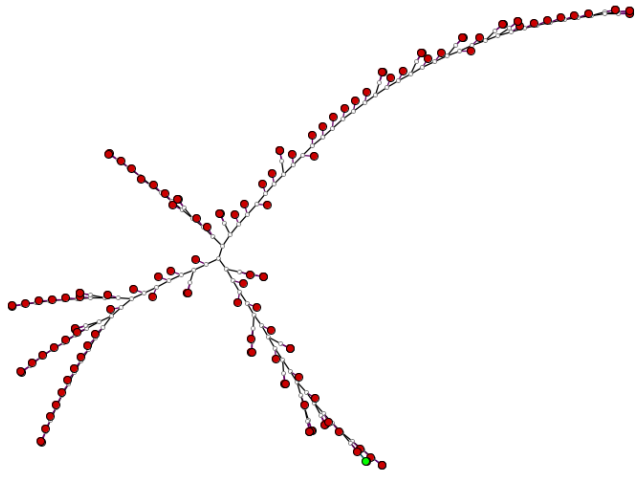

(b)

Figura 5.19: a)Visualização $N J$ do conjunto de imagens 8 , caracterizado pelo extrator $C C V$, usando a distância logarítmica. Abaixo, a avaliação com a medida silhueta no espaço original e no espaço projetado. b) Visualização $N J$ das 128 características usando a matriz transposta e a distância Jaccard, onde cada ponto representa uma característica.

\section{Experimento 2}

A Figura $5.19 b$ apresenta a visualização das características, que foram extraídas usando $C C V$ (128 características), do conjunto de imagens 8 (coil 720) usando a distância Jaccard. Um pré-processamento é realizado para os dados transpostos mediante a normalização com o algoritmo z-score.

Realizam-se três casos de seleções de características, ilustradas nas Figuras 5.20(seleção 1), 5.21 (seleção 2), 5.22(seleção 3). A Tabela 5.7 ilustra as medidas de silhueta obtidas considerando o conjunto com todas as características selecionadas. A seguir discutem-se os resultados apresentados:

- As três seleções realizadas conseguem superar os valores da silhueta antes da seleção, no espaço original e no espaço projetado.

- Os valores de silhueta no espaço projetado após a seleção superam também os valores no espaço original. 


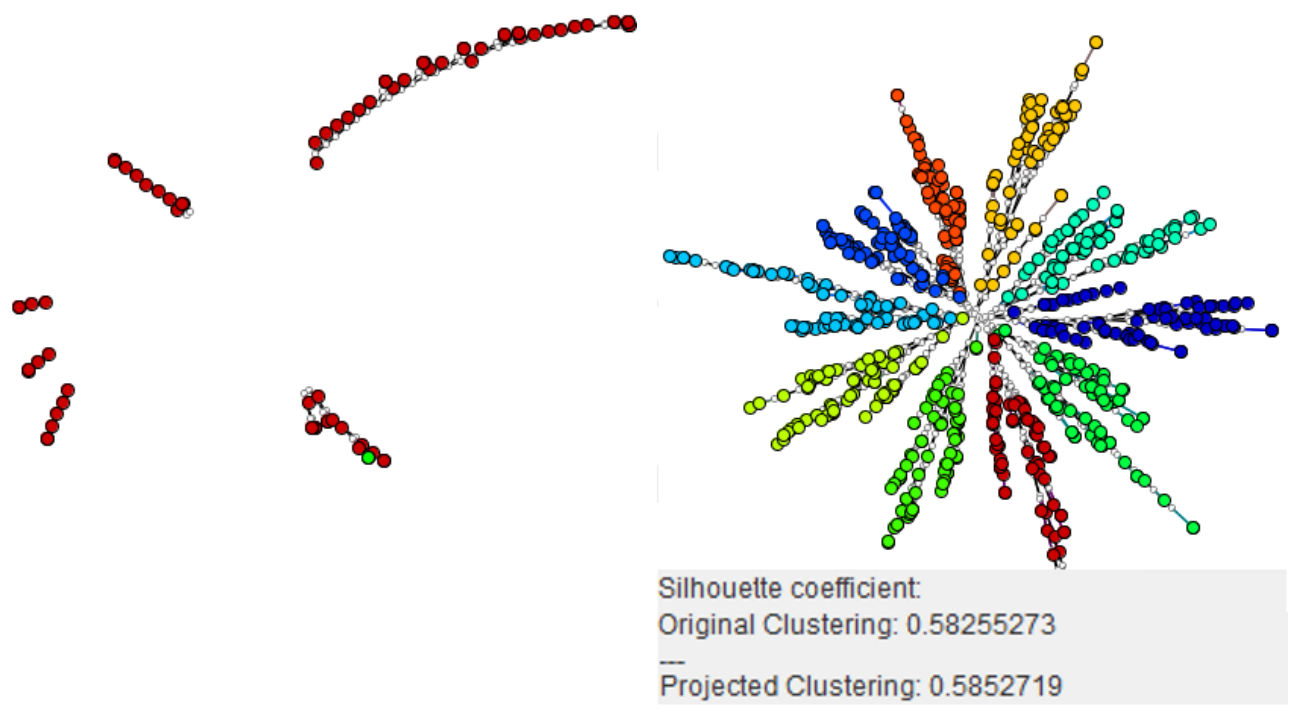

(a)

(b)

Figura 5.20: Seleção 1. a)Visualização das 76 características selecionadas na árvore da Figura $5.19 \mathrm{~b}$. Elas foram escolhidas considerando pontos projetados isolados, nos extremos da árvore (seguindo os resultados do experimento anterior). b) Visualização do conjunto de imagens representados pelas características selecionadas em a).

- Ao se comparar as medidas de silhueta obtidas, o extrator $C C V$ consegue representar melhor o conjunto 8 que o conjunto 3 , como foi observado no experimento anterior.

- Observando os resultados dessas seleções, a seleção 3 com maiores valor silhueta (no espaço original e no espaço projetado), são necessárias apenas 62 características de 128 características para representar bem o conjunto de dados original.

- Percebe-se que a qualidade visual é mantida, em ambos testes, ao observar que nas árvores geradas após a seleção de características, as classes são apresentadas separadamente, semelhante com a árvore inicial.

Tabela 5.7: Medidas de silhueta obtidas das seleções manuais ilustradas nas Figuras 5.20, 5.21 e 5.22, realizadas para o conjunto 8 (coil 720 ), caracterizado pelo extrator $C C V$.

\begin{tabular}{|l|r|r|r|r|}
\hline & $\begin{array}{r}\text { Silhueta } \\
\text { Esp. Orig. }\end{array}$ & $\begin{array}{r}\text { Silhueta } \\
\text { Esp. Proj. }\end{array}$ & $\begin{array}{r}\text { Número de } \\
\text { Características }\end{array}$ & $\begin{array}{r}\text { Porcentagem \% de } \\
\text { Características }\end{array}$ \\
\hline Antes da seleção & 0,5623 & 0,5594 & 128 & $100 \%$ \\
\hline Após a seleção 1 & 0,5825 & 0,5852 & 76 & $59,37 \%$ \\
\hline Após a seleção 2 & 0,5685 & 0,5710 & 62 & $48,43 \%$ \\
\hline Após a seleção 3 & 0,5916 & 0,6103 & 45 & $35,15 \%$ \\
\hline
\end{tabular}




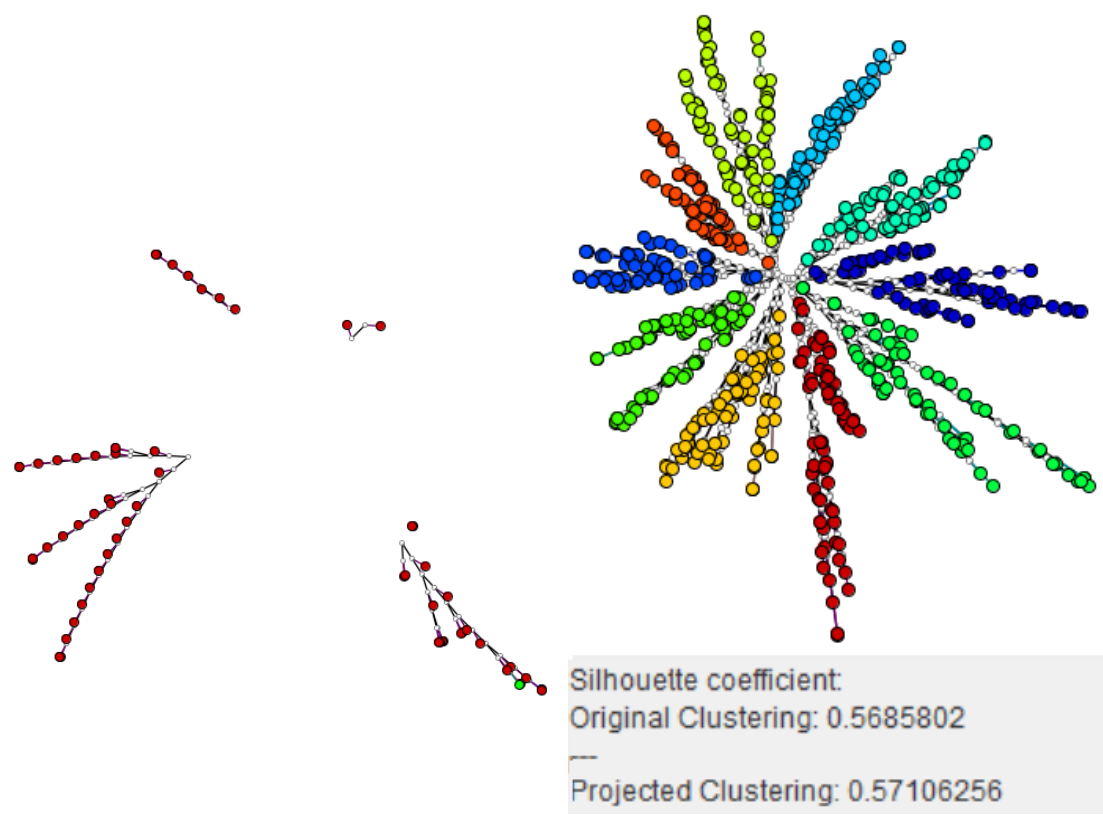

(a)

(b)

Figura 5.21: Seleção 2. a) Visualização do subconjunto de características selecionadas a partir da visualização da Figura 5.19b. Elas foram escolhidas considerando os pontos projetados isolados, nos extremos dos ramos mais curtas da árvore, tentando ignorar os pontos do ramo mais cumprido. Foram escolhidas no total de 62 características. b) Visualização do conjunto de imagens representados pelas características selecionadas em a).

\section{Experimento 3}

O conjunto de imagens 6 (COIL 2520), cujas características foram extraídas usando BIC, é visualizado em uma árvore $N J$ usando a distância logarítmica, como é ilustrado na Figura $5.23 \mathrm{a}$. Em seguida, este conjunto de características foi transposto e visualizado em uma árvore $N J$ usando a distância Jaccard, revelando alguns grupos formados pelos ramos da árvore, conforme pode ser observado na Figura 5.23b. A matriz transposta das características foi normalizada usando o algoritmo $z$-score e agrupada previamente pelo algoritmo $K$-médias, $\operatorname{com} k=3$. Isto foi feito apenas para ressaltar o agrupamento revelado pela árvore.

Realizam-se 3 processos de seleção manuais de características, que são ilustradas nas Figuras 5.24(seleção 1), 5.25 (seleção 2) e 5.26(seleção 3). As avaliações são apresentadas na Tabela 5.8, e observando os valores obtidos da medida silhueta apresentam-se as discussões sob os resultados obtidos:

- Com a primeira seleção diminui o valor da silhueta comparando com os valores antes da seleção. 


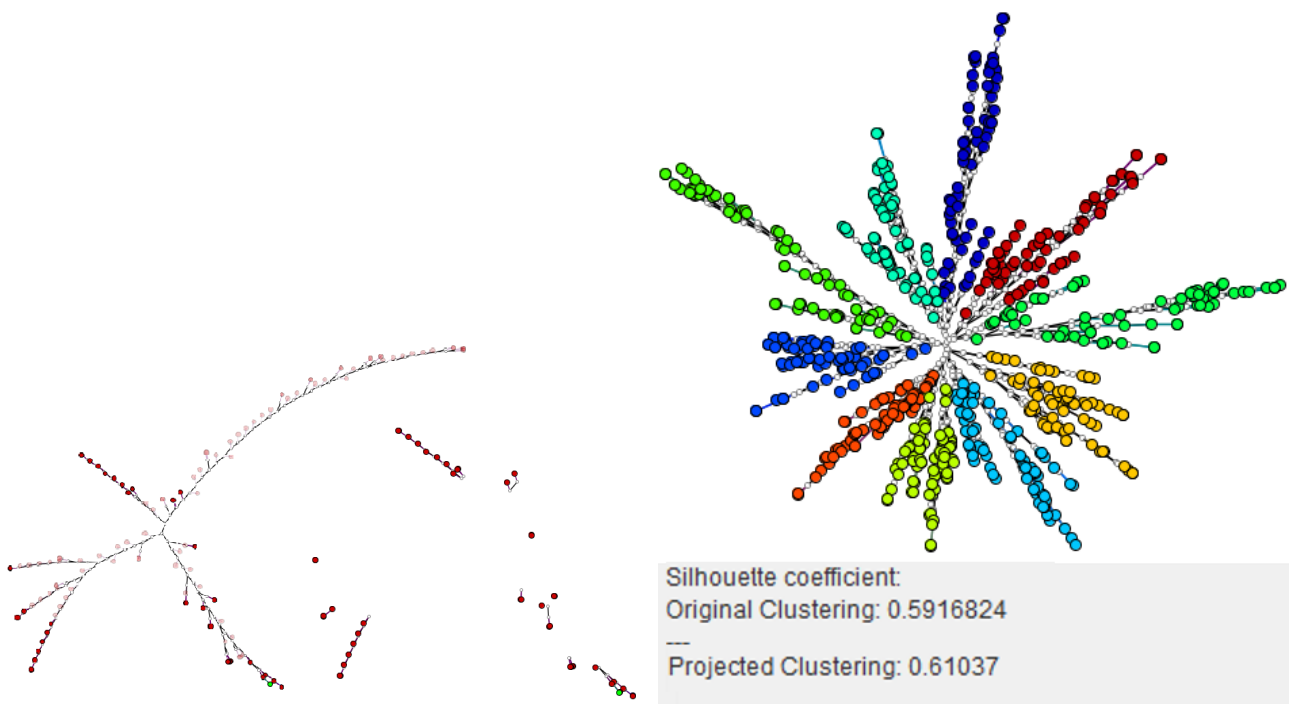

(a)

(b)

Figura 5.22: Seleção 3. a) Visualização do subconjunto de características selecionadas a partir da visualização da Figura 5.19b. Elas foram escolhidas considerando só os pontos extremos dos ramos mais curtos da árvore. São escolhidas 45 características escolhidas. b) Visualização do conjunto de imagens representados pelas características selecionadas em a).

- Com as outras duas seleções mantém-se os valores de silhueta no espaço original e no espaço projetado, mas não usando as mesmas características. Na segunda seleção considera-se o critério de selecionar pontos dos ramos curtos da árvore e na terceira seleção consideram-se os pontos mais isolados da árvore sem perder uma densidade considerável de características.

- Neste caso não houve grande impacto na seleção, sugerindo que 91 características seriam suficientes.

- Não houve impacto da seleção na qualidade visual do layout.

\subsubsection{Avaliações de critérios na seleção manual de características obtidas pela seleção de um subconjunto de imagens repre- sentativas}

Através da escolha de um subconjunto de imagens chamadas de representativas para cada conjunto de imagens, escolhem-se manualmente as características, usando também a visualização em árvore $N J$. A seleção é realizada como nos experimentos anteriores. 


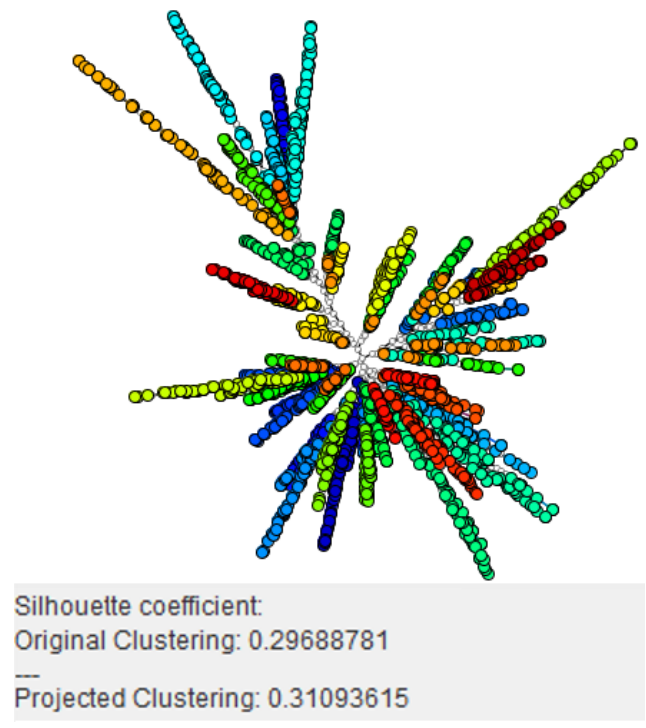

(a)

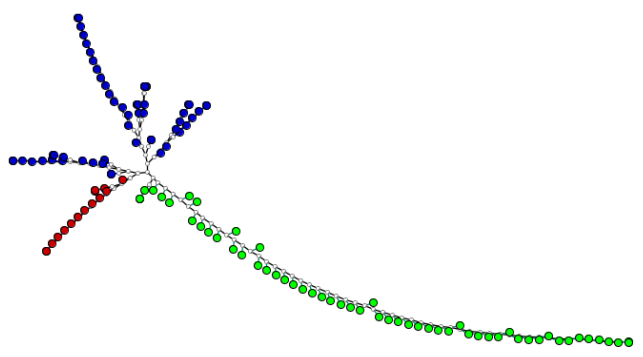

(b)

Figura 5.23: a)Visualização $N J$ do conjunto de imagens 6 , caracterizado pelo extrator $B I C$, usando a distância logarítmica. Abaixo, a /avaliação com a medida silhueta no espaço original e no espaço projetado. b) Visualização $N J$ das 128 características usando a matriz transposta do conjunto de imagens e a distância Jaccard, onde cada ponto representa uma característica. Observa-se que o agrupamento prévio à visualização cumpre com os grupos identificados pelos ramos das árvores.

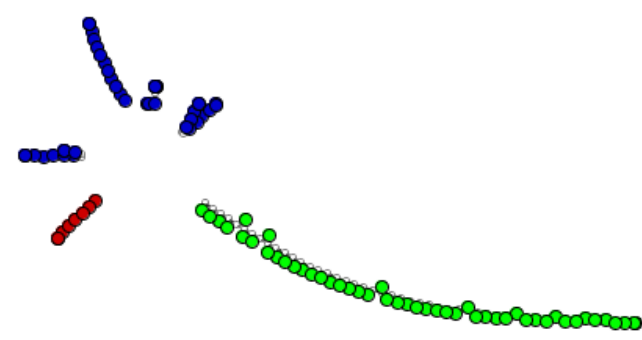

(a)

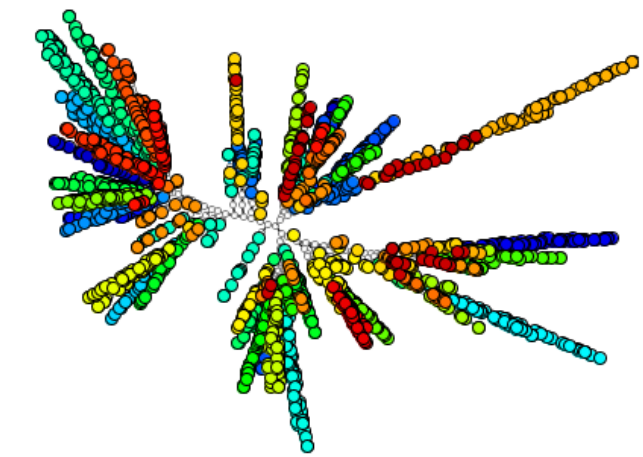

Silhouette coefficient:

Original Clustering: 0.2735769

Projected Clustering: 0.21913728

(b)

Figura 5.24: Seleção 1. a)Visualização das 96 características selecionadas na árvore Figura 5.23b. Elas foram escolhidas considerando os pontos projetados isolados, nos extremos dos ramos da árvore (seguindo os resultados do experimento anterior). b) Visualização do conjunto de imagens representados pelas características selecionadas em a). 


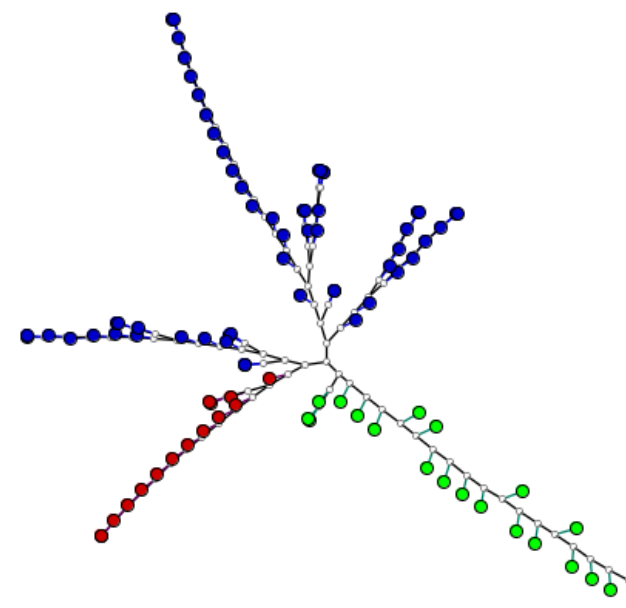

(a)

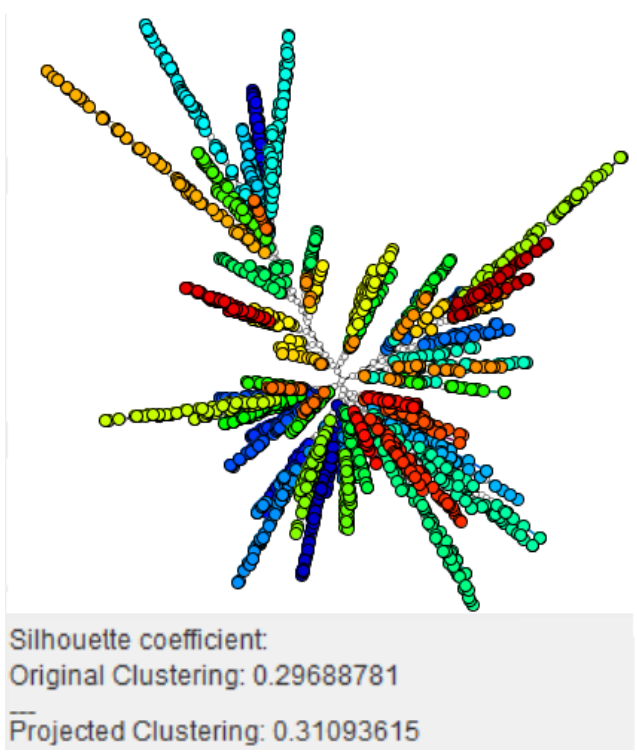

(b)

Figura 5.25: Seleção 2. a)Visualização do subconjunto de características selecionadas a partir da visualização da Figura 5.23b. Elas foram escolhidas considerando os pontos que pertencem aos ramos curtos da árvore. São escolhidas 91 características selecionadas. b) Visualização do conjunto de imagens representados pelas características selecionadas em a).

Tabela 5.8: Medidas de silhueta obtidas das seleções manuais ilustradas nas Figuras 5.24,5.25 e 5.26, realizadas para o conjunto 6 (COIL 2520), caracterizado pelo extrator BIC.

\begin{tabular}{|l|r|r|r|r|}
\hline & $\begin{array}{r}\text { Silhueta } \\
\text { Esp. Orig. }\end{array}$ & $\begin{array}{r}\text { Silhueta } \\
\text { Esp. Proj. }\end{array}$ & $\begin{array}{r}\text { Número de } \\
\text { Características }\end{array}$ & $\begin{array}{r}\text { Porcentagem \% de } \\
\text { Características }\end{array}$ \\
\hline Antes da seleção & 0,2968 & 0,3109 & 128 & $100 \%$ \\
\hline Após a seleção 1 & 0,2735 & 0,2191 & 96 & $75 \%$ \\
\hline Após a seleção 2 & 0,2968 & 0,3109 & 91 & $71,09 \%$ \\
\hline Após a seleção 3 & 0,2968 & 0,3109 & 106 & $82,81 \%$ \\
\hline
\end{tabular}

\section{Experimento 1}

A Figura 5.27a apresenta a visualização do conjunto de imagens 3 (Supermarket - Produce 1440), cujas características foram extraídas por meio do $G C H$. Usa-se a distância logarítmica, para refletir a similaridade entre as imagens na visualização. Ressalta-se, na figura que existem pontos que são mais iluminados que outros, as quais são considerados os pontos que denotam as imagens representativas. O subconjunto de imagens foi escolhido considerando os ramos das árvores com maior número de pontos da mesma cor, isto é, as imagens que representam 


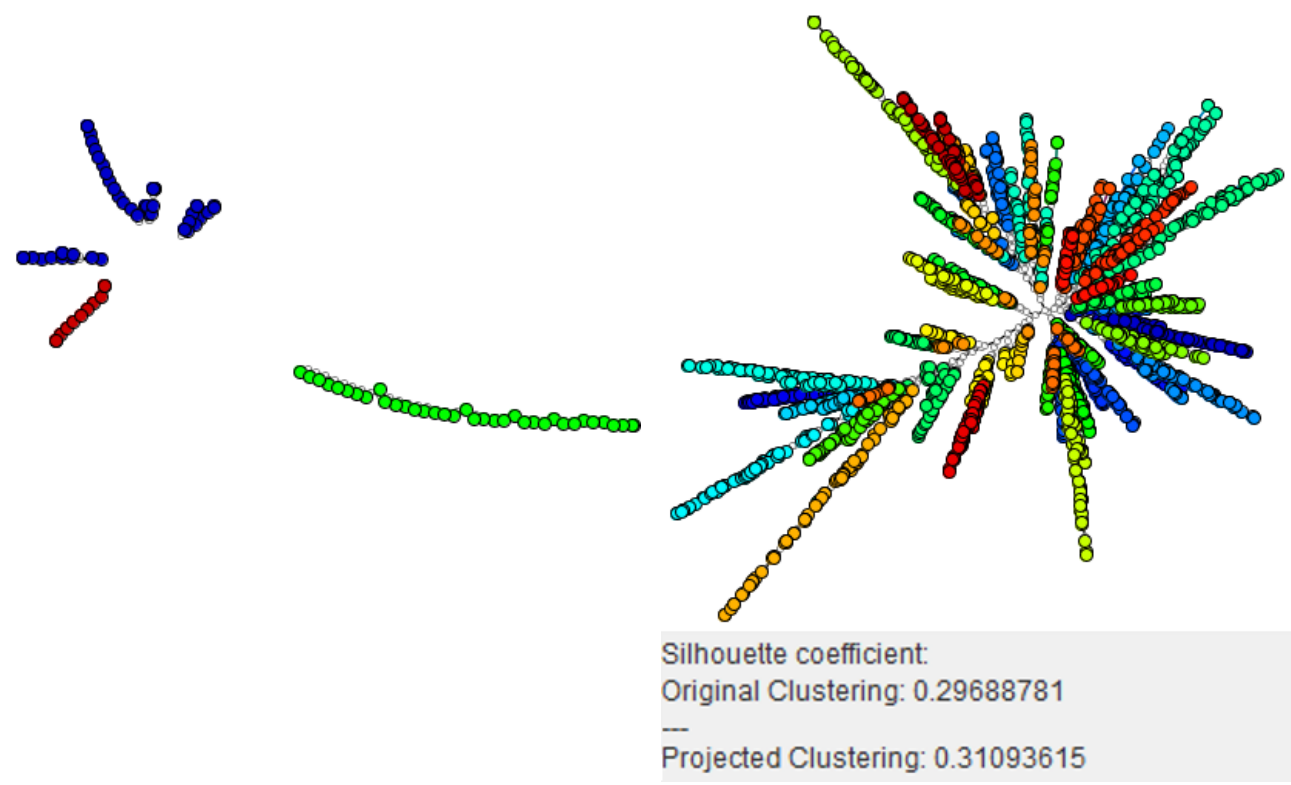

(a)

(b)

Figura 5.26: Seleção 3. a)Visualização do subconjunto de características selecionadas a partir da visualização da Figura 5.23b. Elas foram escolhidas considerando os pontos projetados isolados, no mais no extremo de cada ramo da árvore. São escolhidas 106 características escolhidas. b) Visualização do conjunto de imagens representados pelas características selecionadas em a).

conjuntos de classes bem definidas; formando assim o subconjunto de imagens representativas. Neste caso ha 1204 imagens representativas.

Sob esse conjunto de imagens representativas gera-se a visualização das suas características usando a distância cosseno, como mostra a Figura 5.27b.

A seguir apresenta-se a seleção manual realizada nesse subconjunto de características. A diferença do processo de avaliação anterior é que a dimensão da matriz transposta diminui devido a que a quantidade de imagens que compõe a matriz transposta é menor, pois são consideradas apenas as imagens representativas.

A visualização das imagens considerando apenas o subconjunto de características selecionado é apresentado na Figura 5.28, e as medidas de silhueta obtidas antes e após a seleção são apresentadas na Tabela 5.9.

As discussões resgatadas após as avaliações são apresentadas a seguir:

- A seleção manual usando as características das imagens representativas, supera os valores de silhueta, em comparação com as avaliações realizadas anteriormente (Tabela 5.6) sob o mesmo conjunto mas com um outro extrator, o $C C V$. Ela supera também a seleção 


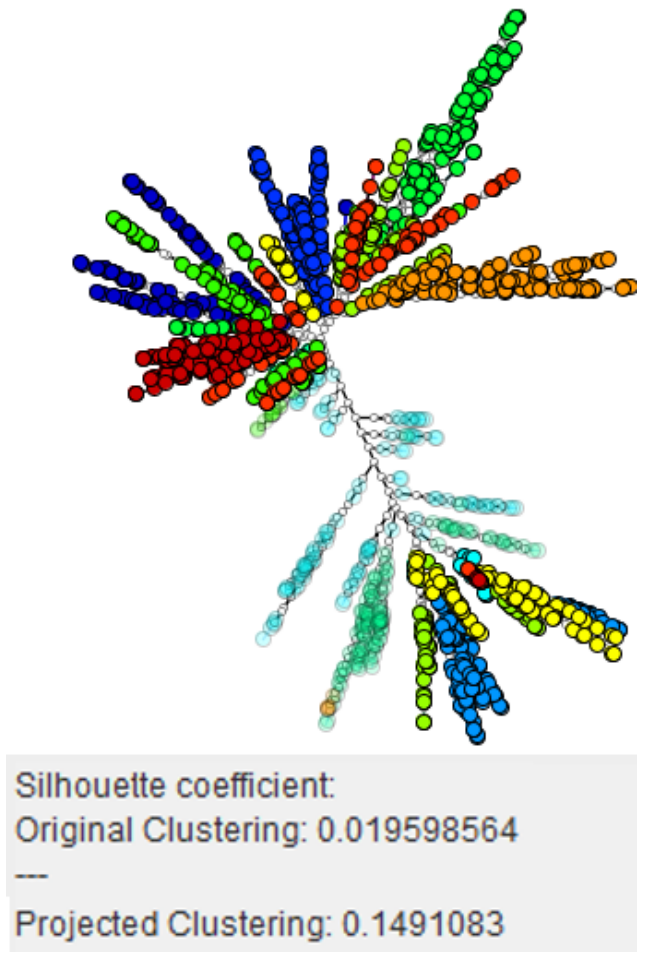

(a)

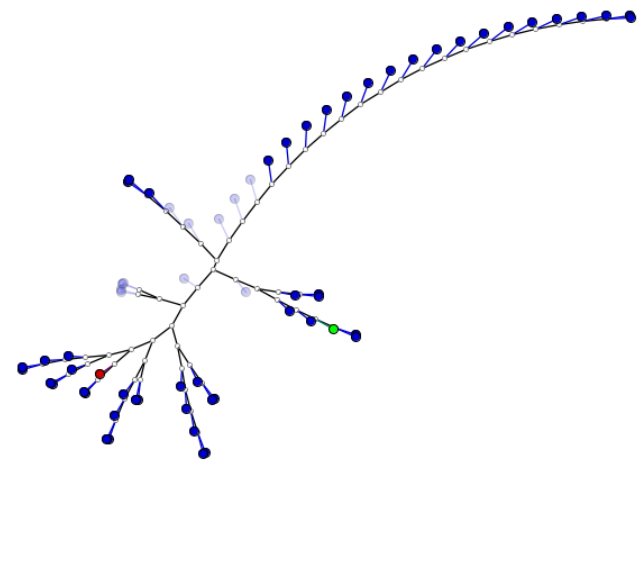

(b)

Figura 5.27: a)Visualização $N J$ do conjunto de imagens 3, caracterizado pelo extrator $G C H$, usando a distância logarítmica. Em ressalte, as imagens representativas. Abaixo, a avaliação com a medida silhueta no espaço original e no espaço projetado. b) Visualização $N J$ das 64 características usando a matriz transposta e a distância cosseno, onde cada ponto representa uma característica.

manual considerando a visualização de todas suas características. Isto pode ser explicado pelo fato do extrator $\mathrm{GCH}$ representar melhor o conjunto, e que, com suas características, podem ser realizadas seleções com maior facilidade e vantagem.

- Com a seleção de 53 características ou 53 cores, considera-se as necessárias para definir o conjunto de imagens 3 . Ressaltando que a redução do número de características é bastante significativa.

- Com a seleção de imagens representativas supera-se os valores da silhueta antes da seleção no espaço original e no espaço projetado. No entanto, nota-se que o valor da silhueta obtido após a seleção de características não supera seu valor no espaço original e no espaço projetado.

- A árvore resultante após a seleção mostra maior grau de separação entre grupos e elementos da mesma classe mais coesos. 


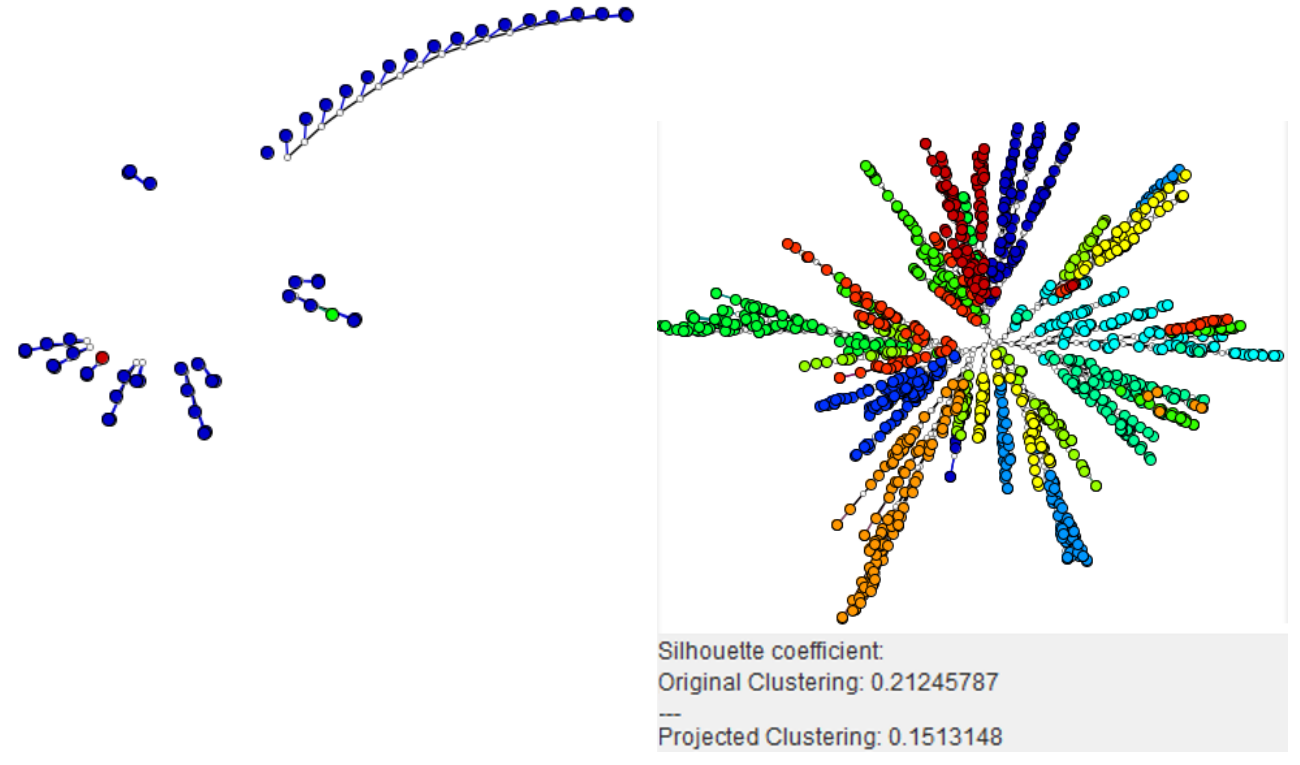

(a)

(b)

Figura 5.28: a)Visualização do subconjunto de características selecionadas na árvore da Figura 5.27b. Elas foram escolhidas considerando os pontos projetados isolados, nos extremos da árvore. São escolhidas 53 características escolhidas. b) Visualização do conjunto de imagens representados pelas características selecionadas em a).

Tabela 5.9: Medidas de silhueta obtidas antes e após a seleção ilustrada na Figura 5.28 usando 1204 imagens representativas realizada para o conjunto 3 (Supermarket-Produce 1440), caracterizado pelo extrator $G C H$.

\begin{tabular}{|l|r|r|r|r|}
\hline & $\begin{array}{r}\text { Silhueta } \\
\text { Esp. Orig. }\end{array}$ & $\begin{array}{r}\text { Silhueta } \\
\text { Esp. Proj. }\end{array}$ & $\begin{array}{r}\text { Número de } \\
\text { Características }\end{array}$ & $\begin{array}{r}\text { Porcentagem \% de } \\
\text { Características }\end{array}$ \\
\hline Antes da seleção & 0,0195 & 0,1491 & 64 & $100 \%$ \\
\hline Após a seleção & 0,2124 & 0,1513 & 53 & $82,81 \%$ \\
\hline
\end{tabular}

\section{Experimento 2}

A Figura 5.29a apresenta a visualização do conjunto de imagens 11 (Flores 120) usando a distância logarítmica, cujas características foram extraídas usando BIC. Os pontos na visualização com cor intensa são os pontos das imagens representativas, pertencentes aos ramos das árvores melhor definidos e com a cor uniforme. Neste caso ha 87 imagens representativas.

$\mathrm{Na}$ Figura 5.29b, mostra-se a visualização das características das imagens representativas. As características não são normalizadas, mas são agrupadas usando o algoritmo $K$-médias, com $k=3$, o que foi feito apenas para ajudar a ressaltar os grupo revelados pela árvore. 


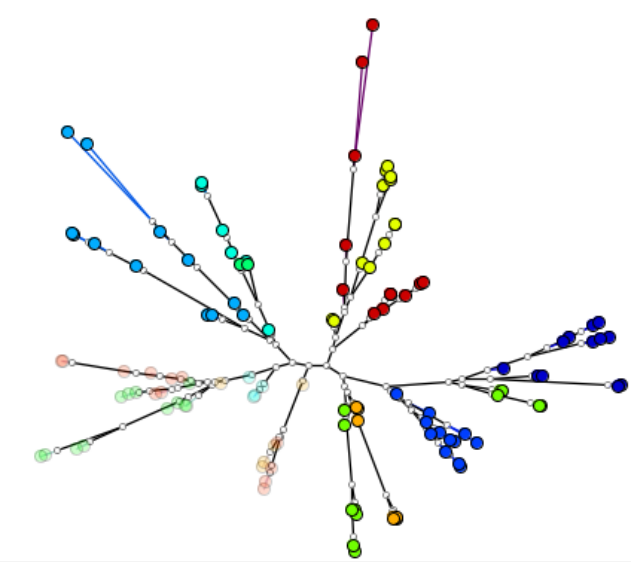

Silhouette coefficient:

Original Clustering: 0.34632364

Projected Clustering: 0.311987

(a)

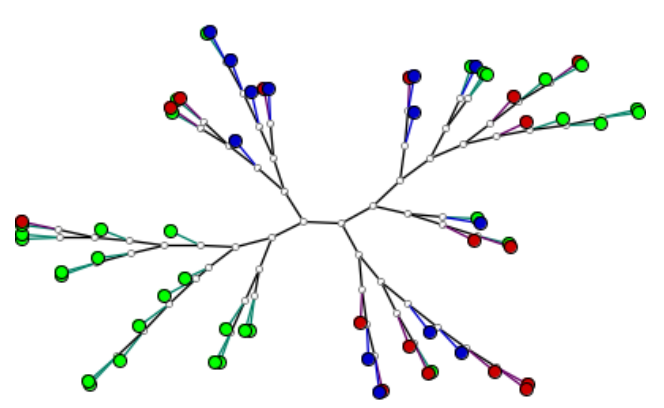

(b)

Figura 5.29: a)Visualização $N J$ do conjunto de imagens 11 , caracterizado pelo extrator $B I C$, usando a distância logarítmica. Os pontos que são mais coloridos intensamente são os pontos que representam as imagens representativas. Abaixo, a avaliação com a medida silhueta no espaço original e no espaço projetado. b) Visualização $N J$ das 64 características usando a matriz transposta e a distância Cosseno, onde cada ponto representa uma característica. 
Realiza-se a seleção manual das características, como é apresentado na Figura 5.30, que apresenta também a visualização das imagens considerando apenas o subconjunto de características selecionado. Os valores das medidas de silhueta antes e após a seleção são apresentadas na Tabela 5.10. As observações relacionadas aos resultados apresentados são destacadas a seguir:

- Com a seleção consegue-se gerar uma nova árvore com valor silhueta maior que aquele obtido quando se utiliza o conjunto completo de características.

- Pode-se perceber que o valor silhueta obtido no espaço original pelo subconjunto selecionado é levemente menor que o valor da silhueta antes da seleção, podendo ser considerado equivalente.

- Deve-se salientar que o critério de seleção é vantajoso na escolha dos pontos extremos dos ramos das árvores de características.

- Das 128 características do $B I C$, foram escolhidas 43 características, menos da metade do total.

- Observando visualmente as árvores é possível verificar variações após a seleção. Identifica-se melhor a separação e coesão de grupos, pois são mais bem distribuídos e discriminados.

Tabela 5.10: Medidas de silhueta obtidas antes e após a seleção ilustrada na Figura 5.30 usando 87 imagens representativas realizada para o conjunto 11 (Flores 120), caracterizado pelo extrator $B I C$.

\begin{tabular}{|l|r|r|r|r|}
\hline & $\begin{array}{r}\text { Silhueta } \\
\text { Esp. Orig. }\end{array}$ & $\begin{array}{r}\text { Silhueta } \\
\text { Esp. Proj. }\end{array}$ & $\begin{array}{r}\text { Número de } \\
\text { Características }\end{array}$ & $\begin{array}{r}\text { Porcentagem \% de } \\
\text { Características }\end{array}$ \\
\hline Antes da seleção & 0,3463 & 0,3119 & 128 & $100 \%$ \\
\hline Após a seleção & 0,3441 & 0,3399 & 43 & $33,59 \%$ \\
\hline
\end{tabular}

\section{Experimento 3}

Realiza-se uma seleção manual de características usando as imagens representativas do conjunto de imagens 7 (coil 1800), cujas características foram extraídas por meio de $C C V$. As imagens representativas são selecionadas escolhendo os ramos das árvores que mantêm a classe definida pela uniformidade da cor presente no ramo, como na Figura 5.31a. Neste caso ha 1697 imagens representativas. As características das imagens representativas são visualizadas usando a distância Jaccard. 


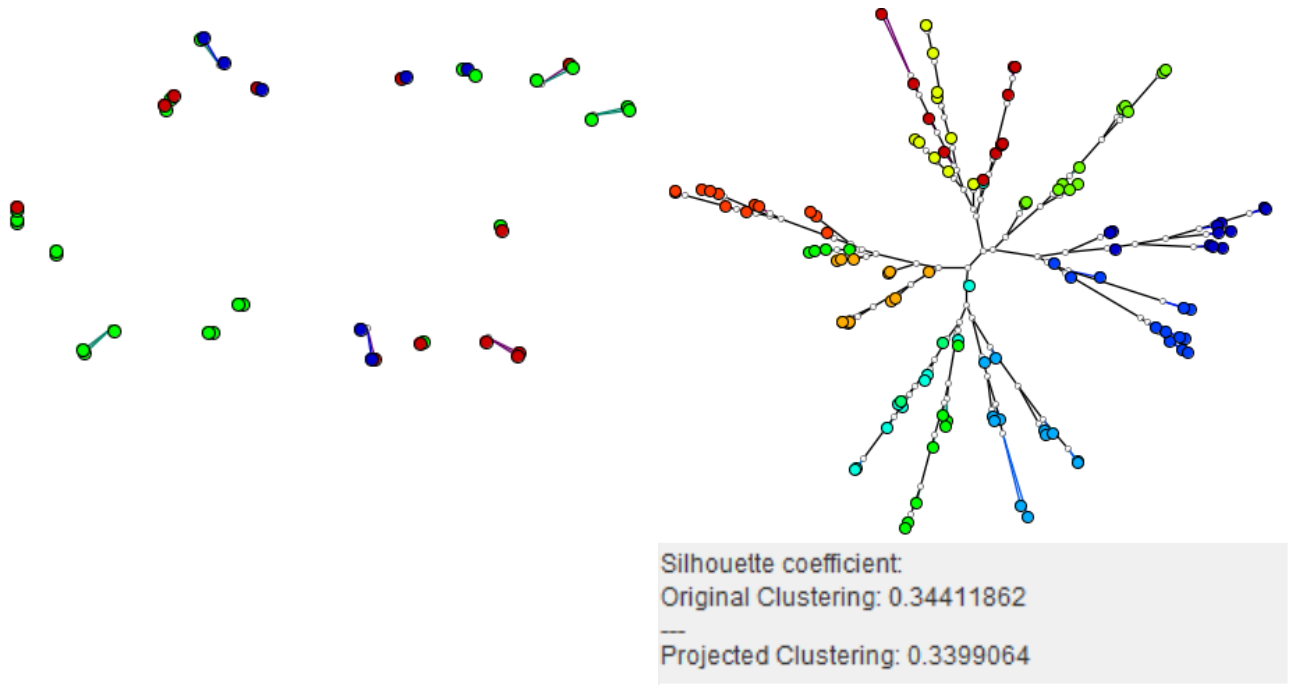

(a)

(b)

Figura 5.30: a)Visualização do subconjunto de características selecionadas na árvore da Figura 5.29b. Elas foram escolhidas considerando os pontos bem extremos e mais isolados da árvore. São escolhidas 43 características selecionadas. b) Visualização do conjunto de imagens representados pelas características selecionadas em a).

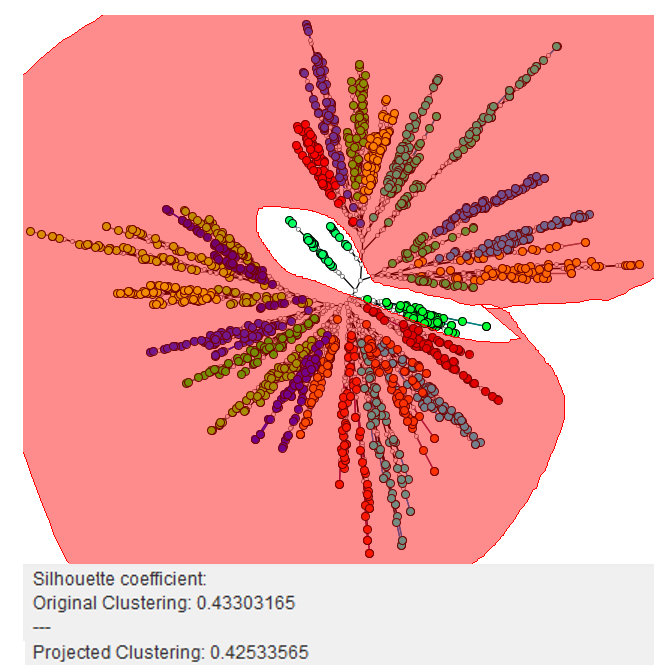

(a)

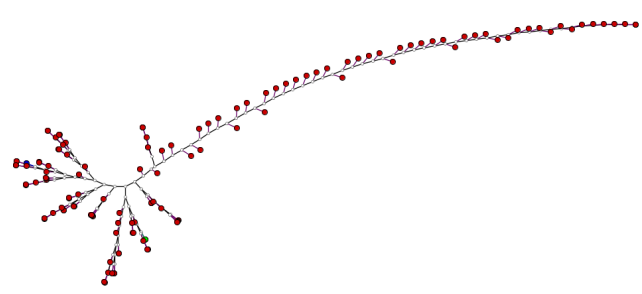

Figura 5.31: a)Visualização $N J$ do conjunto de imagens 7 , caracterizado pelo extrator $B I C$, usando a distância logarítmica. Os pontos que são cobertos por uma tela de cor são os pontos que representam as imagens representativas. Abaixo, a avaliação com a medida silhueta no espaço original e no espaço projetado. b) Visualização $N J$ das 128 características usando a matriz transposta e a distância Jaccard, onde cada ponto representa uma característica. 
A visualização das imagens considerando apenas o subconjunto de características selecionado é apresentado na Figura 5.32. As medidas de silhueta obtidas são apresentadas na Tabela 5.11, e observando-se os valores obtidos, discute-se:

- Redução significativa do tamanho do vetor de características após a seleção.

- De acordo a escolha de características realizada, considera-se que as características mais importantes ficam próximas nos ramos curtos da árvore.

- Considera-se 74 características suficientes para representar o conjunto de dados, ao invés de 128.

- Um resultado importante que deve ser considerado é que os grupos da árvore são mais definidos após a seleção.
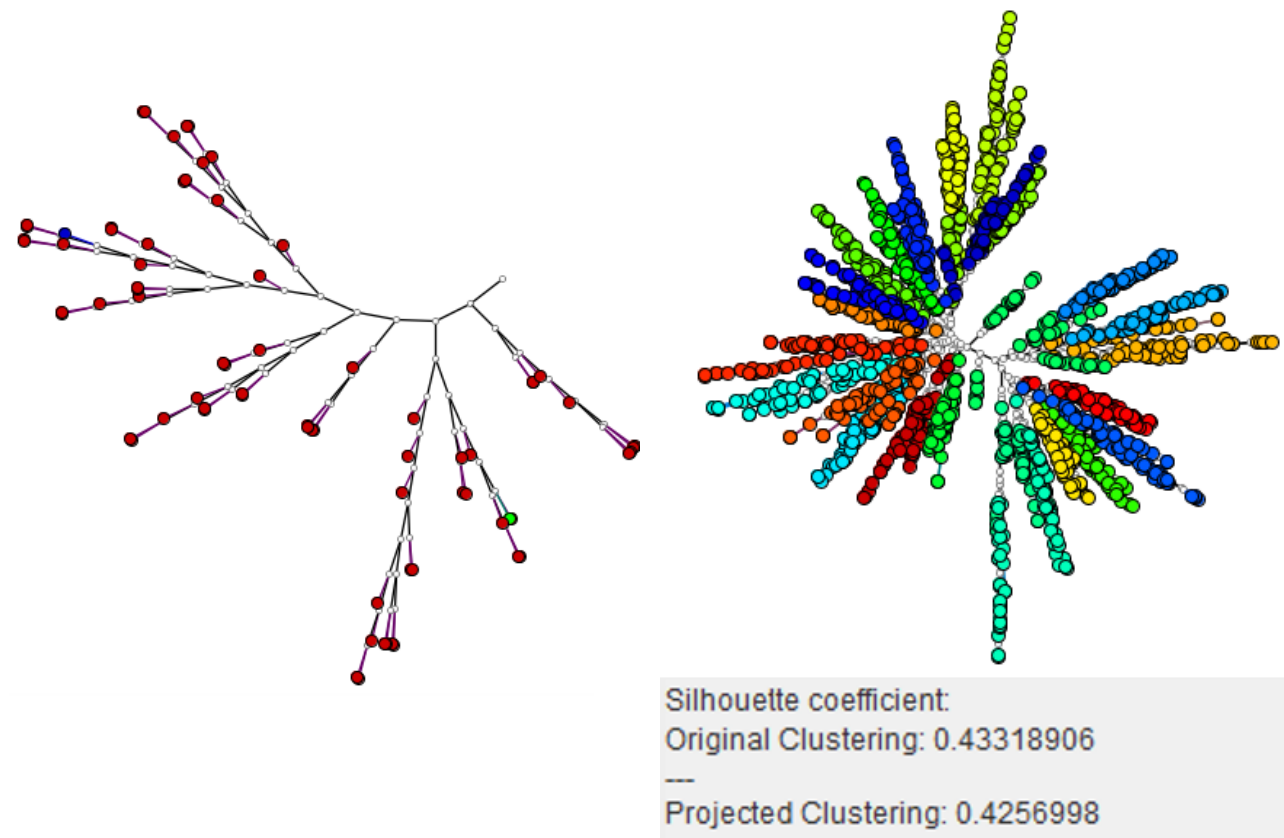

(a)

(b)

Figura 5.32: a)Visualização do subconjunto de características selecionadas na árvore da Figura 5.31b. Elas foram escolhidas considerando os pontos que pertencem aos ramos curtos da árvore. São escolhidas 74 características selecionadas. b) Visualização do conjunto de imagens representados pelas características selecionadas em a). 
Tabela 5.11: Medidas de silhueta obtidas antes e após a seleção ilustrada na Figura 5.32 usando 1697 imagens representativas realizada para o conjunto número 7 (COIL 1800), caracterizado pelo extrator $C C V$.

\begin{tabular}{|l|r|r|r|r|}
\hline & $\begin{array}{r}\text { Silhueta } \\
\text { Esp. Orig. }\end{array}$ & $\begin{array}{r}\text { Silhueta } \\
\text { Esp. Proj. }\end{array}$ & $\begin{array}{r}\text { Número de } \\
\text { Características }\end{array}$ & $\begin{array}{r}\text { Porcentagem \% de } \\
\text { Características }\end{array}$ \\
\hline Antes da seleção & 0,4330 & 0,4253 & 128 & $100 \%$ \\
\hline Após a seleção & 0,4331 & 0,4256 & 74 & $57,81 \%$ \\
\hline
\end{tabular}

\subsubsection{Avaliações nas seleções das $k$-características em grupos formados pela visualização em árvore}

Neste experimento, identificam-se os grupos visualmente marcados pelos ramos da visualização $N J$ das características. Para cada grupo identificado, automaticamente são selecionados o centróide e seus $k$ vizinhos mais próximos, os quais formam o subconjunto de características selecionado.

\section{Experimento 1}

O conjunto de imagens 4 (Supermarket - Produce 600), cujas características foram extraídas usando $G C H$, é visualizado em uma árvore $N J$ usando a distância logarítmica, como é ilustrado na Figura 5.33a. Em seguida, este conjunto de características foi transposto e visualizado em uma árvore $N J$ usando a distância Jaccard revelando alguns grupos formados pelos ramos da árvore, conforme pode ser observado na Figura 5.33b.

Identifica-se na Figura 5.34a o agrupamento definido manualmente de 5 ramos ou grupos triangulados da árvore e em cada ramo ressalta-se 8 pontos, que são o centróide e seus 7-vizinhos mais próximos. Esses pontos ressaltados são os pontos que representam as características selecionadas do conjunto.

A visualização das imagens considerando apenas o subconjunto de características selecionado é avaliado e apresentado na Figura 5.34b, e sob as medidas de silhueta obtidas apresentasse as seguintes discussões:

- Após a seleção realizada, não se verifica melhora no valor da silhueta no espaço original nem no espaço projetado.

- Em relação à seleção dos pontos vizinhos ao centro do ramo, considera-se que não é a melhor escolha. 


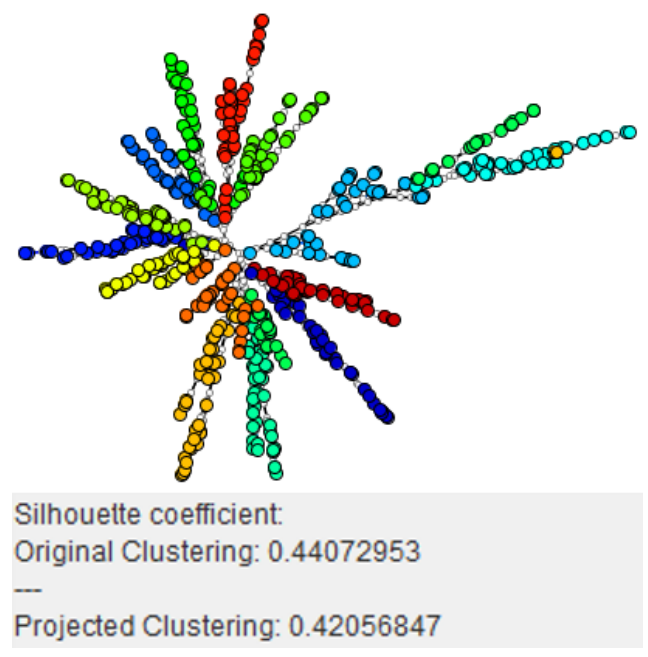

(a)

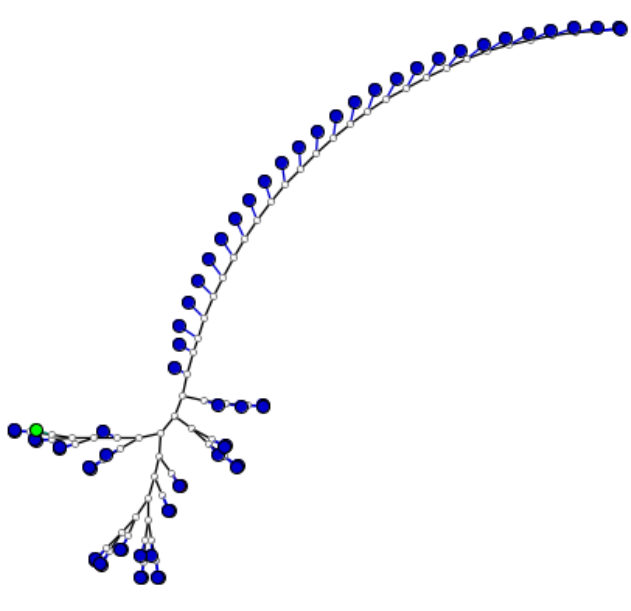

(b)

Figura 5.33: a)Visualização $N J$ do conjunto de imagens 4, caracterizado pelo extrator $G C H$, usando a distância logarítmica. Abaixo, a avaliação com a medida silhueta no espaço original e no espaço projetado. b) Visualização $N J$ das 64 características usando a matriz transposta e a distância Jaccard, onde cada ponto representa uma característica.

- Deduz-se que faltam atributos importantes para a discriminação da similaridade entre as imagens, comparado, por exemplo, com a escolha manual de pontos extremos na árvore, considerada nos experimentos anteriores.

- A árvore resultante após a seleção, não possui melhoria na qualidade visual.

Tabela 5.12: Medidas de silhueta obtidas antes e após a seleção ilustrada na Figura 5.34 usando as 8-características centrais dos ramos realizada para o conjunto 4 (Supermarket-Produce 600), caracterizado pelo extrator $G C H$.

\begin{tabular}{|l|r|r|r|r|}
\hline & $\begin{array}{r}\text { Silhueta } \\
\text { Esp. Orig. }\end{array}$ & $\begin{array}{r}\text { Silhueta } \\
\text { Esp. Proj. }\end{array}$ & $\begin{array}{r}\text { Número de } \\
\text { Características }\end{array}$ & $\begin{array}{r}\text { Porcentagem \% de } \\
\text { Características }\end{array}$ \\
\hline Antes da seleção & 0,4407 & 0,4205 & 64 & $100 \%$ \\
\hline Após a seleção & 0,3500 & 0,3631 & 40 & $62,5 \%$ \\
\hline
\end{tabular}

\section{Experimento 2}

A Figura $5.35 a$ mostra a visualização do conjunto de imagens 1 (Supermarket-Produce 2035) usando a distância logarítmica, cujas características foram extraídas por meio do BIC. A visualização das características do conjunto de imagens é apresentado na Figura 5.35b. Essas 


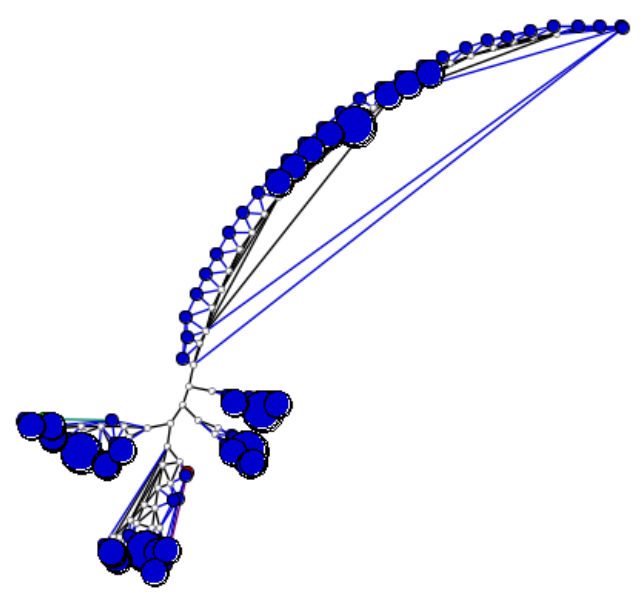

Silhouette coefficient:

Original Clustering: 0.35009238

Projected Clustering: 0.36318898

(a)

(b)

Figura 5.34: a)Visualização do subconjunto de características, identificando 5 grupos definidos pelos ramos triangulados das árvores. Apresenta-se 8 pontos em destaque para cada grupo que são os pontos que pertencem ao grupo de características selecionadas. b) Visualização do conjunto de imagens representados pelas 40 características selecionadas em a).

características são pré-processadas usando a normalização com o algoritmo z-score e agrupado previamente com o algoritmo $K$-médias, com $k=3$. Esse agrupamento prévio é realizado apenas para ressaltar os agrupamentos revelados pela árvore.

Identifica-se, na Figura 5.36a, 5 ramos triangulados e 21 pontos em destaque para cada ramo, que são qualificados com as características relevantes, as quais pertencem ao grupo de características selecionadas. Isto é, para cada ramo, identifica-se o centro e de seus 20 -vizinhos próximos.

A visualização das imagens considerando apenas o subconjunto de características selecionado é apresentado na Figura 5.36b e as medidas de silhueta antes e após a seleção é apresentado na Tabela 5.13, para serem comparadas e discutidas: 


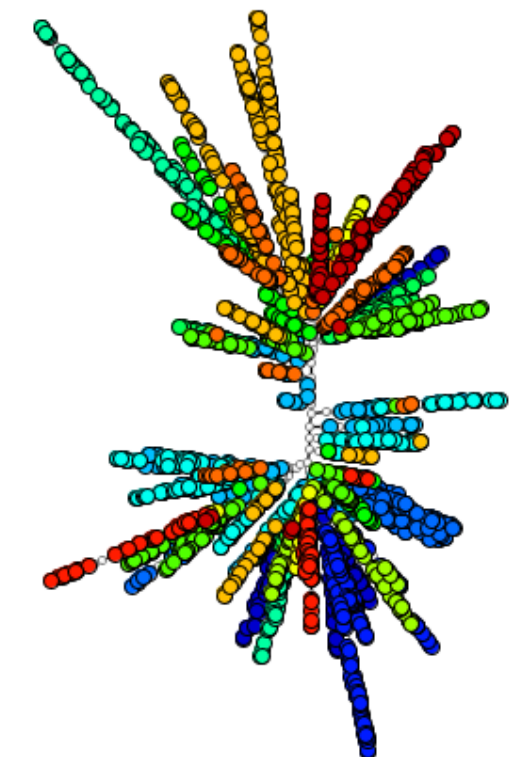

Silhouette coefficient: Original Clustering: 0.077498265

Projected Clustering: 0.01514732

(a)

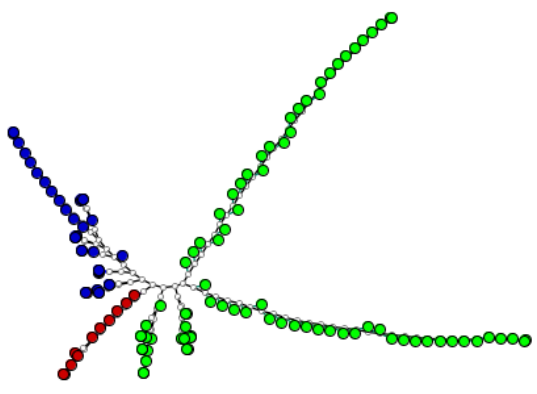

(b)

Figura 5.35: a)Visualização $N J$ do conjunto de imagens 1 , caracterizado pelo extrator $B I C$, usando a distância logarítmica. Abaixo, a avaliação com a medida silhueta no espaço original e no espaço projetado. b) Visualização $N J$ das 128 características usando a matriz transposta e a distância Jaccard, onde cada ponto representa uma característica.

- Os valores da silhueta apresentados não são favoráveis, pois a seleção não supera o valor da silhueta no espaço original, mas mantém seu valor no espaço projetado.

- O subconjunto de características selecionado têm representatividade inferior.

- Acredita-se que este resultado pode ser causado pela identificação de grupos de características relevantes na árvore e a falta de características com poder discriminatório.

- Em relação à avaliação visual, percebe-se que o grau de separação entre os grupos da mesma classe são mais coesos. Apresentando uma qualidade visual satisfatória das imagens.

\section{Experimento 3}

A matriz transposta das características do conjunto de imagens número 6 (COIL 2520), cujas características foram extraídas usando $G C H$ é normalizada usando o algoritmo z-score. A Fi- 

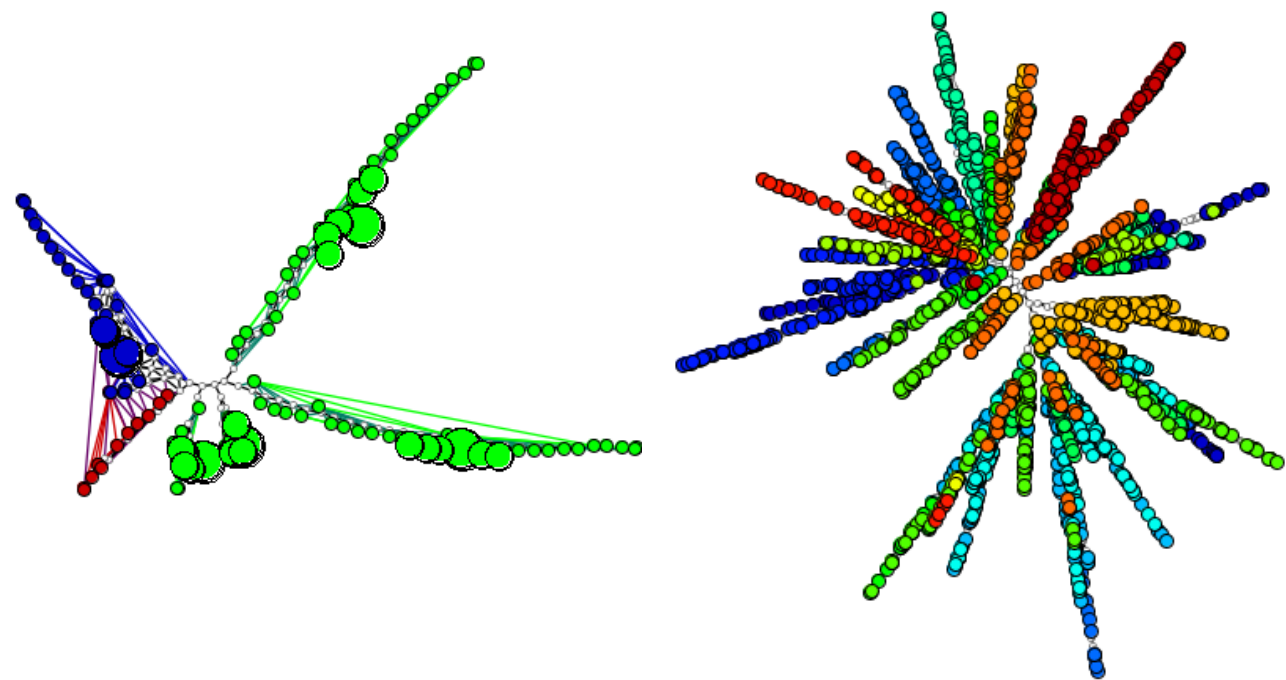

Silhouette coefficient:

Original Clustering: 0.06843188

Projected Clustering: 0.014704237

(a)

(b)

Figura 5.36: a)Visualização do subconjunto de características, agrupadas em 5 grupos que são identificados pelos ramos triangulados das árvores. Apresenta-se 21 pontos em destaque para cada grupo, que são os pontos que pertencem ao grupo de características selecionadas. b) Visualização do conjunto de imagens representados pelas 105 características selecionadas em a).

Tabela 5.13: Medidas de silhueta obtidas antes e após a seleção ilustrada na Figura 5.36 usando as 21-características centrais dos ramos realizada para o conjunto 1 (Supermarket-Produce 2035), caracterizado pelo extrator BIC.

\begin{tabular}{|l|r|r|r|r|}
\hline & $\begin{array}{r}\text { Silhueta } \\
\text { Esp. Orig. }\end{array}$ & $\begin{array}{r}\text { Silhueta } \\
\text { Esp. Proj. }\end{array}$ & $\begin{array}{r}\text { Número de } \\
\text { Características }\end{array}$ & $\begin{array}{r}\text { Porcentagem \% de } \\
\text { Características }\end{array}$ \\
\hline Antes da seleção & 0,0774 & 0,0151 & 128 & $100 \%$ \\
\hline Após a seleção & 0,0684 & 0,0147 & 105 & $82,03 \%$ \\
\hline
\end{tabular}

gura $5.37 \mathrm{~b}$, representa a visualização das características, usando a matriz transposta e a distância Jaccard.

Identificam-se 3 ramos ou grupos, nos quais são detectados 16 pontos para cada ramo, que são o centróide e seus 15-vizinhos próximos (ver Figura 5.38a). Esses pontos unidos formam o conjunto de características selecionado, cujo resultado é visualizado na Figura $5.38 \mathrm{~b}$.

As avaliações são apresentadas na Tabela 5.14. Observa-se que os valores obtidos usando a medida silhueta não mostram melhoria com a seleção. Outras discussões são apresentadas a seguir: 


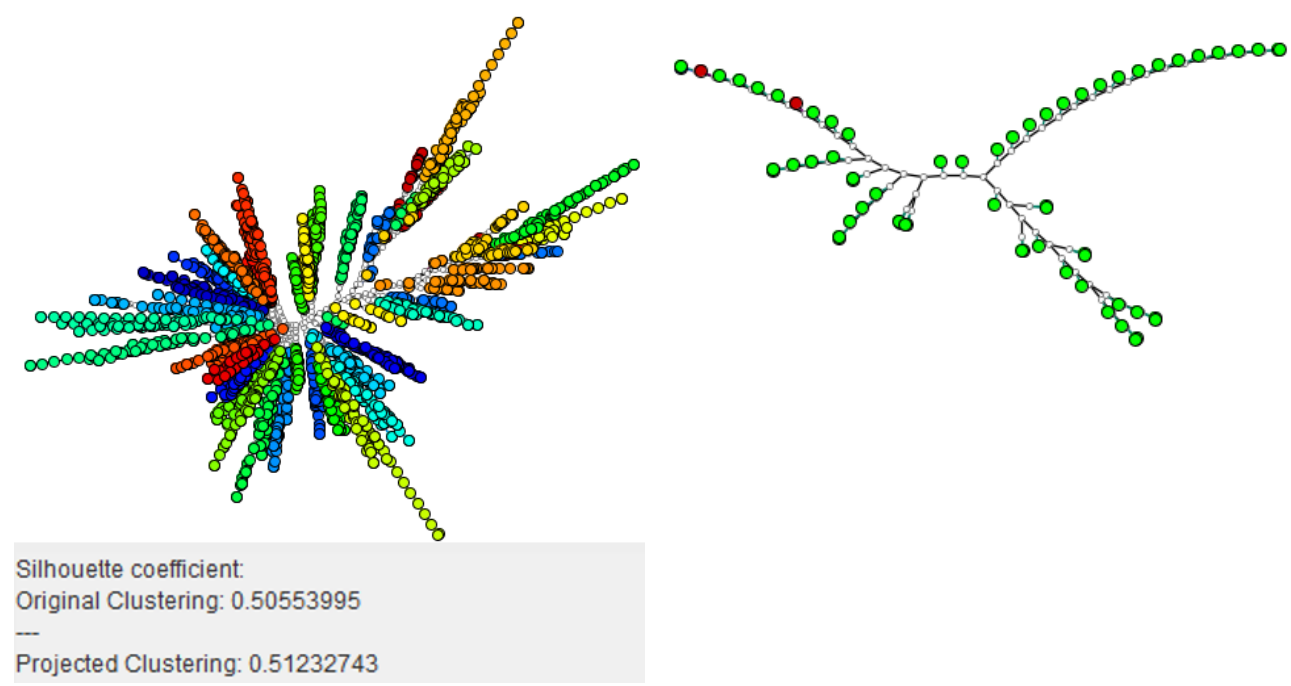

(a)

(b)

Figura 5.37: a)Visualização $N J$ do conjunto de imagens 6 , caracterizado pelo extrator $G C H$, usando a distância logarítmica. Abaixo, a avaliação com a medida silhueta no espaço original e no espaço projetado. b) Visualização $N J$ das 64 características usando a matriz transposta e a distância Jaccard, onde cada ponto representa uma característica. 
- Ao se comparar as medidas de silhueta no espaço projetado obtidas considerando o subconjunto de características selecionado, nota-se que o valor diminui após a seleção.

- Com essa seleção, não se supera a diferença da silhueta entre o espaço original e o espaço projetado.

- Observando a qualidade visual, essa é mantida, com poder discriminatório semelhante nos grupos de imagens.

- Considera-se que o critério de achar pontos centrais dos ramos não é a melhor escolha, embora consigam definir uma redução boa no numero de características de custo mínimo em termos da silhueta.
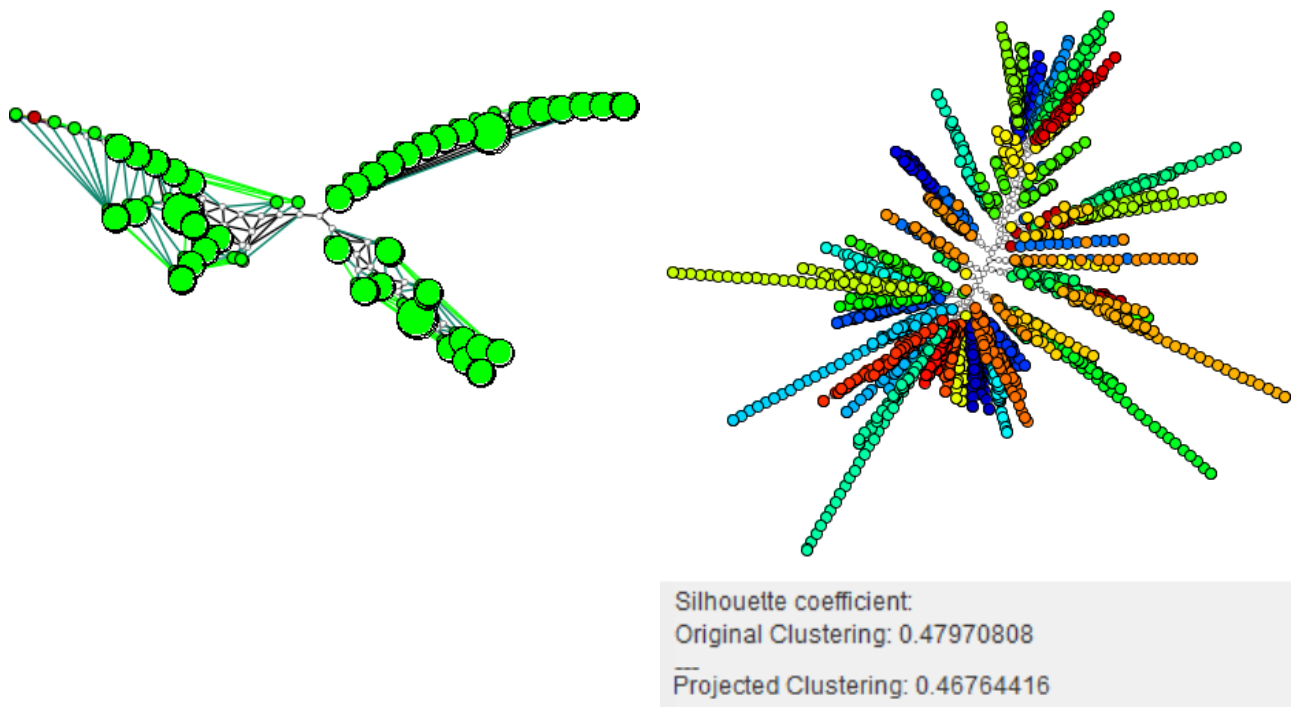

(a)

(b)

Figura 5.38: a)Visualização do subconjunto de características, identificando 3 grupos pelos ramos triangulados das árvores. Apresenta-se 16 pontos em destaque para cada grupo que são os pontos que pertencem ao grupo de características selecionadas. b) Visualização do conjunto de imagens representados pelas 48 características selecionadas em a).

\subsubsection{Avaliação dos espaços de características selecionados atra- vés de algoritmos de classificação}

Este estudo empregou os novos espaços de características gerados pelas seleções de características usando a visualização, num processo de classificação por MLP (Multilayer Perceptron) e 
Tabela 5.14: Medidas de silhueta obtidas antes e após a seleção ilustrada na Figura 5.38 usando as 16-características centrais dos ramos realizada para o conjunto 6 (COIL 2520), caracterizado pelo extrator $\mathrm{GCH}$.

\begin{tabular}{|l|r|r|r|r|}
\hline & $\begin{array}{r}\text { Silhueta } \\
\text { Esp. Orig. }\end{array}$ & $\begin{array}{r}\text { Silhueta } \\
\text { Esp. Proj. }\end{array}$ & $\begin{array}{r}\text { Número de } \\
\text { Características }\end{array}$ & $\begin{array}{r}\text { Porcentagem \% de } \\
\text { Características }\end{array}$ \\
\hline Antes da seleção & 0,5055 & 0,5123 & 64 & $100 \%$ \\
\hline Após a seleção & 0,4797 & 0,4676 & 48 & $75 \%$ \\
\hline
\end{tabular}

Naive-Bayes, usando a ferramenta WEKA e 10-fold cross-validation. As Tabelas 5.15 e 5.16 apresentam os resultados das classificações, mostrando as porcentagens das instâncias corretamente classificadas. Observa-se que os resultados são favoráveis para a maioria das seleções realizadas, garantindo assim que os critérios usados de seleção usando a visualização sendo simples possuem alto poder de influenciar na representatividade adequada de classes de um conjunto de imagens fora do espaço de visualização.

Observando os resultados das tabelas, as diferenças das porcentagens das instâncias corretamente classificadas com MLP e Naive Bayes antes e após das seleções usando a abordagem visual obtêm-se na maioria resultados iguais ou com diferenças depreciáveis e desconsideradas. Apresentam-se dois casos que superam os valores considerando o espaço original de características, isto é, nos casos do conjunto 3 representado usando o extrator $G C H$ e o conjunto 6 com o extrator $B I C$. Esses resultados representam duas idéias claras, uma é que esta avaliação e comparação são realizadas no espaço original com algoritmos de classificação supervisionados, ainda que alguns de eles fossem positivos, outros se mantiveram do espaço original. Outra idéia observada é a falta de um estudo supervisionado para avaliação na classificação dos dados no espaço original tal como é a apresentado pelos autores Paiva et al. (2012).

\subsubsection{Avaliações de outras abordagens de seleção de caracterís- ticas}

Este estudo tem como objetivo avaliar outras abordagens de seleção de características empregando os conjuntos de imagens que foram usados para avaliar os critérios de seleção usando a visualização de características, já mencionados e testados. Com o objetivo de medir a confiabilidade das abordagens propostas, as abordagens são aferidas comparando-se seus resultados com as avaliações das diferentes abordagens de seleção de características. Usam-se o método para redução de dimensionalidade $P C A$, método de filtragem e wrapper. Para as dois últimos, utilizou-se a ferramenta WEKA. 
Tabela 5.15: Resultados das classificações dos dados gerados pelas seleções realizadas usando a visualização $N J$, mostrando as porcentagens das instâncias corretamente classificadas.

\begin{tabular}{|c|c|c|c|}
\hline $\begin{array}{l}\text { Conjunto de } \\
\text { Imagens/ } \\
\text { Extrator de Ca- } \\
\text { racterísticas }\end{array}$ & Técnica de & $\begin{array}{l}\text { Instâncias Cor- } \\
\text { retamente } \\
\text { Classificadas } \\
\text { com } M L P \%\end{array}$ & $\begin{array}{l}\text { Instâncias Cor- } \\
\text { retamente } \\
\text { Classificadas } \\
\text { com Naive } \\
\text { Bayes \% }\end{array}$ \\
\hline $1 B I C$ & Antes da seleção & $87.1629 \%$ & $77.744 \%$ \\
\hline $1 B I C$ & $\begin{array}{l}\text { Seleção } \\
\text { usando as } \\
k \text {-características } \\
\text { centrais dos } \\
\text { ramos }\end{array}$ & $83.1371 \%$ & $74.1360 \%$ \\
\hline $3 C C V$ & Antes da seleção & $97.0833 \%$ & $90.7639 \%$ \\
\hline $3 C C V$ & Seleção manual 1 & $96.9444 \%$ & $90.1389 \%$ \\
\hline $3 C C V$ & Seleção manual 2 & $96.1806 \%$ & $90.3472 \%$ \\
\hline $3 C C V$ & Seleção manual 3 & $94.4444 \%$ & $85.9028 \%$ \\
\hline $3 G C H$ & Antes da seleção & $94.7917 \%$ & $87.8472 \%$ \\
\hline $3 G C H$ & $\begin{array}{l}\text { Seleção manual } \\
\text { usando imagens } \\
\text { representativas }\end{array}$ & $94.8611 \%$ & $94.0873 \%$ \\
\hline $4 \mathrm{GCH}$ & Antes da seleção & $95.3333 \%$ & $96.3333 \%$ \\
\hline $4 G C H$ & $\begin{array}{l}\text { Seleção } \\
\text { usando as } \\
k \text {-características } \\
\text { centrais dos } \\
\text { ramos }\end{array}$ & $92.6667 \%$ & $91.3333 \%$ \\
\hline
\end{tabular}

Dentre os métodos de filtragem mais populares na literatura, usa-se o método Correlation based Feature Selection (CFS) e para o método wrapper utiliza-se o algoritmo de classificação dos $k$-vizinhos mais próximos $(k-\mathrm{NN})$.

Da Tabelas 5.17 até 5.23, são apresentados os resultados das medidas de silhueta feitas sob as visualizações da árvore $N J$ usando a distância logarítmica para todos os conjuntos de imagens com as características das seleções. Apenas para a técnica PCA, usa-se a distância canberra, que apresenta melhor desempenho.

Discutem-se a seguir os resultados dos valores da silhueta.

- Para o conjunto de imagens 1 , observa-se na Tabela 5.17 que a técnica de seleção com melhor desempenho no espaço original, é a técnica $C F S$, com uma melhoria de 0,0127. 
Tabela 5.16: Resultados das classificações dos dados gerados pelas seleções realizadas usando a visualização $N J$, mostrando as porcentagens das instâncias corretamente classificadas.

\begin{tabular}{|c|c|c|c|}
\hline $\begin{array}{l}\text { Conjunto de } \\
\text { Imagens/ } \\
\text { Extrator de Ca- } \\
\text { racterísticas }\end{array}$ & Técnica de & $\begin{array}{l}\text { Instâncias Cor- } \\
\text { retamente } \\
\text { Classificadas } \\
\text { com } M L P \%\end{array}$ & $\begin{array}{l}\text { Instâncias Cor- } \\
\text { retamente } \\
\text { Classificadas } \\
\text { com Naive } \\
\text { Bayes \% }\end{array}$ \\
\hline $6 B I C$ & Antes da seleção & $92.3413 \%$ & $87.2222 \%$ \\
\hline $6 B I C$ & Seleção manual 1 & $87.7381 \%$ & $81.8651 \%$ \\
\hline $6 B I C$ & Seleção manual 2 & $91.8651 \%$ & $87.2222 \%$ \\
\hline $6 B I C$ & Seleção manual 3 & $90.7937 \%$ & $87.2222 \%$ \\
\hline $6 \mathrm{GCH}$ & Antes da seleção & $99.0873 \%$ & $98.5714 \%$ \\
\hline $6 G C H$ & $\begin{array}{l}\text { Seleção } \\
\text { usando as } \\
k \text {-características } \\
\text { centrais dos } \\
\text { ramos }\end{array}$ & $91.8651 \%$ & $94.0873 \%$ \\
\hline $7 C C V$ & Antes da seleção & $99.3889 \%$ & $98.5556 \%$ \\
\hline $7 \mathrm{CCV}$ & $\begin{array}{l}\text { Seleção manual } \\
\text { usando imagens } \\
\text { representativas }\end{array}$ & $99.2222 \%$ & $98.5556 \%$ \\
\hline $8 C C V$ & Antes da seleção & $100 \%$ & $100 \%$ \\
\hline $8 C C V$ & Seleção manual 1 & $100 \%$ & $100 \%$ \\
\hline $8 C C V$ & Seleção manual 2 & $100 \%$ & $100 \%$ \\
\hline $8 C C V$ & Seleção manual 3 & $100 \%$ & $100 \%$ \\
\hline $11 B I C$ & Antes da seleção & $95.8333 \%$ & $90 \%$ \\
\hline $11 B I C$ & $\begin{array}{l}\text { Seleção manual } \\
\text { usando imagens } \\
\text { representativas }\end{array}$ & $92.500 \%$ & $90.8333 \%$ \\
\hline
\end{tabular}

No espaço projetado a melhor técnica é a PCA com o melhor desempenho de 0,0118 . A técnica com pior desempenho é da seleção wrapper usando o classificador $k$-NN.

- Para o conjunto de imagens 3, observa-se na Tabela 5.18 .

A técnica de seleção com melhor desempenho usando o extrator $C C V$ no espaço original é a técnica da seleção wrapper usando o classificador $k$-NN, melhorando 0,1284 . E no espaço projetado, a melhor técnica é a seleção manual do experimento 2 , que melhora com 0,0559 . 
Com o $G C H$, a seleção manual usando imagens representativas tem melhor desempenho comparado com as outras técnicas de seleção. Com respeito ao espaço antes da seleção, ela melhora o valor da silhueta no espaço original em 0,1929 , e no espaço projetado em 0,0022. O pior desempenho é a atribuída à técnica PCA em ambos casos.

Deduz-se que, usando o extrator $G C H$ e a seleção manual de imagens representativas, melhora-se o espaço projetado do conjunto de imagens 3. Usando o extrator $C C V$ e a técnica de seleção wrapper com o classificador $k$-NN, supera os valores do espaço original do conjunto de imagens analisado.

- Para o conjunto de imagens 4, observa-se na Tabela 5.19 que nenhuma técnica supera os valores da silhueta comparado com o espaço antes da seleção. Mas comparando entre os valores de silhueta após da seleção, a técnica $C F S$ apresenta uma vantagem no espaço original e no espaço projetado. A técnica PCA tem os valores da silhueta mais baixos da tabela.

- Para o conjunto de imagens 6, observa-se na Tabela 5.20 que usando o extrator BIC, nenhuma técnica supera os valores da silhueta comparado com o espaço antes da seleção. Mas comparando-se entre eles, a técnica $C F S$ apresenta vantagem no espaço original e no espaço projetado quando é comparada com as outras técnicas. A técnica de seleção wrapper usando o classificador $k$-NN apresenta o pior desempenho. Usando o extrator $G C H$, a técnica $C F S$ obtém valores altos no espaço projetado, comparando-se com as outras técnicas, e no espaço original usando a seleção das 48 características centrais dos ramos; e o pior desempenho é atribuído à técnica $P C A$.

- Para o conjunto de imagens 7, observa-se na Tabela 5.21 que a técnica de seleção manual usando imagens representativas, melhora o valor silhueta o espaço original e o espaço projetado. Considera-se que 74 características são suficientes para representar esse conjunto de imagens. A técnica PCA mostra o pior desempenho com 100 características.

- Para o conjunto de imagens 8, observa-se na Tabela 5.22 que o uso da seleção manual supera as outras técnicas de seleção conhecidas. A seleção manual do experimento 3 supera em 0,0293 no espaço original e 0,0509 no espaço projetado. Com pior desempenho tem-se novamente a técnica $P C A$, demonstrando que o número de dimensões não é correto para o conjunto de imagens.

- Para o conjunto de imagens 11, observa-se na Tabela 5.23 que no espaço original após a seleção, a técnica $C F S$ apresenta melhor desempenho com uma diferença de 0,0434, e no espaço projetado, a seleção manual usando as imagens representativas melhora em 0,028. 
Os mais baixos desempenhos são atribuídos às técnicas $P C A$ e a seleção wrapper com o classificador $k$-NN.

- Olhando apenas os valores da silhueta obtidos no espaço projetado, na maioria dos casos apresentados a seleção de características pela abordagem visual, supera as técnicas de seleção automáticas mais conhecidas na literatura.

Tabela 5.17: Medidas de silhueta obtidas antes e após as seleções de características realizadas sob o conjunto de imagens 1 (Supermarket-Produce 2035), caracterizado pelo extrator $B I C$.

\begin{tabular}{|l|c|r|r|}
\hline $\begin{array}{l}\text { Técnica de } \\
\text { Redução }\end{array}$ & $\begin{array}{l}\text { Número de } \\
\text { Dimensionalidade }\end{array}$ & $\begin{array}{l}\text { Silhueta } \\
\text { Esp. Orig. }\end{array}$ & $\begin{array}{l}\text { Silhueta } \\
\text { Esp. Proj. }\end{array}$ \\
\hline Antes da seleção & 128 & 0,0774 & 0,0151 \\
\hline $\begin{array}{l}\text { Seleção usando as } \\
k \text {-características cen- } \\
\text { trais dos ramos }\end{array}$ & 105 & 0,0684 & 0,0147 \\
\hline PCA & 100 & 0,0434 & $\mathbf{0 , 0 2 6 9}$ \\
\hline CFS & 27 & $\mathbf{0 , 0 9 0 1}$ & 0,0120 \\
\hline Wrapper- $k-N N$ & 7 & 0,0030 & - \\
\hline
\end{tabular}

Tabela 5.18: Medidas de silhueta obtidas das seleções de características realizadas para o conjunto número 3 (Supermarket - Produce 1440).

\begin{tabular}{|l|l|c|r|r|}
\hline $\begin{array}{l}\text { Extrator } \\
\text { de Característi- } \\
\text { cas }\end{array}$ & $\begin{array}{l}\text { Técnica de } \\
\text { Redução }\end{array}$ & $\begin{array}{l}\text { Número de } \\
\text { Dimensionalidade }\end{array}$ & $\begin{array}{l}\text { Silhueta } \\
\text { Esp. Orig. }\end{array}$ & \multicolumn{1}{l|}{ Esp. Proj. } \\
\hline$C C V$ & Antes da seleção & 128 & 0,1770 & 0,0849 \\
\hline$C C V$ & Seleção manual 1 & 81 & 0,1789 & 0,1267 \\
\hline$C C V$ & Seleção manual 2 & 93 & 0,1838 & $\mathbf{0 , 1 4 0 8}$ \\
\hline$C C V$ & Seleção manual 3 & 84 & 0,1834 & 0,1239 \\
\hline$C C V$ & $P C A$ & 100 & 0,0430 & 0,0223 \\
\hline$C C V$ & $C F S$ & 26 & 0,1911 & 0,0988 \\
\hline$C C V$ & Wrapper- $k$-NN & 4 & $\mathbf{0 , 3 0 5 4}$ & 0,1318 \\
\hline$G C H$ & Antes da seleção & 64 & 0,0195 & 0,1491 \\
\hline$G C H$ & Seleção manual & & & \\
& usando imagens & 53 & $\mathbf{0 , 2 1 2 4}$ & $\mathbf{0 , 1 5 1 3}$ \\
\hline$G C H$ & representativas & & & 0,0741 \\
\hline$G C H$ & $P C A$ & 50 & 0,1988 & 0,1261 \\
\hline$G C H$ & $C F S$ & 17 & 0,1263 & 0,0756 \\
\hline
\end{tabular}


Tabela 5.19: Medidas de silhueta obtidas antes e após a seleções de características realizadas para o conjunto número 4 (Supermarket-Produce 600), caracterizado pelo extrator GCH.

\begin{tabular}{|l|c|r|r|}
\hline $\begin{array}{l}\text { Técnica de } \\
\text { Redução }\end{array}$ & $\begin{array}{l}\text { Número de } \\
\text { Dimensionalidade }\end{array}$ & $\begin{array}{l}\text { Silhueta } \\
\text { Esp. Orig. }\end{array}$ & $\begin{array}{l}\text { Silhueta } \\
\text { Esp. Proj. }\end{array}$ \\
\hline Antes da seleção & 64 & 0,4407 & 0,4205 \\
\hline $\begin{array}{l}\text { Seleção usando as } \\
k \text {-características cen- } \\
\text { trais dos ramos }\end{array}$ & 40 & 0,3500 & 0,3631 \\
\hline$P C A$ & 50 & 0,1153 & 0,0800 \\
\hline CFS & 20 & $\mathbf{0 , 4 3 0 0}$ & $\mathbf{0 , 3 9 9 4}$ \\
\hline Wrapper- $k$-NN & 4 & 0,2954 & 0,2165 \\
\hline
\end{tabular}

Tabela 5.20: Medidas de silhueta obtidas das seleções de características realizadas para o conjunto número 6 (COIL 2520).

\begin{tabular}{|c|c|c|c|c|}
\hline $\begin{array}{l}\text { Extrator } \\
\text { de Característi- } \\
\text { cas }\end{array}$ & $\begin{array}{l}\text { Técnica de } \\
\text { Redução }\end{array}$ & $\begin{array}{l}\text { Número de } \\
\text { Dimensionalidade }\end{array}$ & $\begin{array}{l}\text { Silhueta } \\
\text { Esp. Orig. }\end{array}$ & $\begin{array}{l}\text { Silhueta } \\
\text { Esp. Proj. }\end{array}$ \\
\hline$B I C$ & Antes da seleção & 128 & 0,2968 & 0,3109 \\
\hline$B I C$ & Seleção manual 1 & 96 & 0,2735 & 0,2191 \\
\hline$B I C$ & Seleção manual 2 & 91 & 0,2968 & 0,3109 \\
\hline$B I C$ & Seleção manual 3 & 106 & 0,2968 & 0,3109 \\
\hline$B I C$ & $P C A$ & 100 & 0,1337 & 0,1483 \\
\hline$B I C$ & CFS & 32 & 0,3098 & 0,3126 \\
\hline$B I C$ & Wrapper- $k$-NN & 5 & 0,0810 & - \\
\hline$G C H$ & Antes da seleção & 64 & 0,5055 & 0,5123 \\
\hline$G C H$ & $\begin{array}{l}\text { Seleção usando as } \\
k \text {-características } \\
\text { centrais dos ramos }\end{array}$ & 48 & $\mathbf{0 , 4 7 9 7}$ & 0,4676 \\
\hline$G C H$ & $P C A$ & 50 & 0,2076 & 0,2219 \\
\hline$\overline{G C H}$ & CFS & 15 & 0,4729 & 0,4809 \\
\hline$G C H$ & Wrapper- $k$-NN & 6 & 0,3666 & 0,3422 \\
\hline
\end{tabular}

\subsubsection{Retroalimentação}

Realiza-se um processo de retroalimentação, onde observando os resultados obtidos (nas avaliações anteriores) após do uso dos algoritmos de seleção do espaço de características, com maior valor silhueta, pode modificar-se os parâmetros nos algoritmos de extração de características. Por exemplo, sabendo quais características foram selecionadas e considerando que uma característica representa uma cor (usando os histogramas $G C H, B I C, G C H$ para cada imagem 
Tabela 5.21: Medidas de silhueta obtidas antes e após a seleções de características realizadas para o conjunto número 7 (COIL 1800), caracterizado pelo extrator $C C V$.

\begin{tabular}{|l|c|r|r|}
\hline $\begin{array}{l}\text { Técnica de } \\
\text { Redução }\end{array}$ & $\begin{array}{l}\text { Número de } \\
\text { Dimensionalidade }\end{array}$ & $\begin{array}{l}\text { Silhueta } \\
\text { Esp. Orig. }\end{array}$ & $\begin{array}{l}\text { Silhueta } \\
\text { Esp. Proj. }\end{array}$ \\
\hline Antes da seleção & 128 & 0,4330 & 0,4253 \\
\hline $\begin{array}{l}\text { Seleção manual } \\
\text { usando imagens } \\
\text { representativas }\end{array}$ & 74 & $\mathbf{0 , 4 3 3 1}$ & $\mathbf{0 , 4 2 5 6}$ \\
\hline$P C A$ & 100 & 0,1654 & 0,1726 \\
\hline$C F S$ & 26 & 0,3911 & 0,3669 \\
\hline Wrapper- $k$-NN & 6 & 0,2311 & 0,0953 \\
\hline
\end{tabular}

Tabela 5.22: Medidas de silhueta obtidas das seleções de características realizadas para o conjunto número 8 (coil 720 ), caracterizado pelo extrator $C C V$.

\begin{tabular}{|l|c|r|r|}
\hline $\begin{array}{l}\text { Técnica de } \\
\text { Redução }\end{array}$ & $\begin{array}{l}\text { Número de } \\
\text { Dimensionalidade }\end{array}$ & $\begin{array}{l}\text { Silhueta } \\
\text { Esp. Orig. }\end{array}$ & $\begin{array}{l}\text { Silhueta } \\
\text { Esp. Proj. }\end{array}$ \\
\hline Antes da seleção & 128 & 0,5623 & 0,5594 \\
\hline Seleção manual 1 & 76 & 0,5825 & 0,5852 \\
\hline Seleção manual 2 & 62 & 0,5685 & 0,5710 \\
\hline Seleção manual 3 & 45 & $\mathbf{0 , 5 9 1 6}$ & $\mathbf{0 , 6 1 0 3}$ \\
\hline$P C A$ & 100 & 0,0744 & 0,0494 \\
\hline$C F S$ & 27 & 0,5427 & 0,5543 \\
\hline Wrapper- $k$-NN & 4 & 0,3054 & 0,1318 \\
\hline
\end{tabular}

Tabela 5.23: Medidas de silhueta obtidas antes e após a seleção de características realizada para o conjunto 11 (Flores 120), caracterizado pelo extrator BIC.

\begin{tabular}{|l|c|r|r|}
\hline $\begin{array}{l}\text { Técnica de } \\
\text { Redução }\end{array}$ & $\begin{array}{l}\text { Numero de } \\
\text { Dimensionalidade }\end{array}$ & $\begin{array}{l}\text { Silhueta } \\
\text { Esp. Orig. }\end{array}$ & $\begin{array}{l}\text { Silhueta } \\
\text { Esp. Proj. }\end{array}$ \\
\hline Antes da seleção & 128 & 0,3463 & 0,3119 \\
\hline $\begin{array}{l}\text { Seleção manual } \\
\text { usando imagens } \\
\text { representativas }\end{array}$ & 43 & 0,3441 & $\mathbf{0 , 3 3 9 9}$ \\
\hline$P C A$ & 50 & 0,1148 & 0,1190 \\
\hline CFS & 32 & $\mathbf{0 , 3 8 9 7}$ & 0,3167 \\
\hline Wrapper- $k$-NN & 2 & - & 0,1191 \\
\hline
\end{tabular}

quantizada a 64 cores) pode-se considerar na execução do algoritmo de extração apenas alguns números de cores. 
Observando os resultados da Tabela 5.17, que apresenta as medidas de silhueta obtidas antes e após as seleções de características realizadas sob o conjunto de imagens 1 (Supermarket-Produce 2035), caracterizado pelo extrator $B I C$, destaca-se o desempenho do extrator $C F S$ que seleciona 27 características, as quais foram identificadas características que formam o histograma a partir da cor 15 usando o BIC. Assim, revisando o algoritmo do BIC, Seção 2.2.2, considera-se, para este conjunto de imagens, as características borda/interior a partir da cor 15 até a cor 64 (em total de 50 características para a borda e 50 para o interior) e com isso obtém-se resultados favoráveis (ver Tabela 5.24) para outro conjunto de imagens 3(Supermarket-Produce 1400), apresentando melhoria no valor silhueta.

Tabela 5.24: Medidas de silhueta obtidas antes e após a seleção das 100 características usando o conjunto 3 (Supermarket-Produce 1440), caracterizado pelo extrator BIC. Com as características selecionadas considerando a posição no histograma a partir da cor maior a 15 , tanto para o histograma da borda como para o histograma do interior, segundo os resultados da Tabela 5.17 para o conjunto de imagens 1 (Supermarket-Produce 2035).

\begin{tabular}{|l|r|r|r|}
\hline & $\begin{array}{r}\text { Silhueta } \\
\text { Esp. Orig. }\end{array}$ & $\begin{array}{r}\text { Silhueta } \\
\text { Esp. Proj. }\end{array}$ & $\begin{array}{r}\text { Número de } \\
\text { Características }\end{array}$ \\
\hline Antes da seleção & 0,1117 & 0,0493 & 128 \\
\hline Após a seleção & 0,1182 & 0,0608 & 100 \\
\hline
\end{tabular}

Outros resultados a serem observados são os da Tabela 5.20, que apresenta as medidas de silhueta obtidas para o conjunto de imagens 6 (COIL 2520), caracterizado pelo extrator BIC. Destaca-se o desempenho do extrator $C F S$ que seleciona 32 características, selecionando as características a partir da cor 4. Então, considera-se, para o conjunto de imagens 6 (COIL 1800), as características borda/interior a partir da cor 4 até a cor 64 (em total de 60 características para a borda e 60 para o interior) e com isso obtém-se resultados favoráveis, apresentando resultados maiores que o original (ver Tabela 5.25).

Tabela 5.25: Medidas de silhueta obtidas antes e após a seleção das 100 características usando o conjunto 6 (COIL 1800), caracterizado pelo extrator BIC. Com as características selecionadas considerando a posição no histograma a partir da cor maior a 4 , tanto para o histograma da borda como para o histograma do interior, segundo os resultados da Tabela 5.20 para o conjunto de imagens 6 (COIL 2520).

\begin{tabular}{|l|r|r|r|}
\hline & $\begin{array}{r}\text { Silhueta } \\
\text { Esp. Orig. }\end{array}$ & $\begin{array}{r}\text { Silhueta } \\
\text { Esp. Proj. }\end{array}$ & $\begin{array}{r}\text { Número de } \\
\text { Características }\end{array}$ \\
\hline Antes da seleção & 0,3397 & 0,3427 & 128 \\
\hline Após a seleção & 0,3398 & 0,3429 & 120 \\
\hline
\end{tabular}


Estes experimentos foram realizados para encaminhar o estudo na pesquisa do processo de visualização para encontrar e avaliar espaços de características usando algoritmos de extração e estratégias de seleção de características pela abordagem visual.

\subsection{Considerações Finais}

A metodologia foi definida de forma a maximizar o proveito da visualização em árvore para avaliar espaços de características e para realizar seleção visual de características, levando-se em conta também limitações na hora de encontrar as características que melhor representem um conjunto de imagens. As seguintes etapas foram definidas para construir a parte experimental deste trabalho:

- Comparação de desempenho dos três extratores de características baseadas em cor.

- Avaliação da qualidade das medidas de distância na visualização usando diferentes espaços de características.

- Confirmação da influência da representação visual das características em um plano, onde percebe-se a coesão e separação entre elas, e onde o usuário pode interagir e selecionar as características que consideram-se importantes.

- Definição e validação da escolha das características baseado nas suas posições em uma árvore $N J$.

- Seleção do melhor subconjunto de características para diferentes conjuntos de imagens usando três métodos: seleção manual de características considerando o conjunto completo de imagens, seleção manual de características obtidas pela seleção de um subconjunto de imagens representativas e as seleções das $k$-características em grupos formados pela visualização em árvore $N J$.

- Avaliação da boa qualidade dos subconjuntos de características escolhidos por meio de valores de silhueta e algoritmos de classificação, fora do espaço de visualização.

- Comparação do bom desempenho das seleções dos subconjuntos de características com outras técnicas de seleção conhecidas, os quais superam na avaliação realizada com a medida silhueta no espaço de visualização.

Depois de ter realizados tais experimentos, continua-se no próximo capitulo com as conclusões finais do trabalho. 



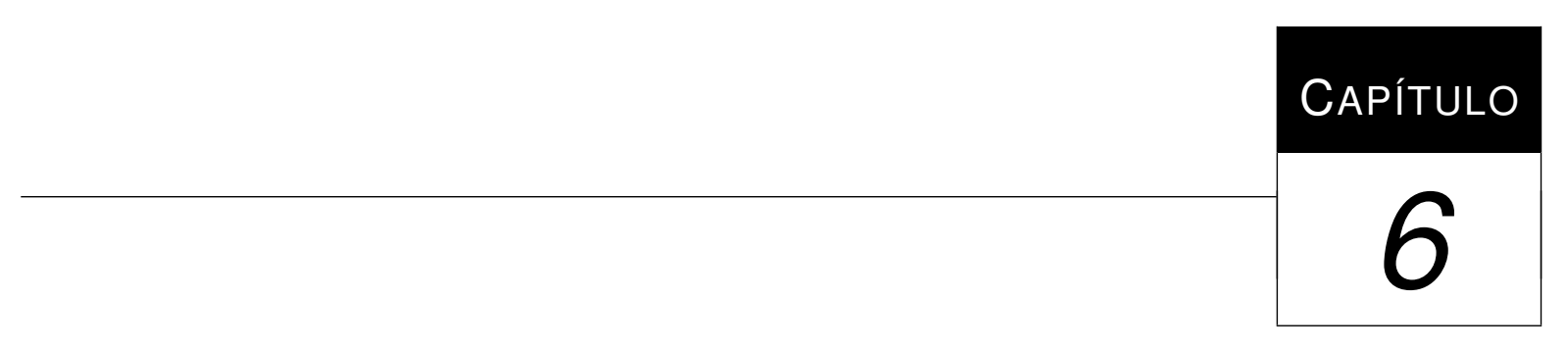

\section{Conclusões}

\subsection{Considerações Finais}

Um aspecto importante da visualização de conjuntos de imagens é a análise realizada sobre a representação visual, usada a fim de revelar informações úteis para os usuários, como o relacionamento entre imagens, a extração de padrões não explícitos encontrados no conjunto de imagens ou simplesmente determinar se a representação baseada em características apropriada para o conjunto de imagens.

Neste contexto, o principal objetivo deste trabalho foi desenvolver estratégias que permitam utilizar a visualização como suporte para avaliar espaços de características gerados por diferentes coleções de imagens. Neste processo, a interação como o usuário em uma plataforma de visualização fornece meios para facilitar a investigação e descoberta de informações que levem a melhorar o processo tal como o da seleção de características.

A partir de uma metodologia proposta, abordagens relacionadas ao serviço de seleção de características foram desenvolvidas. Estendendo o trabalho de Botelho e Batista Neto (2010), foram criadas, adaptadas e integradas ferramentas que apóiem a seleção de características baseada na visualização das características, usando o algoritmo NJ. Como resultado, obtém-se um processo de seleção personalizado mais preciso e eficaz do que as abordagens tradicionais reportadas na literatura, e conforme apresentado nas avaliações descritas no Capitulo 5 . Além disso, a observação imediata do efeito das seleçoes é uma vantagem da abordagem visual. 
A maior parte dos experimentos relacionados à seleção de características usando a visualização $N J$ das características e das variações propostas respondem positivamente para diferentes conjuntos de imagens representados por vários extratores.

\subsection{Principais Contribuições}

A principal contribuição deste trabalho é a metodologia para avaliar e encontrar o melhor espaço de características, com forte participação do usuário. A metodologia utiliza informação proveniente da interação entre o usuário e o conteúdo visual para fornecer o suporte necessário para determinar se o espaço de características representa bem ou não um conjunto de imagens e para melhorar esse espaço. Essa metodologia apresenta as seguintes características e vantagens, que não são exploradas pelos trabalhos relacionados:

- A metodologia obteve ótimos resultados mostrando-se eficaz na visualização em árvore $N J$, como apoio para escolher os critérios na seleção manual de características. A árvore $N J$ demonstrou pela sua precisão em agrupar adequadamente as características, ser uma boa técnica visual para a tarefa de identificação de características importantes refletidas nos agrupamentos. Escolher pontos extremos isolados dos ramos da árvore é uma boa opção para escolha, pois são pontos menos relacionados, que os outros; isto é, com menor hierarquia. Este ponto de visão, não foi considerado no trabalho de Botelho e Batista Neto (2010).

- Outra variação proposta neste trabalho é o uso de imagens representativas, que superam outras estratégias conhecidas para a seleção de características. Usar só as características das imagens representativas possibilita identificar com maior precisão as diferentes relações entre elas.

- Entre os benefícios diretos derivados deste trabalho encontra-se a contribuição de identificar agrupamentos na árvore, definidos pelos ramos que possuem muitos elementos de uma classe única, e sobre eles encontrar as $k$-características centrais dos ramos. A obtenção do número de grupos formados do conjunto de características é outra questão que não foi tratada no trabalho de Botelho e Batista Neto (2010). Ainda que os resultados com a seleção não contribuam a melhorar o espaço de características, considera-se observando os resultados que este método supera os valores de silhueta quando é comparado com outras técnicas de seleção de características. A seleção pela abordagem na grande maioria das vezes não piora o espaço original, o que justifica a seleção. 
- Outra contribuição deste trabalho é a adaptação do gráfico precisão/revocação como medida de avaliação para visualização em árvore $N J$, o que requer a identificação de grupos visíveis determinados pelos ramos da árvore, e sob eles determinar as medidas de precisão/revocação para criar o gráfico.

- A metodologia apresenta redução de esforços para a determinação de melhores espaços de características, pois parte dessa atividade é delegada aos usuários, que contribuem com a identificação de informação importante para cumprir o objetivo. Observa-se um processo de seleção de características de imagens contribuindo na melhoria da produtividade e redução de custos, em um tempo menor e com menos cálculo.

- Cabe ressaltar que os métodos propostos neste trabalho obtiveram os melhores resultados quando comparados com outras técnicas encontrados na literatura, e.g. técnicas de redução de dimensionalidade e técnicas de seleção de características usando filtragem e funções wrapper.

- Este trabalho apresentou contribuições na área de visualização de imagens e mineração de imagens, bem como para aplicações que analisam coleções de imagens. Os resultados mostrados indicam que a metodologia proposta é capaz de reduzir problemas conhecidos nessas áreas, em particular, os problemas de seleção de características com interação do usuário criando um procedimento melhorado.

- Este trabalho introduz ferramentas interativas e novas funcionalidades para a ferramenta Vispipeline a fim de ajudar ao usuário a encontrar o melhor espaço de características para um conjunto de imagens.

\subsection{Limitações}

Processos visuais de seleção são tipicamente imprecisos, embora forneça ao usuário a flexibilidade de escolha na observação imediata do resultado desta escolha, gera uma variedade de possibilidade, nem todas com garantias de melhoria.

Para melhorar as limitações da abordagem, os critérios de seleção manual de características poderiam ser memorizados e gerenciados por um algoritmo de aprendizado, que para casos similares apresentados recomende as características selecionadas, anteriormente com sucesso.

Além disso, na escolha de imagens representativas, é importante a detecção automática de grupos de imagens pertencentes a ramos da árvore bem definidos, onde a classe prioritária seja única. 
Apesar do problema da influência do usuário, outra limitação existente é que o processo de seleção considerando as $k$-características centrais aos grupos ou ramos da árvore $N J$, que não supera os valores de silhueta quando são comparados com o conjunto de características antes a seleção. Apesar desta abordagem superar outras, como foi observado na Seção 5.5.4, uma solução a sua limitação poderia ser adicionar um processo de agregação de rankings; isto é, a identificação dentro de cada ramo quais características apresentam maior influência.

Com respeito ao processo de retroalimentação que é realizado manualmente neste trabalho, identifica-se que é difícil prover uma técnica automática que realize este processo. Uma vez que as características são identificadas e selecionadas, e o novo conjunto de características é avaliado, saber quais parâmetros mudar no algoritmo de extração é dependente da observação e decisão direita do usuário.

Por fim, ao transpor a matriz com as características das imagens, usa-se uma medida de distância diferente à que é utilizada sem a transposição por se tratar de entidades diferentes; o problema observado é a escolha da medida de distância a usar, considerando a influência para a apresentação das características na tela de visualização, e consequentemente para a seleção das características. Não há muitos estudos sobre funções de similaridade entre características.

\subsection{Trabalhos Futuros}

Os trabalhos realizados ao longo deste projeto de mestrado possibilitam o desenvolvimento de extensões dos métodos propostos. Apresentam-se algumas sugestões de trabalhos futuros a seguir:

- Devem ser conduzidas novas avaliações automáticas sobre os conjuntos de características obtidos antes e após a seleção.

- Novas formas de amostragem dos grupos representados pelos ramos devem ser testados. Introduzir o conceito de relevância e ranking, como nos trabalhos de Auffarth et al. (2010); Avalhais et al. (2012); Huang et al. (1998); Luo (2004); Yu e Liu (2004). O conceito poderia ser abordado em cada grupo ou ramo da árvore, identificando os pontos com maior relevância, baseados em técnicas que envolvam funções de avaliação de ranking e relevância.

- Pretende-se investigar o contraste obtido entre os valores de silhueta no espaço projetado como os gráficos Neighborhood Hit, Neighborhood Preservation e o gráfico Precisão/Revocação. Os diversos experimentos realizados não permitiram que se estabelecesse 
uma relação entre estas medidas. Acredita-se que tal resultado seja causado por alguma configuração dos grupos identificados na árvore em que a medida silhueta se baseia.

- Avaliações da interface de interação devem ser relacionadas com usuários reais e em vários domínios de aplicação.

- A metodologia deve ser estendida para ser aplicada em diversas áreas que lidam com a pesquisa e a exploração de grandes conjuntos de dados, e.g., vídeo, modelo em 3D, textos, séries temporais e grafos, dentre outros. 



\section{Referências Bibliográficas}

Alencar, A. B.; Paulovich, F. V.; Minghim, R.; Filho, M. G. D. A.; Oliveira, M. C. F. D. Similarity-based visualization of time series collections: An application to analysis of streamflows. In: Proceedings of the 2008 12th International Conference Information Visualisation, Washington, DC, USA: IEEE Computer Society, 2008, p. 280-286. 59

Ankerst, M.; Ester, M.; KRIEgel, H.-P. Towards an effective cooperation of the user and the computer for classification. Proceedings of the sixth ACM SIGKDD international conference on Knowledge discovery and data mining - KDD ’00, p. 179-188, 2000. 19

Arevalillo-Herráez, M.; Domingo, J.; Ferri, F. J. Combining similarity measures in content-based image retrieval. Pattern Recognition Letters, v. 29, n. 16, p. 2174-2181, 2008. 73

Artero, O.; Oliveira, M.; Levkowitz, H. Enhanced High Dimensional Data Visualization through Dimension Reduction and Attribute Arrangement. Tenth International Conference on Information Visualisation (IV'06), p. 707-712, 2006. 15

Auffarth, B.; López, M.; Cerquides, J. Comparison of redundancy and relevance measures for feature selection in tissue classification of CT images. Advances in Data Mining. Applications, p. 248-262, 2010. 15, 61, 126

Avalhais, L. P. S.; Silva, S. F.; Rodrigues, J. J. F.; TrainA, A. J. M. Image retrieval employing genetic dissimilarity weighting and feature space transformation functions. In: Proceedings of the 27th Annual ACM Symposium on Applied Computing, New York, NY, USA: ACM, 2012, p. 1012-1017. 15, 20, 61, 126

BAeZA-YATES, R.; RibeiRo-Neto, B. Modern information retrieval. 2nd ed. USA: Addison-Wesley Publishing Company, 2008. 74

BALQIS, D. P. Metode fuzzy color histogram untuk temu kembali citra bunga. Tese de Doutoramento, University of Pertanian Bogor, Bogor - Indonesia, 2006. 71

BerChtold, S.; BöHM, C.; KRIEGAL, H.-P. The pyramid-technique: towards breaking the curse of dimensionality. SIGMOD Rec., v. 27, n. 2, p. 142-153, 1998. 15 
Berg, M.; Kreveld, M.; OVermars, M.; SchwarzKopf, O. Computational geometry: Algorithms and applications. Second ed. Springer-Verlag, 367 p., 2000. 59

Botelho, G. M.; Batista Neto, J. E. S. Seleção de características apoiada por mineração visual de dados Seleção de características apoiada por mineração visual de dados. In: Workshop de Visão Computacional, 2010, Presidente Prudente., Presidente Prudente, Brasil, 2010. 1, 2, 39, 40, 52, 55, 67, 123, 124

Brandoli, B.; Eler, D.; Paulovich, F.; Minghim, R.; Batista, J. Visual data exploration to feature space definition. In: 2010 23rd SIBGRAPI Conference on Graphics, Patterns and Images, 2011, p. 32 -39. 1, 46, 47, 65

Bremm, S.; LAndesberger, T.; Bernard, J.; Schreck, T. Assisted Descriptor Selection Based on Visual Comparative Data Analysis. Computer Graphics Forum, v. 30, n. 3, p. 891-900, 2011. 61

Burghouts, G. J.; Geusebroek, J.-M. Performance evaluation of local colour invariants. Computer Vision and Image Understanding, v. 113, n. 1, p. 48-62, 2009. 6

Camargo, J.; Jorge, F.; Torres, R. Visualization of Large Collection of Medical Images. VI Congreso Colombiano de Computación, 2009. 34

Chen, C.; Gagaudakis, G. Similarity-based image browsing. Proceedings of the 16th IFIP World Computer, 2000. 7, 34, 35

Chengzhi, Q.; Chenghu, Z. Taxonomy of Visualization Techniques ans Systems - Concerns between Users and Developers are Different. Asia GIS Conference, p. 1-14, 2003. 41

Cox, T.; Cox, M. Multidimensional scaling. Monographs on statistics and applied probability. Chapman \& Hall/CRC, 2001. 24

Cuadros, A. M.; Paulovich, F. V.; Minghim, R.; Telles, G. P. Point Placement by Phylogenetic Trees and its Application to Visual Analysis of Document Collections. IEEE Symposium on Visual Analytics Science and Technology, p. 99-106, 2007. 21, 22, 23, 29, 32, 64. 67

DAS, S. Filters, wrappers and a boosting-based hybrid for feature selection. In: Proceedings of the Eighteenth International Conference on Machine Learning, San Francisco, CA, USA: Morgan Kaufmann Publishers Inc., 2001, p. 74-81. 19

Dash, M.; LiU, H. Feature selection for classification. Intelligent Data Analysis, v. 1, n. 1-4, p. 131-156, 1997. 15, 17, 19

Duchesnay, E.; Cachia, A.; Boddaert, N.; Chabane, N.; Mangin, J.-F.; Martinot, J.-L.; BRUNELlE, F.; ZILBOVICIUS, M. Feature selection and classification of imbalanced datasets Application to PET images of children with autistic spectrum disorders. NeuroImage, v. 57, n. 3, p. 1003-1014, 2011. 15 
DY, J. G.; BRODLEY, C. E. Feature subset selection and order identification for unsupervised learning. In: In Proc. 17th International Conf. on Machine Learning, Morgan Kaufmann, 2000a, p. 247-254. 2, 19

Dy, J. G.; BRODLEY, C. E. Visualization and interactive feature selection for unsupervised data. conference on Knowledge discovery and data, p. 360-364, 2000b. 39

Eickmeyer, K.; Huggins, P.; Pachter, L.; Yoshida, R. On the optimality of the neighbor-joining algorithm. Algorithms for molecular biology : AMB, v. 3, p. 5, 2008. 29

Eler, D. M.; Nakazaki, M. Y.; Paulovich, F. V.; Santos, D. P.; Andery, G. F.; Oliveira, M. C. F.; Batista Neto, J. A.; Minghim, R. Visual analysis of image collections. The Visual Computer, v. 25, n. 10, p. 923-937, 2009. 33, 61, 67

Eler, D. M.; Nakazaki, M. Y.; Paulovich, F. V.; Santos, D. P.; Oliveira, M. C. F.; Neto, J. A. E. S. B.; Minghim, R. Multidimensional Visualization to Support Analysis of Image Collections. XXI Brazilian Symposium on Computer Graphics and Image Processing, p. 289-296, 2008. 22, 36, 38, 42, 47

Elias, I.; Lagergren, J. Fast neighbor joining. Theor. Comput. Sci., v. 410, n. 21-23, p. 1993-2000, 2009. 29, 31, 32

EMRAN, S. M.; YE, N. Robustness of canberra metric in computer intrusion detection. In: 2nd IEEE SMC Inform. Assurance Workshop, 2001. 14

Engel, D.; Rosenbaum, R.; Hamann, B.; Hagen, H. Structural Decomposition Trees. Computer Graphics Forum, v. 30, n. 3, p. 921-930, 2011. 56

Evans, J.; Sheneman, L.; Foster, J. Relaxed Neighbor Joining: a Fast Distance-Based Phylogenetic Tree Construction Method. Journal of Molecular Evolution, v. 62, n. 6, p. 785-792, 2006. 22, 29, 31

Faceli, K.; Lorena, A. C.; Gama, J.; CARvalho, A. Inteligência artificial: Uma abordagem de aprendizado de máquina, versão 2.0 (unpublished manuscript). 1 ed. LTC, 2011. 17

FAN, J.; GAO, Y.; LUO, H. Hierarchical classification for automatic image annotation. Proceedings of the 30th annual international ACM SIGIR conference on Research and development in information retrieval - SIGIR '07, p. 111, 2007. 35, 37

Fruchterman, T. M. J.; Reingold, E. M. Graph drawing by force-directed placement. Softw. Pract. Exper., v. 21, n. 11, p. 1129-1164, 1991. 22, 23, 24

GANG, H.; QIGANG, G. An Interactive Image Feature Visualization System for Supporting CBIR Study. Image Analysis and Recognition, p. 239-247, 2009. 7

Gomi, A.; Iтон, T. Miaow: A 3d image browser applying a location-and time-based hierarchical data visualization technique. Proceedings of the International Conference on, p. $225-232,2010$. 38 
Gonzalez, R. C.; Woods, R. E. Digital image processing (3rd edition). Upper Saddle River, NJ, USA: Prentice-Hall, Inc., 2006. 6, 7

Grinstein, G.; Ankerst, M.; Keim, D. Visual data mining: Background, applications, and drug discovery applications. In: Tutorial at ACM SIGKDD'2002, 2002. 41

GuO, B.; DAmPer, R.; Gunn, S. R.; Nelson, J. A fast separability-based feature-selection method for high-dimensional remotely sensed image classification. Pattern Recognition, v. 41, n. 5 , p. $1653-1662,2008$. 15

Hadjidemetriou, E.; Grossberg, M. D.; Nayar, S. K. Multiresolution histograms and their use for recognition. IEEE transactions on pattern analysis and machine intelligence, v. 26, n. 7 , p. $831-47,2004.7$

Hall, M. A. Correlation-based feature subset selection for machine learning. Tese de Doutoramento, University of Waikato, Hamilton, New Zealand, 1998. 2, 15, 19

Huang, T.; Ortega, M.; Mehrotra, S. Relevance feedback: a power tool for interactive content-based image retrieval. IEEE Transactions on Circuits and Systems for Video Technology, v. 8, n. 5, p. 644-655, 1998. 61, 126

Jain, R.; Murthy, S.; Chen, P. Similarity measures for image databases. Fuzzy Systems, 1995., p. 1247-1254, 1995. 12,13

JAnKun-Kelly, T.; KWAN-LiU, M. MoireGraphs: Radial focus+ context visualization and interaction for graphs with visual nodes. INFOVIS 2003., v. 2003, 2003. 35, 36, 62

JÄHnE, B. Digital image processing. N. 1 in 1. Springer, 2005. 6

JOHANSSON, S.; JOHANSSON, J. Interactive dimensionality reduction through user-defined combinations of quality metrics. IEEE transactions on visualization and computer graphics, v. 15 , n. 6 , p. $993-1000,2009.15$

John, George, H.; Kohavi, R.; Pfleger, K. Irrelevant features and the subset selection problem. In: Machine Learning: Proceedings of The Eleventh International, Morgan Kaufmann, 1994, p. 121-129. 19

Joia, P.; Nieto, E.; Botelho, G. Projection-Based Image Retrieval Using Class-Specific Metrics. Graphics Patterns, 2011. 1, 40, 41, 47, 56

Jolliffe, I. T. Principal component analysis. New York: Springer, 2002. 23

Jourdan, F. Multiscale hybrid MDS. Information Visualisation, 2004. IV, p. 2-7, 2004. 22, 24

Kaufman, L.; Rousseeuw, P. J. Finding groups in data. an introduction to cluster analysis. John Wiley and Sons, Inc., 1-67 p., 2008. 47

KeIM, D. Visual exploration of large data sets. Communications of the ACM, v. 44, n. 8, p. $38-44,2001.42$ 
Kleinke, D.; WeAVER, J.; LYNCH-CARIS, T. A function based taxonomy to connect engineering design to biological solutions. In: NCIIA: National Collegiate Inventors and Innovators Alliance, NCIIA, 2012. 71

Kohavi, R.; John, G. H. Wrappers for feature subset selection. Artif. Intell., v. 97, p. 273-324, 1997. 17,19

LAmPing, J.; RaO, R.; Pirolli, P. A focus+context technique based on hyperbolic geometry for visualizing large hierarchies. Proceedings of the SIGCHI conference on Human factors in computing systems - CHI '95, p. 401-408, 1995. 22, 27

LI, J.; WANG, J. Z. Automatic linguistic indexing of pictures by a statistical modeling approach. Pattern Analysis and Machine Intelligence, v. 25, n. 9, p. 1075-1088, 2003. 70

LiU, H.; Setiono, R. A probabilistic approach to feature selection, a filter solution. In: Proceedings of International Conference on Machine Learning, 1996. 19

LuO, J. Content-based sub-image retrieval using relevance feedback. Proceedings of the 2nd ACM international, 2004. 73, 126

Mailund, T.; Brodal, G.; Fagerberg, R.; Pedersen, C.; Phillips, D. Recrafting the neighbor-joining method. BMC Bioinformatics, v. 7, n. 1, p. 29, 2006. 29, 31

Mihaescu, R.; Levy, D.; Pachter, L. Why Neighbor-Joining Works. Algorithmica, v. 54, n. 1, p. $1-24,2007.30$

MoghaddAM, B.; LESH, N.; HUANG, T. PDH: a human-centric interface for image libraries. Proceedings. IEEE International Conference on Multimedia and Expo, p. 901-904, 2002. 33

Nene, S.; Nayar, S. Columbia object image library (coil-100). Dept. Comput. Sci., Columbia, 1996. Xiii, 33, 55, 70

NGUYen, G. Similarity based visualization of image collections. Visual Content and Information Visualization, 2005. 36, 70

NGUYen, G.; WorRing, M. Interactive access to large image collections using similarity-based visualization. Journal of Visual Languages \& Computing, v. 19, n. 2, p. 203-224, 2008a. 33, 36, 37, 62

NguYen, G. P.; WorRing, M. Optimization of interactive visual-similarity-based search. ACM Transactions on Multimedia Computing, Communications, and Applications, v. 4, n. 1, p. 1-23, 2008b. 70

Nguyen, Q.; Huang, M. L. A space-optimized tree visualization. IEEE Symposium on Information Visualization, 2002. INFOVIS 2002., v. 2002, p. 85-92, 2002. 22, 25, 26

Oliveira, M. C.; Levkowitz, H. From visual data exploration to visual data mining: A survey. IEEE Transactions on Visualization and Computer Graphics, v. 9, p. 378-394, 2003. 22 
Paiva, J. G. S.; Florian-Cruz, L.; Pedrini, H.; Telles, G. P.; Minghim, R. Improved similarity trees and their application to visual data classification. IEEE transactions on visualization and computer graphics, v. 17, n. 12, p. 2459-68, 2011. xiii, 22, 29, 32, 47, 55, 59, 64, 67

Paiva, J. G. S.; Schwartz, W. R.; Pedrini, H.; Minghim, R. Semi-supervised dimensionality reduction based on partial least squares for visual analysis of high dimensional data. Computer Graphics Forum, v. 31, p. 1345-1354, 2012. 15, 113

PASS, G.; ZABIH, R.; Miller, J. Comparing images using color coherence vectors. Proceedings of the fourth ACM international conference on Multimedia, p. 65-73, 1996. 9, 10

PAUlovich, F. Mapeamento de dados multi-dimensionais integrando mineração e visualização. Tese de Doutoramento, Universidade de São Paulo, 2008. 23

Paulovich, F. V.; Nonato, L. G.; Minghim, R.; Levkowitz, H. Least square projection: a fast high-precision multidimensional projection technique and its application to document mapping. IEEE transactions on visualization and computer graphics, v. 14, n. 3 , p. 564-75, 2008. 23, 24, 47, 48, 73,

Paulovich, F. V.; Oliveira, M. C. F.; Minghim, R. The Projection Explorer: A Flexible Tool for Projection-based Multidimensional Visualization. XX Brazilian Symposium on Computer Graphics and Image Processing (SIBGRAPI 2007), p. 27-36, 2007. 3, 22, 23

PeArson, K. On lines and planes of closest fit to systems of points in space. Philosophical Magazine, v. 2, n. 6, p. 559-572, 1901. 16

Poco, J.; Etemadpour, R.; Paulovich, F.; Long, T.; Rosenthal, P.; Oliveira, M.; Linsen, L.; Minghim, R. A framework for exploring multidimensional data with $3 \mathrm{~d}$ projections. Computer Graphics Forum, v. 30, n. 3, p. 1111-1120, 2011. 48

Quadrianto, N.; Kersting, K.; Tuytelaars, T.; Buntine, W. L. Beyond 2d-grids: a dependence maximization view on image browsing. In: Proceedings of the international conference on Multimedia information retrieval, New York, NY, USA: ACM, 2010, p. 339-348 (MIR '10, v.5). 7

Ribeiro, M.; Balan, A.; Felipe, J.; Traina, A.; Traina, C. Mining statistical association rules to select the most relevant medical image features. In: ZIGHED, D.; Tsumoto, S.; RAS, Z.; HACID, H., eds. Mining Complex Data, v. 165 de Studies in Computational Intelligence, Springer Berlin / Heidelberg, p. 113-131, 2009. 15

Robertson, G.; Mackinlay, J. Cone trees: animated 3D visualizations of hierarchical information. Proceedings of the SIGCHI, 1991. 22, 26, 27

Rocha, A.; Haungge, D. C.; Wainer, J.; Goldenstein, S. Automatic fruit and vegetable classification from images. Computers and Electronics in Agriculture, v. 70, n. 1, p. $96-104,2010.59,70$ 
Rodrigues, J. J.; TrainA, A. Enhanced visual evaluation of feature extractors for image mining. Computer Systems and, 2005. 20, 33, 73

SAITOU, N.; NeI, M. The neighbor-joining method: a new method for reconstructing phylogenetic trees. Molecular biology and evolution, v. 4, n. 4, p. 406-25, 1987. 22, 28, 29

SAMMON, J. A nonlinear mapping for data structure analysis. IEEE Transactions on Computers, v. C-18, n. 5, p. 401 - 409, 1969. 23, 24

SCHAEFER, G. A next generation browsing environment for large image repositories. Multimedia Tools and Applications, v. 47, n. 1, p. 105-120, 2009. 7

SCHVANEVELDT, R. W. Pathfinder associative networks: studies in knowledge organization. Norwood, NJ, USA: Ablex Publishing Corp., 1990. 35

ShNEIDERMAN, B. Tree visualization with tree-maps: 2-d space-filling approach. ACM Transactions on Graphics, v. 11, n. 1, p. 92-99, 1992. 27, 28

Simonsen, M.; Mailund, T. Rapid neighbour-joining. Algorithms in Bioinformatics, 2008. 29, 31, 32

Stehling, R.; NAscimento, M. A compact and efficient image retrieval approach based on border/interior pixel classification. Proceedings of the eleventh, p. 102-109, 2002. 11. 33

STREHL, A. Relationship-based clustering and cluster ensembles for high-dimensional data mining. Tese de Doutoramento, The University of Texas at Austin, 2002.

Disponível em http://strehl.com/download/strehl-phd.pdf 14

SWAin, M. J.; BALlaRd, D. H. Color indexing. International Journal of Computer Vision, v. 7, p. 11-32, 1991. 9

TAN, P.-N.; Steinbach, M.; Kumar, V. Introduction to data mining. Pearson Education, 2006. 13, 17, 18, 19, 21, 51, 73

Tejada, E.; Minghim, R.; Nonato, L. On improved projection techniques to support visual exploration of multi-dimensional data sets. Information Visualization, p. 1-17, 2003. 22

Torgerson, W. Multidimensional scaling: I. theory and method. Psychometrika, v. 17, p. 401-419, 1952. 23

Traina, A. J. M.; Paulo, A.-M. The metric histogram: A new and efficient approach for content-based image retrieval. Sixth IFIP VDB, 2002. 9, 20

VASCONCElos, M.; VASCONCELOS, N. Natural image statistics and low-complexity feature selection. IEEE transactions on pattern analysis and machine intelligence, v. 31, n. 2, p. 228-44, 2009. 70 
Vendramin, L.; CAMPEllo, R. On the Comparison of Relative Clustering Validity Criteria. on Data Mining, SIAM, p. 733-744, 2009. 47

WANG, J.; PENG, W.; WARD, M. Interactive hierarchical dimension ordering, spacing and filtering for exploration of high dimensional datasets. INFOVIS 2003., v. 2003, 2003. 15, 58

WARD, M.; RUndensteIner, E. Exploration of Dimensionality Reduction for Text Visualization. Coordinated and Multiple Views in Exploratory Visualization (CMV'05), p. 63-74, 2005. 22, 62

Worring, M.; RoOIJ, O.; RiJn, T. Browsing visual collections using graphs. Proceedings of the international workshop on Workshop on multimedia information retrieval - MIR '07, p. $307,2007.33$

XING, E. P.; JORDAN, M. I.; KARP, R. M. Feature selection for high-dimensional genomic microarray data. In: In Proceedings of the Eighteenth International Conference on Machine Learning, Morgan Kaufmann, 2001, p. 601-608. 2, 19

YANG, H.; Moody, J. Data visualization and feature selection: New algorithms for nongaussian data. Advances in Neural Information Processing Systems, 2000. 39

Yang, J.; Fan, J.; Hubball, D.; GaO, Y.; Luo, H.; Ribarsky, W.; Ward, M. Semantic Image Browser: Bridging Information Visualization with Automated Intelligent Image Analysis. 2006 IEEE Symposium On Visual Analytics And Technology, p. 191-198, 2006. 7, 71

YAnG, J.; WARD, M. O.; Rundensteiner, E. A.; HuAng, S. Visual hierarchical dimension reduction for exploration of high dimensional datasets. In: Proceedings of the symposium on Data visualisation, Aire-la-Ville, Switzerland, Switzerland: Eurographics Association, 2003, p. 19-28. 15, 58

YU, L.; LiU, H. Efficient feature selection via analysis of relevance and redundancy. $\quad J$. Mach. Learn. Res., v. 5, p. 1205-1224, 2004. 17, 126

ZHANG, D.; LU, G. Evaluation of similarity measurement for image retrieval. Proceedings of the 2003 International Conference on Neural Networks and Signal Processing, 2003., 2003. 13

ZHANG, J. Visualization for information retrieval. 1 ed. Springer, 2008. 24

ZHANG, Y. On the use of CBIR in Image Mosaic Generation On the use of CBIR in Image Mosaic Generation. Tese de Doutoramento, University of Alberta Edmonton, 2002. 8, 71 